\title{
Análise de um programa de treinamento e de seus resultados: um estudo de caso do MBA Gestão Pública - Banco do Brasil
}

Dissertação apresentada a Faculdade de Economia, Administração e Contabilidade de Ribeirão Preto, da Universidade de São Paulo, para a obtenção do título de Mestre em Administração de Organizações.

Área de Concentração: Administração de Recursos Humanos

Orientadora: Prof. Dr. ${ }^{\text {a }}$ Irene Kazumi Miura

RIBEIRÃO PRETO

2006 
Profa. Dra. Suely Vilela, Reitora da Universidade de São Paulo. Prof. Dr. Marcos Cortez Campomar, Diretor da Faculdade de Economia, Administração e Contabilidade de Ribeirão Preto.

Prof. Dr. Márcio Mattos Borges de Oliveira, Chefe do Departamento de Administração. 

autor.

É vedada a reprodução do todo ou de parte desta obra sem a autorização expressa do

Catalogação na Publicação

Serviço de Documentação da Biblioteca Central - PCARP

Faculdade de Administração, Contabilidade e Economia de Ribeirão Preto da Universidade de São Paulo

Inocente , David Forli

Análise de um programa de treinamento e de seus resultados: um estudo de caso do MBA Gestão Pública - Banco do Brasil. Ribeirão Preto, 2006.

$$
268 \text { p. : il. ; } 30 \mathrm{~cm}
$$

Dissertação de Mestrado, apresentada à Faculdade de Economia, Administração e Contabilidade de Ribeirão Preto/USP - Área de concentração: Administração de Recursos Humanos.

Orientadora: Miura, Irene Kazumi.

1. Treinamento. 2. Resultados de Treinamento. 3. Análise de Treinamento. 4. Vantagem Competitiva Sustentável. 
"A convicção é um luxo, que só cabe a quem apenas observa" autor desconhecido 
David Forli Inocente

Análise de um programa de treinamento

e de seus resultados: um estudo de caso

do MBA Gestão Pública - Banco do Brasil

Dissertação apresentada a Faculdade de Economia, Administração e Contabilidade de Ribeirão Preto, da Universidade de São Paulo, para a obtenção do título de Mestre em Administração de Organizações.

Aprovado em: 19 de Abril de 2006

Banca Examinadora

Profa. Dra. Vânia Maria Jorge Nassif

Instituição: Universidade Presbiteriana Mackenzie Assinatura:

Prof. Dr. André Lucirton Costa

Instituição: Faculdade de Economia Administração e Contabilidade de Ribeirão

Preto - Universidade de São Paulo Assinatura:

Profa. Dra. Irene Kazumi Miura - Orientadora

Instituição: Faculdade de Economia Administração e Contabilidade de Ribeirão

Preto - Universidade de São Paulo Assinatura: 
Dedico este trabalho às duas pessoas fundamentais na minha vida, que independente de qualquer tormenta sempre estarão ao meu lado: minha mãe e minha esposa, pela força e confiança que permitiram que esse trabalho fosse concluído. Ainda, e, sobretudo, a Deus, por ... Tudo! 


\section{AGRADECIMENTOS}

Há muitas pessoas a quem devo agradecer por este trabalho, não pelo ato agradecer em si, mas pela real gratidão que realmente sinto por cada um de vocês, espero me lembrar de todos, sem ter o menor constrangimento em me estender.

Primeiramente a minha orientadora, Professora Irene Miura, que acreditou que seríamos capazes de realizar este trabalho, que esteve sempre disposta a responder às dúzias de dúvidas que apresentei, muito, muito obrigado mesmo, o processo de orientação se tornou uma inspiração ao ofício de mestre!

Ao professor André Costa que desde o início me incentivou a tentar o Mestrado, fazendo questão de lembrar que haveria dificuldades, mas que podia dar certo, obrigado pela confiança.

Ao professor Alberto Matias que inspirou muito do meu gosto pela academia, me fazendo entender a importância de aproximar a ciência do mercado.

A professora Adriana Backx, que ensinou Estatística a um bacharel, inacreditável, obrigado!

Ao professor Gilberto Shyniashiki, que me apresentou aos grandes autores da área de treinamento e que me ajudou a sistematizar idéias, muito obrigado.

Aos demais professores da FEARP por construírem um Programa de Pós-graduação do qual podemos nos orgulhar.

Ao amigo Beto Campello pela ajuda de toda a ordem, pelas constantes conversas, pelas criticas que muito contribuíram com este trabalho.

Aos professores Márcio Mattos e Sonia Borges, João e Cláudia Passador e Tabajara, pelos bons conselhos e amizade.

Aos professores Maria Christina, Geciane Silveira Porto, Edgard Monforte Merlo pelas excelentes aulas. 
A Professora Gardênia Abbad, da Universidade de Brasília, por ter me concedido seu trabalho como obra de referência e por ser uma grande inspiração neste interessante campo de estudo. A professora Vânia Nassif pela contribuições que apresentou no exame de qualificação, muito apoiando o desenvolvimento deste trabalho.

Ao pessoal da secretaria de pós-graduação da FEARP, especialmente Érika e Eduardo, pela paciência constante.

À Faculdade de Economia, Administração e Contabilidade de Ribeirão Preto da Universidade de São Paulo, pela oportunidade de realizar este curso.

Ao Banco do Brasil, com admiração pela coragem em realizar cinco turmas de um curso de longa duração que certamente em muito tem apoiado o desenvolvimento deste país.

À Universidade Corporativa do Banco do Brasil, em especial ao Sr Pedro Paulo Carbone, que acreditou na importância do projeto e abriu tantas portas quantas foram necessárias.

Ao Gerson da UniBB pelo desapego de ter analisado este projeto com tanta agilidade.

A Maria Inês Torrecillas, pelo empenho e profissionalismo durante a realização do treinamento e pela gentileza de me conceder a entrevista constante neste trabalho.

Ao Sylvio Maestrelli por ter atendido tão rapidamente o pedido da entrevista que aqui consta.

A Diretoria de Governo do Banco do Brasil, em especial Dr. Ricardo Conceição pela sabedoria e estratégia de ter levado este projeto à frente que se mostrou tão eficiente, ao Sr. Sérgio Ricardo Miranda Nazaré e ao Sr. João Pinto Rabello, parabéns pelo pioneirismo e pela coragem.

Ao Marcão e ao Jean Claude, também da DIGOV pela constante e enorme paciência em fornecer dados, apoiar o agendamento de reuniões etc. muito obrigado sem vocês não haveria dados. Ao Felcar pela concessão da entrevista que aqui consta e engrandece este trabalho.

Aos amigos e antigos alunos da DIGOV: Paulo César Neto, Anderson Caíres, Regina Carmélia Ribeiro Miranda, Luismar Vieira Machado, Lauro Fernando Ribeiro Filho, 
José Avelar Matias Lopes, Maria Augusta, Ricardo Newman, Rui Hirata, Gilson Calixto, Luis Afonso Gomes Vieira, Alessandra Aranda, Flávio Carlos Pereira, Paulo Roberto Menezes Lima, Alcides Pegorer, José do Carmo Rocha Filho, Marília Gonzaga de Siqueira, Marcelo Lopes Correa, Mauricio Amado dos Santos e José Jairo, que despenderam horas de seu dia para realizar os grupos focais.

Ao Antônio Carlos Servo (Toninho) e ao Fabrício Foganhole, pela amizade e rápida leitura aprovando irrestritamente a publicação de todos os dados deste estudo.

Aos colegas Edson Bergamaschi e Karina Abraão pela enorme e inconteste paciência nas resolução das dúzias de exercícios de estatística, se não fossem vocês não haveria defesa, não tenho dúvidas disso.

Aos colegas de turma, Alexandre Maschieto, Amanda Ribeiro, Ana Luiza, Andréia Maciel, Antonio Carlos, Carolina Santos, Débora Duarte, Élcio Santana, Luciano Caldeira, Marcelo Moraes, Marco Antonio, Paula Spinelli e Ricardo Morgado por terem feito desta uma turma inesquecivelmente divertida.

Ao colega Aníbal Betrán, in memorian, pelo exemplo, pela força de vontade, por ter acreditado, por ter enfrentado, por ter feito dar certo.

A Claudinha pela digitação das entrevistas e grupos focais.

A Raquel Costa pela ajuda na revisão de língua portuguesa.

A Mônica da Biblioteca Central pela ajuda quanto ao atendimento das Normas USP para elaboração de Teses e Dissertações.

A minha enorme, amada e inumerável família, em especial ao Caco, Fernandinha, Carlinha, Junior e Vovó Lucinda, Vovô Alberto e Vovó Evangelina, por terem agüentado esse papo de dissertação na ceia de Natal nos filmes, nas festas e aos meus amigos, Silvia, Ju, Pi, Lê, Wellington, Cleofi, Luciana, Fabrício e Ju, Helton e Sil, pela mesma razão. 
Aos colegas de trabalho e amigos, Sandra, Paulo Pessoa, João, Rosangela, Juliana, Henrique, Guilherme, Erica, Janua, Aládia, Marlon, Fabiola, Fernando, Lidiane, Carol, Marcão, Simone, Luiz, Daniel, Patrícia, Juliana Bezzon, Fábio, Paulo, Ricardo, Marina, e Edson, por terem segurado a barra nas muitas ausências e por terem sido compreensivos com stress que acompanha esse processo. 


\section{RESUMO}

INOCENTE, David Forli. Análise de um programa de treinamento e de seus resultados: um estudo de caso do MBA Gestão Pública - Banco do Brasil. 2006. 220 f. Dissertação (Mestrado) - Faculdade de Economia, Administração e Contabilidade de Ribeirão Preto da Universidade de São Paulo.

O cenário de competição empresarial exige das empresas diversas posturas diferenciadoras, dentre estas, posturas que sejam capazes de desenvolver vantagens competitivas sustentáveis. Como resultado de sua busca pela competitividade, as empresas procuram desenvolver suas competências essenciais por meio das pessoas que a compõe. Dentre as formas de desenvolvimento organizacional, solidificou-se a realização de treinamentos no ambiente das corporações. O pensamento científico relacionado ao tema, observa a necessidade de que o treinamento esteja alinhado às estratégias da empresa e que seja capaz de produzir resultados. Surge a necessidade de se avaliar sistematicamente o treinamento e em especial seus resultados. Com o objetivo de delinear as características particulares do fenômeno, este estudo analisou as dimensões qualitativas de um programa de treinamento o MBA (Master in Business Administration) Gestão Pública realizado no Banco do Brasil. A metodologia utilizada foi o estudo de caso, valendo-se da realização de grupos focais, de entrevistas semiestruturadas e de análise de dados secundários para a obtenção de evidências que ofereceram elementos de análise do treinamento realizado. Conclui-se que o programa produziu resultados no contexto da Diretoria de Governo do Banco do Brasil, tendo atingido os objetivos de proposição do treinamento. Foram estudados quatro modelos de avalaição de treinamento, tendo sido defindo o Modelo MAIS como adequado para explorar o curso estudado. A avaliação de treinamento delineou o quanto o programa atendeu ao modelo, tendo sido observada a presença maioria dos parâmetros e ausência de alguns outros. Observou-se resultados objetivos do curso, como o planejamento de produtos e o dimensionamento de estratégias organizacionais. Muitos dos resultados observados encontram-se no contexto de outras ações organizacionais da Diretoria estudada e não podem ser apontados como resultado do treinamento, por outro lado o treinamento é apontado como um dos elementos de contexto que contribuíram com este resultado. Foram identificados ainda resultados que podem ser classificados como fonte de Vantagem Competitiva Sustentável da Diretoria de Governo do Banco do Brasil e que estão associados ao programa MBA Gestão Pública.

Palavras-chave: Treinamento. Resultados de Treinamento. Análise de Treinamento. Vantagem Competitiva Sustentável. 


\begin{abstract}
INOCENTE, David Forli. Analysis of the training program and your results: a case study of the MBA Public Management - Banco do Brasil. 2006. 220 f. (Master Degree) Faculdade de Economia, Administração e Contabilidade de Ribeirão Preto da Universidade de São Paulo.
\end{abstract}

The competitive business environment demands differentiation postures from every company, especially, postures that are capable to develop sustainable competitive advantages. In consequence of their search for competitiveness, companies look for developing their essential abilities through the people who compose it. Amongst different forms of organizational development, training becomes a frequent practice in companies' environment. The scientific thought related to the subject emphasizes a necessity of alignment between training and companies' strategies, and the capability of producing results. Systematic evaluation of the training and especially its results becomes necessary. In order to delineate the particular characteristics of the phenomenon, this study analyzed qualitative dimensions of a training program called MBA Public Management implemented at Banco do Brasil. The methodology was a case study, based on focus groups, half-structuralized interviews, and secondary data analysis to attain evidences that offered analysis elements of the studied training. It is concluded that the program produced results in the context of the Government Board of the Banco do Brasil, and reached the proposal objectives of the training. Four models of evaluation of training had been studied, and the Model MAIS was considered adjusted to explore the studied course. The training evaluation delineated how much of the model was attended by the program it was observed the presence of the majority of the parameters and absence of some others. It was also observed objective results of the course, for instance the planning of products and the sizing of organizational strategies. There were many of the observed results, which are related to other organizational actions of the studied Board, and they cannot be pointed as resulted from the training. However, the training is pointed as one of the context elements that had contributed with these results. It was also identified results that can be classified as sources of Sustainable Competitive Advantage of the Government Board of the Banco do Brasil, which are associated to MBA Public Management program.

Key-word-: Training. Training Results. Training Analysis. Sustainable Competitive Advantage. 


\section{LISTA DE FIGURAS}

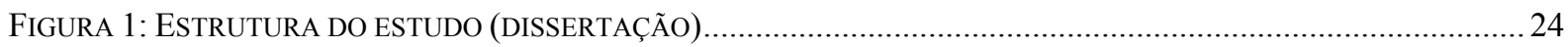

FIGURA 2: TREINAMENTO COMO FONTE DE VANTAGEM COMPETITIVA SUSTENTÁVEL ............................................2 26

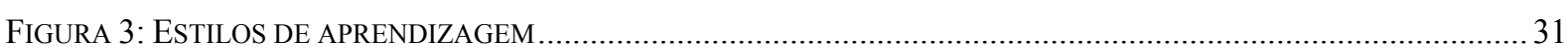

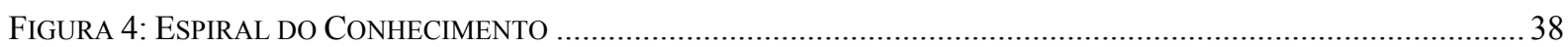

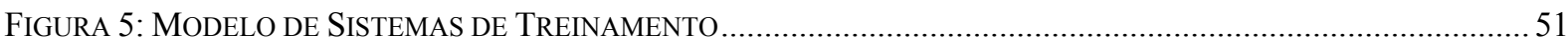

FigURA 6: REPRESENTAÇÃo GRÁFICA DA SEQÜÊNCIA DE ATIVIDADES NECESSÁRIAS AO LEVANTAMENTO DE

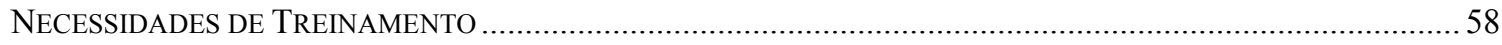

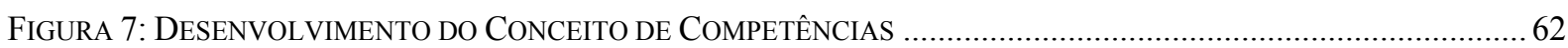

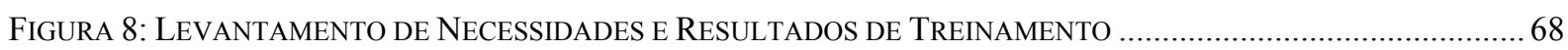

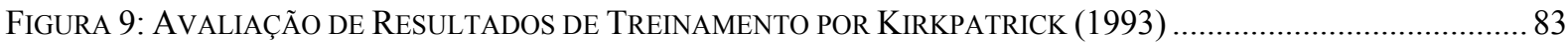

FIGURA 10: AVALIAÇÃO DE RESULTADOS DE TREINAMENTO EM HAMBLIN (1978) .................................................. 85

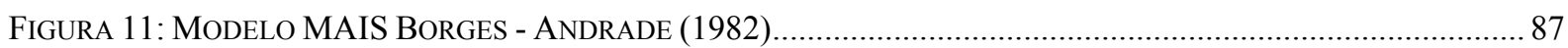

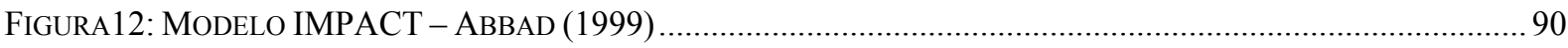

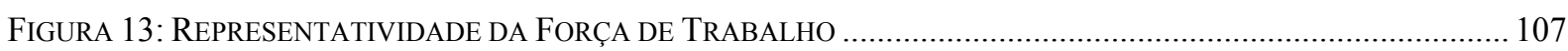

Figura 14: EvoluÇão do Conceito da VANTAGEM ComPETITIVA SuSTENTÁVEL .............................................. 109

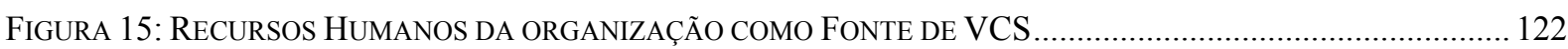

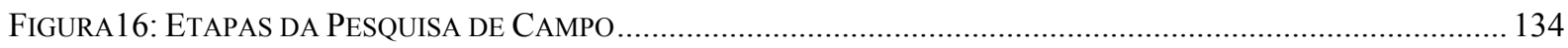

FigURA 17: ATRIBUTOS DA VANTAGEM COMPETITIVA SUSTENTÁVEL ……...................................................... 151 


\section{LISTA DE QUADROS}

QUADRO 1 - TREINAMENTO E DESENVOLVIMENTO TRADICIONAL X UNIVERSIDADES CORPORATIVAS .................43

QUADRO 2 - TREINAMENTO BASEADO NO INDIVÍDUO E TREINAMENTO COM FOCO NA ORGANIZAÇÃO ..................50

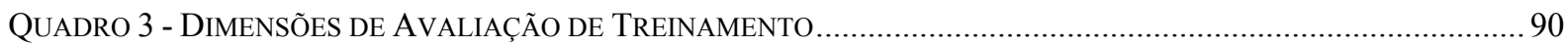

QUADRO 4 - GRADE DE AGENDAMENTO DE GRUPOS FoCAIS ..................................................................... 141

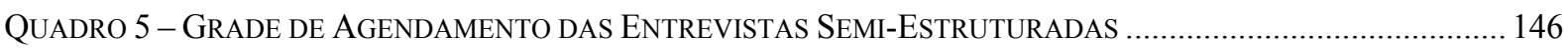

Quadro 7 - Plano DE ANÁlise dA PESQuisa de CAMPO, FonTE: AUTOR ….................................................. 155

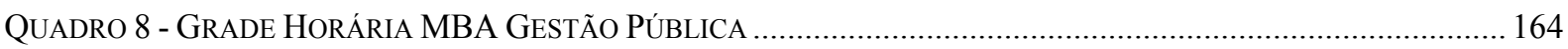




\section{LISTA DE TABELAS}

TABELA 1 - DISTRIBUIÇÃO DE PARTICIPANTES NOS GRUPOS FOCAIS DIVIDIDOS POR TURMA …………………….... 142

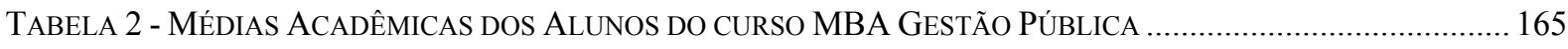

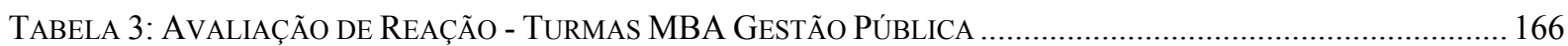




\section{LISTA DE TERMOS TÉCNICOS}

MBA in Company - Programa MBA realizado no ambiente de uma única instituição.

Treinando - participante de programa de treinamento.

Gestor - para o Banco do Brasil, o termo gestor aplica-se aos executivos dirigente de unidades estratégicas da organização pesquisada. Esta terminologia foi escolhida por ser a adotada pela organização pesquisada.

Gerente - para o Banco do Brasil, ocupante de cargo gerencial em diversos níveis, envolvidos com atividade comercial. 


\section{LISTA DE ABREVIATURAS}

ASTD - American Society for Training and Development.

BSC - Balanced Scorecard.

CHA - Conhecimento, Habilidade e Atitude.

DIGOV - Diretoria de Gvoverno.

MBA - Master in Business Administration.

MBA EGP - MBA Gestão Pública.

FUNDACE - Fundação para o Desenvolvimento da Administração, Contabilidade e Economia.

P \& D - Pesquisa e Desenvolvimento.

RNC - Relatório de não Conformidade.

ROI - Retorno sobre o investimento.

UCs - Universidades Corporativas.

VBR - Visão Baseada em Recursos.

VCS - Vantagem Competitiva Sustentável.

UniBB - Universidade Corporativa Banco do Brasil. 


\section{SUMÁRIO}

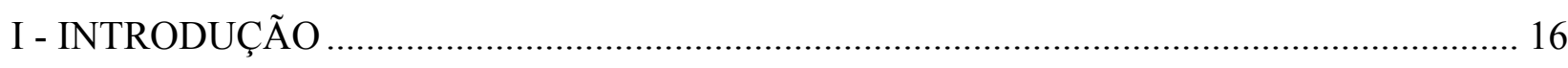

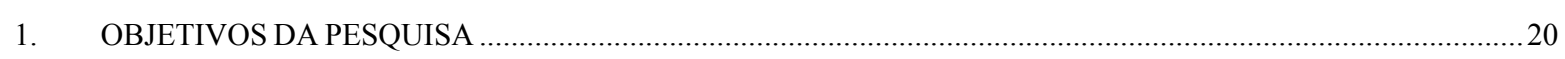

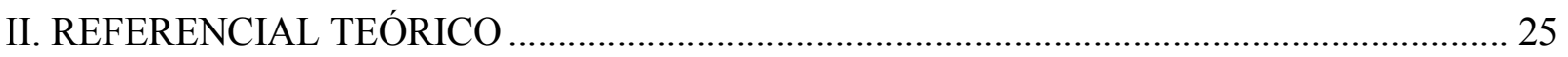

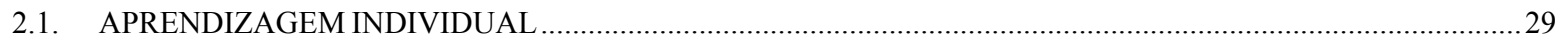

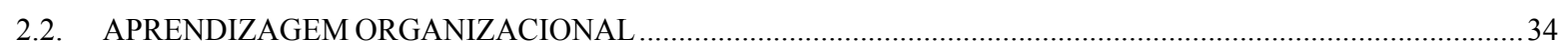

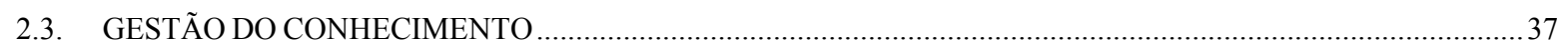

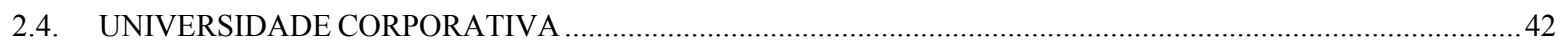

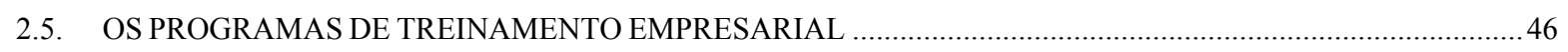

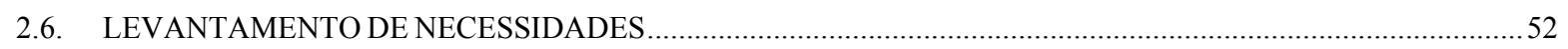

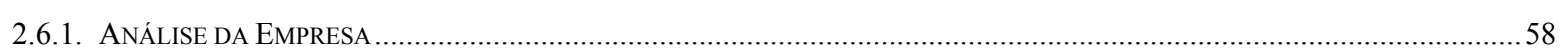

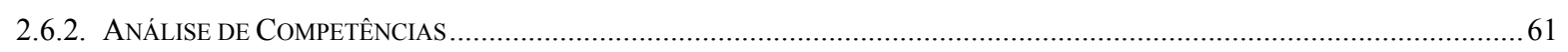

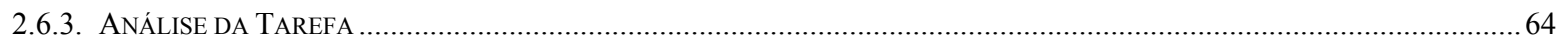

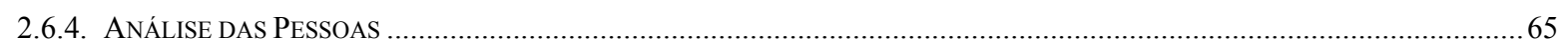

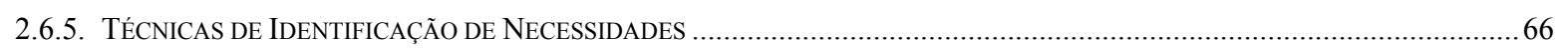

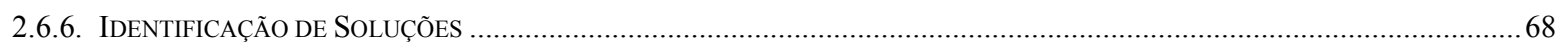

2.6.7. ESPECIFICAÇÃO DAS NECESSIDADES DE TREINAMENTO..................................................................................

2.7. ELABORAÇÃO E IMPLEMENTAÇÃO DO TREINAMENTO ………………………………………..........72

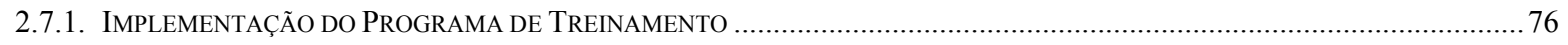

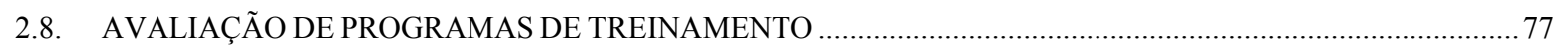

2.8.1. KIRKPATRICK (1993) - O Modelo DOS QUATRO NíveIS ................................................................................. 82

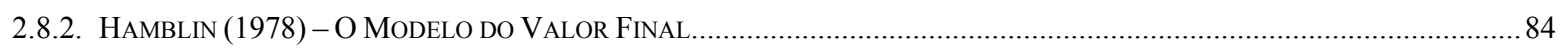

2.8.3. BORGES - ANDRADE (1982) - O MODELO MAIS .............................................................................................. 85

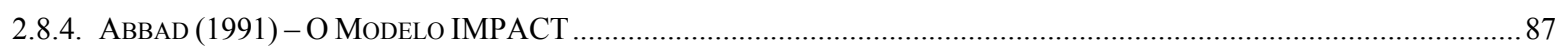

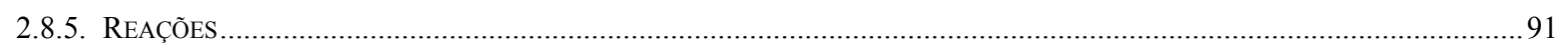

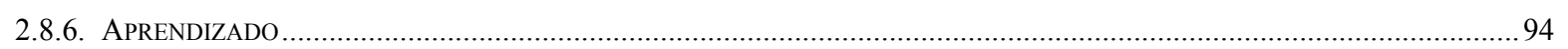

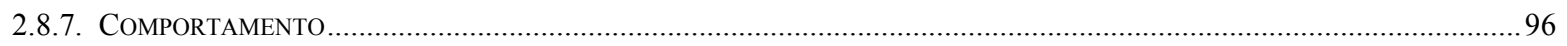

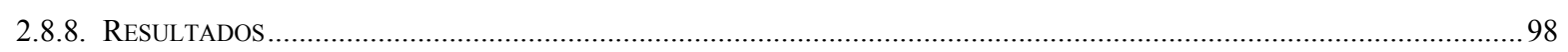

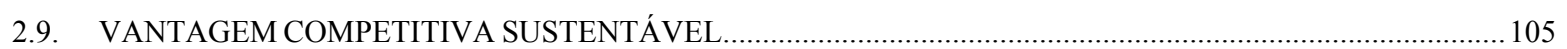

III. PROCEDIMENTOS METODOLÓGICOS ..................................................................... 124

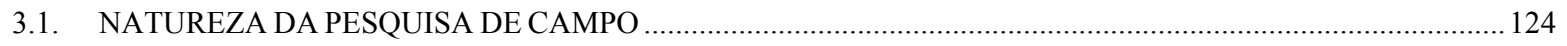

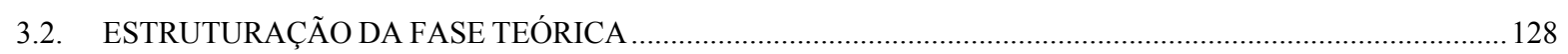

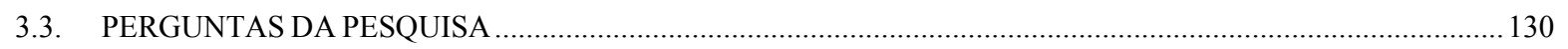

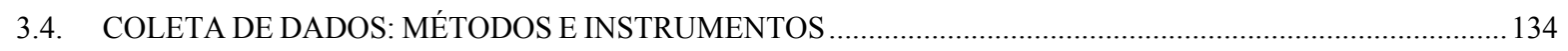

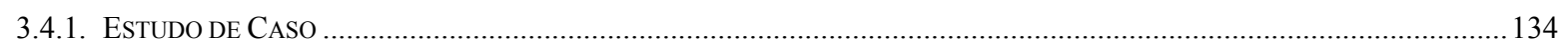

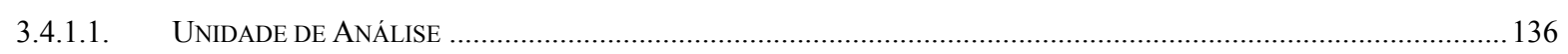

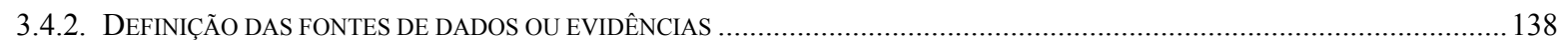

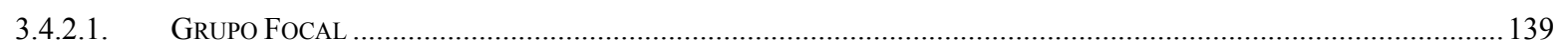

3.4.2.2. Grupo Focal MBA Gestão Pública Banco do Brasil: Direcionamento E Etapas .................................. 142

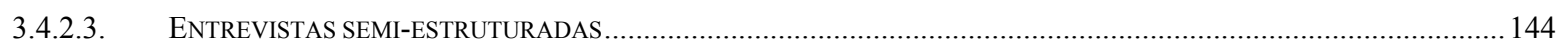

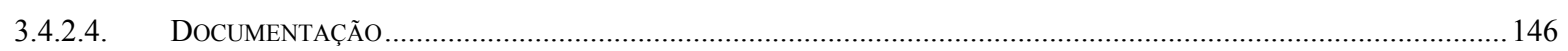




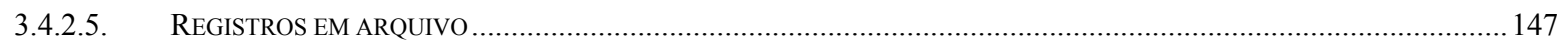

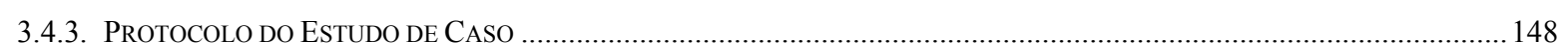

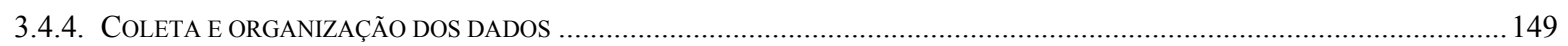

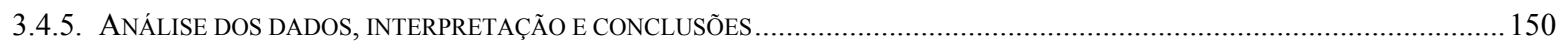

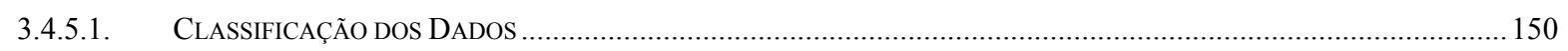

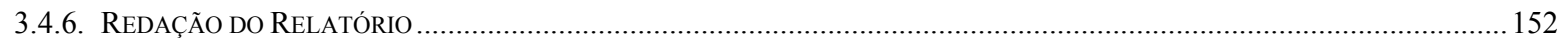

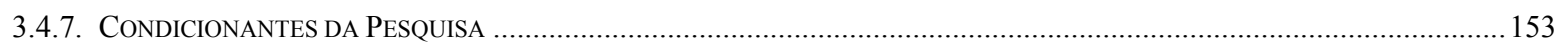

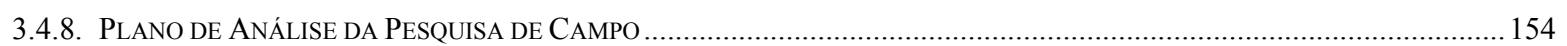

IV. RESULTADOS OBTIDOS NA PESQUISA DE CAMPO ……………………………..... 156

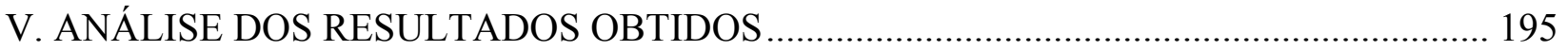

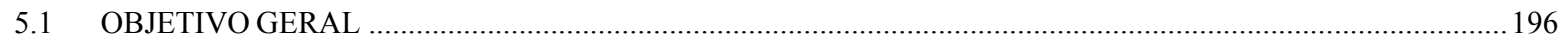

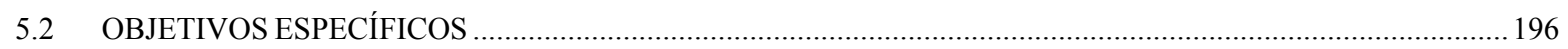

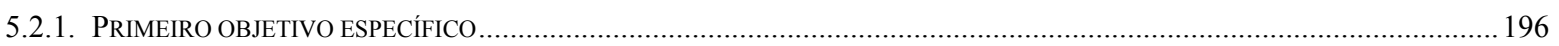

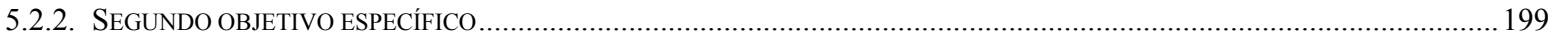

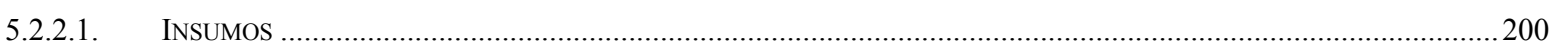

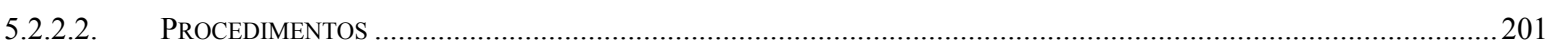

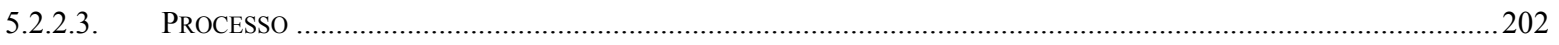

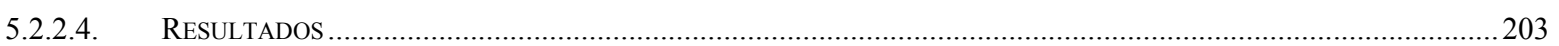

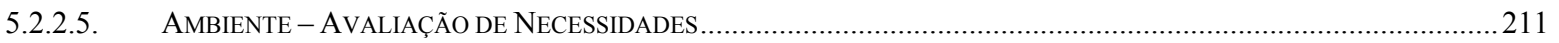

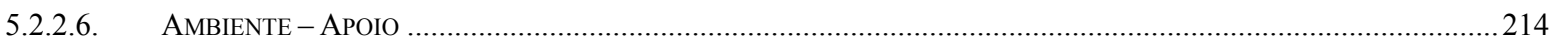

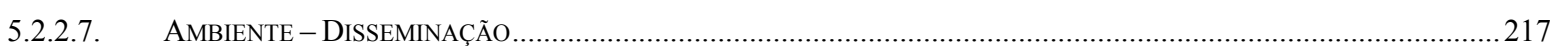

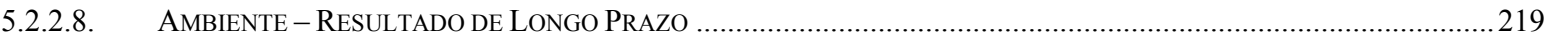

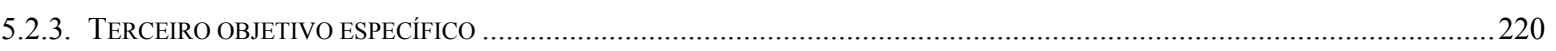

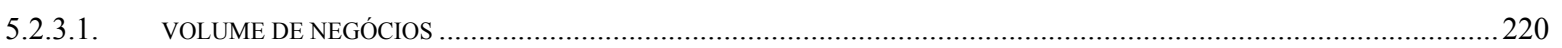

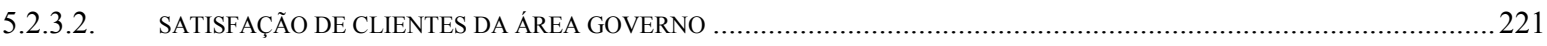

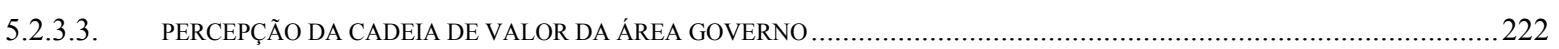

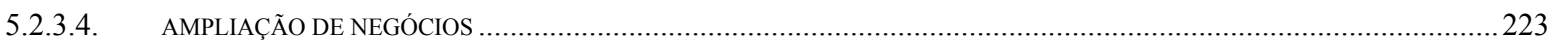

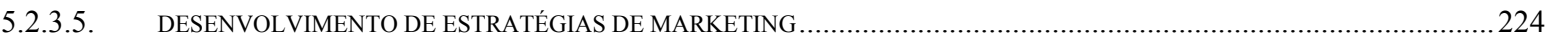

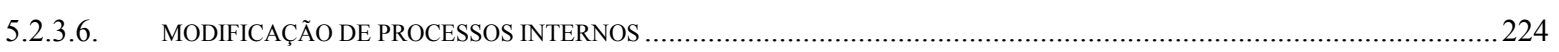

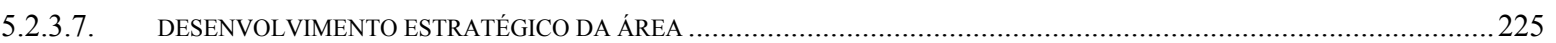

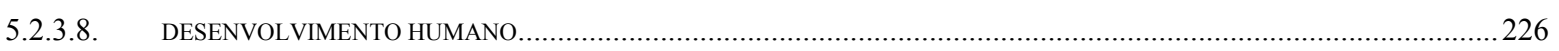

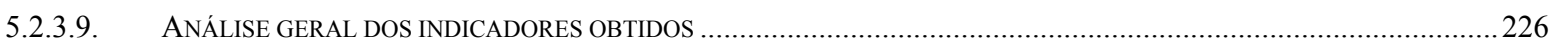

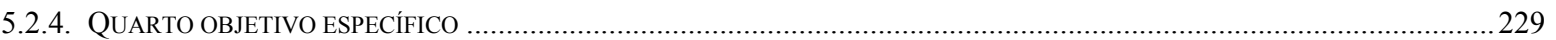

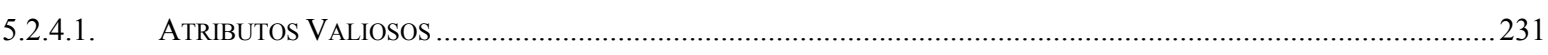

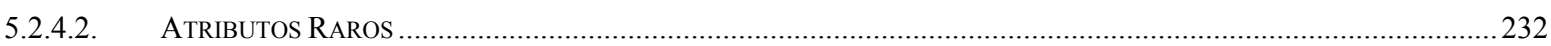

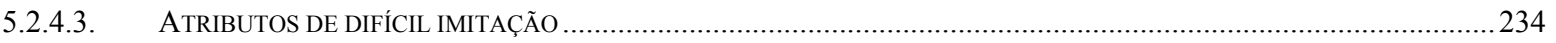

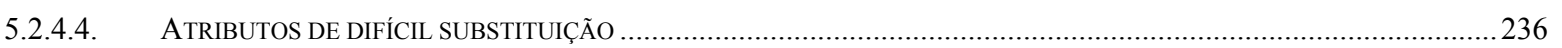

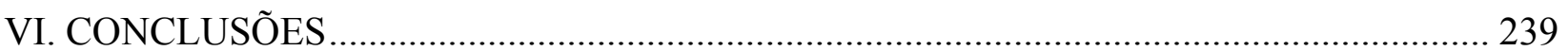

VI. REFERÊNCIAS BIBLIOGRÁFICAS ...................................................................... 247

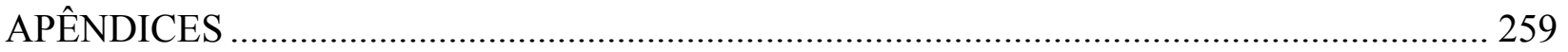

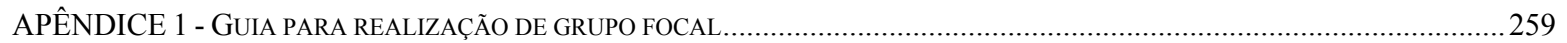


APÊNDICE 2 - GUIA PARA REALIZAÇÃO DE ENTREVISTA - DiRETORIA DE GOVERNO 261

APÊNDICE 3 - GUIA PARA REALIZAÇÃo DE ENTREVISTA UNIVERSIDADE CORPORATIVA .262

APÊNDICE 4 - IMPLEMENTAÇ̃̃o EFETIVA DE TRABALHos dE CONClusão de CURSO .263 APÊNDICE 5 - MovimentaÇ̃̃o de Pessoal da DiRetoria de Governo .266 AnEXo 1 - CONTROLE DE QuAlidade DAS Aulas - FUNDACE. 


\section{I - INTRODUÇÃO}

Organizações de diversos setores e portes, que pretendem atuar em mercados concorrenciais, despontando como líderes de seu segmento, dependem de seus empregados para sustentarem sua competitividade. Estas empresas lutam constantemente para obter competências, consideradas, "conjuntos básicos de conhecimentos e experiências que dão a elas uma vantagem sobre seus concorrentes" (QUINN; ANDERSON; FINKELSTEIN, 2000, p. 275).

O desenvolvimento das competências de uma organização ocorre por meio de múltiplos processos de aprendizagem. Por intermédio de educação formal e continuada, conhecimentos teóricos, informações, conhecimentos sobre procedimentos são transmitidos para o indivíduo. A experiência profissional e a experiência social traduzem esse conhecimento para a prática das organizações, num processo de aprendizagem em que o conhecimento começa a se transformar em competências (FLEURY, 1999).

Sinais dessa transformação podem ser demonstrados por meio das mudanças verificadas na economia e no tipo de trabalho que as empresas realizam, indicando que haverá profundas transformações na força de trabalho. Este novo cenário exigirá pessoas cada vez mais preparadas. Desta forma, torna-se essencial investir na articulação de programas de treinamento que sejam capazes de instrumentalizar as empresas para esta nova realidade (CASCIO, 1995).

$\mathrm{O}$ uso do termo treinamento exige um rápido comentário. $\mathrm{O}$ termo treinamento conforme Milkovich e Boudreau (2000), Bohlander, Snell e Sherman ( 2003) é utilizado para referenciar qualquer esforço que a organização faça no sentido de estimular o aprendizado de seus funcionários e mudar seu comportamento de maneira permanente. Segundo estes autores, este termo estaria mais associado com ações concernentes a desempenhos de curto prazo, e o termo desenvolvimento seria mais oportuno para identificar ações de ampliação das 
habilidades dos funcionários, preparando-os para assumir responsabilidades futuras. Os termos treinamento e desenvolvimento, assim apresentados, servem para definir todas as atividades combinadas que as empresas realizam, com o objetivo de ampliar as capacidades dos funcionários.

Neste estudo o termo treinamento será destinado a indicação das atividades que uma empresa realiza, visando oferecer conteúdos de formação aos seus funcionários, esperando obter como retorno a ampliação de suas capacidades para o trabalho e auxiliando a melhoria dos indicadores da empresa.

Esta definição conjuga-se com a de Goldstein (1991) ${ }^{1}$ apud Abbad (1999, p. 8): “o processo de treinamento é visto como a aquisição sistemática de atitudes, conceitos, conhecimentos, regras e habilidades que resultam em uma melhoria do desempenho no trabalho". Para Abbad (1999), esta definição é uma das mais aceitas pela literatura estrangeira.

Observa-se que o uso do termo treinamento, se dá com o objetivo de acompanhar a literatura especializada, que o aplica para definir curso de formação dos mais diversos níveis, incluindo os de educação continuada, não representando, neste estudo, cursos profissionalizantes, especialmente aqueles destinados a atividades operacionais.

O termo desenvolvimento será utilizado, neste trabalho, para identificar as atividades da empresa destinadas ao preparo de longo prazo de seus funcionários, vinculada a aquisição de competências e habilidades vinculadas ao desenvolvimento da própria organização.

Por sua vez o investimento em capacitação assume especial relevância no aspecto do desenvolvimento de estratégias competitivas. Segundo Porter (1999), por estratégias competitivas entendem-se as estratégias valiosas que não podem ser plenamente copiadas pelos concorrentes, por causa de barreiras que dificultam sua imitação, e por sua capacidade

\footnotetext{
${ }^{1}$ GOLDSTEIN, I.L. Training in work organizations. Dunnette \& Hough (Orgs.), Handbook of Industrial and Organizational Psychology 2a edição, pp.507-619, 1991.
} 
de sustentação por um longo período de tempo, estas estratégias devem direcionar as empresas à obtenção de uma vantagem competitiva sustentável.

Para Cascio (1995), o investimento em programas de treinamento instrumentaliza os profissionais para a realidade dos mercados e apóia o desenvolvimento de capacidades humanas que estabelecerão a vantagem competitiva sustentável da organização.

Compreende-se que as organizações lutam constantemente para obter competências (QUINN; ANDERSON; FINKELSTEIN, 2000) e que há múltiplos processos pelos quais elas desenvolvem essas competências, dentre eles a educação continuada (FLEURY, 1999).

Partindo do fato de que as empresas precisam desenvolver ações que favoreçam o desenvolvimento de suas competências críticas, o treinamento pode ser visto como “integrante das políticas de desenvolvimento e implementação de estratégias nas organizações” (BOHLANDER; SNELL; SHERMAN, 2003, p.134).

Dada a importância estratégica do desenvolvimento de competências críticas nas organizações e de sua capacidade de realização por meio de treinamento, surge a necessidade de dimensionar o quanto esta capacidade se verifica como resultados dos programas de educação continuada como ações de desenvolvimento organizacional.

Há uma crescente preocupação dos pesquisadores da área de treinamento e desenvolvimento em obter indicadores de sua eficácia, principalmente em razão do aumento do volume de investimentos na área (FREITAS e BORGES-ANDRADE, 2004). A American Society for Training and Development (ASTD) afirma que aproximadamente dois terços dos gerentes responsáveis por programas de treinamento, sofrem pressão da organização para demonstrar que seus programas geram resultados financeiros (COOK, 1998).

Conforme a ABNT (2001), a avaliação é útil para saber se os objetivos do programa de treinamento, e por conseqüência da organização, foram atingidos. A avaliação do programa é fundamental para observar seus resultados, pois na medida em que são realizados os 
investimentos em treinamento amplia-se a justificativa por sua necessidade (BOHLANDER; SNELL; SHERMAN, 2003).

O investimento em treinamento é uma constante e, num mercado de alta concorrência que pressiona as organizações por eficiência, compreender como se dão seus resultados passa a ser tão relevante quanto a própria realização do treinamento (FREITAS e BORGESANDRADE, 2004; COOK, 1998). Os programas MBA in company são considerados como uma modalidade de treinamento corporativo, é realizado por instituições de ensino de pósgraduação no ambiente interno das organizações contratantes.

Para fins legais o MBA é considerado uma especialização, ou seja uma pós-graduação Lato Sensu. A regularidade do curso é determinada pelo atendimento às disposições da Resolução CNE / CES nº 001/01 (BRASIL, 2001)

A viabilidade do projeto alicerça-se em razão de que o estudo dos resultados de programas de treinamento interessa sobretudo às organizações contratantes deste tipo de ação de capacitação. Tal como revelou o referencial teórico até aqui, esta análise deve ser promovida em razão da necessidade de se justificar os investimentos realizados e avaliar a oportunidade de intensificação e reorientação da ação de treinamento.

Compreender como se dão os resultados de programas de treinamento in company surge como uma necessidade organizacional à medida que se ampliam os investimentos em sua realização; a literatura reforça esta importância e o presente estudo visa se inserir neste contexto, identificando indicadores que possam ser apontados como válidos para demonstrar os resultados apresentados pelo curso.

O estudo realizado é de natureza qualitativa e a investigação proposta se dará por meio da metodologia de estudo de caso. Esta escolha, detalhada no capítulo referente aos procedimentos metodológicos, visa delinear as características mais particulares do fenômeno. A unidade de análise estudada será a Diretoria de Governo do Banco do Brasil (DIGOV), que 
patrocinou as cinco turmas do programa MBA Gestão Pública, objeto deste estudo, e onde se busca identificar os resultados do programa de treinamento. Serão utilizadas como técnicas de apoio do estudo de caso a realização de grupos focais e entrevistas semi-estruturadas. Participaram dos grupos focais, alunos de uma das cinco turmas do curso em estudo. Esta técnica de apoio visa identificar junto aos participantes como se apresentaram os elementos constitutivos do planejamento e da execução do treinamento, bem como os resultados que de fato puderam ser observados como decorrência do curso. O guia para realização dos grupos focais encontra-se no apêndice 1. Como produto dos grupos focais, esperava-se que os participantes indicassem resultados de alguma forma fossem originados pelo programa MBA Gestão Pública. Foam realizadas ainda entrevistas semi-estruturadas com gestores do pilar governo do Banco do Brasil e da Universidade Corporativa do Banco do Brasil. Estas entrevistas tiveram a finalidade de ampliar as evidências obtidas como resultados dos grupos focais. Os dados obtidos serão analisados com base na teoria da Vantagem Competitiva Sustentável (BARNEY, 1991).

Inserido no contexto e relevância do tema apresentado, com base na metodologia exposta, surge o seguinte problema de investigação: Como se apresentam os resultados do programa MBA Gestão Pública da Diretoria de Governo do Banco do Brasil?

\section{OBJETIVOS DA PESQUISA}

Entendendo-se o treinamento como um instrumento de sustentabilidade da vantagem competitiva da organização, é necessário observar sua capacidade de demonstração de resultados. Conforme o referencial teórico, a verificação de impacto do treinamento no contexto da organização é tema que merece ampliação, tanto por sua insipiência, quanto pela 
dificuldade de isolamento das variáveis que podem influenciar os resultados obtidos por meio do treinamento.

O objetivo geral do trabalho é conhecer os resultados do programa MBA Gestão Pública, no contexto da Diretoria de Governo do Banco do Brasil.

Os objetivos específicos são:

1. verificar se os objetivos propostos pelo programa de treinamento MBA Gestão Pública foram atingidos como resultados na Diretoria de Governo;

2. descrever as fases do programa de treinamento MBA Gestão Pública tendo como referência o Modelo MAIS de avaliação de treinamento (BORGES-ANDRADE, 1982);

3. descrever possíveis indicadores de resultado que possam ser associados ao programa de treinamento, tendo como referência as seguintes fontes de observação:
a. volume de negócios;
b. satisfação de clientes da área governo;
c. percepção da cadeia de valor da área governo
d. ampliação de negócios ;
e. desenvolvimento de estratégias de marketing;
f. modificação de processos internos;
g. desenvolvimento estratégico da área;
h. perspectivas, novos produtos e formas de realização de negócios; e
i. desenvolvimento humano.

4. classificar os resultados obtidos no programa MBA Gestão Pública com base na Teoria da Vantagem Competitiva Sustentável (BARNEY, 1991). 
Este estudo divide-se em seis capítulos, o primeiro capítulo contém a parte introdutória onde se contempla inicialmente a justificativa do tema, o problema de investigação e os objetivos da dissertação.

O segundo capítulo contempla o referencial teórico e está dividido em:

Aprendizagem Individual, cujos autores são, Piaget (1973), Rogers (1975), Farnsworth (1976), Bruner (1977), Stammers e Patrick (1978) Knowles (1981), Kolb (1984), Vigotsky (1988), Malglaive (1995), Dutra (1999) e Perrenoud (2001);

Aprendizagem Organizacional estudado por Kim (1993), Pantoja e BorgesAndrade (2004), Garvin (1998) e Senge (1999);

$\checkmark$ Gestão do Conhecimento abordado em Nonaka e Takeuchi (1997), Davenport et alii (1998), Spender (2001), Shoemaker e Amit (1997) Oliveira Jr. (2001) e Ruas (2001);

Universidade Corporativa segundo Meister (1999), Eboli (1999), Fleury (1999), Vergara (2000), Schön (2000) e Dutra (2004);

$\checkmark$ O tema Programas de Treinamento Empresarial foi estudado com base em Turra et alii, (1975), Farnsworth (1976), Stammers e Patrick (1978), Nadler (1984) apud Abbad (1999), Wexley (1984), Bastos (1991), Tannenbaum e Yukl (1992), Cascio, (1995), Milkovich (1997), Abbad (1999), Decenzo; Robbins (1999), Borges-Andrade (2000), Silva (2002), Nóbrega Jr. (2003), Bohlander, Snell e Sherman, (2003), Freitas e Borges-Andrade (2004), Roesner e Walesc apud Freitas e Borges -Andrade (2004) e Eboli (2004);

Levantamento de Necessidades que teve como base Boydell (1972), Byhan (1977), Nogueira (1980), Abbad (1999), ABNT (2001), Kroehnter (2001), Prahalad e Hamel (1990), Zemke (1999), Teixeira, (1999), Decenzo; Robbins 
(1999), Cappelli (1999), Dutra (1999 e 2001), Perrenoud (2001), Bohlander, Snell e Sherman (2003), Milioni (2003), Dessler (2003) e Dutra (2004);

$\checkmark$ Planejamento e Implementação do Treinamento fundamentado em Mager (1977), Abbad (1999), Milkovich e Boudreau (2000), Bohlander, Snell e Sherman, (2003), Dessler (2003);

$\checkmark$ Avaliação de Programas de Treinamento que utilizou como referências, Kirkpatrick (1993), Farnsworth (1976), Hamblin (1978), Borges-Andrade (1982), Ávilla et alii (1983), Baldwin e Ford (1988), Alliger e Janak (1989), Pfeffer (1997), Ulrich (1997), Philips (1997), Stewart (1998), Cook, (1998), Abbad (1999), Decenzo; Robbins (1999), Milione (1999), Abbad, Gama e BorgesAndrade (2000), Borges-Andrade (2000), Fitz-enz (2001), Salas e CannonBowers (2001), Dimenstein (2002), Bohlander; Snell e Sherman (2003) e Pantoja e Borges-Andrade (2004);

Vantagem Competitiva Sustentável segundo, Penrose (1959), Wernerfelt (1984) apud Fernandes (2004), Coyne (1986), Dierickx e Cool (1989), Porter (1989), Prahalad e Hamel (1990), Barney (1991 e 1995), Hall e Hall (1990), Drucker (1993), Hill e Jones (1998), Stewart (1998), Green (1999), Meister (1999), Kretzer (2002), Kaplan e Norton (2004) e Fernandes (2004).

O terceiro capítulo apresenta a metodologia utilizada para a realização da pesquisa de campo.

O quarto capítulo apresentará os resultados obtidos pela análise dos dados coletados. O quinto capítulo apresentará as conclusões finais e limitações do estudo.

Na seqüência, apresenta-se a estrutura deste estudo, representada pela Figura 1, com o objetivo de fornecer uma visão geral das etapas do trabalho. 


\section{Introdução}

\section{Objetivos da Pesquisa}

\section{Referencial Teórico}
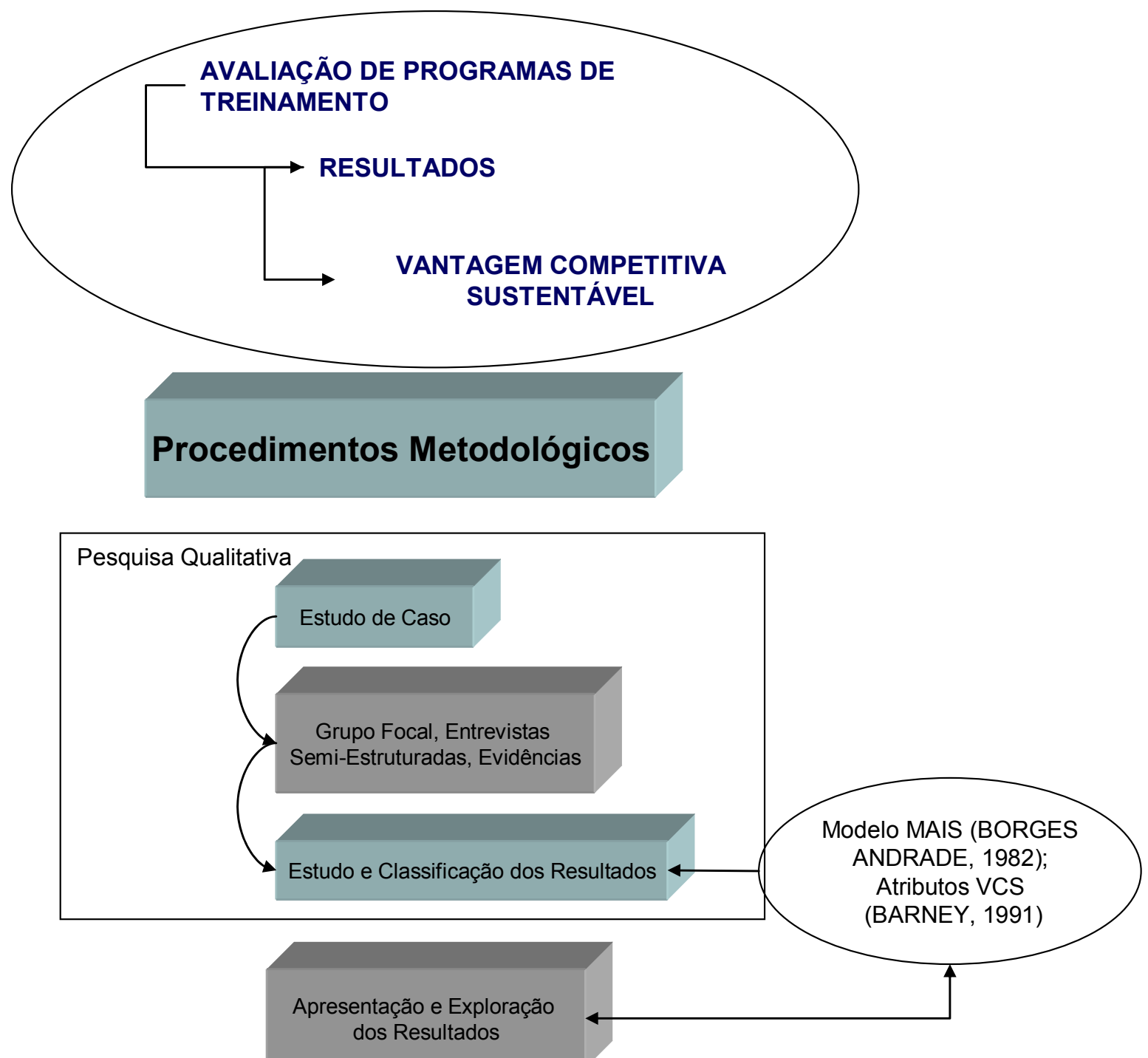

Figura 1: Estrutura do estudo (dissertação)

Fonte: autor 


\section{REFERENCIAL TEÓRICO}

O referencial teórico apresentará algumas reflexões em torno do treinamento como fonte de vantagem competitiva sustentável, passando por conteúdos de aprendizagem individual, que se constituem na primeira instância de aquisição de conhecimento para a empresa, e de aprendizagem organizacional, que deve ser objeto de políticas de gestão do conhecimento pela organização, o que mais recentemente tem sido tratado pelas Universidades Corporativas (UCs) das organizações.

As UCs, antigas áreas de treinamento das organizações, a partir da disseminação do uso desta nomenclatura, alcançaram projeção de braço estratégico da organização. Dessa forma, as UCs além de congregarem todo o treinamento realizado na empresa, tornaram-se responsáveis pelo planejamento de treinamentos alinhados estrategicamente aos objetivos da organização. Este alinhamento obtém comprovação quando há a realização do levantamento de necessidades de treinamento e que, por fim, sejam avaliados os resultados de seus programas de treinamento, face os objetivos organizacionais que motivaram sua realização.

Procura-se demonstrar a forma pela qual os resultados dos programas de treinamento realizados no contexto de Universidades Corporativas podem-se constituir como a fonte geradora Vantagem Competitiva Sustentável de uma organização, sustentando seu desenvolvimento contínuo e a valorização de seu capital intelectual.

Como forma de representação dos elementos que compõe o referencial teórico, apresenta-se a Figura 2: 

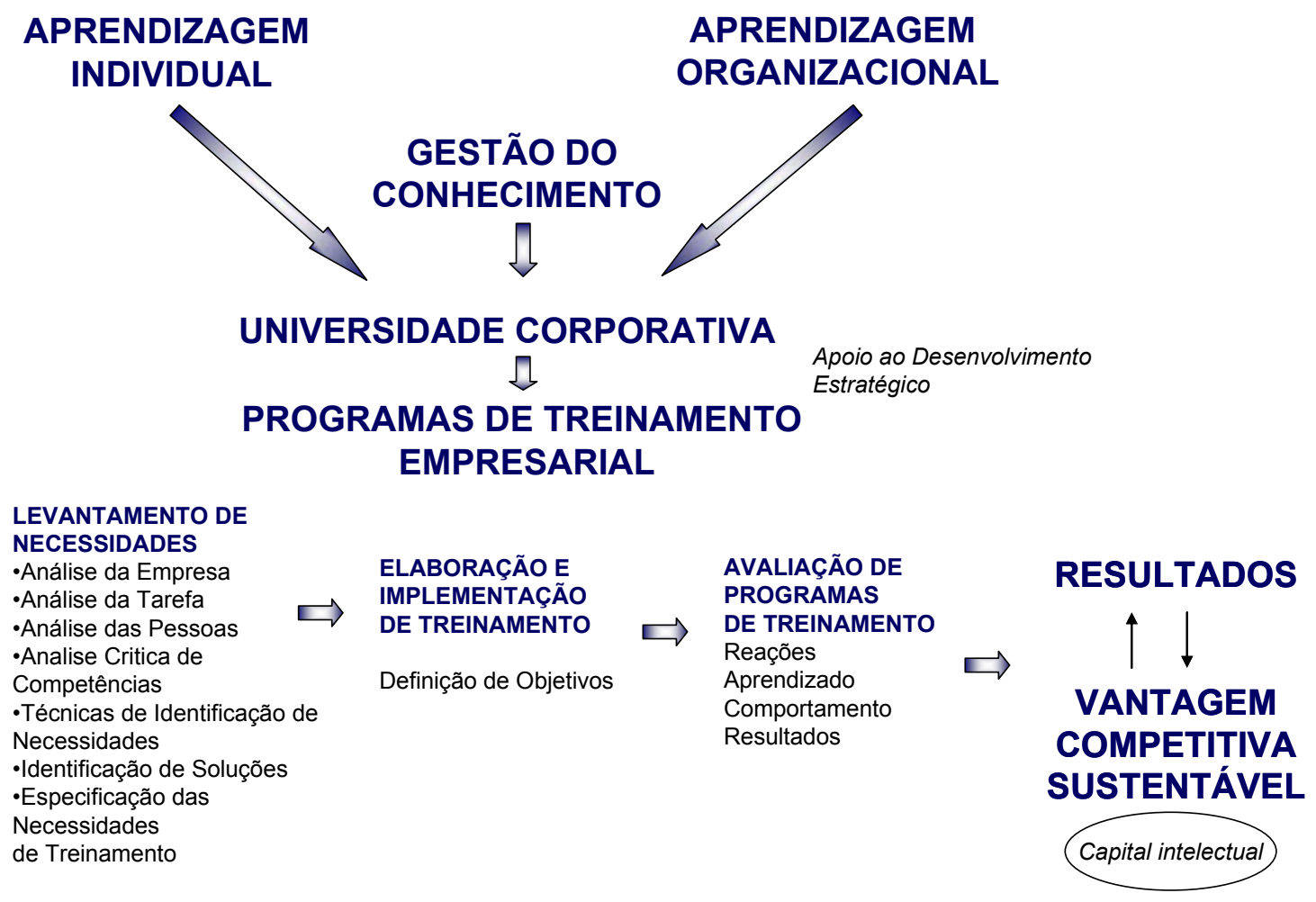

Figura 2: Treinamento como fonte de vantagem competitiva sustentável Fonte: autor

Desenvolvido pelo autor com base em Bruner (1977), Piaget (1973), Kolb (1984), Vigotsky (1988), Rogers (1975), Malglaive (1995), Knowles (1981), Kim (1993), Garvin (2001), Senge (1999) Nonaka e Takeuchi (1997), Fleury e Oliveira Jr., (2001), Meister (1999), Bohlander, Snell e Sherman (2003), Dessler (2003), Nogueira (1980); Kroehnter (2001), Milioni (2003), Milkovich (1997), Cascio (1995), Decenzo; Robbins (1999), (ABNT, 2001), Abbad (1999), Kirkpatrick (1993), Hamblin (1978), Borges-Andrade (1982), Abbad (1999), Edvinson e Malone (1998), Stewart (1998), Antunes (2000), Barney (1991 e 1995), Porter (1989) e Prahalad e Hamel (1990).

A abordagem demonstrada busca explorar os diversos aspectos relacionados ao desenvolvimento de um programa de treinamento na empresa.

O referencial parte do estudo a respeito de como o indivíduo adulto aprende suas relações com o saber e com sistemas de incorporação de novos conteúdos ao seu conjunto de conhecimentos. A revisão discute como estes conhecimentos são trocados com a realidade e 
como eles passam a se incorporar em suas capacidades para o trabalho conforme Knowles (1981), Kolb (1984) e Malglaive (1995).

Paralelamente à compreensão de como se dá o aprendizado no nível individual, a revisão procura compreender como se dá a aprendizagem no nível organizacional, em que se sentido a soma dos aprendizados dos trabalhadores de uma empresa pode ser constituída em aprendizado para a organização. A discussão passa pela forma de sistematização da aprendizagem na empresa e quais suas fontes de alimentação Garvin (2001) e Senge (1999).

A gestão do conhecimento na empresa deve ser considerada como um instrumento de incorporação do conhecimento, transformando-se o conhecimento tácito em explícito, conforme Nonaka e Takeuchi (1997). Observa-se, por fim, a necessidade de que a organização se aproprie deste conhecimento em favor de suas práticas gerenciais, tal como se vê em Fleury e Oliveira Jr., (2001).

Estuda-se em seguida as Universidades Corporativas (UCs) e como elas se integram à gestão e ao desenvolvimento da estratégia da organização. Estuda-se como as UCs trabalham o aprendizado dos funcionários como meio de desenvolvimento da empresa tendo como referência Meister (1999) e Eboli (1999).

A partir da compreensão da organização das UCs, estuda-se mais detidamente as características dos programas de treinamento empresarial, os tipos de treinamento realizáveis e os de cunho gerencial, foco deste estudo. Apresentam-se os sistemas de treinamento como um processo sistêmico da organização, detalhando-se em seguida seus elementos constitutivos, estudados à luz de Bohlander; Snell e Sherman (2003), Dessler (2003), Nogueira (1980); Kroehnter (2001), Milkovich (1997) e Cascio (1995).

Como primeiro dos elementos constitutivos do treinamento, estuda-se o processo de levantamento de necessidades de treinamento. Inicia-se pela análise da empresa, da tarefa, das pessoas e das competências requeridas pela função. Neste mesmo ponto, estudam-se técnicas 
de identificação de necessidades de treinamento, os meios de identificação de solução para o problema organizacional diagnosticado e detalha-se a forma de apresentação e especificação das necessidades de treinamento, tendo como referência Decenzo; Robbins (1999), (ABNT, 2001) e Abbad (1999).

Após o entendimento de como se dá o processo do levantamento das necessidades, estuda-se o planejamento e a implementação do treinamento, neste ponto é importante compreender as relações de interdependência que se criam entre as necessidades identificadas e a descrição de objetivos que se pretende atingir, estuda-se meios de implementação e adequação de técnicas para objetivos específicos, sendo utilizados neste ponto Kroehnter (2001), Milkovich (1997) e Cascio (1995).

Em seguida, estudam-se os aspectos ligados à avaliação de programas de treinamento e seus diversos sistemas de realização, abordam-se quatro modelos distintos, cronologicamente derivados uns dos outros. Estuda-se ainda as dimensões de avaliação no âmbito das reações, aprendizado, comportamento e resultados, partindo de Kirkpatrick (1993), Hamblin (1978), Borges-Andrade (1982) e Abbad (1999).

No aspecto dos resultados, detém-se maior atenção, distinguindo-se as posições dos diversos autores e as ressalvas de cada um deles quanto à observação dos resultados de programas de treinamento.

No contexto desta discussão aborda-se o desenvolvimento do capital intelectual da organização por meio de Edvinson e Malone (1998), Stewart (1998), Antunes (2000).

Finaliza-se o conjunto teórico discutindo como se dá a criação da vantagem competitiva sustentável da organização, baseado em Barney (1991 e 1995), Porter (1989) e Prahalad e Hamel (1990).

Inicia-se a exploração do referencial bibliográfico com o estudo da aprendizagem individual. 


\subsection{APRENDIZAGEM INDIVIDUAL}

As mudanças do mercado, a incorporação de novas tecnologias no trabalho e o desejo de autodesenvolvimento, podem ser considerados fatores que motivam o adulto a aprender, por esta razão vale discutir brevemente a aprendizagem e em especial a aprendizagem de adultos.

Para Bruner (1977), a aprendizagem na Teoria Construtivista é um processo ativo por meio do qual os aprendizes constroem novas idéias ou conceitos baseados nos seus conhecimentos antigos ou atuais. O aprendiz seleciona e transforma as informações, constrói hipóteses e toma decisões baseado em sua própria estrutura cognitiva.

Nesta visão de aprendizagem, o estudante elege as informações mais relevantes às suas necessidades.

Para Piaget (1973), as etapas do aprendizado se constituem num constante processo de adaptação do homem ao mundo, quando há sua adaptação às exigências do mundo, a pessoa se desenvolve e se conhece. Esta adaptação ocorre como resultado do processo que tenta equilibrar a percepção que o sujeito tem da realidade com os seus próprios conhecimentos. Esse estado ganha dinamismo à medida que novas realidades são observadas, relacionam-se e produzem novos repertórios de conhecimento.

Dessa forma, o aprendizado para Piaget (1973) pode ser considerado um processo constante de adaptação à realidade que gera novos conhecimentos e novas formas de interpretação da realidade.

Para Stammers e Patrick (1978, p. 29), “aprendizagem é um estado hipotético que só pode ser inferido a partir da observação de um desempenho mensurável”. Comporta 
esclarecer a diferenciação entre os conceitos de aprendizagem e desempenho, pois nem sempre aquilo que foi aprendido vai alterar o comportamento do treinando.

Para Vigotsky (1988), a aprendizagem pode ser definida como o processo pelo qual o indivíduo adquire informações, habilidades, atitudes e valores, a partir de seu contato com a realidade, com o meio ambiente e com as outras pessoas. Esta visão torna o aprendiz interdepende do meio que o cerca, trocando com ele suas impressões, influenciando-o e sendo por ele influenciado.

Na visão da teoria humanista de Rogers (1975), a educação visa desenvolver nos alunos o senso de iniciativa, a consciência de suas capacidades em assumir responsabilidades, realizar escolhas, adaptarem-se a mudanças, agirem de forma criativa e de realizarem trabalho cooperativo. Para este autor, o foco da aprendizagem está no desenvolvimento da capacidade do estudante em se relacionar com a mudança, estando ele no centro do processo de aprendizagem, é necessário compreender seus estilos.

Para Kolb (1984), a aprendizagem pode ser imaginada como um processo de duas fases, envolvendo-se a percepção e o processamento da informação, conforme se observa na Figura 3. Na fase da percepção, há pessoas que preferem aprender pela impressão que a nova informação lhes causa, outras preferem aprender relacionando ou ponderando sobre a nova experiência. Na fase de processamento da informação, algumas pessoas preferem prestar atenção e observar enquanto outras preferem se tornar pessoal e ativamente envolvidas.

Segundo os estilos de aprendizagem, o surgimento do conhecimento ocorre quando se confrontam a observação do fato e a interação com a realidade.

Ilustrativamente os estilos de aprendizagem para Kolb (1984) são apresentados na seguinte seqüência: 


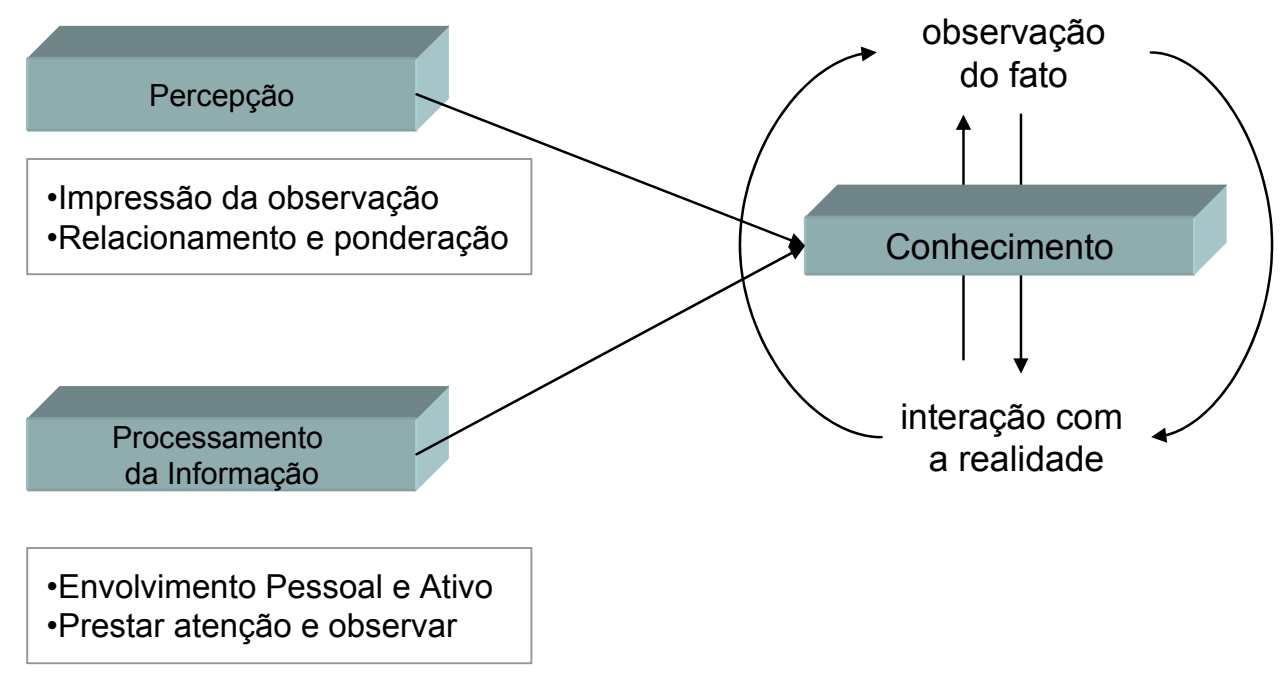

Figura 3: Estilos de aprendizagem Fonte: Adaptado de Kolb (1984)

A Figura 3 demonstra o conhecimento como resultado da interação entre a percepção do sujeito e sua forma de processamento das informações. No momento da percepção, o sujeito constrói impressões, se relaciona e pondera a respeito do objeto de aprendizagem. Para que haja o processamento das informações aprendidas, o sujeito atenta e se relaciona pessoal e ativamente com o objeto que pretende conhecer. Conjugando-se a observação do fato e a interação com a realidade, obtém-se como produto o conhecimento do tema.

Este aprendizado interativo interessa aos programas de treinamento empresarial, que têm como público-alvo alunos adultos, portanto, deve-se considerar a relevância de sua forma de aprendizado como fator crítico de sucesso para o evento. Adultos interessam-se por situações práticas e aplicáveis de forma imediata em suas necessidades, considerar a relevância deste enquadramento certamente facilitará o sucesso do programa (MALGLAIVE, 1995).

Knowles (1981) observa que o aprendizado para a criança começa quando ela adentra ao mundo, em condições iniciais de total dependência, descobrindo e aprendendo tudo o que existe como instrumento de sua convivência com o ambiente. 
Segundo o autor, para o adulto que é detentor de personalidade auto-diretiva, não é assim. O adulto é capaz de tomar suas próprias decisões, é responsável por enfrentar as conseqüências de seus atos, como conseqüência relaciona-se com o aprendizado de maneira freqüentemente questionadora.

Conforme o autor, o adulto projeta na relação de aprendizagem sua necessidade de autonomia do conhecimento.

O adulto adota em seu processo de aprendizado a premissa da relação de savoir fair de Perrenoud (2001), ou seja, o aprendizado de determinadas competências incorpora-se a seu conjunto de saberes e o torna capaz de praticar novas atitudes, certamente acompanhadas de novos desempenhos.

Ainda nesta linha de pensamento de que a formação de adultos exige formatação customizada:

\begin{abstract}
A verdade é que nem o mais talentoso dos oradores pode ensinar nada a ninguém, a menos que esse alguém esteja disposto a aprender e tenha compreendido que, aprendendo, terá condições de alcançar seus objetivos pessoais. Ele poderá aplaudir o virtuosismo do orador, da mesma maneira que poderá aplaudir a apresentação de um cantor ou comediante favorito na televisão. Mas o efeito duradouro sobre seu desempenho como gerente não será maior do que o de um programa de televisão sobre sua capacidade de cantar ou contar piadas (Farnsworth, 1976, p. 5).
\end{abstract}

Em seguida o mesmo autor observa que se os métodos tradicionais de apresentação foram abolidos do ensino de crianças, utilizá-los como adequados às necessidades de profissionais experientes pode ser considerado um equívoco (FARNSWORTH, 1976).

O adulto, em especial, o executivo em formação, conta com um repertório de experiências pessoais que relaciona o tempo todo com os conteúdos a ele apresentados. É fundamental que o executivo perceba aplicação dos conteúdos às atividades de sua responsabilidade ou, do contrário, a experiência do aprendizado se perde.

No campo da educação profissional, é preciso que a aprendizagem seja eleita pelo estudante como necessária a seu conjunto de saberes (BRUNER, 1977), seja objeto de sua 
capacidade de adaptação à realidade (PIAGET, 1973), e relacionamento de interdependência com esta realidade (VIGOTSKY, 1988), sendo possível a verificação de uma alteração em seu comportamento (STAMMERS; PATRICK, 1978). É preciso ainda que a aprendizagem seja capaz de preparar o estudante para o enfrentamento da mudança (ROGERS, 1975). Deve considerar o estilo de aprendizagem do estudante e ser capaz de relacioná-lo com a realidade (KOLB, 1984), preferencialmente aproximada de situações práticas e aplicáveis de forma imediata às necessidades do estudante adulto (FARNSWORTH, 1976; MALGLAIVE, 1995).

Segundo McGregor (1992), a educação pode ser considerada como um processo de influência por integração e autocontrole, existindo vários tipos de aprendizagem como a aquisição do conhecimento intelectual, a aquisição de habilidades manuais, a aquisição de habilidades em solução de problemas, a aquisição de habilidades de interação social, entre outras. Estes tipos de aprendizagem, em ambiente profissional, destinam-se a composição de perfis de atuação adequados às diferentes funções na organização.

Para Bruner (1977), a discussão do desenvolvimento contínuo, por meio de programas de treinamento, deve identificar práticas pedagógicas que tenham alcançado maiores índices de sucesso. Tais práticas devem facilitar a aprendizagem, entendida como o processo de captação de relações entre os fatos de aquisição de novas informações e de sua transformação e transferência para novas situações do ambiente organizacional.

Tendo-se compreendido sinteticamente o processo de aprendizagem das pessoas no contexto da organização, é preciso compreender o processo de transferência do aprendizado das pessoas para a organização.

\footnotetext{
Ao colocarmos organização e as pessoas lado a lado, podemos verificar um processo contínuo de troca de competências. A organização transfere seu patrimônio de conhecimentos para as pessoas, enriquecendo-as e preparando-as para enfrentar novas situações profissionais e pessoais, quer na organização ou fora dela. As pessoas, ao desenvolverem sua capacidade individual, transferem para a organização seu aprendizado capacitando a organização para enfrentar novos desafios (DUTRA, 1999, p. 23).
} 
Dessa forma, quando o indivíduo aprende, transfere à empresa seus conhecimentos, tornando-a um repositório dinâmico de novos saberes com maior capacidade de gerar conteúdos de aprendizagem aos demais colaboradores, criando-se assim o ciclo da aprendizagem organizacional.

\subsection{APRENDIZAGEM ORGANIZACIONAL}

O termo aprendizagem organizacional representa como idéia central a forma como as organizações aprendem, como a organização se relaciona com o meio e dele extrai observações que incorpora com o objetivo de manter-se em constante desenvolvimento.

Conforme Kim (1993), pode-se pensar nas organizações que aprendem como uma metáfora derivada do entendimento da aprendizagem individual, pois em última análise as empresas aprendem por meio dos indivíduos. Aprendizagem organizacional é definida como "um aumento na capacidade da organização em tomar ações efetivas" (KIM, 1993, p. 43), ou seja, a ampliação das capacidades individuais e sua maior capacidade de promover ações efetivas se reflete na capacidade decisória da organização.

Esta visão é polarizada por Pantoja e Borges-Andrade (2004), que destacam as organizações como sistemas multiníveis, onde ocorre a integração de processos de natureza individual, em grupo e organizacional, considerando a aprendizagem como um processo psicológico que ocorre apenas no primeiro destes níveis. Em sua visão, "no sentido preciso e primordial desse processo e contrariando certa literatura contemporânea em administração, equipes e organizações não aprendem" (PANTOJA; BORGES-ANDRADE, 2004, p. 116).

Parece haver uma discordância entre Kim (1993) e Pantoja e Borges-Andrade (2004), quanto à taxionomia a ser empregada relativamente ao tema. 
Cabe observar que a literatura, referente à aprendizagem organizacional, utiliza este termo entendendo que a aprendizagem organizacional deve ser vista como uma decorrência dos aprendizados individuais de seus colaboradores e como um resultado maior do que a somatória simples destes aprendizados.

Os resultados desta aprendizagem podem ser vistos, por exemplo, na modificação de processos que ocorrem na organização. Se num primeiro momento, as mudanças no processo ocorreram em razão da influência direta e como produto do aprendizado de uma pessoa, após sua implantação e adoção do novo processo como forma de trabalho, desfaz-se o vínculo de dependência entre o aprendizado da pessoa e da organização.

Admitindo este raciocínio, segue-se referencial bibliográfico concordante com a visão de que o aprendizado organizacional é o aumento das capacidades da organização como resultado do aumento das capacidades individuais de sua força de trabalho.

Garvin (1998) considera que a motivação do aprendizado organizacional não deve ser reativa, mas intencional, eficaz e conectada aos objetivos e estratégias da organização. Deve prever desafios, ameaças e oportunidades e não apenas reagir às crises. Dessa forma, o aprendizado cria flexibilidade e agilidade para que a organização possa lidar com a incerteza. Em sua visão, as mudanças que caminham lado a lado com o aprendizado, criam raízes.

A aprendizagem organizacional apresenta-se como uma política de desenvolvimento organizacional vinculada à estratégia da organização e utilizada como instrumento de assimilação do aprendizado das pessoas.

Como atributos do sistema de aprendizagem organizacional, Garvin (2001) define a necessidade de que as empresas detenham habilidades em cinco áreas:

"solução de problemas de maneira sistemática, experimentação de novas abordagens, aprendizado com as próprias experiências e antecedentes, aprendizado com as experiências e melhores práticas de outras organizações, concorrentes ou não e finalmente pela transferência de conhecimento rápida e eficiente em toda organização". Garvin (2001, p. 55) 
O autor sugere ainda que haja a sistematização dos registros destas práticas como forma de prover a empresa de conhecimento.

A organização deve ter uma política de administração de seu conhecimento, mas ao mesmo tempo ser capaz de inovar, deve observar suas melhores práticas e as de seus concorrentes, incorporando-as em seu sistema de gestão de forma dinâmica e principalmente sendo capaz de fazer com que o conhecimento se dissemine pela instituição.

Para Senge (1999), a proposta da organização que aprende foi primeiramente desenvolvida para identificar as empresas empenhadas na busca de resultados em razão de um processo de constante aprendizado. Para este autor, a resposta aos desafios do mercado competitivo e em permanente transformação está em uma nova e sistêmica forma de pensamento que envolva múltiplas visões de mundo e em uma educação permanente, que promova o ser humano em seu desenvolvimento pessoal e profissional.

Ainda segundo Senge (1999), a aprendizagem organizacional ocorre basicamente de duas formas: aprendizagem adaptativa, neste sentido reativa e relacionada ao enfrentamento do ambiente; e a aprendizagem generativa, relacionada à criatividade e à capacidade que a organização deve desenvolver para enxergar os sistemas que controlam eventos capazes de modificar o ambiente e agir junto a estes.

A aprendizagem generativa para Senge (1999) é considerada superior à aprendizagem adaptativa, por implicar maior valor competitivo para a organização, já que sua proposição age de maneira sistêmica e não pontual, o que sugere a necessidade da criação de complexos sistemas de inteligência capazes de prover a organização com as informações necessárias ao seu desenvolvimento.

Dessa forma, a aprendizagem organizacional ocorre, onde haja um sistema organizacional de monitoramento dos resultados da organização, com capacidade de rápida disseminação dessas informações (GARVIN, 1988), fruto do pensamento sistêmico e de ações 
de educação permanente, capacitando a organização para o enfrentamento da mudança e das incertezas (SENGE, 1999).

Nessas organizações, os funcionários precisam estar envolvidos no processo de definição de metas organizacionais, de suas principais tecnologias, bem como imbuídos do desejo e da capacidade de trabalhar em conjunto para criar o novo conhecimento. O campo do aprendizado é um modelo simples que faz a combinação entre o que precisa ser aprendido e quem precisa aprender, criando flexibilidade e agilidade para que a organização possa lidar com a incerteza, e onde as pessoas possam gerar novas formas de criar os resultados.

Ao promover a aprendizagem organizacional, a organização deve ser capaz de incorporar em suas práticas o aprendizado que provém destas ações. Os mecanismos de incorporação dessas práticas são estudados pela gestão do conhecimento na empresa.

\subsection{GESTÃO DO CONHECIMENTO}

Nonaka e Takeuchi (1997) definem o conhecimento em duas categorias, tácito e explícito. Explícito é o conhecimento exteriorizado por práticas e declarado pela empresa. O conhecimento tácito, mais difícil de demonstrar, se encontra latente na forma como a organização interage com o meio.

A gestão do conhecimento coloca-se como um processo em que sua criação resulta da espiral de aquisição do conhecimento. Um processo de transformação do conhecimento tácito em explícito.

Os autores discutem o tema na organização de negócios, acreditando que nela, além do processamento do conhecimento, pode ocorrer também sua criação. 
O conhecimento explícito e o conhecimento tácito apresentam-se como itens mutuamente complementares para a gestão de conhecimento da organização.

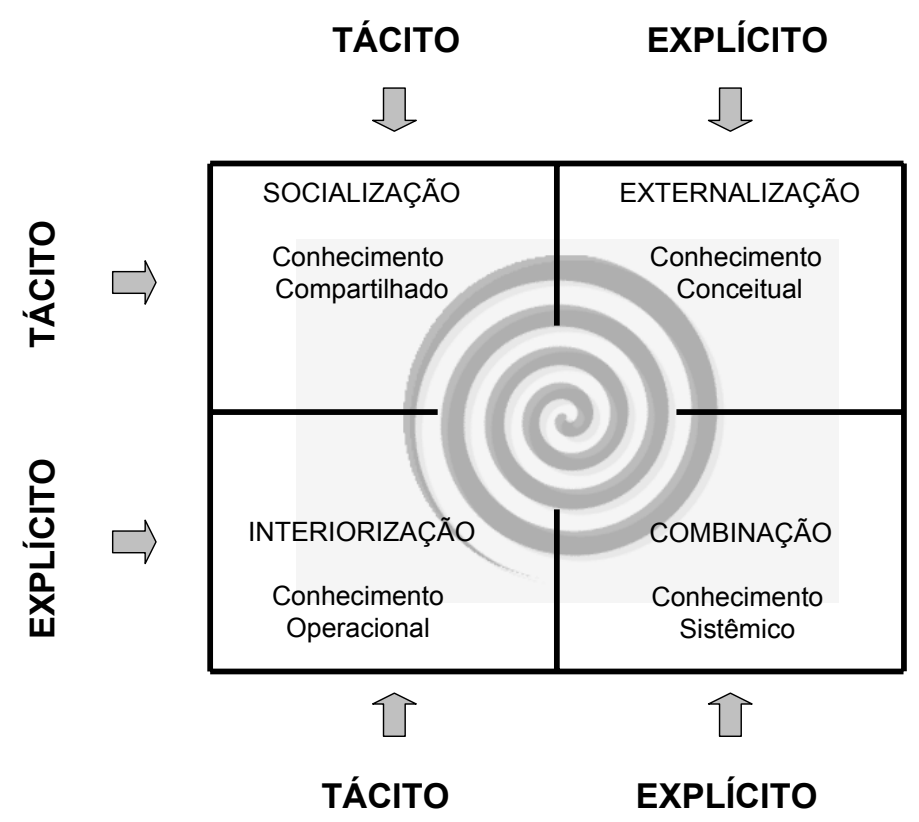

Figura 4: Espiral do Conhecimento

Fonte: Adaptado de Nonaka e Takeuchi (1997)

Conforme se vê na figura, o conhecimento explícito caracteriza o tipo de conteúdo a ser compilado pela organização. A compilação deste conhecimento ocorre por meio de registros formais e sistemáticos, tais como manuais organizacionais, especificações de atividades, expressões matemáticas e outras formas de registro. Esse conhecimento é formal e a organização o utiliza em diversos aspectos, para a manutenção e acompanhamento de suas atividades (NONAKA; TAKEUCHI, 1997).

O conhecimento tácito envolve as experiências individuais dos trabalhadores da organização. Divide-se em duas dimensões: a dimensão técnica e a dimensão cognitiva.

A dimensão técnica compreende habilidades e talentos pessoais informais dos trabalhadores da organização, está inserida no processo de aprendizado individual de cada ser humano, sendo o seu know-how pessoal. Sua constituição relata que a partir da mesma atividade, diferentes pessoas são capazes de gerar diferentes resultados e conhecimentos que 
em última análise constituem-se em fontes de vantagem competitiva (NONAKA; TAKEUCHI, 1997).

A dimensão cognitiva constitui-se das crenças, valores, ideais, esquemas e modelos mentais que os indivíduos desenvolvem de maneira pessoal e se incorporam em seu sistema de compreensão do mundo, admitidos pessoalmente como verdadeiros. Portanto, a dimensão cognitiva apresenta-se assim como as capacidades individuais de cada pessoa.

Apesar de sua difícil articulação, a dimensão do conhecimento tácito modela a forma como cada indivíduo percebe o mundo. Este conhecimento é considerado o mais importante dos conhecimentos na organização (NONAKA; TAKEUCHI, 1997). Essa importância surge em razão de sua constituição, que se relaciona com a diversidade de conhecimentos do conjunto das pessoas.

Em torno da implantação da gestão do conhecimento na organização, Davenport et alii (1998) constataram quatro estágios para a prática da gestão do conhecimento na organização: criar um repositório de conhecimento; prover acesso ao conhecimento produzido pela empresa e relacionado ao mercado de sua atuação; criar um ambiente de conhecimento, envolvendo a criação, a transferência e o uso mais eficaz do conhecimento (onde esta prática incorpore-se na gestão estratégica da organização) e, por fim, afirmam que a gestão do conhecimento deve constituir-se em objetivo da organização e o controle do conhecimento deve ser visto como um recurso de seu capital. Os autores citam como experiências de sucesso deste controle, os casos da Dow Chemical e da Skandia, que a partir de práticas da gestão de conhecimento alcançaram maior valorização de suas ações no mercado.

Essa visão apresenta a gestão do conhecimento como uma política de gestão que deve se incorporar à prática gerencial da organização, criando, facilitando o acesso, tornando o ambiente propício e sendo capaz de controlar o conhecimento da organização. 
Em consonância com Davenport et alii (1998), Spender (2001) considera a organização como um sistema capaz de gerar, comunicar e aplicar o conhecimento, aproximando sua prática de maneira mais objetiva ao monitoramento do mercado. Para este autor, a gestão do conhecimento deve ajudar os gerentes a refletirem sobre como maximizar a responsividade da organização para modificar as condições do mercado e assim refletir com maior assertividade sua habilidade competitiva, tornando a gestão de conhecimento um instrumento de competitividade empresarial.

$\mathrm{Na}$ mesma linha que observa a gestão do conhecimento como instrumento de desenvolvimento da competitividade empresarial, Shoemaker e Amit (1997) dimensionam o conhecimento organizacional como estratégico à medida que os ativos intangíveis da organização, tais como o conhecimento organizacional, não podem ser replicados pelos competidores devem estar fortemente associados a história e a cultura da organização. Essa definição parece situar a gestão do conhecimento numa dimensão de relevância estratégica que a incorpora aos atributos essenciais da organização. As práticas de recursos humanos e o treinamento por conseguinte podem ser caracterizados como uma das práticas acessórias de gestão do conhecimento, devendo dessa forma responsabilizarem-se pela aquisição ou desenvolvimento de competências para a organização.

Para Oliveira Jr. (2001), o principal ponto de pesquisa em teoria da administração estratégica está no desafio de serem descobertas as formas pelas quais as empresas desenvolvem e mantém sua competitividade. Para o autor, as competências essenciais da empresa estão intimamente associadas ao seu know-how coletivo, desta forma a administração do conhecimento pode contribuir para o desenvolvimento de uma vantagem competitiva sustentável para a empresa. 
Conforme já foi demonstrado, as organizações devem ser capazes de aprender. Esse aprendizado passa por práticas gerenciais que sejam capazes de fazer com que a organização tenha um relacionamento de mútuo conhecimento com o mercado.

O intercâmbio de conhecimento da organização com o mercado pode e deve ser impulsionado e até mesmo criado pelo desenvolvimento de competências gerenciais, como resultado que se espera do treinamento empresarial (RUAS, 2001).

A forma como a organização incorpora o aprendizado em suas práticas é objeto de estudo da gestão do conhecimento, o que se constata é que o desenvolvimento das capacidades humanas na organização (suas competências), qualifica e maximiza a capacidade das organizações em incorporar estas práticas, ou seja, o desenvolvimento das pessoas amplia a capacidade das empresas em torno da gestão do conhecimento.

No contexto das organizações, a gestão do conhecimento deve ser objeto de política específica, passando a organização a ser responsável pelo registro sistemático de seus indicadores de conhecimento, e pela transposição do conhecimento técnico e cognitivo, que depende exclusivamente da capacidade das pessoas para a organização (NONAKA; TAKEUCHI, 1997).

A gestão do conhecimento deve se apresentar como uma política de incentivo à criação, à transferência e ao uso do conhecimento, sendo objeto de controle da organização. A gestão do conhecimento pode proporcionar a valorização da empresa, pois constitui-se num instrumento de manutenção e ampliação de seu capital intelectual (DAVENPORT et alii 1998).

A gestão do conhecimento deve ainda atuar como instrumento de inteligência para direcionamento da atuação de mercado da organização (SPENDER, 2001).

Define-se a gestão do conhecimento como estratégica, pois a construção do conhecimento, vinculada aos valores da empresa, encerra grande dificuldade de imitação 
pelos competidores (SHOEMAKER; AMIT, 1997) e pode representar uma fonte de vantagem competitiva sustentável (OLIVEIRA JR., 2001), sendo incentivada e criada pelo desenvolvimento de competências gerenciais resultantes do treinamento empresarial (RUAS, 2001).

Entendida como necessidade, a aprendizagem organizacional passou a ser sistematizada por meio da gestão do conhecimento e continuamente impulsionada, elevando a condição dos centros de treinamento empresariais à de Universidades Corporativas.

As Universidades Corporativas, UCs, calcaram esta nomenclatura pela capacidade de orientar a produção e realização de treinamentos corporativos alinhados com os objetivos estratégicos da empresa, substituindo a produção de programas de treinamento pouco relacionados entre si, evitando dessa forma os programas instrucionais de prateleira.

\subsection{UNIVERSIDADE CORPORATIVA}

A literatura que em geral refere-se ao tema das Universidades Corporativas concorda que a educação formal e primária deve ser adquirida pelos profissionais em ambientes externos à universidade corporativa, pois esta última tem como responsabilidade $\mathrm{o}$ direcionamento técnico da formação profissional, alinhada em última análise a objetivos de desenvolvimento organizacional. Neste sentido, compreende-se em geral que a formação deve ser capaz de ir além das técnicas, sendo adquirida assim externamente à corporação.

Conceitualmente, Meister (1999) define UC como o elemento de agregação do desenvolvimento e educação de funcionários, clientes e fornecedores, com o objetivo de atender às estratégias empresariais da organização. 
As UCs possuem ênfase no desenvolvimento das capacidades de autogerenciamento, de realizações individuais e em equipes, bem como na identificação e aperfeiçoamento do conjunto de qualificações do funcionário.

Para Meister (1999), UCs atuam como um centro estratégico de formação, onde as demandas de desenvolvimento de pessoal interno e de pessoal relacionado aos interesses da organização serão constantemente desenvolvidas, como meio de apoiar a organização.

Eboli (1999) vê as Universidades Corporativas como um avanço das organizações em relação aos centros de treinamento tradicionais, que ilustrativamente podem assim ser comparados:

\begin{tabular}{|l|c|l|}
\hline $\begin{array}{l}\text { Departamento de } \\
\text { Treinamento Tradicional }\end{array}$ & & Universidade Corporativa \\
\hline Habilidades & Objetivo & Competências críticas \\
\hline Aprendizado individual & Foco & Aprendizado organizacional \\
\hline Tático & Escopo & Estratégico \\
\hline Necessidades individuais & Enfase & Estratégias de negócio \\
\hline Interno & Público & Interno e externo \\
\hline Aumento de habilidades & Resultado & Aumento de desempenho \\
\hline
\end{tabular}

Quadro 1 - Treinamento e Desenvolvimento tradicional x Universidades Corporativas Fonte: Eboli (1999, p.115)

Conforme Meister (1999), a compreensão das Universidades Corporativas passa pelo entendimento do contexto ambiental em que se inseriam as organizações, quando o conceito começou a ser discutido. Naquele momento havia premência por organizações nãohierárquicas, enxutas e flexíveis, capazes de responder de maneira rápida ao ambiente empresarial; concomitantemente deu-se o surgimento e consolidação da "economia do conhecimento" como nova base de geração de riqueza, emergiu ainda um novo foco sobre o conceito de empregabilidade em que o contrato de trabalho passou do nível relacional para o transacional, e finalmente surgiram mudanças na educação, em especial na educação corporativa, evidenciando-se a necessidade de formar pessoas com visão global e perspectiva internacional dos negócios. 
Segundo Meister (1999), essas tendências apontam para o comprometimento da empresa com a educação e o desenvolvimento dos funcionários como fonte de criação da vantagem competitiva sustentável, exigindo que todas as pessoas, nos diversos níveis organizacionais, tenham desenvolvido a capacidade de criar trabalho e conhecimento organizacional, contribuindo para o sucesso da organização.

A implementação de UCs, segundo Meister (1999), deve considerar em seu escopo a definição de competências essenciais da organização, base sobre a qual o treinamento será organizado. Lembra ainda que o projeto de UC pode ser fortemente apoiado por iniciativas de fortalecimento da cultura corporativa voltada à aprendizagem.

A mesma autora observa que o treinamento no contexto da UC pode e deve se estender à cadeia de valor da organização, pois os resultados das ações de educação continuada geram, em seu favor, benefícios sistêmicos.

Nessa linha, para Fleury (1999), as UCs devem ser vistas como agregadoras de novas formas de aprendizagem, gerando permutas entre clientes e fornecedores, criando ações que possam ser disseminadas por toda a cadeia de valor a qual pertence a organização, criando um círculo virtuoso de capacitação profisssional.

Eboli (1999) ressalta que os programas de treinamento realizados pelas UCs, considerados os mais bem sucedidos, são aqueles realizados em parceira com Universidades independentes que tenham experiência com este tipo de atividade, porque assim são capazes de auxiliar a gestão do conhecimento, além do beneficio implícito de serem capazes de “oxigenar” a capacitação do pessoal interno com insumo de formação independente.

Meister (1999) comenta que a universidade corporativa deve se organizar em torno dos princípios e objetivos da empresa tendo como foco o desenvolvimento das capacidades dos funcionários para que tornem a empresa cada vez mais competitiva e apta ao mercado globalizado. 
Segundo Eboli (1999), o que relaciona o impacto positivo das UCs ao sucesso obtido pelas empresas que a adotaram é a utilização de sistemas educacionais competitivos, que privilegiam o desenvolvimento de atitudes, posturas e habilidades, e não apenas o conhecimento técnico e instrumental dos colaboradores. Observando-se este desenvolvimento complementar como instrumento de capacitação ampla do profissional, depreende-se que esta formação complexa será capaz de oferecer maiores contribuições à organização.

As UCs devem criar oportunidades de aprendizagem ativa e contínua que dêem suporte aos objetivos críticos da organização.

As Universidades Corporativas são vistas desse modo como elemento de diferenciação das organizações, contudo é necessário polarizar essa visão, no que diz respeito a possível endogenia no pensamento da organização, neste sentido Vergara (2000, p.187) adverte:

\footnotetext{
“...a Universidade Corporativa, voltando-se tanto para seus objetivos, estratégias e atividades específicas, corre o risco de formar "apertadores de parafuso", no sentido chapliniano, e perder sua competitividade por não dispor de pessoas que dominem o pensamento abstrato, os conceitos, que não desenvolvam as habilidades requeridas a um aprendizado contínuo, pessoas capazes de ler o que não está escrito, de ver o que não é mostrado, de ouvir o que não é falado. Enfim, pessoas capazes de fazer a diferença em um mundo de constantes e velozes mudanças".
}

Compreende-se que a UC deve ser vista com um elemento de diferenciação da organização, mas é preciso que considere em seu escopo elementos de formação problematizante, capaz de formar para o imponderável, para além dos elementos de tangibilidade imediata, ampliando-se os conteúdos dos programas para que sejam capazes de formar um profissional com maiores capacidades reflexivas.

Conforme Schön (2000), formar profissionais reflexivos amplia a utilidade da ação de educação, pois os torna capazes de analisar suas ações e questionar de forma continuada se os resultados obtidos poderiam ser ampliados e como eles se comunicam com os demais elementos da organização e da sociedade. 
Este entendimento alinha-se com o de Dutra (2004) de que as ações de desenvolvimento das competências organizacionais surtirão maior efeito quando estiverem alinhadas às competências individuais das pessoas, sendo assim, fruto de seu interesse pessoal.

Compreende-se que as UCs são um elemento estratégico no desenvolvimento do corpo funcional. Meister (1999) vê as UCs emergindo com a via de desenvolvimento da organização moderna inserida na economia do conhecimento. Para Eboli (1999), constituem-se numa evolução dos centros de treinamento tradicionais, inserindo clientes e fornecedores na cadeia de disseminação de conhecimento. Contudo Vergara (2000) observa que deve-se prevenir as organizações para que os critérios de orientação para formação não se tornem apenas utilitários, mas que, conforme Schön (2000), sejam capazes de formar para o intangível.

Tendo-se compreendido o valor da aprendizagem organizacional, a necessidade da gestão desse conhecimento e a possibilidade de sua orientação estratégica por meio da universidade corporativa, passa-se a compreensão pormenorizada dos programas de treinamento empresarial.

\subsection{OS PROGRAMAS DE TREINAMENTO EMPRESARIAL}

Como forma de alinhamento de nomenclatura, deve-se compreender o significado dos termos treinamento, educação e desenvolvimento no contexto da organização.

Para Nadler (1984) $)^{2}$, apud Abbad (1999), Borges-Andrade (2000), Silva (2002) e Nóbrega Jr. (2003), treinamento refere-se a aprendizagem relacionada ao trabalho do indivíduo, educação visa a preparação do empregado para ocupar diferente posto de trabalho

\footnotetext{
${ }^{2}$ NADLER, L. The handbook of human resources development, $1^{\text {a }}$ edição. New York: Wiley, 1984.
} 
na organização e desenvolvimento é a aprendizagem destinada ao crescimento do indivíduo, não relacionada especificamente ao trabalho atual ou futuro, mas, em conformidade com Goldstein (1991), apud ABBAD (1999), vinculadas aos objetivos da organização.

Stammers e Patrick (1978) e Bastos (1991) diferem educação de treinamento pela abrangência dos termos. Na visão desses autores, educação estaria mais vinculada ao homem fora do contexto do trabalho e o treinamento estaria mais relacionado ao trabalho.

Silva (2002) apresenta o termo treinamento como a habilitação sistemática do empregado para o exercício do trabalho na organização, o que entra em concordância com Stammers e Patrick (1978) e Bastos (1991).

Wexley (1984) compreende o treinamento como um esforço planejado da organização para facilitar a aprendizagem de comportamentos orientados para o trabalho.

Ampliando-se o termo treinamento para uma percepção mais abrangente, deve ser compreendido como um "sistema composto por elementos ou subsistemas que mantêm entre si e com o ambiente externo um estreito relacionamento de interdependência" (ABBAD, p.9, 1999). A autora relaciona como elementos de composição desse sistema a avaliação de necessidades de treinamento; o planejamento de treinamento e a avaliação do treinamento. Afirma ainda que esses componentes devem comunicar-se entre si, assumindo que a avaliação de treinamento é o responsável pelo fornecimento de informações para aperfeiçoamento constante do sistema de treinamento.

Tal como se apontou anteriormente neste estudo, o termo treinamento será destinado a indicação das atividades que uma empresa realiza, visando oferecer conteúdos de formação aos seus funcionários, esperando obter como retorno a ampliação de suas capacidades para o trabalho, auxiliando a melhoria dos indicadores da empresa.

A visão de treinamento no contexto das organizações remete à idéia de que o treinamento deve atender à demanda interna de desenvolvimento. 
Os objetivos do treinamento no contexto de uma organização devem sempre se alinhar com os objetivos de desenvolvimento estratégico da empresa, gestores devem manter-se atentos às metas e estratégias da empresa, orientando o treinamento de seus empregados de acordo com elas (BOHLANDER; SNELL; SHERMAN, 2003). As melhores companhias integram o treinamento sistematicamente às demais políticas de recursos humanos (MILKOVICH, 1997).

Em sentido estratégico a maior necessidade de realização de treinamento por parte das empresas é que a era do conhecimento nas organizações exige que elas sejam capazes de lutar contra a obsolescência (CASCIO, 1995). Esta afirmação parece fazer especial sentido quando se fala em treinamento de caráter gerencial, os gerentes da organização são os responsáveis por seu direcionamento estratégico, por seu posicionamento de mercado, em última análise são responsáveis por manter a empresa atualizada e competitiva.

Os tipos de treinamento podem subdividir-se em treinamento gerencial e não gerencial, quanto ao nível de especificação, podem ser geral ou específico, quanto ao domínio podem ser cognitivo, afetivo ou psicomotor (TURRA et alii, 1975).

Descreve-se na metodologia deste estudo, que a unidade de análise será o programa MBA Gestão Pública, curso de formação específica do Banco do Brasil, de caráter gerencial e de domínio cognitivo.

Farnsworth (1976) afirma que a eficácia do desenvolvimento de executivos requer uma política sólida de ancoragem na estratégia da organização, em que se descreva a finalidade perseguida com a realização da ação de treinamento, reforça ainda a idéia de que o treinamento deve estar integrado aos objetivos da empresa.

Para Tannenbaum e Yukl (1992, p. 401), “treinamentos deveriam dar suporte à direção estratégica da organização, e os objetivos de treinamento deveriam estar alinhados com os 
objetivos organizacionais". Portanto o treinamento deve ser planejado a partir da identificação de necessidades estratégicas da organização, desenvolvendo-se como seu apoiador.

Atualizando o conceito, em torno da discussão das competências críticas, Eboli (2004) afirma que desenvolver competências críticas por meio de treinamento alinhado à estratégia da empresa é a função primordial da área de treinamento, em especial das Universidades Corporativas que, como já foi visto, atuam como centros de desenvolvimento humano orientados ao apoio da estratégia da corporação.

Dessa forma, Farnsworth (1976), Tannenbaum e Yukl (1992), e Eboli (2004) caracterizam o treinamento como instrumento de desenvolvimento estratégico das organizações.

Tendo como premissa o envolvimento do treinamento com o desenvolvimento estratégico das organizações, este deve realizar-se destacando elementos de diferenciação em relação ao treinamento que se realizava com base nas necessidades do indivíduo. Roesner e Walesc $^{3}$, apud Freitas e Borges-Andrade (2004), assim diferenciam tais conceitos:

\footnotetext{
${ }^{3}$ ROESNER, L.A. WALESC, S.G. Corporate University: Consulting firm case study. Journal at management in Engineering. v 14. n 2. p. 56-63. mar/abr: 1998
} 


\begin{tabular}{|c|c|}
\hline Treinamento baseado no Indivíduo & Treinamento com foco na Organização \\
\hline $\begin{array}{l}\text { Aprendizagem ocorre fora do local de } \\
\text { trabalho ou em seminário; }\end{array}$ & $\begin{array}{l}\text { Aprender é realizado em ambiente interno e } \\
\text { externo, realizado em vários formatos de } \\
\text { comunicação, selecionados com base em } \\
\text { custo efetivo; }\end{array}$ \\
\hline Privilegia o local do treinamento; & $\begin{array}{l}\text { Predomina o processo } \text { desejado no } \\
\text { treinamento; }\end{array}$ \\
\hline $\begin{array}{l}\text { Treinamento é função do setor de Recursos } \\
\text { Humanos, depende da oportunidade; }\end{array}$ & $\begin{array}{l}\text { O acesso é igual para treinamento ou } \\
\text { educação, independente da localização } \\
\text { geográfica; }\end{array}$ \\
\hline Alguns participantes obtêm certificados; & $\begin{array}{l}\text { A organização é premiada por ofertar a } \\
\text { formação e educação continuada pela IACET }\end{array}$ \\
\hline $\begin{array}{l}\text { Somente os empregados da empresa } \\
\text { participam; }\end{array}$ & $\begin{array}{l}\text { Funcionários e fornecedores são convidados a } \\
\text { participar }\end{array}$ \\
\hline A organização paga tudo; & $\begin{array}{l}\text { Há comprometimento social entre individuo e } \\
\text { organização; }\end{array}$ \\
\hline $\begin{array}{l}\text { O Indivíduo pode selecionar o assunto em } \\
\text { que deseja ser treinado }\end{array}$ & $\begin{array}{l}\text { A organização seleciona e aprova o conteúdo } \\
\text { de aprendizagem; }\end{array}$ \\
\hline $\begin{array}{l}\text { Calcula-se o tempo do curso e o orçamento } \\
\text { em relação a cada indivíduo treinado; }\end{array}$ & $\begin{array}{l}\text { Custo x beneficio é a relação entre tempo } \\
\text { individual e o orçamento das despesas é } \\
\text { limitado; }\end{array}$ \\
\hline $\begin{array}{l}\text { Somente uma pequena fração dos } \\
\text { empregados pode participar; e }\end{array}$ & Espera-se que todos participem; e \\
\hline $\begin{array}{l}\text { Qualquer forma de educação e treinamento é } \\
\text { vista como ganho do setor. }\end{array}$ & $\begin{array}{l}\text { Todo treinamento é considerado parte do } \\
\text { negócio, espera-se retorno sobre o } \\
\text { investimento. }\end{array}$ \\
\hline
\end{tabular}

Quadro 2 - Treinamento baseado no Indivíduo e Treinamento com foco na Organização

Fonte: Roesner e Walesc apud Freitas e Borges Andrade (2004)

Tendo-se compreendido os elementos de diferenciação do treinamento com foco na organização, deve-se compreender como ele ocorre de fato. 
Para Bohlander, Snell e Sherman (2003), visão próxima do que menciona Abbad (1999), para se ter certeza de que os investimentos realizados em treinamento sejam capazes de causar o máximo de impacto, deve-se recorrer à abordagem sistêmica do treinamento, para sua implantação na organização, conforme descrito na figura:

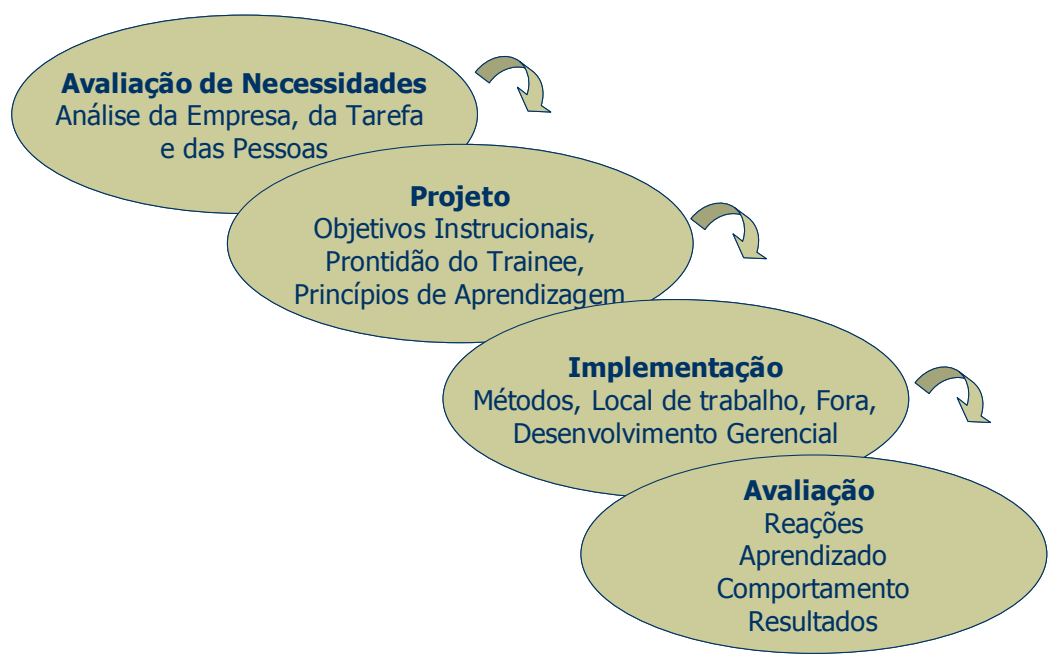

Figura 5: Modelo de Sistemas de Treinamento Fonte: Bohlander, Snell e Sherman, (2003, p. 136)

A abordagem sistêmica demonstrada na Figura 5 indica que o processo de treinamento deve iniciar-se com a avaliação das necessidades de treinamento. A abordagem sistêmica informa que esta fase deve passar pelas instâncias de análise da empresa, da tarefa que gerou a avaliação de necessidade do treinamento e análise das pessoas que realizam a tarefa. Esta fase conclui-se com um relatório que demonstra os objetivos a ser alcançados pelo treinamento e a finalidade a que ele se propõe. Esta finalidade deve estar alinhada a principal lacuna de competência identificada e que motiva o treinamento.

Ainda explorando a representação da Figura 5, o processo de treinamento passa para a fase de projeto do treinamento. Definem-se objetivos instrucionais, que tipo de alunos serão parte do treinamento, bem como os princípios de aprendizagem que se envolvem no programa. 
O treinamento deve então ser implementado. Definem-se métodos de treinamento, se este ocorrerá no ambiente de trabalho ou fora dele, se o objeto do treinamento é o desenvolvimento gerencial ou se atém ao nível operacional.

$\mathrm{Na}$ fase final do processo de treinamento, deve proceder-se a uma criteriosa avaliação de suas dimensões: a reação, o aprendizado, o comportamento e os resultados que o treinamento gerou.

A reação identifica se o treinando gostou do treinamento e se sua operacionalização transcorreu bem.

A avaliação de aprendizado tem como objetivo identificar o quanto o participante aprendeu. Seguindo-se a avaliação deve-se observar o comportamento do aluno, e principalmente, se houve as alterações comportamentais desejáveis.

A avaliação dos resultados produzidos pelo programa, confrontando-se os resultados com o levantamento de necessidades, concluindo-se os resultados do programa de treinamento.

Detalhando-se o processo de treinamento é válido compreender cada uma de suas fases, iniciando-se pela realização do levantamento de necessidades.

\subsection{LEVANTAMENTO DE NECESSIDADES}

A ASTD aponta que em razão dos custos, do tempo consumido e da lacuna de competência interna, as organizações que treinam não realizam levantamento de necessidades antecipado. Este dado remete a conclusão de que a falta do adequado levantamento de necessidades pode ser responsável pela realização de treinamentos inadequados, o que 
provavelmente vai provocar a necessidade de se realizar um novo treinamento (BOHLANDER; SNELL; SHERMAN, 2003).

Quando uma organização resolve avaliar suas necessidades de treinamento, significa que foi identificada uma lacuna de competências, a organização constata que há um claro entre o desempenho esperado e o desempenho observado. Essa constatação indica que a organização deve aprofundar-se na compreensão desta lacuna, e distinguir, se o problema identificado é ou não um problema organizacional que pode ser solucionado por uma ação de treinamento (NOGUEIRA; 1980; MILIONI, 2003).

De maneira objetiva, Nogueira (1980) aponta que as necessidades de treinamento podem ser determinadas pelo confronto do que está acontecendo presentemente e do que deveria estar acontecendo no futuro; segundo este autor, a diferença, se existir, fornecerá subsídios para a escolha da categoria de necessidades de treinamento.

Dessler (2003) alerta para que antes mesmo do levantamento de necessidades, há de se observar se o ambiente e as condições de trabalho são suficientes para o desenvolvimento do pleno potencial do trabalhador. É preciso considerar que o desempenho que motiva o levantamento de necessidades pode apresentar indicadores deficitários porque os equipamentos de trabalho disponíveis não são os adequados para a função, ou porque falta material para a realização completa do trabalho.

Há situações em que o ambiente de trabalho obstrui o desenvolvimento do funcionário ou mesmo que haja sobre ele uma sobrecarga que o impeça de ter um desempenho favorável. Pode ser ainda que o problema de desempenho seja oriundo da motivação do empregado.

Conforme Dessler (2003), quando os problemas de desempenho do empregado acontecem em razão dos motivos apresentados, ações de treinamento não serão capazes de sanar o problema. 
O treinamento surte efeito positivo quando a pessoa que executa uma função que está apresentando deficiência de desempenho não está preparada para fazê-lo, a ação do treinamento direciona-se a realizar esta preparação, (MILIONI, 2003).

Isolando-se as possibilidades de que variáveis ambientais, tais como as apresentadas, sejam responsáveis pelo gap de competências que motivou a necessidade do treinamento e tendo-se chegado a conclusão de que a melhor ação de desenvolvimento organizacional é a realização do treinamento, deve-se proceder a avaliação de necessidades de treinamento.

Para que haja a maximização dos resultados da avaliação de necessidades, esta deve ocorrer depois que a empresa define quais as competências necessárias a realização de seus objetivos (BOHLANDER; SNELL; SHERMAN, 2003).

A definição dos objetivos instrucionais deve incorporar-se ao sistema de gerenciamento da organização e as ações de treinamento devem agir sempre no sentido de apoiar esse sistema (ABNT, 2001), tal critério, visto como política de administração, torna o levantamento de necessidades um passo sistêmico do treinamento.

Existe uma necessidade de treinamento quando há uma lacuna entre o que é exigido de uma pessoa para cumprir seus deveres de forma competente e aquilo que ela sabe de fato e que tem capacidade de realizar (KROEHNTER, 2001). A realização do treinamento visa eliminar a diferença entre o que se exige e o que a pessoa oferece (DESSLER, 2003).

Ainda neste sentido, Boydell (1972) enfoca a necessidade de treinamento como a limitação que se pode corrigir mediante treinamento, sendo essa limitação verificada a partir de situações de trabalho.

Estas percepções colocam o levantamento de necessidades como um passo crucial para o desenho do programa de treinamento, ressaltando o fato de que a necessidade identificada deve ser passível de melhoria por meio de treinamento. 
Conforme Nogueira (1980), para o delineamento de um programa de treinamento é necessário conhecer os resultados de desempenho, presente e requerido pela função que se está analisando, esta informação orienta o perfil de entrada dos participantes para o treinamento, constituindo-se num elemento de análise das pessoas. Deve apontar ainda a diferença entre o comportamento de entrada dos treinandos e o desempenho requerido pela organização, o que determina o valor do treinamento para a organização. Deve ainda apontar os tipos de atividade ou ações a ser desenvolvidas pelo treinamento.

Para Abbad (1999, p. 6), “dentre os propósitos mais tradicionais do treinamento estão aqueles relacionados à identificação e superação de deficiências no desempenho de empregados, preparação de empregados para novas funções e retreinamento para adaptação da mão-de-obra à introdução de novas tecnologias de trabalho”.

Essa visão coloca o treinamento sempre vinculado com uma forma de desenvolvimento das capacidades humanas instaladas na empresa.

Numa compreensão mais específica, essas necessidades podem ser apontadas ainda por indicadores como baixa produtividade de funcionários, altos índices de reclamações de clientes, um maior número de sobras de produção (DeCENZO; ROBBINS, 1999). Aumentos nos índices de acidentes de trabalho ou a realização de novas formas de trabalho, em razão de avanços tecnológicos da empresa, podem ser indicadores de que há necessidade de se realizar um programa de treinamento.

Indisponibilidade de mão-de-obra para contratação, mudanças de objetivos, políticas ou diretrizes organizacionais (NOGUEIRA, 1980) são outras razões que podem levar à necessidade de treinamento.

Em sentido mais estratégico, pode-se identificar que há a necessidade de treinamento quando percebe-se que as core competences da organização estão sendo negligenciadas, 
devendo-se então estabelecer programas de treinamento para reorientar o corpo de gestores neste sentido (PRAHALAD; HAMEL, 1990).

Discussão anterior apresentou o treinamento como forma de desenvolvimento das competências estratégicas da organização. Compreende-se que a união das expertises e esforços de empresa e empregados constrói sua vantagem competitiva (DUTRA, 1999).

Pensar sobre a construção da vantagem competitiva, no momento do levantamento de necessidades de treinamento, alinha-o aos objetivos estratégicos da organização.

Proceder o levantamento de necessidades de treinamento é considerado fator de sucesso do treinamento, como relata Nogueira $(1980$, p.10) "o insucesso de muitos programas de treinamento de supervisores ou mesmo de pessoal técnico, é devido principalmente à falta de levantamento de necessidades de treinamento". A falta de clareza quanto ao que precisa ser melhorado torna a resolução do problema muito mais difícil, constituindo-se num exercício de julgamento por suposição quanto ao que sejam as reais necessidades da organização.

Para Byhan (1977, p.10), a falta do diagnóstico das necessidades de treinamento torna impossível a realização de um treinamento eficaz, corre-se o risco de "treinar as pessoas erradas, sobre as coisas erradas, em tempos errados".

Viu-se que apesar de as empresas não realizarem o levantamento de necessidades (BOHLANDER; SNELL; SHERMAN, 2003), sua conveniência demonstra-se justificada por ser o instrumento capaz de definir primeiramente se o problema organizacional identificado é ou não passível de correção por meio da ação de treinamento (NOGUEIRA; 1980; MILIONI, 2003). Compreendeu-se que a ação de treinamento conta com maior probabilidade de sucesso e assertividade quando atua sobre problemas ou necessidades relacionados a desempenho e é voltada assim ao desenvolvimento do treinando (MILIONI, 2003). O levantamento de necessidades identifica a lacuna entre o que se espera da pessoa que está em determinada função e o que ela de fato entrega como produto de seu trabalho (KROEHNTER, 2001), tendo 
então o objetivo de eliminar essa diferença (DESSLER, 2003). O problema de desempenho evidenciado pelo levantamento pode ser de ordem operacional (NOGUEIRA, 1980; DeCENZO; ROBBINS, 1999) ou estratégica (PRAHALAD; HAMEL, 1990) e ser capaz de construir sua vantagem competitiva sustentável (DUTRA, 1999). Dessa forma, pode ser considerado elemento que se agrega com o objetivo de garantir o sucesso do treinamento (NOGUEIRA, 1980).

Estando clara a relevância da realização do levantamento de necessidades de treinamento, é necessário acrescentar que, para sua identificação, devem ser consideradas as seguintes dimensões:

$\checkmark$ análise da empresa, análise de tarefas, análise das pessoas (BOHLANDER; SNELL; SHERMAN, 2003);

$\checkmark$ análise crítica de competências (ABNT, 2001);

$\checkmark$ técnicas de identificação de necessidades (BOHLANDER; SNELL; SHERMAN, 2003);

$\checkmark$ identificação de soluções (ABNT, 2001); e

$\checkmark$ especificação das necessidades de treinamento (ABNT, 2001).

A Figura 6 representar a seqüência de atividades necessárias para a realização do Levantamento de Necessidades de Treinamento: 


\section{LEVANTAMENTO DE NECESSIDADES DE TREINAMENTO}

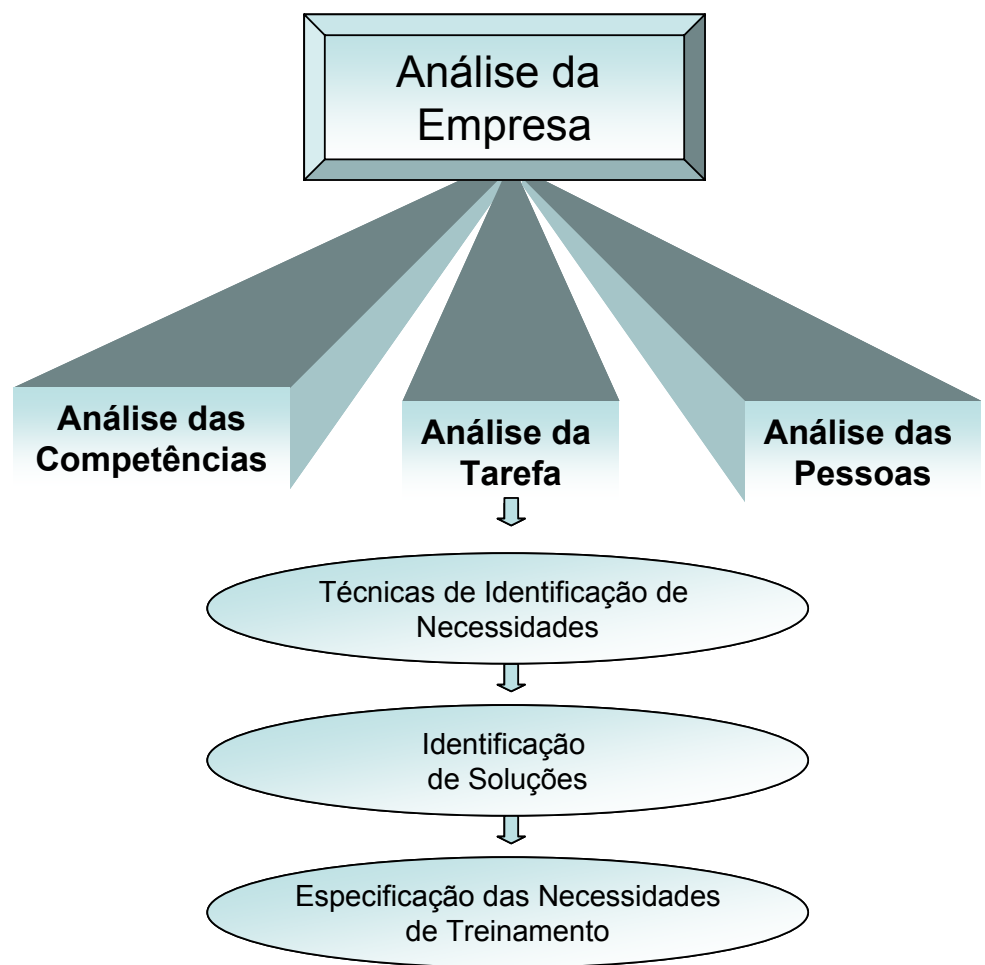

Figura 6: Representação Gráfica da seqüência de atividades necessárias ao Levantamento de Necessidades de Treinamento

Fonte: Autor, baseado em Milkovich (1997), Cascio (1995), Dessler (2003), Decenzo, Robbins (1999), (ABNT, 2001), Nogueira (1980) e Abbad (1999).

A partir da Figura 6, segue explicação das fases do levantamento de necessidades de treinamento.

\subsubsection{Análise da Empresa}

O alinhamento do treinamento com o perfil e as necessidades da empresa é o responsável mais expressivo pelo sucesso do programa de treinamento (MILKOVICH, 1997). Concomitante à análise da empresa, faz-se necessária a análise do ambiente externo da organização e também de seu clima interno, essenciais para o planejamento do programa de treinamento (CASCIO, 1995). 
A análise da empresa e do ambiente em que esta inserida, torna-se importante à medida que orienta a estratégia de realização do programa de treinamento.

Esta análise visa identificar os objetivos estratégicos da empresa e sua estrutura instalada, definindo o ambiente em que se contextualizará a atuação dos treinandos, segundo Bohlander; Snell e Sherman (2003).

A análise da empresa deve considerar, na análise do ambiente, seus competidores, seu público alvo, seus fornecedores e a legislação relacionada a sua atividade, em especial da área a ser atendida pelo treinamento. Essa visão do ambiente revela o contexto em que a organização se insere. $\mathrm{O}$ desenho do programa de treinamento se alimenta dessas informações direcionando-o a melhoria de pontos falhos, a exploração de oportunidades, a prevenção de ameaças e consideração sobre demais outros aspectos externos relacionados ao negócio da organização.

Um diagnóstico interno deve também ser considerado, objetivando avaliar questões de clima organizacional, como a situação de relacionamento instalada após a realização de uma fusão ou aquisição, ou por questões de natureza operacional, como a implantação de novos softwares de gerenciamento, programas de qualidade ou outros acontecimentos que estejam alterando temporária ou definitivamente a rotina de trabalho da organização (BOHLANDER; SNELL; SHERMAN, 2003).

Segundo a norma ISO 14015 (ABNT, 2001), devem ainda ser considerados no escopo da análise da empresa, a natureza dos produtos fornecidos, a rotatividade do pessoal interno, as flutuações sazonais, a necessidade de certificação interna para realização de tarefas, bem como, as solicitações de empregados que indiquem oportunidades de desenvolvimento pessoal. Esses critérios buscam evidenciar se o clima interno é ou não favorável à realização do treinamento. 
A norma recomenda ainda que sejam procedidas análises de resultados de críticas de processo e ações corretivas originárias de reclamações de clientes ou Relatórios de Não Conformidade (RNC), originários de processos de auditoria interna ou externa (ABNT, 2001).

Deve ainda haver um dimensionamento de recursos financeiro, tecnológico, humano e operacional, bem como a disponibilidade de mão-de-obra direta e indireta e a qualidade de bens e serviços oferecidos pela empresa (BOHLANDER; SNELL; SHERMAN, 2003). O estudo destes recursos deve-se ater ao que interessa ao programa de treinamento.

O direcionamento estratégico e o desempenho da empresa no que diz respeito ao foco do treinamento, devem ser amplamente considerados. O treinamento coloca-se como uma forma de apoio ao desenvolvimento organizacional, e como tal realça sua validade apoiando o alcance de objetivos estratégicos da organização.

Há ainda que se considerar que a complexidade do levantamento de dados na empresa, destinados ao programa será mais ou menos complexa dependendo dos objetivos do programa de treinamento. $\mathrm{O}$ treinamento da equipe de call center da empresa certamente exigirá um levantamento de necessidades menor do que um treinamento que tenha como tema a visão estratégica da empresa, do qual deve participar todo o seu staff.

Compreende-se dessa forma que a análise da empresa deve iniciar-se pelo entendimento das características do ambiente e de competição em que esta se encontra. Devese observar as características de cultura e clima da organização que são de natureza estável. E ainda as características de natureza inconstante que se constatam no momento da realização do treinamento (BOHLANDER; SNELL; SHERMAN, 2003).

Deve-se considerar ainda a natureza dos produtos e o mercado ao qual ela se destina (ABNT, 2001).

Em linhas gerais, deve-se observar quais características da empresa e como elas podem influenciar o resultado e a qualidade do treinamento realizado. 
Tendo-se compreendido as dimensões, características e inserção da organização no ambiente, é necessário que o levantamento de necessidades de treinamento avalie, por ordem, as competências requeridas pelos profissionais que se pretende treinar, as tarefas que lhes competem e as pessoas que as realizarão. Segue-se a análise de competências.

\subsubsection{Análise de Competências}

Programas de treinamento baseados em análise de competências têm maior durabilidade do que aqueles que se basearam apenas na analise das tarefas (ZEMKE, 1999). Essa afirmação apóia-se na premissa de que as competências definidas pela organização, como necessárias ao seu desenvolvimento, refletem suas necessidades de perfil interno. É válido explorar brevemente o conceito de competências com o objetivo de esclarecer a necessidade de sua avaliação no ambiente da empresa.

Para Perrenoud (2001), competências são o conjunto formado por savoir fairs, posturas, mas também as ações e atitudes necessárias para o exercício da profissão.

Dutra (2004) amplia a compreensão do conceito de competências, associando à idéia de que competências são o conjunto de conhecimentos, habilidades e atitudes necessárias (CHAs) para que a pessoa desenvolva suas atribuições e responsabilidades, a sua capacidade de entrega e geração de valor para a organização.

Em trabalho anterior, Dutra (2001) aproxima a idéia de competência ao conceito de entrega, ou seja, competência seria a capacidade que a pessoa tem de entrega à organização. A noção de entrega deve ser compreendia sem ser imediatamente associada a idéia de resultados, que possuem natureza muitas vezes passageira. A entrega de que se fala está relacionada a um estado permanente de capacidade, onde resultados surgirão como produtos em diversas oportunidades. 
A análise das competências informa ao profissional, que desenha o treinamento, qual o perfil de atuação desejado para a função, dessa maneira o programa de treinamento pode contemplar em seu contexto o aprofundamento dessas competências.

Parry (1996; p. 50) ${ }^{4}$, apud Dutra (2004; p. 29) resume o conceito de competência como "um cluster de conhecimentos, skills e atitudes relacionados que afetam a maior parte de um job (papel ou responsabilidade), que se relaciona com a performance do job, que possa ser medida contra parâmetros bem aceitos e que pode ser melhorada através de treinamento e desenvolvimento".

Dutra (2004) afirma que as organizações encontram-se em diferentes estágios de avanço em relação à utilização das competências como política integrada de recursos humanos. Sua escala avança em quatro estágios, partindo do mais simples para o mais complexo. Graficamente assim se pode representar as escalas de Dutra:

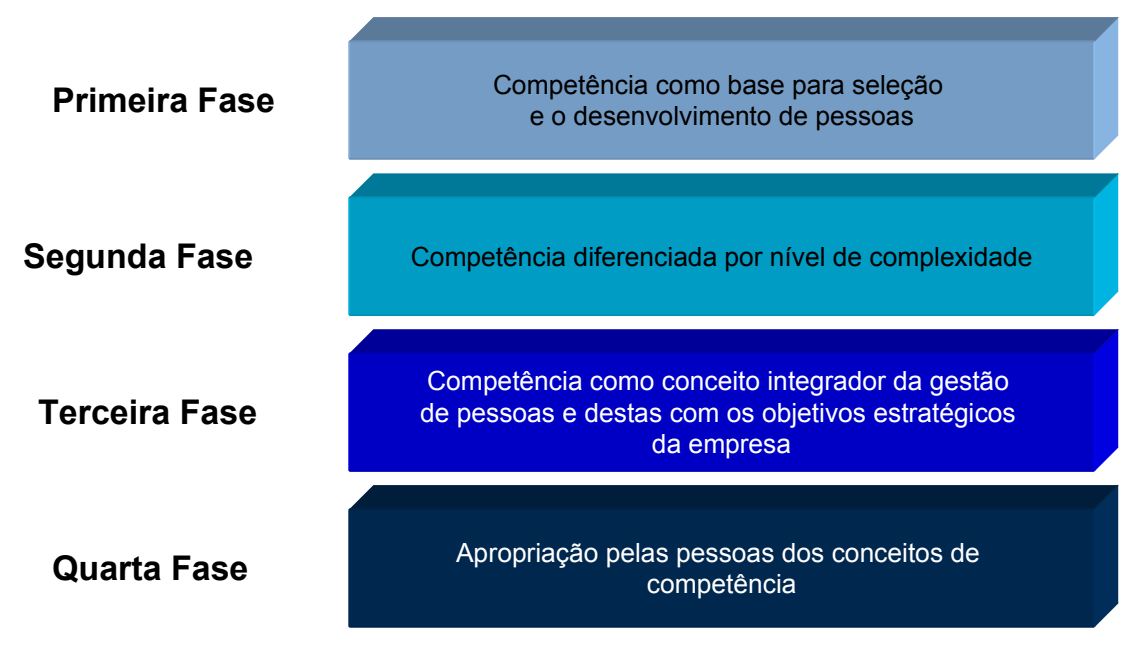

Figura 7: Desenvolvimento do Conceito de Competências Fonte: Adaptado de Dutra (2004, págs. 33 a 35)

Comentando a Figura 7, numa primeira fase, as competências seriam definidas com base nas competências dos executivos apontados pela organização como os de maior sucesso na realização de suas funções. A identificação de suas características serviria então para

\footnotetext{
${ }^{4}$ PARRY, S.B. The quest for competencies. Training, p 48-54, jul. 1996
} 
basear as competências de seus pares e para orientar processos de seleção e afins. Na segunda fase, o procedimento adotado parece-se com o da primeira, porém acrescenta-se ao processo a diferenciação de competências por nível de complexidade da função. Na terceira fase, as competências humanas derivam das competências organizacionais e por conseguinte dos objetivos estratégicos da organização, integrando as pessoas entre si e avançando sua percepção de competência ao conceito de entrega de valor. A quarta fase seria a da apropriação pelas pessoas do conceito de competências, na qual as pessoas efetivamente aderem ao desenho interno de competências apoiando o desenvolvimento da organização.

Para o interesse desse estudo, a compreensão da fase em que se encontra a organização, é fundamental para orientar o desenho do programa de treinamento. O programa pode tanto adequar-se a fase em que se encontra a organização como apoiar seu avanço para outra fase.

A partir da compreensão oferecida por Dutra (2004), infere-se que a realização de treinamento em empresas, que se encontram no quarto estágio de desenvolvimento, tem maiores chances de obter sucesso.

Quando a análise do levantamento de necessidades se faz por meio da comparação entre as competências instaladas e as competências desejáveis o material de observação se torna muito mais rico.

É necessário observar que a organização precisa contar com um desenho de competências suficientemente abrangente, representativo de suas competências essenciais, derivado em "cascata" das competências organizacionais para as individuais.

Baseada nestas premissas, a ação de treinamento conta com representativos elementos de sucesso. 
Pode-se concluir que o treinamento baseado nas competências da organização e das pessoas, além de maior adequação, possui maior durabilidade, preparando os treinandos, de maneira continuada, para o desenvolvimento das estratégias organizacionais.

\subsubsection{Análise da Tarefa}

Em menor grau de complexidade do que a análise das competências, o levantamento de necessidades de treinamento, utiliza-se da análise da tarefa para determinar as necessidades de treinamento de funcionários comparando seu desempenho real com o requerido pela tarefa. A meta da análise da tarefa é identificar os conhecimentos e habilidades necessários para a realização mais competente possível da tarefa em estudo (DESSLER, 2003).

Um das medidas mais importantes do levantamento de necessidades de treinamento é obtida pela avaliação da diferença entre o ponto de eficiência onde as pessoas estão em comparação com o ponto onde elas deveriam estar (NOGUEIRA, 1980; KROEHNTER, 2001; MILIONI, 2003).

A análise da tarefa parece ter mais sentido quando se fala em treinamento de cunho operacional relacionado à funções estanques da organização.

A análise da tarefa, pode envolver ainda a descrição de cargos e especificação de atividades, avaliando-se a competência do empregado, necessária ao desempenho superior do trabalho, a descrição dos Conhecimentos, Habilidades e Atitudes (CHA) necessários ao cargo, certamente oferecerá indicadores valiosos para se avaliar a comparação da descrição da tarefa com sucessos em sua realização (BOHLANDER; SNELL; SHERMAN, 2003), a descrição dos CHAs deve ser utilizada para que delas se derivem as atividades de composição da tarefa.

Nesse sentido, a análise da tarefa aproximar-se-ia do conceito de competência anterior, de maior abrangência, sem contudo confundir-se com ele. 
A análise da tarefa fornece indicadores efetivos sobre o desempenho dos empregados, nas funções para as quais a empresa os determinou como responsáveis, sua análise adequada aponta como deve ser dimensionado o treinamento.

\subsubsection{Análise das Pessoas}

A condução de treinamentos no ambiente das organizações deve passar por uma cuidadosa análise das diferenças individuais das pessoas que serão treinadas (MILKOVICH, 1997).

Teixeira (1999) sinaliza que resultados superiores nos programas de treinamento quando são desenhados para alcançar não somente as necessidades da organização, mas também as necessidades individuais dos participantes, de forma a relacionar o programa com elementos de motivação interna do participante.

Deve-se avaliar quais funcionários precisam do treinamento, se há entre eles pessoas que por alguma razão não querem fazer o treinamento. Identificar as características de formação que permeiam o grupo, quais seus referenciais culturais e socioeconômicos e quanto eles podem influenciar positiva ou negativamente o programa de treinamento.

Esses elementos são de grande relevância para o desenho do programa. Um adequado perfil do grupo que se pretende treinar pode apoiar amplamente o resultado final do treinamento, pois a admissão planejada de suas características no escopo do treinamento, pode potencializar os resultados do programa de treinamento eliminando possíveis fontes de conflito (TEIXEIRA, 1999).

DeCenzo e Robbins (1999) recomendam que quando se analisa as pessoas para o levantamento de necessidade de treinamento deve se fazer as perguntas: a lacuna de desempenho pode ser suprida com uma ação de treinamento? Há outra ação de desenvolvimento capaz de solucionar o problema de forma mais adequada? 
Estas perguntas feitas na dimensão dos empregados, que são candidatos ao programa de treinamento, orientam como a condução do programa pode ser melhorada.

É preciso relembrar que se o gap de desempenho se dá em razão de baixa capacidade do grupo ou da pessoa, o treinamento será eficaz, porém, se razão do baixo desempenho ocorre porque o funcionário é pouco motivado ou não detém ferramentas necessárias a realização do trabalho, provavelmente o treinamento não produzirá os efeitos desejados (DeCENZO; ROBBINS, 1999).

A empresa deve selecionar os candidatos ao treinamento baseada na descrição de cargos ou competências que aponte afinidade com o programa de treinamento a ser realizado.

Os participantes do treinamento devem estar relacionados com as necessidades verificadas e terem capacidade suficientemente representativa para, a partir do treinamento, produzir resultados que ajam sobre o foco do problema identificado no levantamento de necessidades.

\subsubsection{Técnicas de Identificacão de Necessidades}

A realização de análises da empresa, das competências, das tarefas e das pessoas envolvidas no processo de trabalho em exame fornecem importantes indicadores de como o treinamento deve proceder. Estas análises constituem o todo dentre os elementos a considerar quando se está procedendo a identificação de necessidades de treinamento.

Quando a necessidade é estabelecida torna-se mais seguro o processo de determinação do conteúdo geral do curso (KROEHNTER, 2001).

Conforme Dessler (2003) e a revisão de Nogueira (1980), no momento de identificarse de forma objetiva as necessidades do treinamento podem-se proceder, dependendo das características da empresa, os seguintes levantamentos de dados: 
as avaliações de desempenho por superiores ou colegas,

auto-avaliação dos funcionários,

avaliação 360 graus,

indicadores de desempenho,

○ preferencialmente obtidos por meio de séries históricas,

○ comparações com as médias do mercado,

○ comparações com outras unidades da mesma empresa.

Dados do funcionário, ou grupo de funcionários que apontem:

\footnotetext{
$\checkmark \quad$ absenteísmo,

$\checkmark$ produtividade,

$\checkmark$ atrasos,

$\checkmark$ acidentes,

$\checkmark \quad$ licenças de curto período,

$\checkmark$ desperdício,

$\checkmark \quad$ qualidade de produto,

$\checkmark$ horas paradas,

$\checkmark$ reparos,

$\checkmark \quad$ utilização de equipamentos,

$\checkmark \quad$ queixas de clientes,

$\checkmark$ observação por supervisor ou especialista,

$\checkmark \quad$ entrevistas com funcionário,

$\checkmark \quad$ realização de testes,

$\checkmark \quad$ estudos de caso e representação de papéis,

$\checkmark \quad$ pesquisas de atitude,
} 


\section{$\checkmark \quad$ tempo excessivo na execução de tarefas, e \\ $\checkmark \quad$ afastamento de pessoal.}

Podem ainda ser considerados outros indicadores capazes de demonstrar que há falhas a sanar por meio do programa de treinamento.

A definição dos indicadores a ser utilizados pelo levantamento de necessidades de treinamento é de extrema importância, visto que serão os mesmos a ser comparados no processo de avaliação dos resultados do treinamento (DESSLER, 2003).

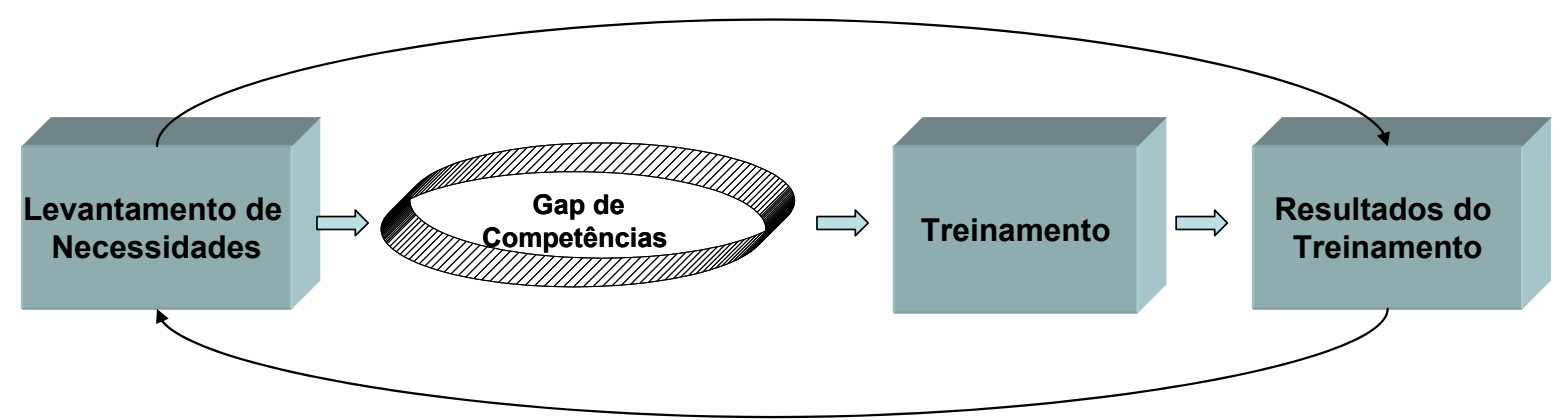

Figura 8: Levantamento de Necessidades e Resultados de Treinamento Fonte: Baseado em Dessler (2003).

Na Figura 8: Levantamento de Necessidades e Resultados de Treinamentorevela o gap de competências da organização. Com base neste gap e nos demais indicadores do levantamento de necessidades, desenha-se o treinamento.

\subsubsection{Identificação de Soluções}

No processo de levantamento das necessidades, ocorre o diagnóstico das lacunas de competência. Estas lacunas são apuradas por meio de técnica adequada e, posteriormente, devem ser objeto da identificação de soluções livres, isso significa que não necessariamente o problema localizado será resolvido com uma ação de treinamento, dependendo do 
diagnóstico, o problema identificado pode ser sanado com a realização de outra ação de desenvolvimento organizacional (DeCENZO; ROBBINS, 1999).

Pode ser ainda que a competência identificada como necessária, tenha prazo de desenvolvimento muito longo e que a premência pelo preenchimento do cargo indique que a necessidade é pelo recrutamento de recurso humano já treinado. Pode ser ainda identificado que a competência deficitária não faça parte das competências essenciais da organização e, neste caso, a terceirização da atividade pode ser recomendada (PRAHALAD; HAMEL, 1990).

A fase de identificação de soluções remete a dualidade que discute a oportunidade de "Fazer ou Comprar" uma determinada competência, tal como analisa Cappelli (1999).

Segundo este autor, essa discussão perpassa pela necessidade que a organização tem de pensar sobre suas escolhas de desenvolvimento organizacional. A cultura organizacional e política de administração de recursos humanos são os principais influenciadores deste processo. Neste momento, a organização pode concluir que é melhor buscar no mercado profissionais que já venham para a empresa após a realização de investimentos pessoais em sua formação. Quando isso ocorre, diz-se que a solução da empresa foi a de "comprar" um talento.

De outra forma, a organização pode decidir que lhe interessa mais investir no desenvolvimento de suas capacidades internas, já que estas responderão de maneira perene a sua necessidade de entrega de melhores capacidades para o trabalho. Quando esta solução é adotada, diz-se que a organização optou por "fazer" um talento.

Após o levantamento de necessidades, o tipo de problema identificado, apontará a solução organizacional que mais faça sentido. Essa fase serve para que a organização analise se o vínculo e a relevância da função que se pretende treinar apresentam as condições necessárias para justificar seu desenvolvimento interno. 
Decidindo-se pela realização do treinamento o levantamento de necessidades deve conter uma especificação de necessidades de treinamento.

\subsubsection{Especificação das Necessidades de Treinamento}

Com base nas informações fornecidas pelo levantamento de necessidades de treinamento estabelecem-se os resultados desejados pelo treinamento. Esta definição, convertida em objetivos de treinamento, deve preferencialmente ser orientada para o desempenho a fim de se poder medir os resultados proporcionados pelo treinamento (ABNT, 2001), seu registro deve ser realizado por meio da especificação das necessidades de treinamento.

Até aqui, observou-se as etapas do Levantamento de Necessidades como análise da empresa, análise de competências, análise da tarefa, análise das pessoas. A realização dessas análises ocorre por meio da utilização de técnicas adequadas de identificação de necessidades. Após a realização deste diagnóstico, pode-se concluir que a solução organizacional, para o problema identificado, é a realização da ação de treinamento, sendo assim, devem-se especificar as necessidades de treinamento e quais os resultados que dele se espera, a fim de medir a efetividade da ação.

A especificação de necessidades de treinamento deve contemplar objetivos e resultados esperados após o treinamento, contendo os requisitos de competência, os resultados de treinamentos realizados anteriormente, os resultados esperados pelo treinamento que se propõe realizar, o que se pretende mudar e até que ponto, para que se tenha antecipadamente, conhecimento quanto ao nível de sucesso obtido ao atingir os objetivos de treinamento (DeCENZO; ROBBINS; 1999). 
É preciso acrescentar a necessidade de que o dimensionamento destes objetivos seja parametrizado por indicadores realistas e mensuráveis, e que este documento deve integrar a especificação do programa de treinamento (ABNT, 2001).

A especificação de necessidade sumariza o que o treinando deve ser capaz de fazer depois de completar com sucesso o programa de treinamento (DESSLER, 2003).

Conforme o que até aqui se viu a respeito do levantamento de necessidades de treinamento, sabe-se que a primeira tarefa é definir qual a lacuna de desempenho que necessita intervenção por meio da ação de treinamento. Em segundo lugar, verificar se esta lacuna pode ou não ser solucionada com uma ação de treinamento (NOGUEIRA, 1980; MILIONI, 2003). É importante não esquecer que o treinamento é válido quando se pretende agir sobre a capacidade daquele que se vai treinar (KROEHNTER, 2001).

Verificou-se ainda que é necessário conhecer as características da empresa que realizará a ação de treinamento e principalmente quais seus objetivos de desenvolvimento estratégico, já que esta amarração entre a estratégia da organização e o programa de treinamento é considerada uma das grandes responsáveis pelo sucesso dos programas de treinamento (MILKOVICH, 1997).

Deve-se ainda contar com uma análise das competências na organização, comparandose as competências necessárias com as disponíveis, definindo-se a partir daí a clientela do programa de treinamento. Deve-se analisar as pessoas à luz dessas competências para que se possa entender o quanto de suas capacidades precisam ser aperfeiçoadas para satisfazer as necessidades da organização.

É preciso ainda analisar as tarefas envolvidas com o projeto do treinamento e como elas podem ser impactadas por este (DESSLER, 2003). 
Procede-se uma análise das pessoas a ser atendidas pelo programa, sabendo-se que o conhecimento dessas características pode ampliar as chances de sucesso do programa (ABBAD, 1999).

Após o registro das necessidades de treinamento, devem se identificar soluções para a dificuldade diagnosticada que serão documentadas em um instrumento de especificação das necessidades de treinamento.

Especificando-se a necessidade do treinamento, e o que se espera que o treinando seja capaz de fazer após sua realização, tem-se uma completa expectativa de entrega com a qual o treinando poderá ser comprometido.

Após a identificação das necessidades de treinamento é importante conhecer brevemente como se dão os processos de elaboração e implementação do treinamento.

\subsection{ELABORAÇÃO E IMPLEMENTACCÃO DO TREINAMENTO}

Para Bohlander, Snell e Sherman (2003), o sucesso de um programa de treinamento depende mais da capacidade de utilizar as informações obtidas no processo do levantamento de necessidades do que de sua elaboração e implementação em si.

Os mesmos autores sugerem que se considere, na elaboração do treinamento, quais os objetivos a serem alcançados pelo treinamento, o nível de motivação dos treinandos e as características dos instrutores. Milkovich e Boudreau (2000) acrescentam que a elaboração do treinamento deve contemplar a indicação das características do ambiente.

Bohlander, Snell e Sherman (2003) sinalizam que a elaboração do treinamento deve estar totalmente baseada no levantamento de necessidades, pois do contrário a definição de objetivos pode estar incorreta, os princípios de aprendizagem observáveis podem estar incorretos, os instrutores podem ser escolhidos sem considerar as premissas necessárias a sua 
capacitação, os autores evidenciam o forte senso de dependência que a elaboração do treinamento tem com o levantamento de necessidades do treinamento.

Os objetivos instrucionais de um programa de treinamento devem ser descritos de forma suficientemente clara, permitindo que ao final do programa se identifique o quanto dos objetivos foram cumpridos.

Milkovich e Boudreau (2000) afirmam que os objetivos devem ser escritos de forma a proporcionar informações que melhorem as futuras decisões, devem ser mensuráveis e definir as habilidades, conhecimentos ou atitudes que serão adquiridos no treinamento.

Mager, observa que

"antes de se preparar a instrução, antes de selecionar os procedimentos instrucionais,
o material ou o assunto, é importante ser capaz de estabelecer com clareza
exatamente quais são os resultados que se pretende obter. Uma formulação clara dos
objetivos instrucionais fornecerá uma base segura para escolher métodos e materiais
instrucionais e para selecionar os meios de avaliar se o treinamento terá êxito ou
não" (MAGER, 1977, p. 70).

Para este autor, objetivos são descrições de resultados almejados, descrevem os padrões de desempenho que se espera que um grupo de alunos alcance ou ultrapasse e é preciso que o desempenho e os itens do teste, que o avalia, sejam adequados aos itens do objetivo.

Mager (1977) elenca uma série de passos que podem ser seguidos para a definição de objetivos claros de treinamento, segundo ele, sendo seguidos esses passos há elementos suficientes que apóiam a mensuração dos objetivos de ensino, são eles:

$\checkmark$ Observar o desempenho enunciado no objetivo, para isso o objetivo deve fazer menção a algum desempenho mensurável posteriormente.

Observar se o desempenho é um propósito principal ou um indicador, já que há objetivos que podem ser chamados de propósito principal, pode-se dizer que é a 
razão pela qual o objetivo foi escrito, e ele deve estar explícito nos objetivos para que possa ser mensurado.

Se o desempenho é um indicador deve se observar o propósito principal, se o desempenho é o propósito principal deve se observar se é implícito ou explícito. Deve-se comparar o indicador com o propósito principal para se verificar se há aderência entre eles, para isso é necessário que o objetivo principal esteja suficientemente claro. Em se tratando de objetivos implícitos deve-se acrescentar indicadores de mensuração para os objetivos.

Ao incluir indicadores, os objetivos devem ser testados e ter facilidade de verificação, além de estar necessariamente incluído no repertório dos alunos.

Havendo uma boa definição de objetivos do treinamento que reflete as exigências evidenciadas no processo do levantamento de necessidades de treinamento, é preciso considerar que há condições apoiadoras para a realização do treinamento (MILKOVICH; BOUDREAU, 2000).

Estas condições podem ser resumidas observando-se a capacidade de aprendizagem do treinando, motivação dos treinandos, o ambiente de realização do treinamento e a capacitação dos instrutores.

O programa de treinamento deve ser programado para uma clientela de determinado nível, deve-se então testar a capacidade dos treinandos para que se tenha deles um perfil médio, assim é necessário avaliar seu nível de conhecimentos e habilidades necessários para absorver o que será apresentado no treinamento. Agrupar treinandos, segundo seu nível médio de conhecimentos anteriores relativos ao treinamento, pode auxiliar a efetividade do treinamento para todo o grupo (BOHLANDER, SNELL; SHERMAN, 2003). 
A respeito da motivação dos treinandos, Milkovich e Boudreau (2000), afirmam que provavelmente a principal motivação que o treinando precisa ter, é a vontade de mudar seus comportamentos e resultados no trabalho.

Milkovich e Boudreau (2000) consideram que elementos como a fixação de metas, o reforço ao treinamento, a consideração da expectativa dos treinandos e o investimento da organização no desenvolvimento da confiança dos treinandos apóiam sua motivação para o programa de treinamento.

Noe (1986) ${ }^{5}$, apud Abbad (1999) acredita que um ambiente favorável afeta direta e positivamente, a motivação para aprender, a motivação para transferir e os resultados do treinamento, entre os quais a transferência. Ambiente neste sentido é entendido como as condições gerais do local de trabalho do participante.

Ainda no contexto do planejamento do treinamento, os instrutores devem ser selecionados segundo a definição dos objetivos instrucionais e as características gerais da clientela. As características gerais passam pelo conhecimento sobre o assunto que é objeto do treinamento, programação do treinamento tendo como base os objetivos estabelecidos, responsividade em relação aos treinandos, capacidade de criação de interesse, senso de humor, clareza de instruções dadas e entusiasmo com o programa (MILKOVICH; BOUDREAU, 2000; BOHLANDER; SNELL; SHERMAN, 2003).

Finalmente é preciso que o planejamento do treinamento considere aspectos operacionais como divulgação de horários e datas, instalações e equipamentos necessários (ABNT, 2001).

Conhecendo-se o planejamento do treinamento, passa-se aos conteúdos relativos a implementação do programa.

\footnotetext{
${ }^{5}$ NOE, R.A. Trainees' attributes and attitudes: Neglected influences on training effectiveness. Academy of Management Review, 11(4), 736-749, 1986
} 


\subsubsection{Implementação do Programa de Treinamento}

A implementação do programa realiza-se como meio de tornar concreta a ação que se iniciou desde o levantamento das necessidades de treinamento até a fase de planejamento e elaboração de seus objetivos instrucionais.

O levantamento de necessidades de treinamento origina os objetivos instrucionais A partir destas duas informações, define-se a forma de implementação do treinamento.

Conforme Dessler (2003), as formas de implementação do treinamento podem ser o treinamento no trabalho, o treinamento por simulação, treinamento a distância (em modalidades como vídeo-conferência, treinamento computadorizado, via cd-rom ou internet).

Os propósitos a que se destinam o treinamento podem ser a alfabetização de parte do corpo funcional, o desenvolvimento de senso de valores da organização, a capacidade de relacionamento com a diversidade na empresa ou mesmo o trabalho em equipe.

Dessler (2003) destina especial atenção ao treinamento gerencial, que pode ser implementado na forma on the job com a rotação de gerentes em diversas áreas, o treinamento em ação, a utilização de métodos de estudo de caso, de jogos de empresas, participação em seminários externos. Para o autor estes, programas podem contar com apoio de universidades externas.

A opção por uma ou outra forma de implementação se dá em função dos elementos identificados no processo do levantamento de necessidades de treinamento e da definição dos objetivos instrucionais.

Após a implementação do treinamento, entender o quanto da ação de treinamento gerou efetivo resultado é fundamental no direcionamento de novos treinamentos; dessa forma, a avaliação dos resultados dos programas de treinamento surge como necessidade de monitoramento da estratégia de desenvolvimento da organização. 


\subsection{AVALIAČ̃̃O DE PROGRAMAS DE TREINAMENTO}

A mensuração de resultados e de indicadores de práticas vinculadas às ações de desenvolvimento de recursos humanos, em especial do treinamento, tem sido alvo de crítica por alguns autores e de incentivo por outros.

Com o objetivo de introduzir a discussão, sem torná-la extensa, é válido conhecer brevemente a polarização de conceitos no tocante a mensuração em gestão de recursos humanos. Para isso serão utilizados três autores: Pfeffer (1997), Ulrich (1997) e Fitz-enz (2001).

Dentre os críticos da mensuração em gestão de recursos humanos está Pfeffer (1997), explicando que as organizações voltaram-se para a mensuração em razão da pressão dos mercados para demonstrar eficiência em custos.

Pfeffer (1997) posiciona-se contra a tentativa de se mensurar as práticas de recursos humanos em razão das dificuldades de se relacionar os comportamentos humanos com os resultados operacionais das organizações. Seu ponto de vista se fortalece principalmente em razão de que as medidas utilizadas tenham sido aprendidas, em comparação e por aproveitamento, de cálculos de eficiência contábil e financeira, sendo assim inapropriados para oferecer medidas de eficiência em gestão de recursos humanos. Em sua visão as medidas utilizadas não são as melhores, sendo muitas vezes, apenas as mais fáceis. $\mathrm{O}$ autor atenta principalmente para o fato de que os custos das práticas de recursos humanos surgem rapidamente e que seus resultados se dão no longo prazo.

O autor observa que é preciso discutir o status de gestão de recursos humanos pois, por comparação, investimentos em Pesquisa e Desenvolvimento ( $\mathrm{P} \& \mathrm{D})$ não são interrompidos porque são vistos como sustentabilidade da organização, em contrapartida 
investimentos em recursos humanos são vistos como fonte de despesas. O autor pondera que sem gestão de recursos humanos não há como sustentar estrategicamente P \& D.

Para finalizar, Pfeffer (1997) afirma que recursos humanos devem ser vistos como uma fonte de vantagem competitiva e não como um portifólio da empresa, que precisa de avaliação para que seja permitido, aos gestores, negociá-lo separadamente como unidade dissociada.

Em contrapartida, Ulrich (1997, p. 1), afirma que "não se pode gerenciar o que não se pode medir" num sentido em que a mensuração se torna instrumento de gerenciamento estratégico dos recursos humanos da empresa, devendo ser capaz de representar o valor adicionado pelos funcionários, na rentabilidade e no desempenho geral da empresa.

Para Ulrich (1997), numa reunião de gestão em uma organização qualquer, habitualmente o gestor de recursos humanos, confrontado por gestores comerciais ou financeiros, que apresentam indicadores objetivos de suas medidas de eficiência, se vêem obrigados a falar de forma abstrata e conceitual sobre elementos intangíveis como, a moral dos empregados, sua rotatividade e comprometimento, dentre outros. Em sua visão, é necessário que recursos humanos preencha seu papel no negócio, e para isso "conceitos precisam ser substituídos por evidências, idéias por resultados, e percepções por avaliações" (ULRICH, 1997, p. 1).

O mesmo autor demonstra por meio da pesquisa Society for Human Resource Management (SHRM) que a utilização de melhores práticas de recursos humanos impactou positivamente os resultados de indicadores objetivos, tais como valor das ações dividido pelos ativos, índice de produtividade, valor das ações e vendas. Em sua visão, evidenciar este tipo de resultado apóia a importância estratégica da gestão de recursos humanos na organização. 
Influenciado por Ulrich (1997), Fitz-enz (2001) considera que é válido alegar que os fatores distintos de conhecimento, habilidade e esforço humanos afetam os resultados das ações de uma empresa.

Para Fitz-enz (2001), a capacidade intelectual das pessoas constitui-se em um catalisador do capital tangível da empresa. Para que haja maximização da capacidade de retorno de investimento realizado em capital humano, é preciso compreender como ele interage com as demais formas de capital e, principalmente, como o capital humano influencia positivamente os resultados dos demais capitais.

De sua perspectiva, para que haja alavancagem do retorno sobre o investimento em capital humano, é preciso que as organizações empreendam ações apoiadoras, tais como desenvolvimento e treinamento, comunicação, remuneração e gerência. Nas pesquisas do autor, o treinamento é visto pelos funcionários como uma forma de obter maiores rendimentos, melhorar sua satisfação no trabalho e como instrumento para auxiliá-los a oferecer maiores resultados à empresa.

Fitz-Enz (2001, p.3) observa que "uma vez que, hoje em dia, os custos de pessoal podem exceder a $40 \%$ dos custos de uma empresa é essencial medir o retorno sobre o investimento em capital humano".

Para este autor, sem medições não se pode prognosticar informações em torno de desempenho, identificar destinação de recompensas, atuar sobre necessidades de incentivo. Para ele as medidas devem ser utilizadas para subsidiar decisões em torno de alocação de recursos.

Em torno do que se apresentou, não há o objetivo de esgotar a discussão, especialmente por não se tratar do foco deste trabalho. Apesar de evidenciar-se a dificuldade de mensuração das práticas de recursos humanos, a pressão por eficiência, custos e 
produtividade instalada no sistema econômico parece ter resolvido a questão da oportunidade de realizar-se ou não as mensurações de resultados.

Tornou-se obrigatório que todas as áreas e pessoas na organização sejam capazes de demonstrar sua capacidade de agregação de valor, dessa maneira, enfrentar a necessidade de mensuração de sucesso das práticas de recursos humanos e no que interessa a este estudo, os resultados de treinamento, estabelece-se como necessidade.

Em continuidade, passa-se a discussão das medidas de avaliação de treinamento.

Como forma de definição Hamblin (1978, p. 21) sumariza o conceito de avaliação de treinamento como "qualquer tentativa no sentido de obter informações (realimentação) sobre os efeitos de um programa de treinamento e para determinar o valor do treinamento à luz dessas informações”. A avaliação pode ser considerada como elemento constitutivo da cadeia de ações do treinamento, agindo no sentido de oferecer informações para seu processo de melhoria.

Hamblin (1978) enfrenta brevemente a discussão quanto à oportunidade de avaliar-se ou não programas de treinamento. Para ele a atividade de avaliação é inerente ao ser humano e sua prática segue como decorrência de qualquer outra atividade para a qual se despendeu algum tipo de investimento. Para este autor, a pergunta cabível no tocante a este tema gira em torno de como o programa de treinamento pode ser melhor avaliado. Como se devem estabelecer os critérios de avaliação, quais métodos de avaliação se podem utilizar e principalmente, como seus resultados podem influenciar a melhoraria da qualidade do treinamento.

Para Hamblin (1978), a finalidade da avaliação é o controle. Neste caso, o controle deve ser visto como forma de administração do treinamento em que se coletam e analisam informações a respeito deste, para instrumentalizar a tomada de decisão, reprogramando-o e preferencialmente, aproximando-o dos objetivos que motivaram sua realização. 
A mensuração de resultados dos programas de treinamento decorre da preocupação sobre a aplicabilidade na atividade profissional do que é aprendido em cursos de educação executiva. Além disso, por meio da mensuração, é preciso discutir a sustentabilidade de seus efeitos e repercussões (DUTRA; OLIVEIRA; GOUVEIA, 2002).

As instituições que contratam esse tipo de serviço estão interessadas em garantir a aplicação dos saberes que o participante adquiriu, de maneira preferencialmente imediata, em sua atividade profissional, e quanto desse aprendizado pode perdurar ao longo do tempo.

Na mesma linha, Salas e Cannon-Bowers (2001) observam que existe uma inquietação por parte das organizações quanto a assertividade do investimento realizado em treinamento. Os autores consideram que este investimento precisa ser justificado pela performance organizacional, refletido em resultados como aumento de produtividade, lucros, ou mesmo ampliação de participação de mercado. Os autores consideram que o questionamento das organizações se ampliará, exigindo a demonstração objetiva do retorno de capital investido nos resultados da organização.

Para DeCenzo e Robbins (1999), o processo de treinamento deve ser avaliado para se mapear o quanto sua contribuição foi capaz de se incorporar ao alinhamento estratégico da organização.

Estando justificado o sentido da avaliação, apresenta-se o referencial teórico utilizado por este trabalho, relacionado a avaliação de impacto no treinamento. Os autores utilizados serão Kirkpatrick (1993), por sua precedência e representatividade internacional no tema, Hamblin (1978) pela ampliação que oferece ao primeiro. Serão ainda utilizados os trabalhos de Borges-Andrade (1982), com o modelo MAIS, por sua precedência nacional no estudo do tema e Abbad (1999) com o modelo IMPACT, por sua atualidade.

Kirkpatrick (1993) influenciou os trabalhos de Hamblin (1978), e mesmo os Philips (1997). 
No Brasil as primeiras publicações sobre o tema, localizadas por este referencial, são de Borges-Andrade (1982), Ávilla et alii (1983) mais recentemente Abbad (1999), Abbad, Gama e Borges-Andrade (2000), Borges-Andrade (2000), Pantoja e Borges-Andrade (2004) e outros.

Passa-se aos aspectos gerais dos autores selecionados.

\subsubsection{Kirkpatrick (1993) - O Modelo dos Quatro Níveis}

Um dos modelos consolidados para avaliação de programas de treinamento é o modelo dos quatro níveis de Kirkpatrick (1993), que avalia subseqüentemente as reações, o aprendizado, a mudança de comportamento observável e os resultados do treinamento.

Conforme o autor, as reações dos treinandos revelam o quanto o treinamento foi bem aceito pelo grupo, avalia-se as condições de infra-estrutura e se houve algum fato relevante a comentar no tocante a qualidade percebida do treinamento. A avaliação de aprendizado importa-se em demonstrar o quanto do treinamento foi apreendido pelo treinando, o quanto dos conteúdos transmitidos incorporaram-se em seu conjunto de saberes. A avaliação de comportamento observável diz respeito ao quanto um treinamento foi capaz de modificar o comportamento do treinando no cargo. Por fim, a avaliação de resultados mensura o quanto o treinamento foi capaz de atingir os resultados esperados, que normalmente devem ser medidos em contrapartida das razões que motivaram a necessidade do treinamento.

Ilustrativamente, a avaliação do treinamento para Kirkpatrick (1993) assim se representa:

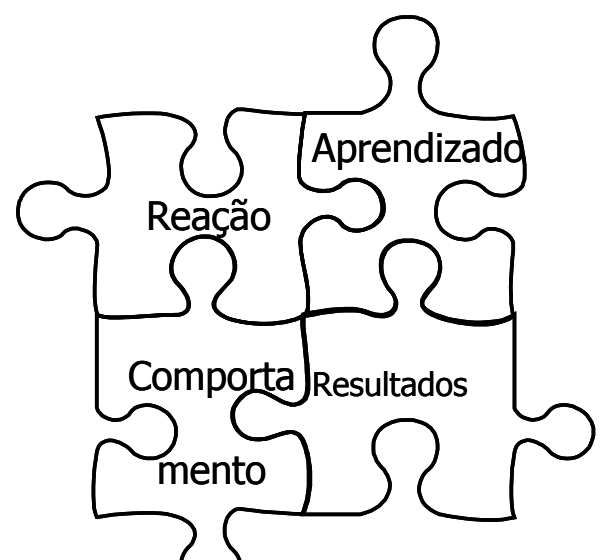


Figura 9: Avaliação de Resultados de Treinamento por Kirkpatrick (1993). Fonte: adaptado de Kirkpatrick (1993) e Bohlander; Snell; Sherman, (2003).

Abbad (1999) e Meneses (2002) citam Alliger e Janak (1989), confrontando alguns dos pressupostos de Kirkpatrick (1993).

Para Alliger e Janak (1989), Kirkpatrick (1993) descreve os quatro níveis com uma articulação de interdependência e seqüência entre si, o autor leva ao entendimento de que medida de reação seria o nível mais primário de informação, seguido pelas medidas de aprendizagem e comportamento e finalmente pela medida de resultado, hierarquicamente mais relevante. Kirkpatrick (1993) sugere que se o treinando gostou do treinamento, isso fará com que ele tenha um melhor aproveitamento de aprendizagem o que o levará a ter seu comportamento modificado possibilitando que haja maiores chances de resultados em razão da ação de treinamento.

Alliger e Janak (1989) consideraram que os pressupostos do modelo de Kirkpatrick, podem conter problemas de inconsistência interna, quando testados cientificamente. Para eles o primeiro pressuposto, de que os níveis de avaliação acrescentariam informações de um para outro, formando uma hierarquia, é falso.

Para Abbad (1999) o equívoco se daria por exemplo "quando não interessasse à organização provocar mudanças em todos os níveis” (ABBAD, 1999, p. 36).

O segundo pressuposto de que há relação de causalidade entre os níveis de avaliação não pode ser observado nas pesquisas empíricas dos autores principalmente porque o item reação parece não ser o causador de nenhum outro: aprendizado, comportamento ou resultado.

Ainda em Alliger e Janak (1989), o terceiro pressuposto, de que há relação positiva entre os níveis, foi testado por meio de extensa pesquisa bibliográfica em periódico de 
relevante reconhecimento na área e constatou que em mais de duas centenas de artigos pesquisados, não se observou o registro de relação de causalidade entre os níveis de avaliação de treinamento.

Para Abbad (1991), “os pesquisadores têm dado pouca atenção à avaliação dos pressupostos do modelo de Kirkpatrick, negligenciado a importância da realização de mais estudos sobre o inter-relacionamento entre os quatro níveis". Ou seja, as bases do construto de Kirkpatrick têm sido admitidas sem questionamento ou aprofundamento.

\subsubsection{Hamblin (1978) - O Modelo do Valor Final}

Hamblin (1978) amplia a dimensão apresentada por Kirkpatrick (1993), concentrandose no fato de que a coleta de informações a respeito do treinamento deve priorizar a análise das mudanças provocadas por ele.

O foco na verificação da mudança observada justifica-se para Hamblin (1978), pois para este autor :

\footnotetext{
"podemos aprender a modificar nosso comportamento como resultado de toda a sorte de experiência; mas se estamos sendo treinados, isto significa que estão nos fazendo passar por uma experiência (ou dando uma oportunidade) que foi propositalmente destinada a fazer-nos aprender" (HAMBLIN, 1978, p. 30).
}

Se a finalidade da ação é provocar um aprendizado que deve se refletir em mudança de comportamento, justifica-se o foco de avaliação do resultado como mudança para a organização e valor definitivo do treinamento.

Quando Hamblin (1978) desdobra o aspecto resultado de Kirkpatrick (1993) para os aspectos da mudança para a organização e valor definitivo do treinamento, quer indicar que, em razão do treinamento, pode ter havido mudança na organização sem que isso tenha gerado qualquer valor para ela. 
Hamblin (1978) concorda com Kirkpatrick (1993) quanto ao seqüenciamento de causa e efeito entre os níveis verificáveis de efeito do treinamento. Para ele uma boa reação provoca um bom aprendizado, que gera mudanças de comportamento nos treinandos que provocará mudanças na organização o que oportunizará resultados finais.

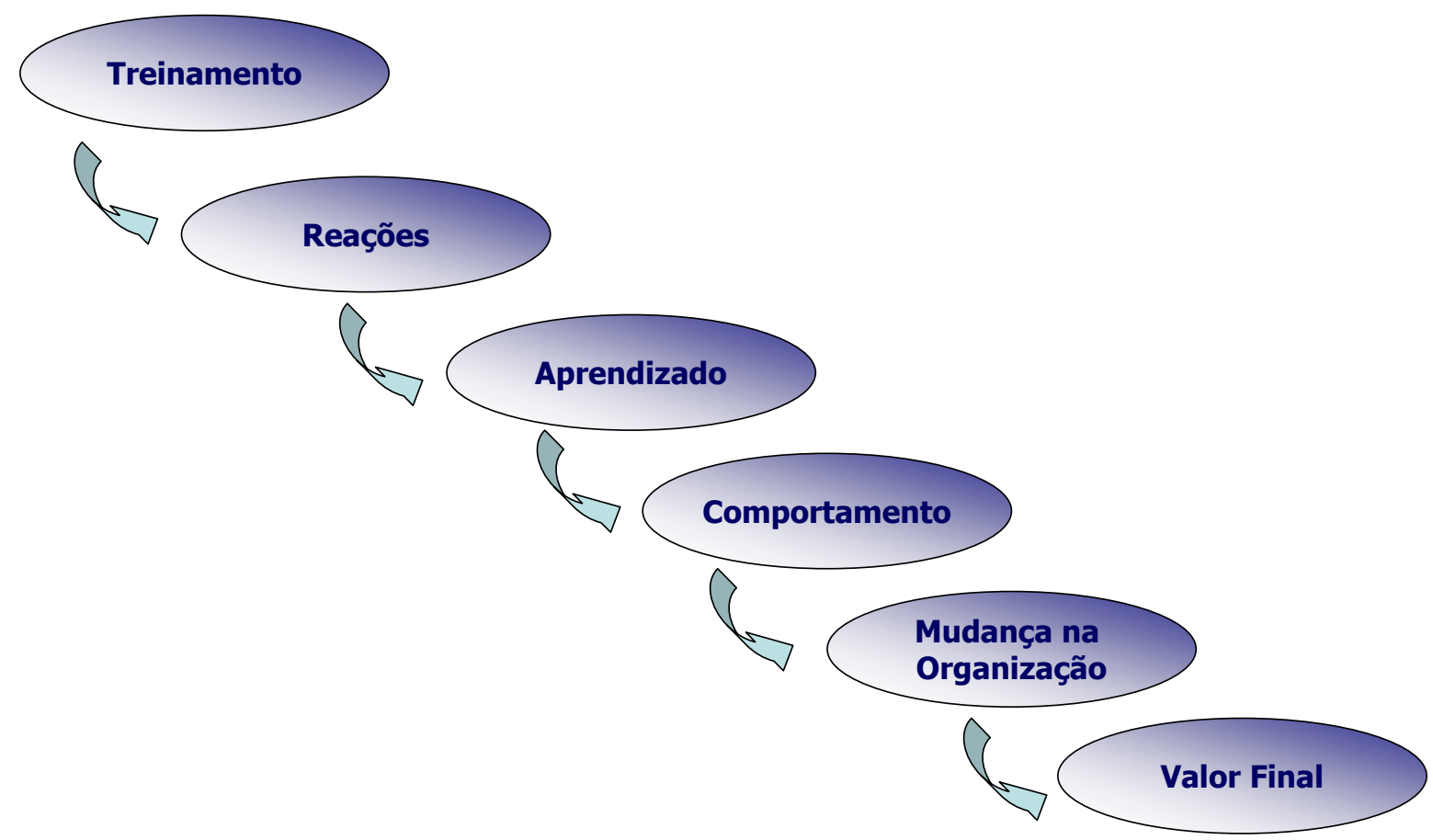

Figura 10: Avaliação de resultados de treinamento em Hamblin (1978)

Fonte: Adaptado de (HAMBLIN, 1978, p. 31)

\subsubsection{Borges - Andrade (1982) - O Modelo MAIS}

O modelo MAIS - Modelo de Avaliação Integrado e Somativo compreende os seguintes elementos de mensuração: insumo, procedimentos, processo, resultados e ambiente.

Em breve detalhamento, insumo compreende fatores físicos e sociais e estados de comportamento relacionados ao público que fará parte do treinamento. Na visão do autor, esta visão do input, que trata de componentes anteriores ao evento do treinamento, influencia os demais resultados do processo de treinamento. 
Os procedimentos compreendem as estratégias didáticas utilizadas na realização do treinamento, incluem-se nesse aspecto procedimentos operacionais do treinamento, como o planejamento da ação e a atuação do instrutor.

O processo abrange ocorrências significativas que sejam resultantes dos procedimentos adotados no treinamento, o processo relaciona-se com características comportamentais do treinando durante o processo de treinamento. Neste aspecto devem ser observados itens como motivação do participante, nível de dedicação e estudo e mesmo resultados obtidos em testes, compreendendo assim aspectos do aprendizado do participante, percebidos em Kirkpatrick (1993) e Hamblin (1978).

No tocante aos resultados, examinam-se as habilidades ou atitudes desenvolvidas em razão do treinamento, o exame deste aspecto deve ocorrer após a realização do evento, e é preciso verificar que os comportamentos observados sejam compatíveis com os objetivos definidos no planejamento do treinamento,

O aspecto ambiente do modelo de Borges-Andrade (1982) diz respeito ao contexto organizacional em que se insere o treinando antes e depois do treinamento. Na visão do autor, o ambiente compõe-se das necessidades que motivaram o treinamento, do apoio que se tem para que o treinando desenvolva uma boa relação de ensino-aprendizagem, da forma como se deu a disseminação da oportunidade do treinamento e, por fim, como se verificam os resultados de longo prazo do programa, ou seja, as conseqüências verificáveis do treinamento após um determinado período de tempo.

Graficamente o modelo de Borges -Andrade assim se representa:

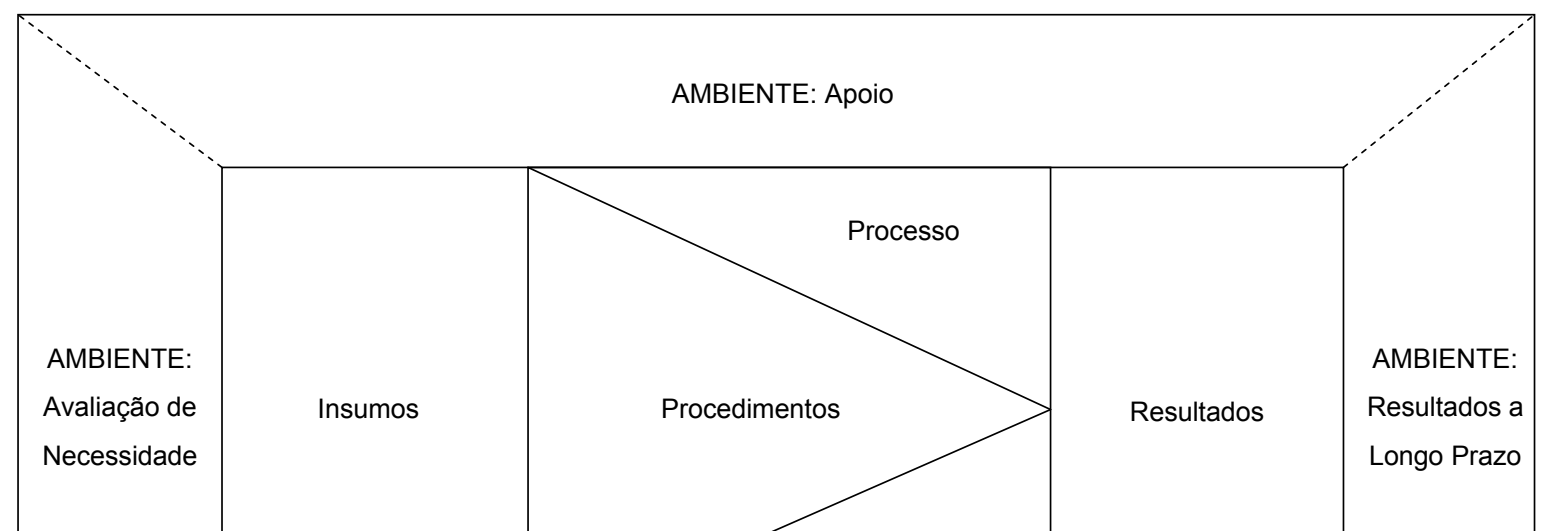


Figura 11: Modelo MAIS Borges - Andrade (1982)

Fonte: Borges Andrade (1982)

O modelo de avaliação de Borges-Andrade (1982) revela um importante elemento de acréscimo aos Modelos de Kirkpatrick (1993) e Hamblin (1978), que é o fato de considerar na avaliação do treinamento, não apenas o alcance dos objetivos propostos, mas também o contexto em que se inserem os treinandos, antes e depois do treinamento.

Mais tarde, estes elementos, chamados preditores e de suporte para a transferência, foram estudados separadamente pelo autor.

\subsubsection{Abbad (1991) - O Modelo IMPACT}

A concepção metodológica de Abbad (1999), para avaliação de treinamento, o IMPACT - Modelo Integrado de Avaliação do Impacto do Treinamento é composta por sete componentes: Percepção de Suporte Organizacional, Características do Treinamento, Características da Clientela, Reação, Aprendizagem, Suporte a Transferência e Impacto do Treinamento no Trabalho.

Em breve detalhamento: A Percepção de Suporte Organizacional apresenta-se como elemento multidimensional, neste aspecto, encontram-se a opinião que os participantes têm sobre as práticas organizacionais de gestão de desempenho, valorização do funcionário e apoio gerencial ao treinamento. Conforme Abbad (1999, p. 99): 


\begin{abstract}
As variáveis de gestão de desempenho referem-se à opinião do participante do treinamento acerca de práticas organizacionais de estabelecimento de metas de trabalho, disponibilização de informações, sistema de recompensas ao desempenho exemplar, investimento em capacitação, orientação técnica, profissional e pessoal dos recursos humanos. Os itens de valorização do servidor representam a opinião do participante sobre as práticas organizacionais que revelam consideração e respeito às idéias, sugestões, esforço e interesses individuais de seus recursos humanos. Apoio gerencial ao treinamento refere-se à opinião do participante do treinamento a respeito do empenho demonstrado pelas chefias para viabilizar a participação dos subordinados em eventos instrucionais.
\end{abstract}

A percepção de suporte organizacional parece investigar o apoio psicossocial com o qual o treinando conta, ou julga contar, no contexto de realização do treinamento.

As Características do Treinamento estão relacionadas efetivamente ao tipo de curso que se está examinando, a área de conhecimento a que pertence. Neste aspecto devem se registrar elementos como duração, objetivo principal, origem institucional, formação e histórico de desempenho do instrutor, além de características didáticas a ele relacionadas.

Neste mesmo tópico, avaliam-se o programa, o material didático e bibliografia recomendada.

No item Características da Clientela, observam-se dados psicosociais do público que fará parte do programa “conjunto de informações demográficas, funcionais, motivacionais e atitudinais relativas aos participantes dos treinamentos estudados" (ABBAD, 1999, p. 100)

Reação é um elemento comum aos demais sistemas de avaliação de treinamento e como nos outros casos atem-se as investigações em torno da opinião que os participantes tiveram a respeito do treinamento. Tem contudo o mérito de abranger avaliações distintas para programação, apoio ao desenvolvimento do módulo, aplicabilidade e utilidade do treinamento, resultados, expectativas de suporte organizacional e desempenho do Instrutor.

Aprendizagem, bem como o item reação, é comum aos demais sistemas de avaliação, e “refere-se ao grau de assimilação e retenção dos conteúdos ensinados no curso, medido em termos dos escores obtidos pelo participante em testes ou provas de conhecimentos aplicadas pelo instrutor ao final do curso" (ABBAD, 1999, p. 102). 
Suporte a Transferência, este aspecto examina o tipo de ambiente encontrado pelo treinando para fazer com que os conteúdos aprendidos sejam "transferidos" para sua atividade. O suporte a transferência possui aspectos materiais e sociais. Esta idéia associa-se fortemente ao respaldo dado pela gerência para que as novas habilidades adquiridas pelo funcionário treinado sejam colocadas em prática.

Impacto do treinamento no Trabalho, constitui-se na auto-avaliação que o participante do treinamento faz sobre os efeitos que percebeu em seus níveis de desempenho, motivação, autoconfiança e abertura a mudanças e processos de trabalho. A autora alerta, e se torna evidente na representação gráfica de seu modelo, o impacto do treinamento no trabalho é fortemente influenciado pelo suporte organizacional que se dá ao treinamento, pelo próprio perfil da clientela atendida pelo programa e como um resultado geral da integração de todos os demais itens.

Graficamente a autora ilustra a seu modelo de avaliação de treinamento da seguinte maneira: 


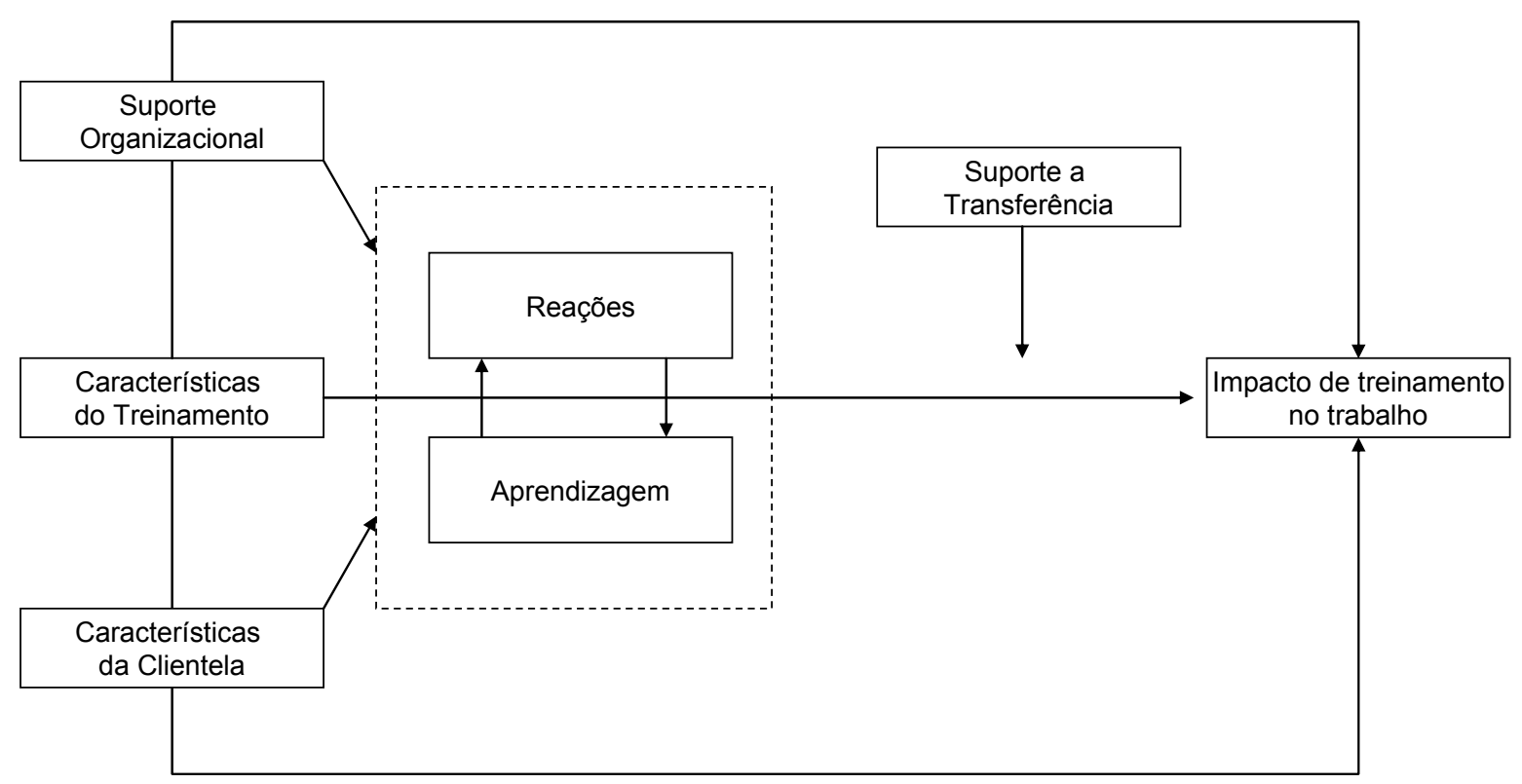

Figura12: Modelo IMPACT - Abbad (1999)

Fonte: (ABBAD, 1999, p. 98)

Tendo-se uma explanação a respeito dos quatro modelos básicos de avaliação do treinamento, sistematiza-se a apresentação da consolidação de seus conceitos por meio do quadro seguinte:

\begin{tabular}{|c|c|c|c|c|c|c|c|c|c|}
\hline $\begin{array}{c}\text { Dimensão } \\
\text { de } \\
\text { Avaliação }\end{array}$ & $\begin{array}{l}\text { Levantamento } \\
\text { de Necessidades }\end{array}$ & $\begin{array}{l}\text { Ambiente } \\
\text { de Suporte }\end{array}$ & $\begin{array}{l}\text { Implementa-. } \\
\text { cão do } \\
\text { Treinamento }\end{array}$ & Reações & $\begin{array}{l}\text { Aprendi- } \\
\text { zado }\end{array}$ & $\begin{array}{l}\text { Comporta- } \\
\text { mento }\end{array}$ & $\begin{array}{c}\text { Suporte a } \\
\text { Transferência }\end{array}$ & $\begin{array}{c}\text { Mudança } \\
\text { na } \\
\text { Organização }\end{array}$ & Resultado \\
\hline \multirow{4}{*}{ Autores } & & & & $\begin{array}{c}\text { Kirkpatrick } \\
\text { (1976) }\end{array}$ & $\begin{array}{c}\text { Kirkpatrick } \\
\text { (1976) }\end{array}$ & $\begin{array}{c}\text { Kirkpatrick } \\
\text { (1976) }\end{array}$ & & & $\begin{array}{l}\text { Kirkpatrick } \\
\text { (1976) }\end{array}$ \\
\hline & & & & $\begin{array}{l}\text { Hamblin } \\
\text { (1978) }\end{array}$ & $\begin{array}{l}\text { Hamblin } \\
\text { (1978) }\end{array}$ & $\begin{array}{l}\text { Hamblin } \\
\text { (1978) }\end{array}$ & & $\begin{array}{l}\text { Hamblin } \\
\text { (1978) }\end{array}$ & $\begin{array}{l}\text { Hamblin } \\
\text { (1978) }\end{array}$ \\
\hline & $\begin{array}{l}\text { Borges- } \\
\text { Andrade } \\
(1982)\end{array}$ & $\begin{array}{c}\text { Borges- } \\
\text { Andrade } \\
(1982)\end{array}$ & $\begin{array}{c}\text { Borges- } \\
\text { Andrade } \\
(1982)\end{array}$ & $\begin{array}{c}\text { Borges- } \\
\text { Andrade } \\
(1982)\end{array}$ & $\begin{array}{l}\text { Borges- } \\
\text { Andrade } \\
(1982)\end{array}$ & $\begin{array}{c}\text { Borges- } \\
\text { Andrade } \\
(1982)\end{array}$ & $\begin{array}{c}\text { Borges- } \\
\text { Andrade } \\
(1982)\end{array}$ & & $\begin{array}{c}\text { Borges- } \\
\text { Andrade } \\
(1982)\end{array}$ \\
\hline & & $\begin{array}{l}\text { Abbad } \\
(1999)\end{array}$ & $\begin{array}{l}\text { Abbad } \\
(1999)\end{array}$ & $\begin{array}{l}\text { Abbad } \\
\text { (1999) }\end{array}$ & $\begin{array}{l}\text { Abbad } \\
(1999)\end{array}$ & $\begin{array}{l}\text { Abbad } \\
\text { (1999) }\end{array}$ & $\begin{array}{l}\text { Abbad } \\
(1999)\end{array}$ & $\begin{array}{l}\text { Abbad } \\
(1999)\end{array}$ & \\
\hline
\end{tabular}

Quadro 3 - Dimensões de Avaliação de Treinamento

Fonte: autor.

Cabe observar que o modelo de Borges - Andrade (1982) encontra-se presente em quase todas as dimensões selecionadas. $O$ autor não consta na dimensão de mudança na organização, porém em seu modelo, este aspecto se incorpora no tópico resultado, levando o 
nome de Resultados a Longo Prazo. Este aspecto presente em Hamblin (1978) e Abbad (1999) tem o mesmo sentido, examinando como o treinamento transformou a organização patrocinadora.

O modelo IMPACT (ABBAD, 1999) é o mais contemporâneo dentre os que se apresentam, porém o último nível de sua análise é o de impacto no trabalho e, neste sentido, examina as mudanças ocorridas em função do treinamento por meio das declarações dos participantes dos cursos examinados, porém não investiga os resultados que dela provém.

O modelo MAIS (BORGES - ANDRADE, 1982) passa por todos os níveis do treinamento, desde seu planejamento até a avaliação de seus resultados. Portanto, em razão da amplitude e de sua adequação a este estudo, o modelo será utilizado como base para a coleta de dados durante a pesquisa de campo.

Os elementos de composição do Levantamento de Necessidades, Ambiente de Suporte e de Elaboração e Implementação do Treinamento, constantes em Borges-Andrade (1982), já foram detalhados por este referencial, em seguida, é preciso compreender o último componente de seu modelo, a avaliação de treinamento nas dimensões de: reação, aprendizado, comportamento e resultados.

Passa-se assim a análise pormenorizada de cada uma destas dimensões.

\subsubsection{Reacões}

Em razão de sua rápida possibilidade de aplicação, normalmente é a mais realizada das mensurações. Sua melhor definição: os treinandos gostaram do treinamento? Nessa etapa da avaliação pergunta-se ao treinando: Quais eram seus objetivos ao entrar no programa? Estes objetivos foram atingidos? Você gostou do programa? Você recomendaria o programa a 
outros que tenham objetivos de aprendizagem semelhantes? Quais suas sugestões para aprimorar o programa? A empresa deve continuar a oferecer o programa?

Kirkpatrick (1993) observa que é importante determinar a satisfação dos treinandos, pois a decisão de repetir o programa de treinamento é baseada em grande parte na percepção de qualidade demonstrada por grupos anteriores.

É importante observar que essa avaliação tem o objetivo de coletar opiniões honestas dos participantes, assim sua realização deve valer-se de metodologias de avaliação anônimas. Para proporcionar resultados capazes de fornecer indicadores médios e isentos. Quando o participante adulto avalia um programa de treinamento, avalia a oportunidade da utilização do que foi aprendido em razão de seu trabalho.

É preciso observar que a reação positiva do treinando não garante a eficiência do programa, esta reação tem pouco significado para a empresa a menos que seja capaz de se traduzir em comportamento gerador de resultados (BOHLANDER; SNELL; SHERMAN, 2003). Gostar do programa simplesmente pode significar referência à capacidade de entretenimento do programa (DeCENZO; ROBBINS, 1999), e a menos que seja esse o interesse que motivou sua realização, ter treinandos mais satisfeitos com um programa de entretenimento parece fazer pouco sentido.

Hamblin (1978) observa que a reação é sempre o primeiro efeito visível do treinamento, e este efeito compõe-se de um elevado nível de subjetividade, assim é necessário que, no processo de avaliação do treinamento, sejam definidos quais são os objetivos de reação observáveis, devendo se distinguir que efeitos de reação precisam ser investigados e de que forma se espera que os treinandos reajam. O autor observa que no momento do registro da avaliação de reação é preciso que o responsável seja capaz de identificar o quanto da reação tem a ver com o interesse de observação do programa, pois sobre o aspecto reação refletem-se efeitos de diversas outras origens que não o treinamento em si. Borges Andrade (1982 e 
2000), Pantoja e Borges-Andrade (2004) e Abbad (1999) conceituaram esse tipo de influência como elementos de suporte ao treinamento.

Hamblin (1978), recomenda que é necessário definir os aspectos de reação que devem ser observados, Abbad (1999) subdivide o item reação em programação do treinamento, apoio ao desenvolvimento do treinamento, aplicabilidade e utilidade do treinamento, resultados, expectativas de suporte organizacional e desempenho do Instrutor.

No tocante a programação do treinamento, observam-se aspectos qualitativos de seu desenvolvimento, além de itens como carga horária, duração, intervalos, conteúdo programático, e quanto dos procedimentos gerais foram observados no programa.

Quanto ao apoio que se deu ao desenvolvimento do treinamento, leva-se em consideração a qualidade das instalações e do material didático.

Quanto à aplicabilidade e utilidade do treinamento, avalia-se junto aos participantes do programa o quanto ele está relacionado com a atividade de trabalho daqueles que participaram do programa.

A respeito dos resultados, o participante oferece sua opinião quanto à efetividade do programa, o quanto este foi capaz de disseminar conhecimentos aplicáveis a realidade de trabalho dos participantes.

No que diz respeito a expectativas de suporte organizacional, o participante demonstra o quanto o "clima" do ambiente em que esta inserido é ou não favorável a aplicação do conteúdo daquilo que aprendeu no curso.

Finalmente, quanto ao desempenho do instrutor, examina-se sua capacidade didática em transmitir os conteúdos de formação, relatando sua capacidade de utilização de estratégicas didáticas envolventes para os participantes e pela criação de um bom ambiente de aprendizado. 
Conforme Abbad, Gama e Borges-Andrade (2000, p. 39) "há forte relacionamento entre reações e impacto do treinamento no trabalho". Os autores previnem que é necessária uma avaliação de eficácia que considere elementos preditores do sucesso do treinamento como suporte a transferência e características da clientela.

\subsubsection{Aprendizado}

A dimensão do aprendizado em Kirkpatrick (1993) preocupa-se em avaliar o quanto um programa de treinamento foi capaz de transferir conhecimento a seus participantes, sua preocupação central é entender o que foi aprendido durante o programa.

A avaliação de aprendizado deve se apresentar de forma objetiva, preferencialmente, utilizando-se de avaliação pré e pós treinamento que produzirá indicadores confiáveis de comparação e que permitirá ainda o tratamento estatístico de dados de aprendizado, sendo possível estabelecer correlações e níveis de confiança.

A mensuração de aprendizado, dirigida a avaliar habilidades simples para o trabalho, tem um grau de complexidade de implantação menor do que a avaliação do aprendizado de novas competências e de saberes mais complexos. Para cada caso será necessário o desenvolvimento de um instrumento de avaliação mais ou menos sofisticado.

Para Hamblin (1978), prover o participante de um programa de aprendizado parece constituir-se no objetivo precípuo da realização de um programa de treinamento.

Hamblin (1978) observa que as pessoas estão propensas ao aprendizado em diversos tipos de experiências, o que determina que o avaliador do processo de treinamento tenha capacidade seletiva em identificar quais são os objetivos de aprendizado pretendidos pelo programa de treinamento. $\mathrm{O}$ autor recomenda que a avaliação de aprendizado seja capaz de satisfazer três condições: 
1. Aptidão básica para o treinamento (inteligência, personalidade, destreza etc.) para poder adquirir conhecimentos, habilidades e atitudes desejados.

2. O estádio de aprendizado existente (conhecimentos, habilidades e atitudes) dos treinandos precisa ser compatível com as suposições feitas nos objetivos do treinamento.

3. É preciso que a reação dos treinandos seja favorável... Significa dizer que os treinandos devem ser receptivos ao treinamento.

(HAMBLIN, 1978, p. 36)

A terceira condição de Hamblin (1978) foi confrontada por Alliger e Janak (1989) e Abbad, Gama e Borges-Andrade (2000) que não conseguiram confirmar empiricamente a relação de interdependência entre reação e aprendizado, ou seja, para que o participante do programa de treinamento tenha um bom aprendizado ele não necessita ter tido uma reação favorável, ter gostado do treinamento.

Abbad, Gama e Borges-Andrade (2000) alertam para o fato de que os baixos índices de simetria entre aprendizagem e os demais critérios observados em Hamblin (1978), reações e impacto, podem não ter sido percebidos por problemas de inconsistência da verificação de aprendizagem que se aplicou.

Esta observação indica que a elaboração desse instrumento deve ser intensamente verificada para que seja capaz de refletir a avaliação dos objetivos propostos pelo treinamento, e da forma como seu deu a transmissão destes conteúdos.

Outra ressalva de Abbad, Gama e Borges-Andrade (2000) dá-se em função de que a aprendizagem dos participantes pode estar fortemente relacionada com as características da clientela e com o nível de suporte organizacional recebido por ela, onde mais uma vez o treinamento em si, não tem capacidade de intervenção.

Grupos de controle podem ser efetivos na demonstração de aprendizado, contudo, não basta identificar se houve ou não aprendizado, é preciso dimensionar porque e para que este aprendizado é útil à organização, nestes termos as mensurações de comportamento e resultados são indispensáveis. 


\subsubsection{Comportamento}

A mudança de comportamento refere-se à transferência efetiva do que foi aprendido no programa de treinamento e o que se exige do comportamento do treinando no trabalho. Dentre os métodos de avaliação do comportamento podem ser citados a observação dos funcionários treinados, entrevistas com seus gerentes e avaliações de desempenho, empregando seus mais diversos métodos (KIRKPATRICK, 1993).

Kirkpatrick (1993) destaca alguns critérios que devem ser relacionados ao se avaliar a mudança de comportamento do treinando: treinandos devem querer melhorar, devem reconhecer suas fraquezas, devem trabalhar em um clima que permita a implantação de mudanças em razão de programas de treinamento, devem ter ajuda de alguém que é interessado e hábil na gestão da mudança de comportamento e devem ter a oportunidade de tentar implementar novas idéias.

Para Pantoja e Borges-Andrade (2004), a idéia de aprendizado está associada à idéia de apreender algo, assim uma capacidade revelada por meio de uma mudança no comportamento, apresenta o relacionamento entre aprendizado e comportamento.

$\mathrm{Na}$ falta de recursos para medidas mais complexas de mensuração de comportamento é possível a pesquisa junto aos treinandos a fim de obter indicadores destas mudanças, parte-se do princípio de que ninguém melhor do que o ocupante no cargo para compreender as transformações de seu próprio comportamento em razão do treinamento recebido (MILIONE, 1999).

Esta avaliação, baseada na declaração dos participantes do treinamento, deve ser apoiada por outras com menores possibilidades de interferência ou vieses, contando assim com elementos objetivos de mensuração de resultado. 
Hamblin (1978) destaca que é imperioso definir o objetivo da avaliação de comportamento. O autor alerta que o comportamento no cargo pode não ser resultante exclusivo do treinamento, mas de outro tipo de esforço, e em razão de outro tipo de motivação que não o treinamento. Sua atenção volta-se para o fato de que, ao se fazer a avaliação de comportamento, tenha-se em mente as razões que justificam a avaliação de mudança de comportamento, no contexto do programa de treinamento que se queira medir.

Hamblin (1978) é pioneiro em diagnosticar que a dificuldade de mensuração do comportamento reside na questão da transferência do conhecimento que foi aprendido no ambiente de aula para a situação de trabalho.

Pantoja e Borges-Andrade (2004) explicam que a transferência pode ser verificada quando a mudança de comportamento ocorre em atividades "não equivalentes às anteriores, ou é verificada em situações distintas daquelas em que ocorreu uma transferência de aprendizagem", ou seja, a transferência só pode ser confirmada quando enfrenta a dificuldade que a constitui, quando um conhecimento é adquirido e incorporado por uma pessoa em uma situação de aprendizagem stricto sensu e transferida para uma situação de trabalho.

Os autores citam Baldwin e Ford (1988) que definem transferência de treinamento como a aplicação, generalização e manutenção, no ambiente de trabalho de CHAs adquiridos em T \& D. Os autores contudo adaptam esse conceito para transferência de aprendizagem "já que a coisa que é transferida seriam os CHAs adquiridos e não tudo o que está incorporado no conceito de T \& D anteriormente apresentado: ações organizacionais + aquisição de CHAs + mudança de comportamento" (PANTOJA; BORGES-ANDRADE, 2004, p. 119).

Novamente firma-se a idéia de que a transferência se dá com a aplicação do que se aprendeu na situação de aprendizagem para o ambiente de trabalho.

Para Abbad (1999), o aspecto transferência, contingente de sua classificação denominada Impacto, se refere à aplicação correta das competências úteis no ambiente de 
trabalho, adquiridas por meio da ação de treinamento, onde concorda com Pantoja e BorgesAndrade (2004) e Hamblin (1978), resguardando-se apenas a diferença de nomenclatura e do aspecto de abrangência conforme se verá no item resultados.

A avaliação de transformações de comportamento, segue-se a avaliação de resultados que o programa foi capaz de proporcionar.

\subsubsection{Resultados}

A dimensão que encontra maior controvérsia e dificuldade de avaliação de treinamento é a dos resultados.

Os autores parecem convergir a respeito desta dificuldade, principalmente em se tratando da necessidade de se isolar as variáveis obtidas como resultados do treinamento das demais variáveis organizacionais que possam ter influenciado estes resultados.

Kirkpatrick (1996) observa que a mensuração dos resultados é a melhor forma de se avaliar um programa de treinamento, e que apesar das dificuldades inerentes a sua realização não deve ser, negligenciada. Sua complexidade evolui da mesma forma que a avaliação de aprendizado, de acordo com a complexidade do treinamento realizado, funções operacionais que foram objeto de programas de treinamento, visando atingir metas, também operacionais, contam com indicadores objetivos, que podem ser comparados antes e depois do treinamento e com as médias de indicadores do mercado.

De sua visão, depreende-se que treinamentos de cunho gerencial contam com maior dificuldade de mensuração, por não disporem de indicadores tão objetivos e pela dificuldade de isolamento das variáveis.

Abbad (1999) observa que a dificuldade desse aspecto se dá em razão das características diversas da clientela que foi atendida pelo treinamento. 
Para Kirkpatrick (1996) os instrumentos de medida disponíveis não são suficientes para abranger a dimensão de resultados de um programa de treinamento.

Apesar da dificuldade anunciada em se medir os resultados de um curso, uma pesquisa da ASTD, demonstra que aproximadamente dois terços dos gerentes de treinamento, afirmam que sofrem pressão da organização para demonstrar que seus programas geram resultados financeiros (COOK, 1998).

Hamblin (1978, p. 22) afirmou categoricamente que "não se pode medir o valor total de um programa de treinamento em termos tanto sociais quanto nos financeiros".

Para Hamblin (1978), no tocante a avaliação de treinamento uma linha de observação parece sempre se voltar para a afirmação de que a única medição válida é a financeira. $\mathrm{O}$ autor destaca que por meio de um treinamento, podem-se atingir diversos objetivos intermediários que no final podem até se refletir em resultados financeiros para a empresa, mas que não necessariamente precisam ser perseguidos como prerrogativa inicial.

Para Hamblin (1978) quando se indica que gerentes realizem um programa de treinamento, mesmo que se tenha como objetivo a melhoria dos indicadores financeiros da empresa, acredita-se que os lucros virão com o aumento do nível de inovação, o que pode ser também uma conseqüência da melhoria da qualidade de comunicação interna, também produto do treinamento, resultados prováveis de uma melhor percepção interpessoal dos gerentes e de seu aprofundamento em termos de auto-conhecimento. Nota-se que o autor não propõe que os resultados serão produto direto do treinamento ocorrido.

Phillips (1997), afirma que dentre as empresas americanas, 100\% realizam mensuração de reação, $49 \%$ realizam avaliação de aprendizado, $16 \%$ avaliam o comportamento no cargo, e apenas $4 \%$ avaliam os resultados do treinamento.

Farnsworth (1976) opôs-se a percepção de que os benefícios de um programas de treinamento pudessem ser dimensionados, segundo ele, as mudanças de atitude que são, em 
sua opinião, a principal condicionante de resultados, não são apenas difíceis de medir, são também objeto de funda discrepância entre o que o gerente diz acreditar e sua real postura ao voltar a seu cargo.

Em termos práticos, Dimenstein (2002), afirma que "250 mil pessoas estão cursando MBA e fazendo especialização no Brasil e no exterior" citando, como fonte de dados, o IBGE. Apesar deste contingente de pessoas, são raros os dados disponíveis quanto ao volume de investimentos em programas $M B A$ in company, apesar disso sabe-se que grandes corporações realizam este tipo de ação de capacitação em grande escala.

O Banco do Brasil como um exemplo, num intervalo de 10 anos formou seis mil funcionários internos a partir deste tipo de programa de treinamento, a um custo médio de $\mathrm{R} \$$ 9 mil reais por participante, tem-se um investimento de R\$ 54 milhões (BANCO DO BRASIL, 2004).

Não obstante a intrínseca dificuldade do processo de mensuração de resultados em treinamento, ela parece caminhar no mesmo sentido de discussão que apresentou argumentos contrários e em favor da mensuração de práticas gerais da gestão de recursos humanos, onde os argumentos de Pfeffer (1997), Ulrich (1997) e Fitz-enz (2001) se contrapuseram quanto tendo-se concluído que a mensuração é um fato inevitável, inerente a conjuntura de um mercado que prima pela eficiência de resultados e assertividade de investimentos.

Conforme Kirkpatrick (1993), os indicadores utilizados na mensuração de resultados incluem critérios de produtividade, redução de queixas de funcionários, redução de custos e aumento de lucratividade, na fase de avaliação de resultados é fundamental comparar os indicadores produzidos pelo levantamento de necessidades, com aqueles que indicam o resultado após o treinamento. Essa comparação deve ser objeto de tratamento de dados estatísticos, permitindo análises de grau de confiança e realização de correlações, sem deixar 
de observar a preocupação com o isolamento das variáveis que influenciaram os resultados do treinamento mas que não foram causadas por ele.

Mais tarde Kirkpatrick (1996), observa que a tomada de dados para avaliação de resultados pode observar os seguintes critérios temporais de mensuração: Pós-Treinamento, Pré-Pós-Treinamento e Pré-Pós-Treinamento com Grupo de Controle.

Para Kirkpatrick (1996), a escolha do método deve-se também a complexidade do treinamento que se realizou, podendo exigir que a mensuração de resultados seja realizada com a técnica de medição Pré-Pós-Treinamento com Grupo de Controle, onde serão avaliados além dos indicadores do grupo que está sendo treinado, um grupo de controle sobre o qual não incide o programa de treinamento com o objetivo de isolar, ou mesmo de diminuir, a influência positiva ou negativa de variáveis ambientais nos resultados do grupo treinado.

Para Hamblin (1978), a dimensão de resultado leva o nome de valor final, onde se devem estudar quaisquer efeitos gerados na empresa, em razão do programa de treinamento. Hamblin (1978) separa a dimensão resultado em organização e valor final.

No que tange a organização deve se observar os indicadores que motivaram a realização do treinamento, como a redução no índice de perdas de produção, melhoria da performance, melhoria da comunicação interna dentre outros. Estes efeitos impactam a organização e sua solução, em primeira análise, cumpre os objetivos pelos quais o treinamento foi proposto.

$\mathrm{Na}$ abrangência de valor final o autor, indica que a organização deve ser capaz de demonstrar o quanto se auferiu de resultado financeiro em razão do treinamento, alertando para o fato de que nem sempre esta mensuração é possível ou mesmo conveniente.

Hamblin (1978) observa que muitas vezes ao se comparar os objetivos dos treinandos com os da empresa, parece haver uma lacuna. Enquanto os treinandos esperam obter recompensa financeira, promoções e melhoria da auto-estima a empresa tem a expectativa de 
obter melhores lucros, esta diferença de expectativas vai provavelmente frustrar alguma das partes envolvidas.

O mesmo autor observa que a empresa realizadora do treinamento precisa contar com um sistema de avaliação do treinamento capaz de contemplar os diversos elos que se apresentam como elementos resultantes de sua avaliação. Mas alerta para o fato de que em algumas situações o custo financeiro da atividade de avaliação pode exceder o beneficio proporcionado pelo treinamento, sendo então um contra senso sua realização.

Impacto do treinamento no trabalho, é a principal variável critério do modelo de avaliação de treinamento proposto por Abbad (1999), e compreende os conceitos de transferência de treinamento e desempenho no trabalho.

\begin{abstract}
"O impacto do treinamento no trabalho nem sempre, (...) se reduz à transferência positiva de treinamento. Habilidades metacognitivas, estratégias de autogerenciamento, uso de ferramentas de informática, lógica, metodologia científica, técnicas de estimulação da criatividade, uma vez aprendidas, podem afetar o desempenho do indivíduo em muitas atividades que executa dentro da organização: seu comprometimento com o trabalho e sua abertura às mudanças, entre outros efeitos. Apesar disso, em psicologia, o impacto do treinamento no trabalho vem sendo estudado, na maior parte das vezes, com base no conceito de transferência de treinamento ou transferência de aprendizagem." (ABBAD, 1999, p. 26)
\end{abstract}

Abbad (1999) ressalta a importância dos preditores que precisam ser avaliados para o entendimento do impacto do treinamento no trabalho.

Dentre estes preditores, destacam-se contexto organizacional, e suporte a transferência.

Por contexto organizacional entenda-se o clima em que se insere o treinando quanto a sua adequação ao treinamento, o que pensa sua chefia, seus colegas e o quanto o programa se integra as suas reais possibilidades de trabalho.

Por suporte à transferência entende-se o quanto o treinando terá de apoio para implementar aquilo que aprendeu por meio do treinamento. 
Freitas e Borges-Andrade (2004) dedicaram-se a pesquisar quanto o treinamento é capaz de impactar o desempenho individual e organizacional das empresas, um estudo de caso do programa MBA Marketing realizado em ambiente interno do Banco do Brasil revelou que o treinamento impactou positivamente diversos aspectos do desempenho individual e organizacional (FREITAS; BORGES-ANDRADE, 2004).

A ABNT (2001) recomenda que a avaliação de resultados não pode ser realizada antes de o treinando estar em situação real de trabalho, ou seja, o treinando deve estar exposto à situação para a qual foi preparado, e, então, seus resultados operacionais devem ser novamente medidos Abbad (1999) e Freitas e Borges-Andrade (2004) respeitaram este critério.

Em se tratando da dificuldade que tangencia o tema resultados, parece haver um aprofundamento desta dificuldade quando se fala em Retorno do Investimento Financeiro. Contudo, há trabalhos que procuram se ocupar desta mensuração.

Philips (1997), sugere que a mensuração do ROI deve considerar os custos do programa de treinamento divididos pelos resultados gerados.

A Motorola chegou a indicadores de que para cada dólar gasto em treinamento 33 retornam à empresa (BOHLANDER; SNELL; SHERMAN, 2003), e revelou ainda indicadores de 139\% de aumento em resultados de vendas (DeCENZO, ROBBINS, 1999), em razão da realização de programas internos de treinamento de vendas.

A avaliação do resultado deve ser realizada com base em uma contabilização envolvendo o relacionamento do custo do treinamento com sua capacidade de gerar retorno, a utilidade do treinamento é maior na medida em que a relação de custo em relação ao benefício proporcionado se tornar mais positiva.

Freitas e Borges-Andrade (2004) destacam neste sentido que a verificação do valor investido não impõe dificuldade de operacionalização, pois exige simplesmente a 
sistematização de todos os custos envolvidos no programa de treinamento, residindo no cálculo dos resultados o problema da mensuração, pois que nessa dimensão exige-se o isolamento das demais variáveis organizacionais que podem ter influenciado os resultados do treinamento.

Ávila et alii (1983), levaram a efeito um estudo que objetivou medir a relação de retorno sobre o investimento de um programa de treinamento da Embrapa, tendo chegado a uma relação positiva de resultados.

Verificou-se que a avaliação dos programas de treinamento se insere em uma complexa discussão a respeito da oportunidade de se realizar ou não mensuração junto as praticas de recursos humanos, Pfeffer (1997), Ulrich (1997) e Fitz-enz (2001). À medida que cada vez mais organizações buscam mensurar o sucesso de cada uma de suas políticas a prática da mensuração se torna mais disseminada e necessária.

Discutiu-se brevemente os sistemas de avaliação propostos por Kirkpatrick (1993), Hamblin (1978) Borges-Andrade (1982) e Abbad (1999).

Tendo-se assim em seguida detalhado os aspectos de avaliação de treinamento em termos de reação, aprendizado, comportamento e resultados, resguardando as diferenças de nomenclatura empregadas pelos autores, de sua hierarquia de priorização interna e de sua definição de pressupostos.

Verificaram-se resultados positivos de correlação entre treinamento e resultados para a organização em Abbad (1999) e Freitas e Borges-Andrade (2004) e Ávila et alii (1983).

Examinado os conceitos relativos a treinamento, levantamento de necessidades de treinamento e sua avaliação, busca-se em seguida um comentário sobre como o conhecimento influencia a forma de se fazer negócios e avaliar empresas, no tocante a composição de seu capital intelectual e em especial da construção da vantagem competitiva sustentável da organização. 


\subsection{VANTAGEM COMPETITIVA SUSTENTÁVEL}

A emergência de temas como a Sociedade do Conhecimento tem suscitado discussões em torno de como as organizações são compostas, de que se constitui sua riqueza e como elas são avaliadas.

A ampliação do uso de conceitos como aprendizagem organizacional, gestão do conhecimento e universidades corporativas empregados neste estudo tem sinalizado que o termo Sociedade do Conhecimento é apropriado ao procurar representar o atual estado das organizações.

A riqueza das organizações, seu patrimônio, passa cada vez mais a concentrar-se nas pessoas, constitui-se assim seu capital intelectual, sendo basicamente o conjunto sinérgico de seu capital humano.

Conforme Edvinson e Malone (1998), toda a capacidade, conhecimento, habilidade ou experiência individuais dos empregados e gerentes, estão incluídos no termo capital humano. Mas o capital humano precisa ser maior do que a soma dessas medidas, devendo, de preferência, captar igualmente a dinâmica de uma organização em um ambiente competitivo e em constante mudança. Ou seja, o que se quer dizer é que o conhecimento dos empregados deve ser transferido para a organização, tal como se viu nos conceitos de aprendizagem organizacional e gestão do conhecimento.

Para Stewart (1998), deve-se, além de ter consciência de que a inteligência das pessoas é o ativo mais importante da organização, identificar onde a inteligência se localiza e que ações estratégicas podem ser adotadas para alcançar um melhor desempenho de sua parte.

Stewart (1998) adota o termo capital intelectual para se referir ao conhecimento existente em uma organização e que pode ser usado para criar uma vantagem diferencial. O 
autor coloca este conhecimento como válido do ponto de vista organizacional, e não individual, o capital humano faz sentido enquanto possa ser utilizado pelas empresas para se acrescentar a sua capacidade de gerar lucros

Ainda segundo Stewart (1998), o capital humano da organização cresce quando a empresa utiliza mais do que as pessoas sabem, e a medida que mais pessoas, sabem mais coisas úteis, melhores resultados serão obtidos.

A discussão em torno do capital intelectual acrescenta-se a discussão da gestão do conhecimento. Nesta última, a orientação dos autores se dá no sentido de que o conhecimento na empresa, adquirido pelas pessoas, deve ser transferido para a organização. O aspecto que se acrescenta em torno do capital intelectual, age no sentido de atribuir-se o elemento de agregação de valor.

Além de considerar-se o conhecimento como elemento estratégico de diferenciação e de gestão, ele passa a poder ser visto como um acumulador de capital (EDVINSON; MALONE, 1998; STEWART, 1998).

Lançando mão desta premissa, Klein e Prussak ${ }^{6}$ apud Stewart (1998), afirmam que a gestão de capital intelectual deve ser objeto de conhecimento e manejo de forma que seu desenvolvimento possa ser estimulado de forma intencional e com maior assertividade tendo como objetivo a geração de lucros.

Stewart (1998), representa graficamente a alocação da representatividade da força de trabalho de trabalho da organização:

\footnotetext{
${ }^{6}$ KLEIN, D. A., PRUSSAK, L. Characterizing Intellectual Capital
} 


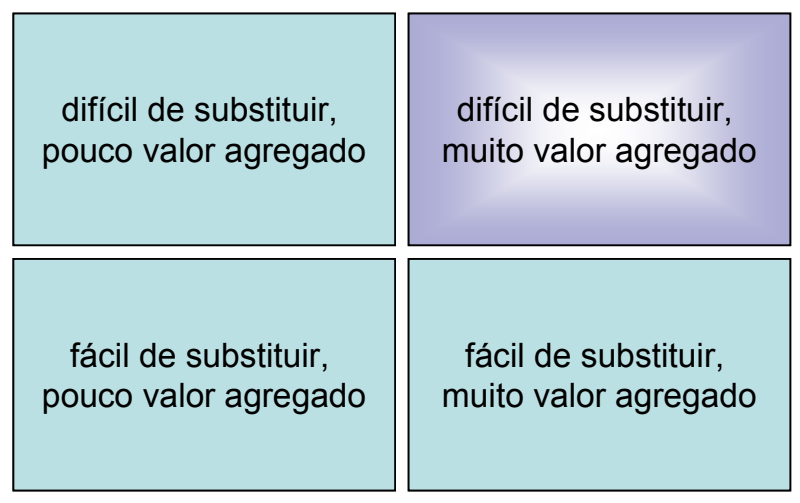

Figura 13: Representatividade da Força de Trabalho Fonte: adaptado de STEWART, (1998, p. 81)

Explorando a figura apresentada, no quadrante inferior esquerdo, encontram-se pessoas que realizam um trabalho importante, mas o sucesso da organização não depende delas como indivíduos, sua substituição é rápida e fácil, pois a baixa especialização de sua função encontra extensa variedade de ofertas de mão-de-obra.

No quadrante superior esquerdo, encontram-se profissionais que possuem trabalho de maior especialidade, mas sua atividade não pode ser considerada a mais relevante na opinião dos clientes, assim sua perda apesar de preocupante não afetará os negócios da organização.

No quadrante inferior direito encontram-se profissionais que apresentam alta agregação de valor para a empresa, mas sua atividade não está alinhada a competência essencial da organização e há bastante oferta de mão-de-obra capaz de substituir estas pessoas.

No quadrante superior direito encontram-se os profissionais que receberam investimentos diversos por parte da organização (tempo, treinamento especializado), e que realizam atividades de difícil substituição. Nestes casos sua substituição, pode onerar em muito o desenvolvimento da organização.

Para Stewart (1998), o capital humano da organização encontra-se no quadrante superior direito, são os profissionais que, em sua visão, criam os produtos e serviços que 
fazem com que os clientes procurem uma empresa e não a outra, são os criadores dos produtos essenciais à organização.

Esta descrição de criação de produtos, alinhada a definição de produtos essenciais de Prahalad e Hamel (1990), como os produtos criados pela externalização das competências essenciais da organização, permite concluir que os profissionais que congregam a maior especialização de mão-de-obra da organização, constituem seu capital humano, sendo os responsáveis pela materialização dos produtos essenciais da organização, externalidades de sua vantagem competitiva.

Segundo Kaplan e Norton (2004), os ativos intangíveis são responsáveis por 75\% do valor da empresa, para os autores, considerando este montante, as organizações devem tratar explicitamente o alinhamento de seus ativos intangíveis, de forma que deles possam obter os melhores resultados.

“O alinhamento estratégico é o princípio dominante na criação de valor pelos ativos intangíveis" (KAPLAN; NORTON, 2004, p. 205).

Sabendo-se que para criar riqueza, o capital intelectual da organização, deve estar alinhado a estratégia da organização, o tratamento dado a ele orienta-se com o objetivo de gerar valor sustentável no futuro.

Na visão de Kaplan e Norton (2004), os objetivos de aprendizado e crescimento descrevem como pessoas, tecnologia e clima organizacional se conjugam para sustentar a estratégia, e mostram como a organização deve implementar essa estratégia.

Em torno da liquidez que se deve apontar no tocante aos ativos intangíveis, Kaplan e Norton (2004), apresentam o conceito de prontidão estratégica, como a capacidade que um ativo intangível tenha de suportar com maior aderência a estratégia da organização. Para estes autores quanto maior a prontidão estratégica de um ativo intangível com maior rapidez ele contribuirá para a geração de caixa da empresa. 
A construção da vantagem competitiva se faz por meio da aquisição ou desenvolvimento destas competências pela organização, empresa e empregados contribuem no conjunto de seus esforços para a realização de objetivos corporativos, ampliando seu capital intelectual e conseqüentemente a sustentabilidade e seu valor.

Assim se pode representar graficamente a evolução do conceito de Vantagem Competitiva Sustentável na organização:

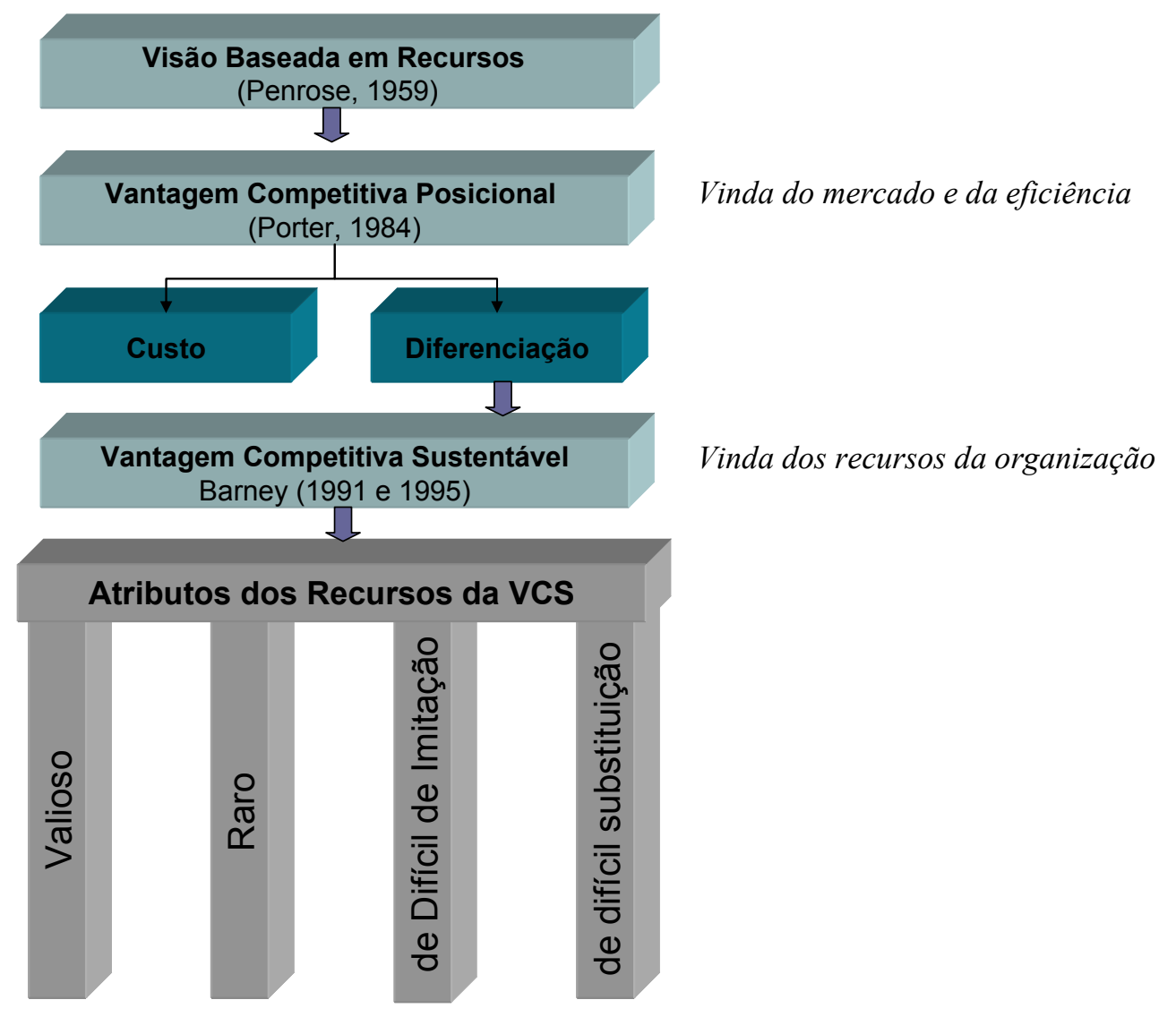

Figura 14: Evolução do Conceito da Vantagem Competitiva Sustentável

Fonte: Autor, baseado em Penrose (1959), Wernerfelt (1984) ${ }^{7}$ apud Fernandes (2004), Porter (1989), Barney (1991 e 1995), Kretzer (2002) e Fernandes (2004).

\footnotetext{
${ }^{7}$ WERNERFEL, B. A resourced based view of the firm. Strategic Management Journal. Hoboken, NJ, v 5, p. $171-180,1984$.
} 
A Figura14 apresenta de forma sintética a evolução do conceito de VCS. Iniciando-se pela compreensão da Visão Baseada em Recursos, que em seguida evolui para a Vantagem Competitiva Posicional, constituída pelo aproveitamento das oportunidades de mercado e da eficiência industrial da organização, obtida por elementos de custo e diferenciação. $\mathrm{O}$ aprofundamento do estudo da vantagem de diferenciação culminou no conceito da Vantagem Competitiva Sustentável e de seus atributos.

Conforme revisão de Fernandes (2004) a visão de vantagem competitiva foi introduzida por Penrose (1959). Segundo esta autora, o grau de controle de recursos da organização direcionará seus níveis de performance organizacional. A performance organizacional pode então ser considerada uma primeira medida de posicionamento comparativo de uma empresa num dado mercado de atuação.

Fernandes (2004) constata que a partir dos anos 80 a visão de competitividade, influenciada por Porter (1989) concentrou seus esforços de pesquisa na compreensão do posicionamento das indústrias, especialmente nos aspectos de eficiência e aproveitamento de oportunidades sinalizadas pelo mercado.

Porter (1989) apresenta então os conceitos de vantagem competitiva de custo e vantagem competitiva de diferenciação.

As vantagens de custo são adquiridas por meio da gestão de seus elementos influenciadores, tais como escala, aprendizagem, capacidade, elos, inter-relações, dentre outros. As vantagens conseguidas por meio da gestão de custos podem ser atingidas ainda por meio da reconfiguração da cadeia de valores da empresa, repensando processos de produção, automação, e demais elementos de eficiência e produtividade.

As vantagens de diferenciação são adquiridas com a gestão dos elementos diferenciais da organização, contemplando itens como a identificação do consumidor com a marca, lealdade dos consumidores, propaganda, fidelização, serviços diferenciados aos clientes, 
pioneirismo num setor (PORTER, 1989), além de peculiaridades acessórias que sejam percebidas pelo público da organização.

Esta visão vinculava de forma acentuada a vantagem competitiva baseada essencialmente na capacidade industrial da organização.

Em Wernerfelt (1984) apud Fernandes (2004), questiona a visão de eficiência industrial para oferecer vantagem competitiva à organização, apresenta assim a necessidade de as empresas desenvolverem e explorarem seus recursos valiosos, sendo pioneiro no emprego do termo.

A partir deste tipo de questionamento iniciou-se a sistematização do estudo da Visão Baseada em Recursos (VBR) que aponta como elemento de competitividade das empresas a maximização do uso dos recursos próprios (FERNANDES, 2004) e não mais o aproveitamento de oportunidades do mercado.

A VBR segundo o autor, pode se apresentar baseada em diversos tipos de recursos. Para o interesse desse estudo o foco recairá sobre como os recursos humanos apóiam o desenvolvimento da competitividade da organização.

Barney (1995) alinha-se a visão da VBR com foco no desenvolvimento dos recursos humanos. O autor pondera que a pesquisa de gestão, ao tratar da análise SWOT (Strengths, Weaknesses, Opportunities, Threats, ou, Forças, Fraquezas, Ameaças e Oportunidades) privilegiou entendimento das ameaças e oportunidades representadas pelo mercado, em detrimento da compreensão das forças e fraquezas internas da organização. Para este autor, a análise das variáveis ambientais é representativa no sucesso das organizações, mas não pode ser dissociada da compreensão de suas forças internas, em sua visão, estas últimas são definitivas na construção da vantagem competitiva das organizações.

Barney (1995) considera como forças internas das empresas seus recursos financeiros, físicos e humanos. Destacando os recursos humanos, o autor imputa a estes a responsabilidade 
pela experiência, conhecimento, julgamento, avaliação de risco e o conhecimento que a organização adquiriu ao longo do tempo.

Ainda buscando a compreensão da forma constitutiva da vantagem competitiva, verifica-se na revisão feita por Kretzer (2002), a distinção entre vantagem competitiva posicional e vantagem competitiva sustentável. Tal como se demonstra, a vantagem competitiva posicional indica como fontes, a exploração de pontos fortes e aproveitamento oportunidades de mercado, baseadas essencialmente em atividades de indústria. Compreendendo a visão baseada em recursos, incluem-se elementos como atratividade de recursos e baixos custos para sua aquisição.

Em contrapartida da vantagem competitiva posicional, Kretzer (2002), apresenta como fontes da vantagem competitiva sustentável a existência de recursos produtivos na organização, tais como habilidades, competências e capacidades (dinâmicas e organizacionais) essenciais. O autor menciona ainda o aprendizado corporativo, no tocante a existência de recursos especializados, co-especializados e complementares, e o compartilhamento do conhecimento, dentre outros elementos que podem ser vistos como fontes de vantagem competitiva sustentável.

Segundo Coyne (1986) ${ }^{8}$ apud Kretzel (2002) as fontes para uma vantagem competitiva sustentável viriam de quatro tipos de capacidades diferenciais:

1. capacidade funcional: resultante do conhecimento, das habilidades, da experiência dos funcionários e outros elementos de composição de sua cadeia de valor;

2. capacidade cultural: que incorpora os hábitos, as atitudes, as crenças e os valores que permeiam os indivíduos e os grupos na organização;

3. capacidade posicional: como conseqüência de atitudes passadas, que produziram algum tipo de reputação com os clientes, algum tipo de vantagem de colocação, etc;

\footnotetext{
${ }^{8}$ COYNE, K. P. Sustainable competitive advantage - What is it and What it isn't. Business Horizons, p. 54-61, Jan./Feb. 1986
} 
4. capacidade regulatória: resultante da posse de questões legais, como direitos de propriedade intelectual, contratos, segredos de troca, etc.

Vê-se que em Coyne (1986) o conceito de VCS associa-se diretamente às capacidades pessoais instaladas na organização, a capacidade funcional situa como fonte de VCS a capacidade de diferenciação gerada pelos funcionários da organização. A capacidade cultural emerge também das pessoas da organização e de como elas utilizam a cultura como política de administração. As capacidades posicional e regulatória, surgem como efeitos da reputação e política de administração da organização, que protegendo seu status de competição (posicional) e seus investimentos em pesquisa e desenvolvimento (regulatória) alcançam uma VCS, mas é evidente que a construção destes dois elementos dependeu diretamente da influência das capacidades humanas instaladas na organização.

Para este autor associam-se a VCS, elementos diferenciais ligados às fontes de conhecimento da empresa, tais como, processos, aprendizado de mercado e especialização de recursos, dente outros originados das capacidades humanas da organização.

Tendo-se compreendido a Vantagem Competitiva Sustentável pela ótica de sua dependência da gestão das capacidades humanas na organização, é valido compreender seus atributos.

Barney (1991) apresenta os atributos que uma organização deve identificar em seus recursos para afirmar que se constituem como fontes de vantagem competitiva sustentável. Ao longo da apresentação destes atributos, serão utilizados autores de apoio com o objetivo de exemplificar as proposições de Barney (1991), para este autor os recursos devem ser:
a) Valiosos;
b) Raros;
c) De difícil imitação; e
d) De difícil substituição. 
Detalham-se a seguir os atributos dos recursos integrantes da VCS.

Recursos Valiosos, podem ser associados às idéias de raridade e escassez, combinadas a possibilidade de obtenção de altas margens de retorno que ele propicie.

Barney (1995) observa que recursos valiosos, podem assumir diversas formas, que dependem essencialmente da combinação de recursos disponíveis e dos objetivos perseguidos pela empresa.

Para este autor, o valor de um recurso pode ser diferente até mesmo para empresas que concorrem no segmento. $\mathrm{O}$ autor exemplifica esta afirmação comparando os posicionamentos da Rolex e da Timex, enquanto a primeira considera valiosos e modela sua organização para exploração de elementos como qualidade diferenciada, excelência e status, a segunda valoriza alta performance, baixos custos e eficiência de produção.

Kretzer (2002), exemplifica:

\begin{abstract}
Um recurso valioso pode ser físico (tal como uma rede de cabos domésticos de uma companhia de TV por assinatura, que em combinação com uma companhia telefônica pode se tornar um negócio vantajoso no mundo de multimídia interativo pontencialidades dos recursos físicos), intangível (tais como nome da marca ou know-how tecnológico) ou uma capacidade organizacional (rotinas, processos e cultura da companhia), (Kretzer, 2002, p. 35)
\end{abstract}

Para Barney (1991), a classificação de recursos como valioso depende de como a organização o considera e como planeja seu desenvolvimento.

Barney (1995) retoma o assunto discutindo as características dos recursos valiosos, para ele o recurso é valioso quando permite que uma organização explore oportunidades e neutralize ameaças.

De acordo com sua visão porém, o valor dos recursos da empresa, dependendo do mercado concorrencial em que se insere, pode mudar no decorrer do tempo. E a questão passa a ser como utilizar forças tradicionais para explorar novas oportunidades de mercado neutralizando suas ameaças. 
Recursos Raros, conforme Barney (1991), um recurso pode ser considerado raro quando não estiver disponível ou acessível a um grande numero de concorrentes num mesmo mercado de atuação. O autor observa que algumas vezes a raridade do recurso não se encontra na sua existência em si, mas na forma como ele se integra na implementação de uma estratégia, em como ele é desenvolvido e acumulado na organização. Para ilustrar este exemplo o autor observa que o trabalho gerencial poderia ser considerado raro por seu relacionamento direto com a implementação direta da estratégia da empresa, porém, em razão de ser comum a maioria das organizações deixa de ser raro por si só. Sua constituição como um recurso raro se dará a medida que o trabalho gerencial for um recurso de tal forma integrado a estratégia da organização, e de tal forma desenvolvido que o nível de interdependência entre eles se constitua numa fonte de vantagem competitiva sustentável rara.

Dierickx e Cool (1989) ${ }^{9}$ apud Kretzel (2002) observam que o trabalho por definição, não pode ser raro, já que é disponível no mercado, mas as pessoas, “uma vez contratadas, são dotadas de habilidades, conhecimentos e valores específicos à firma; elas incorporam outros recursos que são acumulados através da experiência, aprendizado e treinamento" (KRETZEL, 2002, p. 38).

Kretzel (2002) exemplifica que recursos raros podem ser "físicos 'terra, minerais, equipamentos específicos, ou até mesmo uma planta' ou intangíveis 'talento específico, informação, patentes, cultura, etc.'” (KRETZEL, 2002, p. 39).

Ainda pelo mesmo autor, as contingências do mercado, condições de regulamentação oficial e o ambiente podem atribuir representatividade à raridade de um recurso.

Segundo este autor, a raridade pode ser entendida como resultado da conexão entre capacidade, durabilidade e natureza. A capacidade é estabelecida pela posição da empresa em seu mercado de concorrência. A durabilidade de um recurso físico determina sua capacidade

\footnotetext{
${ }^{9}$ DIERICKX, I.; COOL, K. Asset stock accumulation an sustainability of competitive advantage. Management Science, vol. 35, n. 12, pp. 1504-1511, 1989
} 
produtiva. E a natureza do recurso e seu relacionamento com inovação determinam por quanto tempo ele será considerado raro, quanto mais essencial for um recurso, mais tempo ele perdurará e mais raro será.

Recursos difíceis de imitar são aqueles em que se reconhece a existência de atributos que os tornam caros para imitação pelos concorrentes (BARNEY, 1991).

Essa situação decorre do fato de que a forma como o recurso foi concebido envolvendo as habilidades, capacidades e recursos únicos numa organização, refletem suas escolhas estratégicas durante seu desenvolvimento. Estes recursos e capacidades estão associados às personalidades, experiências e relacionamentos que só podem existir numa organização em especifico, tal como observa, "a aquisição ou desenvolvimento de recursos valiosos e raros depende de circunstâncias históricas únicas, a imitação destes recursos implicará uma desvantagem de custo na sua construção” (BARNEY , 1995, p. 53).

Para Barney (1995), recursos e capacidades socialmente complexos, apesar de não patenteáveis, são muito difíceis de imitar, recursos como reputação, confiança, amizade, trabalho em equipe e cultura, assumem tal interdependência que sua imitação se torna muito difícil. Esta vantagem surge como produto de numerosas inter-relações projetadas pelas organizações ao longo de anos, no aproveitamento de oportunidades de mercado e em seu empenho de neutralização de fraquezas.

Como exemplo, Barney (1995) menciona a Caterpillar, indústria pesada de classe mundial. Segundo ele a empresa só atingiu esta posição em razão das condições que a colocaram como fornecedora de diversos países aliados em batalha na segunda guerra mundial, segundo o autor, se uma industria pretender concorrer com a Caterpillar imitando suas capacidades instaladas terá que assumir sozinha todo o custo da decorrência histórica que a Caterpillar aproveitou como uma contingência de mercado, e isso provavelmente a tornaria inviável. 
Recursos de difícil substituição, segundo Barney (1991), sugere-se que organizações com potencial de concorrência, que não disponham de recursos que contemplam os atributos de VCS como ser valiosos, raros e difíceis de imitar, podem apelar para a estratégia de tornar o recurso da organização que detém VCS substituível.

O recurso pode se tornar precário, substituível, de duas maneiras, pela geração de recursos similares ou diferentes. Conforme Barney (1991) se uma organização desenvolver sua própria equipe gerencial, capacitada como a equipe gerencial da empresa que detém VCS, e atingir resultados similares a esta, o recurso não poderá mais ser considerado difícil de substituir.

A substituição por recursos diferentes, pode se dar quando, por exemplo, duas empresas desenvolvem uma visão do futuro, o que é um elemento de competitividade, porém uma delas o faz por ter um líder carismático e visionário, e a outra por adotar um processo formal de planejamento estratégico. Se duas empresas desenvolvem esta visão num mesmo mercado, nenhuma delas pode afirmar que tem uma VCS em função disso.

O recurso só pode ser considerado de difícil substituição quando não puder ser alvo desse tipo de estratégia de equiparação.

A constituição de um recurso como de difícil substituição se dá quando o atingimento de seus atributos por uma empresa de concorrência seja tão caro ou difícil que o preservem.

Entendendo-se os atributos que compõe a Vantagem Competitiva Sustentável é preciso avançar o conceito na direção de suas características e meios de desenvolvimento.

Conforme Kretzel (2002), uma abordagem contemporânea neste aspecto remete ao estudo das competências empresariais, cujos recursos estratégicos internos, são os meios pelos quais as empresas buscam a diferenciação.

Essa abordagem desenvolve o conceito de que os recursos essenciais e habilidades intrínsecas que as empresas possuem, podem originar diferentes desempenhos no mercado, 
além de servir à defesa de posições e vantagens competitivas adquiridas (PRAHALAD; HAMEL,1990).

Prahalad e Hamel (1990) discutiram o conceito de competências essenciais como um objetivo a ser perseguido por organizações que pretendem desenvolver características que sejam capazes de sustentar seu crescimento no tempo.

Os autores afirmam que até os anos 90, o desempenho dos executivos era medido por sua capacidade de promover a reestruturação de organizações, mantendo suas funções ativas e suas unidades de negócio lucrativas. Segundo os autores, após os anos 90, a avaliação dos executivos esteve, e estará daqui para frente, alinhada à capacidade de: identificar, explorar e cultivar as core competences, as competências essenciais da organização. Os autores deixam claro que a construção das competências essenciais passa pela gestão e pelo desenvolvimento dos recursos humanos na organização.

Prahalad e Hamel (1990) estabeleceram a necessidade de que a empresa defina suas competências específicas e seja capaz de dividi-las até que atinjam o nível individual, dessa forma apontando as competências individuais que se deve desenvolver para a construção da competência organizacional. Os autores apontaram ainda a necessidade de ligação entre os programas de treinamento e a definição de competências da organização.

De certa forma sugerem que as competências essenciais da organização constroem sua a vantagem competitiva. Isso se dá especialmente em razão do aprendizado coletivo e do acesso a mercados que as competência essenciais proporcionam.

Prahalad e Hamel (1990) acenaram para o fato de que as empresas que desenvolvem suas competências essenciais, direcionando seus esforços e políticas de administração para apoiá-las, constroem sua vantagem competitiva sustentável.

Ainda em torno da discussão que permeia a constituição da VCS, interessa a esse estudo compreender teoricamente como se relacionam o desenvolvimento das capacidades 
humanas na organização ao conceito de vantagem competitiva sustentável, e em análise acessória como podem ser associados ao treinamento.

Neste sentido Drucker (1993) afirmou que o recurso controlador e decisivo de produção deixou de ser o capital, a terra ou a força de trabalho, este fator decisivo passou a ser o conhecimento. Esta afirmação conjugada com a de Wernerfelt (1984) apud Fernandes (2004) de que à visão de eficiência industrial deveria se somar a análise e exploração das capacidades internas da organização, permite concluir que a construção da vantagem competitiva sustentável pode ser fortemente associada às características constitutivas das capacidades humanas instaladas na organização.

Para Porter (1989) a estratégia é a forma de se atingir a vantagem competitiva, conceitua liderança de mercado não como competitividade e sim como vantagem competitiva, que em sua percepção "é afetada diretamente pelo treinamento, que tem papel fundamental na consolidação de metodologias de trabalho da organização” (PORTER, 1989, p. 39).

Nesta mesma linha de pensamento, Meister (1999) afirma que em razão da comoditização de produtos e serviços diminui-se o espaço de competição com base em elementos tangíveis, tais como produtividade e diferenciação. Portanto, resta assim às organizações a possibilidade de se diferenciarem de seus concorrentes com base em elementos intangíveis, tais como os sistemas e processos humanos por trás de seus produtos e serviços. A autora afirma ainda que a forma de se viabilizar e incentivar a diferenciação por meio de processos humanos é o investimento em treinamento, não só do corpo funcional da organização mas também dos elementos que se integram a sua cadeia de valor.

Hall e Hall (1990) ressaltam a necessidade de assertividade dos treinamentos quanto às efetivas necessidades da empresa, isso se dá em razão do porte cada vez mais destacado do volume de investimentos que o treinamento abriga. Os autores observam que apesar da pouca evidência operacional capaz de relacionar o treinamento com a vantagem competitiva da 
organização ela se tornará cada vez mais evidente, num sentido estratégico, ampliando sua importância no contexto da organização.

Para Green (1999), as competências individuais devem determinar os objetivos instrucionais do treinamento. $\mathrm{O}$ autor entende competências individuais como a descrição de comportamentos de trabalho mensuráveis, dessa forma alteráveis por meio de programas de treinamento. O treinamento assume assim uma dimensão de caráter estratégico para a organização, à medida em que desenvolve as competências individuais que compõem as core competences da organização.

Entendendo a vantagem competitiva sustentável como aquela que será capaz de manter o crescimento da organização pelo tempo e que o recurso controlador de produção é o conhecimento, pode-se inferir que o conhecimento sustenta a vantagem competitiva da organização. Ao ampliar o conhecimento na organização pode-se inferir que o treinamento amplia a sustentabilidade de sua vantagem competitiva.

Parece haver uma espécie de "percepção favorável” por parte daqueles que promovem treinamento em entendê-lo como um instrumento de construção de vantagem competitiva sustentável.

Stewart (1998, p. 72), explorou o caso do investimento em treinamento da empresa Taco, fabricante de bombas e válvulas que investiu “cerca de U\$ 250 mil na construção de um centro de treinamento e ampliou este investimento anualmente em mais U\$ 300 mil, U\$ 200 mil na operação do centro de treinamento e U\$ 100 mil em salários e produção adiada". O autor aborda a capacidade de retorno do investimento em treinamento:

Todos esse gastos com treinamento, formação e cidadania - serão apenas bondade de um octogenário idealista ou investimento de um velho inteligente no futuro de um negócio da família? "Se tem retorno para nós? Claro que sim, afirma White. No entanto, nega-se a associar um valor monetário ao retorno: "o retorno se dá em forma de atitude. As pessoas acreditam que fazem parte do jogo em vez de sentirem apenas uma bola, sendo jogada de um lado para outro". (STEWART, 1998, p. 73) 
O autor segue afirmando que se "não se pode quantificar os benefícios do centro de treinamento da empresa, também não se pode negá-lo" (STEWART, 1998, p. 73). O autor descreve sucintamente a história da Taco, que em um momento de crucial de crise em seu setor, investiu seus recursos no desenvolvimento de seus trabalhadores superando a crise e crescendo suas margens de vendas em vinte por cento, sustentando seu crescimento e capacidade de competição por um longo período de tempo.

O depoimento acima, analisado no conjunto da teoria da vantagem competitiva sustentável apóia a conclusão de que o treinamento pode ser visto como fonte de geração da VCS na organização.

Concluindo, pôde-se observar que o conceito de VCS, teve sua primeira abordagem por Penrose (1959), ainda em nível de analise de performance organizacional, esta visão evoluiu para a de Porter (1989) em que o posicionamento das indústrias foi conceituado como eficiência e aproveitamento de oportunidades pela empresa, segmentado em vantagem competitiva de custo e de diferenciação.

Ampliando-se a visão de eficiência industrial, Wernerfelt (1984), apud Fernandes (2004), apresentou a necessidade de as empresas desenvolverem e explorarem seus recursos valiosos. Que foram conceituados por Barney (1991). Para este autor as forças internas são definitivas na construção da vantagem competitiva das organizações com destaque para os recursos humanos da empresa.

Barney (1991) define que os recursos devem ser valiosos, raros, de difícil imitação e de difícil substituição, para que se constituam como fonte de VCS.

Prahalad e Hamel (1990) orientam a necessidade de que empresa defina suas competências essenciais, fracionando-as até que atinjam o nível individual. Com as competências segregadas até o nível individual a organização pode identificar oportunidades de desenvolvimento de competências por meio de programas de treinamento. 
Neste sentido Meister (1999) reforça a possibilidade de diferenciação com base em elementos intangíveis, tais como os sistemas e processos humanos e que a forma de se viabilizar esta diferenciação é o treinamento.

Tendo-se demonstrado os recursos humanos da organização como elementos de sustentação da vantagem competitiva e sabendo que os recursos humanos podem ser desenvolvidos por meio de treinamento permite-se inferir que o treinamento, ao desenvolver os recursos humanos de uma organização suporta o desenvolvimento de sua vantagem competitiva sustentável.

Pode-se demonstrar ilustrativamente esta conclusão, por meio da Figura15:

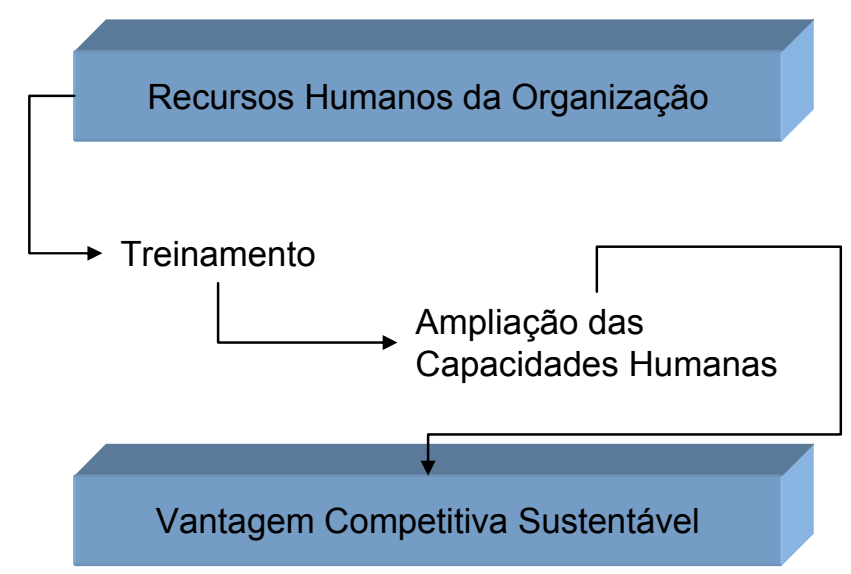

Figura 15: Recursos Humanos da organização como Fonte de VCS

Fonte: autor.

Conforme se verá no capitulo referente aos procedimentos metodológicos, os dados obtidos na pesquisa de campo serão classificados segundo os atributos de VCS de Barney (1991).

Esta escolha se justifica pela amplitude classificatória do autor, quando divididos em valiosos, raros, difíceis de imitar e difíceis de substituir os recursos constitutivos da Vantagem 
Competitiva da Organização compreendem vasta possibilidade de identificação, permitindo que se destaque os diferentes aspectos dos dados obtidos na pesquisa de campo. 


\section{PROCEDIMENTOS METODOLÓGICOS}

Para Popper (1975), o método científico deve ser adotado em ciências sociais com a finalidade de assegurar que os enunciados científicos sejam submetidos à prova, para este autor não se deve esperar verdades profundas da parte da metodologia, não obstante, em muitos casos, ela possa auxiliar a ver mais claramente a situação lógica e mesmo a resolver alguns problemas de longo alcance, que até sua interferência tenham se revelado insuscetíveis ao tratamento.

O método deve então, orientar o leitor na compreensão de como se realizou o estudo do fenômeno, definindo-se os limites da pesquisa e as necessidades de sua adaptação, buscando principalmente estabelecer as possibilidades de verificação da causalidade entre o fenômeno e seu resultado.

\subsection{NATUREZA DA PESQUISA DE CAMPO}

O objetivo deste estudo é conhecer os resultados do programa MBA Gestão Pública, no contexto da Diretoria de Governo do Banco do Brasil.

Para atender ao objetivo proposto, este trabalho utilizou uma pesquisa do tipo qualitativa.

Para Richardson (1999), o método qualitativo difere do quantitativo à medida que não emprega um instrumental estatístico como base do processo de análise do fenômeno, que além de se constituir em opção do pesquisador, justifica sua aplicabilidade como sendo a forma mais adequada de explorar um fenômeno de caráter social, especialmente que constitua como objeto, o estudo de fatos passados. A prevalência do método qualitativo sobre o método 
quantitativo deve ocorrer quando o pesquisador deseja conhecer detalhes do fenômeno que os instrumentos quantitativos não seriam capazes de alcançar.

As pesquisas encontradas sobre avaliação de treinamento, destacando-se em especial, Abbad (1999), Abbad, Gama, e Borges-Andrade (2004), Bastos (1991), Borges-Andrade (1982), Borges-Andrade (1982), Freitas e Borges - Andrade (2004), Nóbrega Junior (2001), e Silva (2002), concentraram sua discussão em aspectos quantitativos. Algumas destas pesquisas corroboraram suas proposições, outras não. Estes autores também testaram teoria anteriormente estabelecida, especialmente as hipóteses levantadas por Kirkpatrick (1993), procuraram assim apoiar o desenvolvimento e o avanço da ciência em diversos aspectos, por meio da análise quantitativa.

O objeto deste estudo, o programa de treinamento MBA Gestão Pública - Banco do Brasil é de natureza essencialmente estratégica, de conteúdo gerencial avançado e destinado a um público com razoável capacidade de transformação organizacional.

Neste sentido a análise quantitativa poderia obstruir o alcance de dimensões relacionadas ao aspecto gerencial do programa. As características e o contexto do treinamento e a exigência de maior liberdade de exploração dos resultados por parte do pesquisador, colocaram a pesquisa no campo qualitativo.

Segundo o entendimento de Richardson (1999) um fenômeno social, tem características próprias e ocupa um lugar no espaço e no tempo, possui uma essência e é objeto do conhecimento cientifico.

Richardson (1999) recomenda que se o pesquisador pensa em termos de fenômeno, sabe que, por definição deve estudar os elementos que compõe o fenômeno e suas características no tempo e no espaço.

A partir desta recomendação pode-se classificar o programa MBA como um fenômeno social, entendendo-se que os fatos explorados são passados, considerando que a última turma 
do programa MBA Gestão Pública foi concluída no início de 2005. O programa ocorreu por iniciativa e necessidade do Banco do Brasil, e foi destinado aos funcionários de nível gerencial e atividade negocial pertencentes à Diretoria de Governo deste banco.

Os resultados observados estão relacionados com o programa de formação gerencial de apoio a estratégia de desenvolvimento da Diretoria de Governo do Banco do Brasil, e estão vinculados com a construção da vantagem competitiva sustentável da organização (Barney, 1991), por esse motivo desde a fase de projeto foram identificados como de difícil mensuração por medidas exatas.

Segundo Richardson (1999), o método científico deve cumprir os critérios de confiabilidade e validade.

Em pesquisa qualitativa, para gozar do critério de confiabilidade externa, a pesquisa deve permitir que outros pesquisadores seguindo o mesmo procedimento, sejam capazes de chegar a resultados similares aos do pesquisador, sendo possível concluir pelas mesmas relações entre conceitos e dados obtidos. Neste sentido o pesquisador deve ser capaz de produzir instrumentos de pesquisa isentos de vieses, e ainda, ser capaz de registrar as informações produzidas pelo fenômeno, garantindo a fidedignidade do registro com a realidade.

O critério de validade exige que o pesquisador proponha um instrumento capaz de "produzir medições adequadas e precisas para chegar a conclusões corretas" (RICHARDSON, 1999, p. 87), deve refletir portanto, a adequação que as conclusões devem guardar com relação aos dados obtidos. Para o mesmo autor, em especial no método qualitativo, as observações não estruturadas, proporcionam ao observador, o conhecimento de detalhes sobre o fenômeno que questionários não seriam capazes de revelar.

Neste sentido, a pesquisa deve explorar a exaustão as características do fenômeno, vislumbrando conhecer seus detalhes. Selltiz et alii (1974) recomenda a utilização do estudo 
exploratório, que permite ao pesquisador maior familiaridade e compreensão profunda de um fenômeno. Essa técnica pode ainda "aumentar o conhecimento do pesquisador acerca do fenômeno que deseja investigar em estudo posterior, mais estruturado, ou da situação em que pretende realizar tal estudo" (SELLTIZ, 1974, p. 60), possibilitando a "consideração dos mais variados aspectos relativos ao caso estudado" (GIL, 2002, p. 41).

Yin (2001, p. 19) observa "quando o pesquisador tem pouco controle sobre os eventos e quando o foco se encontra em fenômenos contemporâneos inseridos em algum contexto da vida real" a técnica de maior adequação é o estudo de caso.

Corroborando ainda a escolha do método, Yin (2001, p. 32), apresenta o estudo de caso como "uma investigação empírica sobre um fenômeno contemporâneo dentro de seu contexto da vida real, especialmente quando os limites entre o fenômeno e o contexto não estão claramente definidos".

A vinculação entre o fenômeno e o contexto é parte central da dificuldade metodológica deste estudo, uma vez que o fenômeno, os resultados do treinamento, encontram-se no contexto macro de resultados da instituição.

Estes resultados foram gerados simultaneamente com a ocorrência de variáveis ambientais tais como o repertório pessoal do grupo estudado (formação pessoal, cursos extracurriculares, experiências profissionais diversas), ações de desenvolvimento institucional da instituição que tenham ocorrido simultaneamente ao treinamento, ou outras ações gerenciais de natureza estratégica que podem influenciar os resultados da observação de pesquisa.

Buscou-se a utilização de diversas fontes de evidências para demonstrar a convergência dos dados obtidos, reforçando a validade interna do trabalho. Será visto no tópico coleta de dados, a seleção dos métodos e instrumentos com que se pretendeu equacionar esta dificuldade. 
Limita-se a capacidade de generalização do estudo por sua própria natureza de caráter qualitativo, sem que seu valor científico e contribuição para a sociedade se percam:

Em muitos aspectos, o modo de conceituar generalização nos estudos quantitativos é estranho à etnografia e à pesquisa social crítica. Para o etnógrafo, é muito mais importante conhecer em profundidade atitudes, crenças e comportamento das pessoas; supõe-se que determinada visão do mundo está relacionada a um contexto específico e que a generalização para outras situações está extremamente limitada. Assim, a pesquisa social crítica baseia-se no suposto de que a sociedade está em movimento constante, que o mundo social e nossa compreensão dele estão mudando constantemente, limitando o valor da generalização (RICHARDSON, 1999, p. 101).

A natureza do fenômeno e sua vinculação com a educação continuada lhe concedem características suficientemente singulares para que seus resultados sejam aplicáveis somente à realidade da Diretoria de Governo do Banco do Brasil, neste caso não se poderá generalizar os resultados obtidos.

\subsection{ESTRUTURAĊ̃̃O DA FASE TEÓRICA}

Para Cervo (2001) a pesquisa bibliográfica se realiza com o intuito de recolher informações e conhecimentos prévios acerca de uma hipótese que se quer experimentar, busca assim o estado da arte sobre o determinado tema.

Já para Seltiz et alii (1974) as teorias apresentam um guia importante para a orientação da pesquisa de campo, pois indicam áreas que tendem a ser produtivas, isto é, em que há probabilidade de encontrar relações significativas. O que para Richardson (1999) implica a revisão do conhecimento acumulado até o momento da pesquisa. Portanto, a estruturação da fase teórica tem o papel de demonstrar os avanços obtidos pela ciência no campo de estudo retratado pelo pesquisador.

O referencial teórico utilizado neste estudo procura oferecer substância à discussão do tema na medida em que sustenta o objetivo do trabalho: conhecer os resultados do programa MBA Gestão Pública, para a Diretoria de Governo do Banco do Brasil. 
O referencial teórico demonstrou que a compreensão dos resultados de um programa de treinamento passa pela necessidade de se conhecer os diversos aspectos que envolvem suas condições de realização, daí a necessidade da compreensão da inter-relação e integração da aprendizagem individual e organizacional para gerar conhecimento para a empresa. O referencial evolui na compreensão de como a Universidade Corporativa realiza programas de treinamento empresarial com o objetivo de apoiar o desenvolvimento estratégico da organização. Em seguida delineiam-se as fases do treinamento, desde o levantamento das necessidades, que analisam a empresa, a tarefa, as pessoas e as competências envolvidas pelo treinamento até seu planejamento e implementação. Finalmente parte-se para a avaliação dos resultados examinando a constituição do capital intelectual da organização e como ele apóia o desenvolvimento de sua vantagem competitiva sustentável.

Portanto, os dois aspectos principais do referencial teórico apresentado são: a avaliação do treinamento e os elementos da vantagem competitiva sustentável.

A respeito da avaliação dos programas de treinamento, apresentaram-se quatro modelos, a exploração destes modelos revelou que o Modelo MAIS (BORGES-ANDRADE, 1982) oferece maior abrangência de observação sobre o treinamento e se adequa ao objetivo central deste estudo, portanto foi utilizado como instrumento de análise do treinamento e de exploração de seus resultados.

A avaliação do treinamento por meio do Modelo MAIS (BORGES-ANDRADE, 1982), deu-se com o objetivo de compreender quais as variáveis científicas adotadas pelo treinamento.

Conquanto ao tema Vantagem Competitiva Sustentável (VCS) foram considerados os atributos definidos por Barney (1991), classificando os resultados do MBA Gestão Pública como raros, valiosos, difíceis de imitar e difíceis de substituir. 
As fontes de consulta utilizadas concentram-se nos autores mais consolidados, e na atualização destes autores por meio de pesquisas empíricas recentes obtidas por meio de sua publicação em revistas e anais de eventos reconhecidos por sua excelência. Foram utilizadas, por este critério, as seguintes fontes: RAE, RAUSP, RAC e ENANPAD. A necessidade de ampliação da exploração de alguns pontos do referencial teórico conduziu a pesquisa a utilização do site de busca de publicações internacionais Proquest.

\subsection{PERGUNTAS DA PESQUISA}

O referencial teórico apresentado revelou que programas de treinamento podem ser vistos como fontes de geração e sustentabilidade de vantagens competitivas para as empresas que os realizam. Observou-se, ainda, que as práticas de recursos humanos tem sido objeto de mensuração pelas empresas, pois é necessário compreender o quanto estas práticas são capazes de contribuir com os objetivos estratégicos da empresa. Neste esteio, os programas de treinamento devem ser avaliados em diversas dimensões e sobretudo em sua capacidade de demonstrar resultados tangíveis obtidos no contexto de sua realização. O objetivo deste trabalho é responder a seguinte pergunta:

Como se apresentam os resultados do programa MBA Gestão Pública da Diretoria de Governo do Banco do Brasil?

Como meio de responder a esta pergunta principal, busca-se responder as seguintes perguntas de apoio:

1. Os objetivos propostos pelo programa de treinamento MBA Gestão Pública correspondem aos resultados que foram atingidos pela Diretoria de Governo do Banco do Brasil? 
2. Como se descrevem as etapas do programa de treinamento MBA Gestão Pública, tendo como referência o Modelo MAIS de avaliação de treinamento? (BORGESANDRADE, 1982).

3. Quais indicadores de resultado podem ser positivamente associados ao programa de treinamento, tendo como referência as seguintes fontes de observação?
a. volume de negócios;
b. satisfação de clientes da área governo;
c. percepção da cadeia de valor da área governo;
d. ampliação de negócios;
e. desenvolvimento de estratégias de marketing;
f. modificação de processos internos;
g. desenvolvimento estratégico da área;
h. perspectivas, novos produtos e formas de realização de negócios;
i. desenvolvimento humano.

4. Como se classificam os resultados obtidos no programa MBA Gestão Pública com base na Teoria da Vantagem Competitiva Sustentável? (BARNEY, 1991)

A pergunta e objetivo geral da presente dissertação abrangem o treinamento com um todo. As respostas para esta pergunta serão obtidas por meio das respostas às perguntas e objetivos específicos.

A primeira pergunta e objetivo específico foi construída conforme prelecionam os autores destacados no referencial teórico (MAGER, 1977; HAMBLIN, 1978; KROEHNERT, 2001), ou seja, a avaliação de resultados de um treinamento deve ser realizada por meio da comparação destes resultados com os objetivos de treinamento que o justificaram. 
A segunda pergunta específica foi elaborada para que se pudesse identificar a técnica empregada na elaboração, planejamento, execução de avaliação do treinamento, baseada para isso no Modelo MAIS de Borges-Andrade (1982).

A terceira pergunta especifica foi baseada no referencial teórico utilizado, adaptando, dentre os indicadores sugeridos, os que pareceram mais adequados a mensuração do programa MBA Gestão Pública. Tal como se sustentou na primeira pergunta específica, os indicadores observados na avaliação dos resultados do treinamento deveriam ter sido identificados e medidos na fase de elaboração do treinamento, para que fossem repetidos na fase de avaliação.

Conforme se verá na apresentação dos resultados da pesquisa de campo, especificamente nos resultados observados para o modelo MAIS (BORGES-ANDRADE, 1982), não houve a identificação destes indicadores.

Assim definiu-se os indicadores apresentados com base na literatura observada:

$\checkmark \quad$ volume de negócios (KIRKPATRICK; 1993);

$\checkmark$ satisfação de clientes (DECENZO; ROBINS, 1999; NOBREGA JÚNIOR, 2003);

$\checkmark$ percepção da cadeia de valor (adaptado de PRAHALAD; HAMEL, 1990);

$\checkmark$ ampliação de negócios (KIRKPATRICK; 1993);

$\checkmark$ desenvolvimento de estratégias de marketing (FREITAS; BORGES-ANDRADE, 2004);

$\checkmark$ desenvolvimento estratégico da área (FREITAS; BORGES-ANDRADE, 2004; adaptado de BOHLANDER; SNEEL; SHERMAN, 2003);

$\checkmark$ modificação de processos internos (adaptado de BOHLANDER; SNEEL; SHERMAN, 2003);

$\checkmark$ perspectivas, novos produtos e formas de realização de negócios (adaptado de KIRKPATRICK, 1993); 


\section{$\checkmark$ desenvolvimento humano (adaptado de RUAS, 2001).}

Quando se diz que os indicadores foram adaptados dos autores citados, trata-se de cuidado metodológico do pesquisador no tratamento do referencial teórico, já que as medidas apontadas pelos autores, são muitas vezes genéricas.

Estes indicadores foram escolhidos por serem representativos de transformação organizacional no contexto do Banco do Brasil. Conforme Kirkpatrick (1993), os indicadores utilizados na mensuração de resultados podem incluir critérios de produtividade, redução de custos e aumento de lucratividade, alegando que na fase de avaliação de resultados é fundamental comparar os indicadores produzidos pelo levantamento de necessidades, com aqueles que indicam o resultado após o treinamento.

Conforme se observou pela análise do programa MBA Gestão Pública tendo como referência o modelo MAIS (BORGES -ANDRADE, 1982), em razão da embrionária natureza da área, não havia indicadores antecedentes que sustentassem a necessidade de treinamento, sendo sua principal razão de criação a necessidade de oferecer um referencial acadêmico e prático aos funcionários da área recém criada.

Desafiando esta circunstância Hamblin (1978), considerou que a única medida de resultado de um programa é a financeira, destacando que diversos resultados intermediários podem ser atingidos levando a um resultado financeiro que seja positivo ao final. Este mesmo autor considera que o nível de inovação pode ser um indicador de resultado do treinamento.

Kirkpatrick (1993) alerta que a complexidade de mensuração do resultado acompanha a complexidade do curso.

Assim os indicadores acima foram elaborados, tendo como critério sua capacidade de serem considerados bons indicadores de desempenho e apoiadores do resultado financeiro e simultaneamente por ser possível sua associação com o treinamento realizado, apesar da natureza complexa do curso. 


\subsection{COLETA DE DADOS: MÉTODOS E INSTRUMENTOS}

A ilustração seguinte demonstra a as etapas seguidas pela pesquisa de campo:

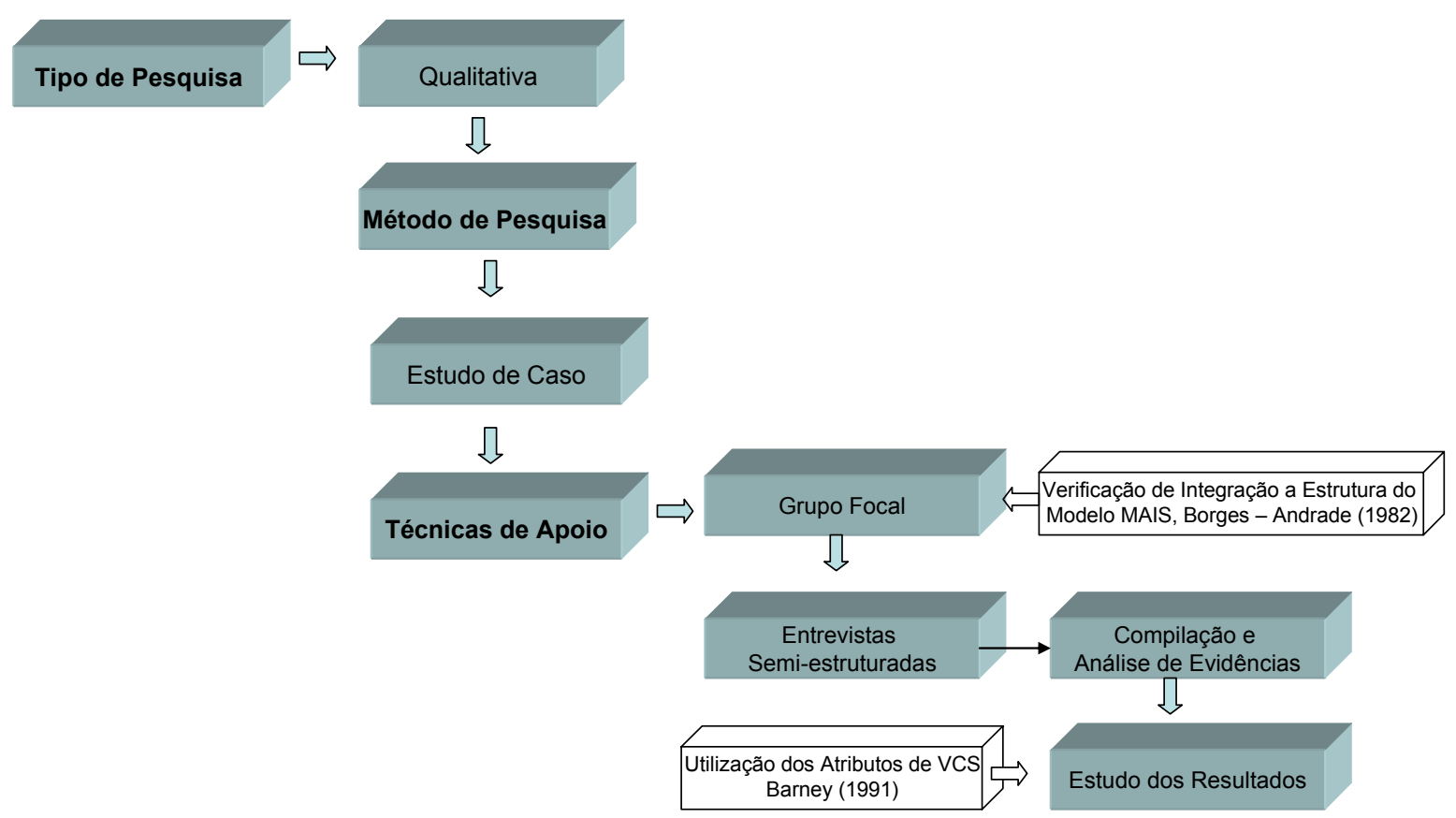

Figura16: Etapas da Pesquisa de Campo Fonte: Autor

\subsubsection{Estudo de Caso}

O Método do Estudo de Caso "... não é uma técnica especifica. É um meio de organizar dados sociais preservando o caráter unitário do objeto social estudado" (GOODE \& HATT, 1969, p. 422).

No mesmo sentido McClintock et alii (1983, p. 150), apud (BRESSAN, 2000, p. 5), afirma que o objetivo do estudo de caso “... é (1) capturar o esquema de referência e a 
definição da situação de um dado participante... (2) permitir um exame detalhado do processo organizacional e (3) esclarecer aqueles fatores particulares ao caso que podem levar a um maior entendimento da causalidade".

Para Yin (2001), a escolha do método de pesquisa, depende de três fatores: o tipo de questão da pesquisa, a amplitude do controle do pesquisador sobre os eventos comportamentais reais e o grau de enfoque em acontecimentos históricos ou contemporâneos. Para este autor quando a forma da questão de pesquisa é do tipo como e por que, quando a pesquisa focaliza fatos contemporâneos, e quando o pesquisador não detém controle sobre os eventos que se pretende estudar, a técnica do estudo de caso é aplicável.

Tendo-se confirmado aderência do método ao objeto da pesquisa procura-se, em seguida, demonstrar suas características e formas de obtenção dos dados.

A investigação de estudo de caso:

Enfrenta uma situação tecnicamente única em que haverá muito mais variáveis de interesse do que pontos de dados, e, como resultado,

- Baseia-se em várias fontes de evidências, com os dados precisando convergir em formato de triângulo, e como outro resultado,

B Beneficia-se do desenvolvimento prévio de proposições teóricas para conduzir a coleta e a análise dos dados (YIN, 2001, p. 32, 33).

Em consideração às observações anteriores, de acordo com os objetivos da pesquisa e suas perguntas decorrentes, há dados a ser observados e que se constituem em fonte de interesse para se depreender os resultados do programa de treinamento em estudo.

A estratégia de pesquisa aqui demonstrada direciona o projeto para que utilize diversas fontes de observação e de análise de dados, conforme recomenda Yin (2001).

Ainda com o objetivo de evidenciar a adequação da técnica ao objeto estudado, considera-se que nas pesquisas de avaliação, os estudos de caso têm lugar de destaque, enumerando-se diversas de suas aplicações Yin (2001, p. 34):

explicar os vínculos causais em intervenções da vida real que são complexas demais para as estratégias experimentais ou aquelas utilizadas em levantamentos; 
descrever uma intervenção e o contexto em que ela ocorre na vida real; ilustrar tópicos de uma avaliação de modo descritivo; e

explorar situações nas quais a intervenção que está sendo avaliada não apresenta um conjunto simples e claro de resultados.

Procurando atender a recomendação de Yin (2001), de que nas pesquisas de avaliação os estudas de caso são adequados, observa-se que este estudo pode ser considerado de avaliação na medida em que aborda os resultados de um programa de treinamento, ou seja, avalia uma ação de desenvolvimento organizacional promovida, tendo como meta explicar o vínculo causal entre resultados da Diretoria de Governo e realização do programa MBA Gestão Pública.

Yin (2001), recomenda que o projeto de pesquisa deve ser estruturado conforme os passos seqüenciais:

1. Delimitação da unidade de análise;

2. Definição das fontes de dados ou evidências;

3. Protocolo para o estudo de caso;

4. Coleta e organização dos dados;

5. Análise dos dados, interpretação e conclusões; e

6. Redação do relatório.

\subsubsection{Unidade de Análise}

Para Yin (2001), a unidade de análise pode ser representada por um indivíduo, um evento, uma entidade, um programa ou processo organizacional, um processo de tomada de decisão etc. Importa ao pesquisador a capacidade de estabelecer proposições que indiquem claramente de que se constitui o caso. $\mathrm{O}$ autor apresenta ainda a ressalva de que em se 
tratando do estudo de caso de um programa, deve-se redobrar os cuidados de delimitação dos pontos iniciais e finais deste programa, (YIN, 2001).

A execução da pesquisa de campo foi feita junto a Diretoria de Governo do Banco do Brasil. Esta diretoria está representada em todos os estados brasileiros. Seu arranjo organizacional concentra a diretoria na cidade de Brasília, de onde são gerenciados todos os seus escritórios regionais. Conforme o próprio Banco do Brasil:

O foco negocial é voltado para os governos Federal, estaduais e municipais e a estratégia adotada é a de parceria com os poderes Executivo, Legislativo e Judiciário e seus funcionários. Em 2003, o BB garantiu soluções administrativas e financeiras adequadas às especificidades de cada um dos nichos do setor público.

O Pilar Governo, por seu lado, atende os governos federal, estaduais e municipais, aí considerados os poderes Executivo, Legislativo e Judiciário e seus funcionários.

3.241 agências, 72 estão ligadas ao pilar Atacado, 38 ao pilar Governo e as demais ao pilar Varejo

O pilar Governo mantém seu foco negocial voltado para o relacionamento com os Governos Federal, estaduais e municipais, atuando nas esferas dos poderes executivo, legislativo e judiciário. A estratégia de atuação do pilar governo tem garantido soluções adequadas às especificidades de cada um dos nichos de seu segmento, atuando de modo a gerar valor pela solução em novos produtos e desburocratização de processos.

(BANCO DO BRASIL, 2004).

A unidade de análise é a Diretoria de Governo do Banco do Brasil já que o objeto de estudo é a exploração dos resultados que o curso provocou e não o curso em si.

Cabe observar que a separação dos resultados particularmente obtidos em razão do programa MBA - Gestão Pública dos demais resultados gerados no contexto da Diretoria de Governo foi objeto de atenção da pesquisa.

A separação destes dados deveria ter sido realizada com a ajuda dos próprios participantes, inseridos na Diretoria de Governo do Banco do Brasil.

Como a presente metodologia antecipou, esta separação entre os resultados advindos do programa de treinamento e os resultados gerais da diretoria estudada não foi possível. Conforme previsto, a vinculação entre o fenômeno (o treinamento) e o objeto de estudo (os resultados) é enorme, além disso, estes resultados, especialmente os que se apresentam por 
meio da seleção de indicadores utilizada, encontram-se influenciados por diversas outras ações de desenvolvimento organizacional não relacionadas ao curso, desse modo, muitos dos resultados observados, podem ser associados ao programa MBA Gestão Pública, sem que se possa no entanto, definir o programa de treinamento com seu único causador.

Os participantes do Programa MBA Gestão Pública, entrevistados, atuam em diferentes níveis organizacionais no chamado Pilar Governo do Banco do Brasil, esta diversidade de atuação se constituiu em base de apoio da pesquisa.

\subsubsection{Definicão das fontes de dados ou evidências}

Para Yin (2001) há que se considerar as seguintes fontes de evidências:

$\checkmark$ documentação;

$\checkmark$ registros em arquivo;

$\checkmark$ entrevistas;

$\checkmark$ observação direta;

$\checkmark$ observação participante; e

$\checkmark$ artefatos físicos.

O autor conclui que não se pode destacar vantagens de uma fonte em relação as outras, verificando-se uma relação de complementaridade quando se constatar a oportunidade de utilização de mais de uma técnica, na mesma pesquisa.

Optou-se pela utilização das seguintes fontes de evidência: documentação, registros em arquivo e entrevistas.

Além das fontes citadas por Yin (2001), verificou-se a necessidade da realização de grupos focais detalhados a seguir.

A seguir apresentam-se as técnicas de implementação da pesquisa. 


\subsubsection{Grupo Focal}

O grupo focal, como técnica de obtenção de dados qualitativos, envolve uma discussão objetiva conduzida ou moderada, que introduz um tópico a um grupo de respondentes e direciona sua discussão sobre o tema, de uma maneira não-estruturada e natural (PARASURAMAN, 1986).

O objeto de análise desta técnica é a interação dentro do grupo, desta forma "os participantes influenciam uns aos outros pelas respostas às idéias e colocações durante a discussão, estimulados por comentários ou questões fornecidos pelo moderador" (GIOVINAZZO, 2001, p. 5). As informações obtidas devem ser transcritas para servirem como objeto de análise pelo pesquisador.

Apresentam-se como características gerais do grupo focal (KREUGER, $1994^{10}$, apud GIOVINAZZO, 2001, p. 5):

$\checkmark$ envolvimento de pessoas;

$\checkmark$ reuniões em série;

$\checkmark$ homogeneidade dos participantes quanto aos aspectos de interesse da pesquisa;

$\checkmark$ geração de dados;

$\checkmark$ natureza qualitativa; e

$\checkmark$ discussão focada em um tópico que é determinado pelo propósito da pesquisa O planejamento do grupo focal deve obedecer os seguintes passos:

a) Definição de quantidade e tamanho dos grupos

10 KREUGER, R. A. Focus Group: a practical guide for applied research. Thousand Oaks: SAGE Publications, 1994 
A quantidade de grupos deve variar em função da capacidade que os grupos tenham de revelar novas informações. Quando o pesquisador identificar homogeneização dos resultados entre os grupos, significa que a coleta de dados pode ser finalizada.

O tamanho dos grupos deve estar entre 8 e 12 participantes, para que seus resultados sejam de boa qualidade. Um número superior a este, pode constranger participantes e reduzir a qualidade dos resultados coletados (MATTAR, 1993).

No presente estudo os grupos estudados tinham todos entre 6 e 8 participantes.

\section{b) Participantes}

Dentre os participantes selecionados, deve haver razoável homogeneidade interna, além de demonstrarem representatividade para o objeto de estudo.

A natureza da realização de negócios do Banco do Brasil junto a entidades do poder público recebe razoável influencia deste último em seu modo de operação, exigindo dos executivos da área governo boa capacidade de mobilização para atender a um segmento de mercado extremamente exigente.

\section{c) Conteúdo da entrevista}

A entrevista deve ser planejada com o objetivo de extrair as percepções dos participantes sobre o tema que motiva a pesquisa. Este planejamento inclui necessariamente a formatação de um roteiro de questões hierarquizadas em ordem de importância e o dimensionamento do tempo a ser despendido pelos participantes. O roteiro da entrevista do grupo focal se encontra no anexo no APÊNDICE 1 - Guia para realização de grupo focal, constante à página 259 .

d) Seleção do local, coleta dos dados e tempo de realização dos gupos focais 
O local selecionado deve ser agradável aos participantes, permitindo que se sintam a vontade para o diálogo franco, desejado pelo pesquisador.

Para este estudo foram utilizadas as dependências da Diretoria de Governo do Banco do Brasil na cidade de Brasília, os grupos focais foram todos realizados no dia 25 de Novembro de 2005, conforme agendamento seguinte:

\begin{tabular}{|c|c|c|c|}
\hline Grupo 1: & & Nome do Aluno & Sigla de Representação \\
\hline \multirow[t]{7}{*}{$8 \mathrm{~h}$ às $10 \mathrm{~h}$} & Aluno 1 & (turma 5) & Entrevistado 1 = E1 \\
\hline & Aluno 2 & (turma 5) & Entrevistado 2 = E2 \\
\hline & Aluno 3 & (turma 1) & Entrevistado $3=\mathrm{E} 3$ \\
\hline & Aluno 4 & (turma 2) & Entrevistado $4=\mathrm{E} 4$ \\
\hline & Aluno 5 & (turma 4) & Entrevistado $5=\mathrm{E} 5$ \\
\hline & Aluno 6 & (turma 2) & Entrevistado $6=\mathrm{E} 6$ \\
\hline & Aluno 7 & (turma 2) & Entrevistado $7=\mathrm{E} 7$ \\
\hline Grupo 2: & & Nome do Aluno & Sigla de Representação \\
\hline \multirow[t]{7}{*}{$\begin{array}{l}10 \mathrm{~h} 30 \text { às } \\
13 \mathrm{~h}\end{array}$} & Aluno 1 & (turma 3) & Entrevistado $8=\mathrm{E} 8$ \\
\hline & Aluno 2 & (turma 3) & Entrevistado $9=\mathrm{E} 9$ \\
\hline & Aluno 3 & (turma 1) & Entrevistado $10=\mathrm{E} 10$ \\
\hline & Aluno 4 & (turma 5) & Entrevistado 11 = E11 \\
\hline & Aluno 5 & (turma 5) & Entrevistado $12=\mathrm{E} 12$ \\
\hline & Aluno 6 & (turma 1) & Entrevistado $13=\mathrm{E} 13$ \\
\hline & Aluno 7 & (turma 1) & (ausente) \\
\hline Grupo 3: & & Nome do Aluno & Sigla de Representação \\
\hline \multirow[t]{6}{*}{$14 \mathrm{~h}$ às $16 \mathrm{~h}$} & Aluno 1 & (turma 2) & Entrevistado 14 = E14 \\
\hline & Aluno 2 & (turma 1) & (ausente) \\
\hline & Aluno 3 & (turma 4) & Entrevistado $15=\mathrm{E} 15$ \\
\hline & Aluno 4 & (turma 2) & Entrevistado $16=\mathrm{E} 16$ \\
\hline & Aluno 5 & (turma 4) & (ausente) \\
\hline & Aluno 6 & (turma 3) & Entrevistado $17=\mathrm{E} 17$ \\
\hline Grupo 4: & & Nome do Aluno & Sigla de Representação \\
\hline \multirow[t]{6}{*}{$16 \mathrm{~h}$ às $18 \mathrm{~h}$} & Aluno 1 & (turma 1) & Entrevistado 18 = E18 \\
\hline & Aluno 2 & (turma 3) & Entrevistado $19=\mathrm{E} 19$ \\
\hline & Aluno 3 & (turma 1) & Entrevistado 20 = E20 \\
\hline & Aluno 4 & (turma 2) & Entrevistado 21 = E21 \\
\hline & Aluno 5 & (turma 5) & Entrevistado 22 = E22 \\
\hline & Aluno 6 & (turma 5) & Entrevistado $23=$ E23 \\
\hline
\end{tabular}

Quadro 4 - Grade de Agendamento de Grupos Focais

Fonte: Autor

Cada uma das reuniões dos grupos focais tiveram a duração aproximada de duas horas. 
O grupo de entrevistados representou de forma razoavelmente homogênea as cinco turmas de realização do curso, com exceção da turma 4 representada por apenas $9 \%$ dos participantes, conforme tabela em seguida:

Tabela 1 - Distribuição de participantes nos grupos focais divididos por turma

\begin{tabular}{cc}
\hline Turma & Representação \\
\hline Turma 1 & $22 \%$ \\
\hline Turma 2 & $26 \%$ \\
\hline Turma 3 & $17 \%$ \\
\hline Turma 4 & $9 \%$ \\
\hline Turma 5 & $26 \%$ \\
\hline
\end{tabular}

Fonte: Autor

\subsubsection{Grupo Focal MBA Gestão Pública Banco do Brasil: Direcionamento e} $\underline{\text { Etapas }}$

A realização do grupo focal destinou-se a obter dados primários junto aos alunos participantes do programa MBA Gestão Pública. Por meio desta técnica obtiveram-se norteadores para os seguintes objetos de estudo:

1. analisar os resultados associados ao programa de treinamento MBA Gestão Pública;

2. relacionar os objetivos propostos pelo programa de treinamento MBA Gestão Pública com os resultados identificados na Diretoria de Governo.

3. descrever as fases do programa de treinamento MBA Gestão Pública tendo como referência o Modelo MAIS de avaliação de treinamento (BORGES-ANDRADE, 1982);

4. analisar a percepção de mudança dos seguintes indicadores em razão da realização do programa MBA Gestão Pública:

a. volume de negócios;

b. satisfação de clientes da área governo;

c. percepção da cadeia de valor da área governo; 
d. ampliação de negócios;

e. desenvolvimento de estratégias de marketing;

f. modificação de processos internos;

g. desenvolvimento estratégico da área;

h. perspectivas, novos produtos e formas de realização de negócios; e

i. desenvolvimento humano.

5. classificar os resultados obtidos no programa MBA Gestão Pública com base na Teoria da Vantagem Competitiva Sustentável (BARNEY, 1991).

A técnica do grupo focal foi levada a efeito considerando as seguintes etapas de planejamento:

1. Definição do roteiro de entrevista a ser utilizado junto ao grupo focal.

2. Estabelecimento de um calendário de reuniões para realização dos quatro grupos focais.

3. Definição dos participantes dos grupos focais, selecionados entre as cinco turmas do MBA Gestão Pública.

4. Realização dos grupos focais.

a. Registro dos dados obtidos em cada grupo.

5. Análise dos dados.

Considerando-se que se está trabalhando um conceito novo para muitos dos participantes dos grupos focais, o de Vantagem Competitiva Sustentável, ao iniciar esta parte da entrevista nos grupos, foi explicado brevemente seu significado, exemplificando-se sua aplicação e tirando dúvidas dos participantes para que sua classificação de atributos pudesse ser considerada o mais precisa possível. 


\subsubsection{Entrevistas semi-estruturadas}

Conforme Gil (2002, p. 41), entrevistas são empregadas com o objetivo de "proporcionar maior familiaridade do pesquisador com o problema, com vistas a torná-lo mais explícito". Esta técnica tem a finalidade de revelar ao pesquisador, informações que dificilmente seriam obtidas por análises de documentos ou outra forma de coleta de dados.

Para o caso das entrevistas semi - estruturadas, segundo Selltiz (1974), a maior relevância e aplicabilidade deste tipo de entrevistas está em sua capacidade de obtenção de informações acerca do que as pessoas sabem, crêem, esperam, sentem ou desejam, pretendem fazer, fazem ou fizeram, bem como acerca de suas explicações ou razões a respeito destes fatos.

A técnica deve ser capaz de revelar o conhecimento único do entrevistado sobre um tema de relevância para a pesquisa, oferecendo seu testemunho em torno de fatos que estão intimamente relacionados com sua realidade.

Triviños (1992), ressalta os atributos da entrevista semi-estruturada, em especial por sua capacidade de a partir de questionamentos básicos, preferencialmente apoiados no referencial teórico preferido pelo pesquisador, oferecer amplo campo de interrogativas a este, frutos de novas hipóteses que se apresentam a medida que o entrevistador descortina percepções únicas do respondente.

A presente pesquisa utilizou a técnica de entrevista semi-estruturada junto aos gestores da Diretoria de Governo do Banco do Brasil e da Universidade Corporativa Banco do Brasil, por meio dos apêndices: APÊNDICE 2 - Guia para realização de entrevista - Diretoria de Governo, página 261 e APÊNDICE 3 - Guia para realização de entrevista Universidade Corporativa, página 262. 
O gestor da Diretoria de Governo entrevistado foi um dos responsáveis pelo direcionamento do conteúdo do treinamento, tendo além de suas atividades comerciais, a necessidade de participação na elaboração do treinamento, atuando junto à instituição que realizou o programa.

A escolha desta pessoa para participação na entrevista deveu-se ao fato de estar diretamente relacionado à definição, implementação e acompanhamento das políticas estratégicas da Diretoria de Governo do Banco do Brasil. Esta posição o colocou em privilegiada condição de fornecimento de informações, pois é um dos responsáveis pelos resultados da unidade.

A realização da entrevista semi - estruturada na Diretoria de Governo, teve como objetivo revelar indicadores referentes ao treinamento. Os entrevistados em grupo focal, discorreram sobre as contribuições do programa em sua atividade profissional, e deveriam ter indicado norteadores dos resultados observados. A entrevista deveria explorar estes norteadores e revelar indicadores objetivos. Conforme se verá na análise dos dados não se obteve estes indicadores.

Os gestores da unidade Universidade Corporativa, realizam o acompanhamento da Diretoria de Governo na proposição do treinamento e são responsáveis por sua dimensão instrucional e pedagógica. Os gestores desta unidade monitoram o levantamento de necessidades de treinamento e observam a qualidade e adequação de sua realização.

A realização das entrevistas semi - estruturadas na UniBB tiveram como objetivo obter dados sobre o levantamento de necessidades de treinamento, o planejamento, a implementação e os resultados do treinamento.

As entrevistas ocorreram após a realização dos grupos focais, sendo uma entrevista na Diretoria de Governo e duas na Universidade Corporativa do Banco do Brasil.

ESE 1 - João Martins Felcar 
ESE 2 - Maria Inês Torrecillas

ESE 3 - Sylvio Maestrelli

Cabe observar que no decorrer da realização de sua entrevista, ESE2 sugeriu a realização de ESE3 com o objetivo de se obter dados complementares a respeito da avaliação de impacto do treinamento.

As entrevistas foram realizadas segundo o seguinte agendamento:

\begin{tabular}{|l|l|l|l|l|l|}
\hline Data & Horário & Nome & Cargo & Área & $\begin{array}{l}\text { Sigla de } \\
\text { Representação }\end{array}$ \\
\hline 06/dez/05 & $11 \mathrm{~h}$ às 13h & $\begin{array}{l}\text { João Martins } \\
\text { Felcar }\end{array}$ & Gestor Governo & DIGOV & ESE 1 \\
\hline 30/jan/06 & $10 \mathrm{~h}$ às 11h & $\begin{array}{l}\text { Maria Inês } \\
\text { Torrecillas }\end{array}$ & $\begin{array}{l}\text { Gestora Contratação } \\
\text { de Treinamento } \\
\text { UniBB }\end{array}$ & UniBB & ESE 2 \\
\hline 30/jan/06 & 11 às 11h30 & Sylvio Maestrelli & $\begin{array}{l}\text { Gestor Impacto de } \\
\text { treinamento Unibb }\end{array}$ & UniBB & ESE 3 \\
\hline
\end{tabular}

Quadro 5 - Grade de Agendamento das Entrevistas Semi-Estruturadas

Fonte: Autor

\subsubsection{Documentacão}

Yin (2001) apresenta como fontes prováveis de apresentação de evidências na dimensão de documentação:

o cartas, memorandos e outros tipos de correspondência;

○ agendas, avisos, minutas de reuniões e relatórios escritos sobre eventos em geral;

o documentos administrativos (propostas, relatórios de aperfeiçoamentos e outros documentos internos);

o estudos ou avaliações formais do mesmo local sob estudo e

o recortes de jornal e outros artigos publicados na mídia.

Para utilidade deste trabalho foram utilizadas avaliações formais e pesquisas de satisfação de FUNDACE (2005), para a obtenção de dados relativos ao desempenho acadêmico dos participantes e de sua reação ao treinamento. 


\subsubsection{Registros em arquivo}

Neste tópico Yin (2001) destaca as seguintes fontes de observação:

o registros de serviços com informações sobre o número de atendimentos em um determinado período;

o registros organizacionais como tabelas e orçamentos.

o mapas e tabelas de características geográficas

o relação de nomes e outros itens relevantes;

○ dados provenientes de levantamentos e

○ registros pessoais (agendas, diários etc.)

Os registros em arquivos não foram utilizados na pesquisa, de um lado os participantes não indicaram fontes de dados que pudessem sustentar as entrevistas e de outro concluiu-se que quaisquer dados obtidos seriam insuficientes para criar o nexo de causalidade necessário, preferindo-se dessa forma utilizar outras fonte de evidências.

Como técnica de apoio à obtenção de dados foi necessário elaborar dois novos instrumentos de coleta, os apêndices 4 e 5 .

O Apêndice 4 - Implementação Efetiva de Trabalhos de Conclusão de Curso, foi elaborado, por sugestão da Diretoria de Governo, com o objetivo de coletar, de todos os participantes do curso, quais as informações disponíveis a respeito da implantação de seus trabalhos de conclusão de curso.

As respostas obtidas foram relacionadas nos resultados da pesquisa de campo representadas como R1, R2, R3 e R4. 
O Apêndice 5 - Movimentação de Pessoal da Diretoria de Governo, foi elaborado após a realização dos grupos focais com o objetivo de compreender se houve movimentação de pessoal interno após a realização do treinamento.

A Diretoria de Governo do Banco do Brasil preencheu o formulário, por ter acesso às informações referentes a seus funcionários e os dados resultantes foram tabulados pelo pesquisador com o objetivo de se obter porcentagens simples de movimentação interna de pessoal.

\subsubsection{Protocolo do Estudo de Caso}

Para Yin (2001), o estudo de caso deve contar com a observação de um protocolo, que além de ser o instrumento de obtenção dos dados, deve conter as regras gerais de utilização desse instrumento. $\mathrm{O}$ autor considera o instrumento essencial para aumentar a confiabilidade do programa. O protocolo deve conter:

$\checkmark$ Uma visão geral do projeto do estudo de caso;

$\checkmark$ Procedimentos de campo;

$\checkmark$ Questões do estudo de caso; e

$\checkmark$ Guia para o relatório do estudo de caso.

O referencial teórico apresentado procura suportar a proposição do protocolo de pesquisa, direcionando as etapas a serem seguidas pelo pesquisador.

No contexto da pesquisa os elementos de constituição do protocolo do estudo de caso apresentam-se da seguinte maneira:

$\checkmark$ Uma visão geral do projeto do estudo de caso.

Consiste da descrição da metodologia, demonstrada por meio do item III. PROCEDIMENTOS METODOLÓGICOS, página 124. 
$\checkmark$ Procedimentos de campo.

Descrito no item 3.3.4.2 Definição das fontes de dados ou evidências constante à página 138.

$\checkmark$ Questões do estudo de caso.

Perguntas de pesquisa apresentadas item 3.3.3. PERGUNTAS DA PESQUISA constante à página 130 .

$\checkmark$ Guia para o relatório do estudo de caso.

Constitui-se na estrutura geral da dissertação.

Para Yin (2001, p. 19), o "método de estudo de caso pode ser complementado com estudos exploratórios ou descritivos”. Neste sentido, foram utilizadas as técnicas exploratórias do grupo focal e de entrevistas semi - estruturadas, antes da aplicação do protocolo de estudo de caso.

\subsubsection{Coleta e organizaç̃o dos dados}

A coleta de dados foi realizada por meio da realização de quatro grupos focais e de duas entrevistas semi-estruturadas realizadas com gestores da Diretoria de Governo e da Universidade Corporativa do Banco do Brasil.

Foram utilizadas as avaliações de reação e as provas aplicadas pela FUNDACE Fundação para a Pesquisa e o Desenvolvimento da Administração, Contabilidade e Economia, instituição realizadora do curso MBA Gestão Pública, para observar os níveis de reação e aprendizado constantes do Modelo MAIS (BORGES - ANDRADE, 1982). 


\subsubsection{Análise dos dados, interpretação e conclusões}

Após a realização dos grupos focais e das entrevistas semi - estruturadas, foram transcritos os resultados da entrevistas.

Seguindo-se a transcrição das entrevistas, os dados relativos a cada elemento de investigação, foram organizados na apresentação dos resultados da pesquisa de campo, constante na página 156 e seguintes, apresentados textualmente como relatados pelos participantes.

Depois de apresentados os resultados de pesquisa, foram analisados a partir da página 195, tendo como orientação o referencial teórico que sustenta o presente estudo.

\subsubsection{Classificação dos Dados}

O referencial teórico demonstrou que os programas de treinamento gerencial contemplam diferentes níveis de dificuldade de análise de seus resultados. Indicadores de crescimento e manutenção de resultados numa unidade de negócios do porte da Diretoria de Governo do Banco do Brasil encontram visível dificuldade de mensuração.

Tendo em vista a dificuldade de análise dos resultados do Programa MBA Gestão Pública os dados observados baseiam-se nos atributos de constituição dos recursos que compõem a vantagem competitiva sustentável (VCS) conforme Barney (1991), ilustrados na Figura seguinte: 


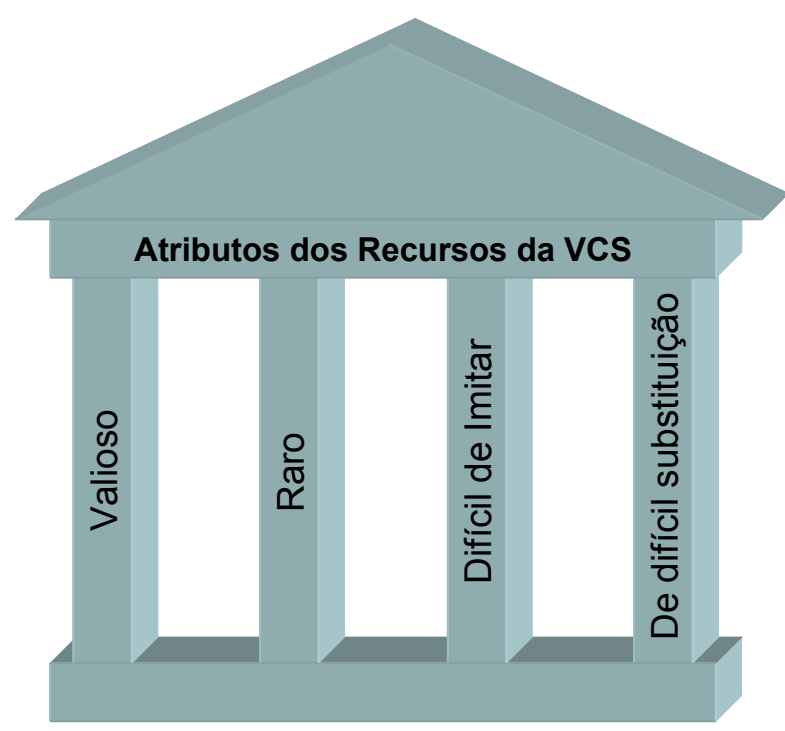

Figura 17: Atributos da Vantagem Competitiva Sustentável Fonte: adaptado de Barney (1991)

Os resultados do programa MBA Gestão Pública, no pilar governo, foram classificados como VCS do Banco do Brasil, verificadas no contexto do programa, sendo assim classificadas como raras, difíceis de imitar e difíceis de substituir.

A escolha desta classificação procura contemplar a dificuldade de demonstração objetiva de resultados de um programa de treinamento de natureza estratégica.

Com base nas técnicas de investigação, os indicadores apontados como representativos dos resultados do programa foram estudados como fontes de VCS e classificados segundo o critério dos autores aqui apresentados.

Pretende-se, com a utilização desta metodologia atender as recomendações de Yin (2001) para que o relatório de estudo de caso seja considerado completo. Portanto, a utilização de um protocolo para o estudo de caso pretende assegurar o encadeamento das evidências e o estabelecimento do banco de dados para dar sustentação às informações necessárias ao estudo de caso. 


\subsubsection{Redação do Relatório}

Yin (2001) recomenda que a redação do relatório deve considerar os seguintes fatores para sua composição:

1. O público a que se destina o estudo de caso;

2. A variedade de composição do estudo de caso;

3. As estruturas ilustrativas do estudo de caso;

4. Os procedimentos a serem adotados ao realizar o relatório do estudo de caso; e

5. Os cuidados para tornar um estudo de caso exemplar.

Como primeira anotação referente a redação do relatório, cabe observar que o presente estudo foi redigido tendo como base as Diretrizes para Apresentação de Dissertações e Teses da USP (2004).

Entende-se que o público a que se destina este estudo de caso é composto por pesquisadores da área e gestores de programas corporativos de treinamento.

Quanto à variedade de composição do estudo de caso, o texto procura seguir a linha científica de investigação, partindo de objetivos que se converteram em perguntas de pesquisa sustentadas por um referencial teórico e investigadas por meio da técnica de estudo de caso.

Quanto às estruturas ilustrativas do estudo de caso, o relatório procurou demonstrar gráfica e esquematicamente as conclusões obtidas por meio das técnicas de apoio como grupos focais e entrevistas semi-estruturadas, para facilitar a transmissão das idéias centrais do caso.

Os procedimentos adotados ao realizar o relatório do estudo de caso, estão refletidos no item 3.4.3 Protocolo do Estudo de Caso, página 148.

Os cuidados para tornar um estudo de caso exemplar, procuraram atender as recomendações de Yin (2001 p.181) para que o estudo seja significativo "não usuais e de 
interesse do público geral, que as questões subjacentes, tenham interesse (...) em termos políticos e práticos”.

Deve ainda se apresentar como um estudo de caso completo, ou seja, deve concentrarse na questão central de sua investigação considerando todos os aspectos de sua composição, procurou-se atender a esta recomendação exaurindo os dados apresentados e destacando um a um os resultados obtidos para cada um dos objetivos de pesquisa.

Para que seja considerado um estudo de caso exemplar deve considerar perspectivas alternativas, prevenindo que o pesquisador seja tendencioso, procurou-se atender a esta prevenção relatando-se exatamente as declarações apresentadas pelos participantes dos grupos focais, produzindo-se conclusões que pudessem ser respaldadas pelos dados obtidos.

Deve também, apresentar evidências suficientes das afirmações que propõe, e isto pode ser conseguido com a construção de um banco de dados suficientemente rico onde as informações obtidas pelos métodos de investigação presentes no estudo possam ser comparadas e contrapostas. Neste estudo o banco de dados foi construído por meio dos depoimentos colhidos nos grupos focais e entrevistas semi-estruturadas.

\subsubsection{Condicionantes da Pesquisa}

Em razão do caráter qualitativo da pesquisa, cumpre apresentar algumas situações condicionantes que fazem parte da complexidade do estudo.

A primeira observação neste sentido, refere-se à necessidade de se conhecer as variáveis ambientais em que os treinandos aplicaram os conhecimentos adquiridos.

A revisão de literatura apontou o conceito de suporte a transferência como de crucial importância para análise dos resultados obtidos por participantes de programas de treinamento (PANTOJA; BORGES-ANDRADE, 2004) 
O que se estuda nesse aspecto é a capacidade do ambiente de trabalho do treinando absorver os impactos do treinamento realizado. Esta condição visa permitir que aqueles que foram treinados tenham possibilidades de implementar as modificações aprendidas no treinamento.

Conforme demonstrado pela literatura, o ambiente de atuação do treinando se torna significante ao observar-se que, se o funcionário treinado encontrar um ambiente muito desfavorável a sua atuação, mesmo que o treinamento tenha provido os conhecimentos necessários, a avaliação de seus resultados de trabalho, está naturalmente prejudicada.

A discussão da condição ambiente de realização das atividades dos treinandos não foi objeto de investigação deste estudo, portanto não foi isolada como variável de impacto, e nem é conhecida a extensão de sua importância nas diversas situações de resultados que se pretende observar, assim os dados presentes foram observados sem a consideração do ambiente em que foram concebidos.

Entendem-se como variáveis ambientais, sazonalidades econômicas, políticas de investimento, políticas institucionais, destinação de recursos de propaganda, entre outros. Elementos como estes podem ter influenciado os resultados da Diretoria de Governo, e não estarem necessariamente relacionados com o Programa MBA Gestão Pública.

Neste sentido, o estudo de caso, a análise das entrevistas e o grupo focal, serviram como fontes de análise de dados e tentaram, onde foi possível, segregar resultados que podem ou não ser positivamente relacionados com o MBA Gestão Pública.

\subsubsection{Plano de Análise da Pesquisa de Campo}

Tendo sido apresentados os objetivos do estudo, as perguntas de pesquisa e os procedimentos metodológicos para sua execução, cumpre apresentar o plano de análise da pesquisa. 


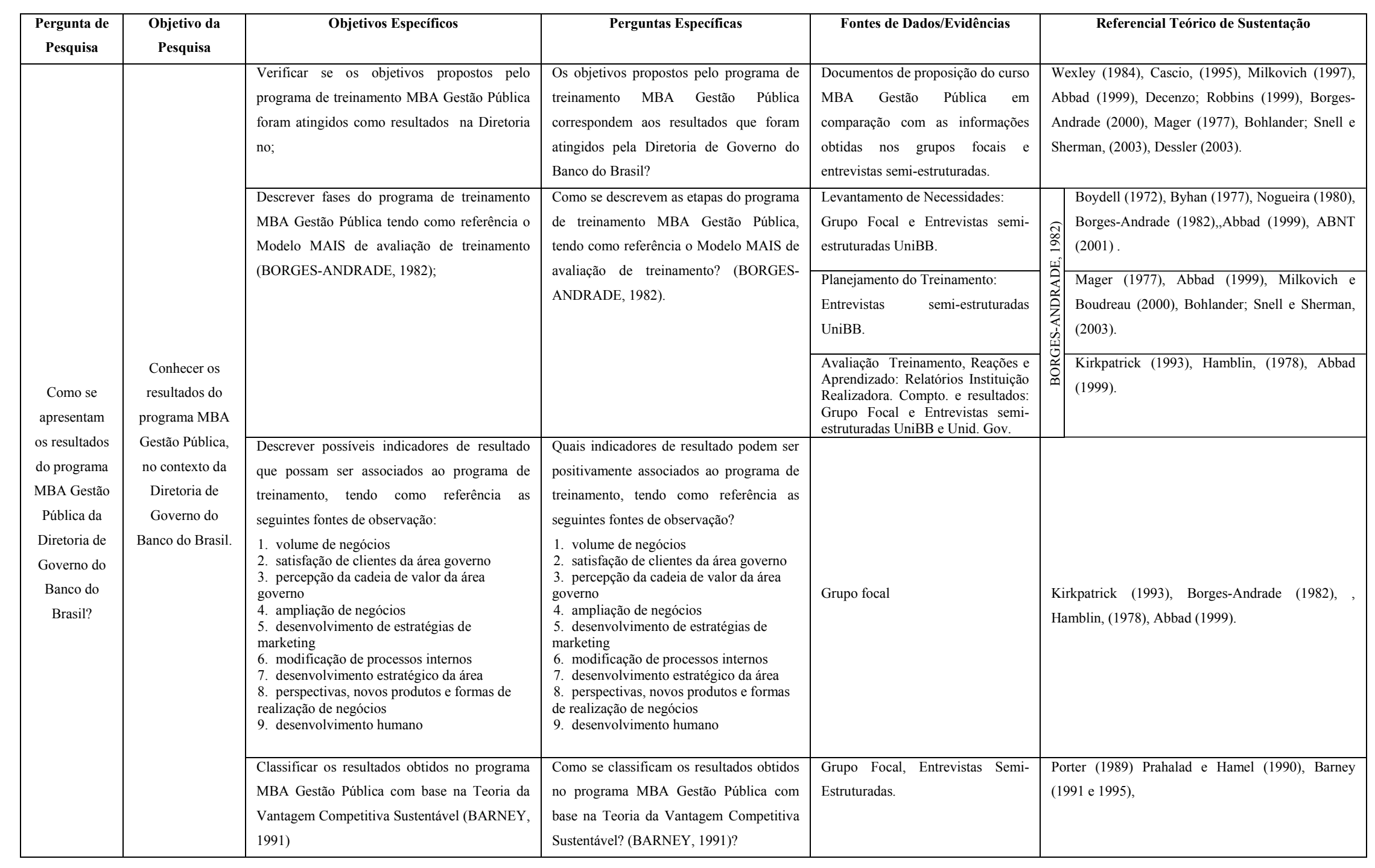

Quadro 6 - Plano de Análise da Pesquisa de Campo, Fonte: Autor 


\section{RESULTADOS OBTIDOS NA PESQUISA DE CAMPO}

Conforme prevê a metodologia do presente estudo, destacada no Plano de Análise da Pesquisa de Campo à página 154, para se identificar os resultados do curso em análise foram utilizadas as seguintes fontes de evidências: Documentos de proposição do curso MBA Gestão Pública, Grupos Focais, Entrevistas semi-estruturadas junto a UniBB e a Diretoria de Governo, além de indicadores oferecidos pelos participantes das entrevistas semi-estruturadas.

Estas evidências estão demonstradas conforme o encadeamento lógico da pesquisa, norteado pela analise seqüencial dos dados obtidos para cada uma de suas fases, iniciando pelo objetivo geral e em seguida pela ordem de aparecimento dos objetivos específicos.

No tocante às referências extraídas das declarações de participantes de grupo focal ou de entrevistas semi-estruturadas, optou-se por destacar na análise dos resultados, comentários que estivessem relacionados à investigação dos objetivos aqui propostos.

\section{Resultados obtidos para pergunta e objetivo geral}

A pergunta de pesquisa que origina o presente estudo é: Como se apresentam os resultados do programa MBA Gestão Pública da Diretoria de Governo do Banco do Brasil?

Esta pergunta levou ao objetivo geral de conhecer os resultados do programa MBA Gestão Pública, no contexto da Diretoria de Governo do Banco do Brasil.

Os resultados obtidos para a pergunta e objetivo geral apresentam-se, por meio dos resultados das quatro perguntas específicas.

Conforme prevê a metodologia deste estudo, a pergunta geral de pesquisa somente pode ser respondida por meio dos resultados obtidos para suas perguntas e objetivos específicos, 
coletados por meio dos grupos focais, entevistas semi-estruturadas e análise de dados secundários.

\section{Resultados obtidos para primeira pergunta específica}

A primeira pergunta específica do estudo é: Os objetivos propostos pelo programa de treinamento MBA Gestão Pública correspondem aos resultados que foram atingidos pela Diretoria de Governo do Banco do Brasil?

O que leva a pesquisa a finalidade de: Verificar se os objetivos propostos pelo programa de treinamento MBA Gestão Pública foram atingidos como resultados na Diretoria de Governo;

A primeira evidência a ser considerada é o Manual de apresentação do Programa MBA Gestão Pública que apresenta a seguinte descrição de objetivos do curso:

O objetivo do CURSO DE ESPECIALIZAÇÃO EM GESTÃO PÚBLICA - PósGraduação lato sensu é formar profissionais para que atuem como transformadores e consultores em organizações públicas. Os profissionais formados pelo curso devem ter a capacidade de oferecer aos clientes governamentais do Banco do Brasil produtos e serviços de qualidade que atendam as especificidades deste setor. O curso busca capacitar o aluno para conhecer e avaliar o setor Governo e suas relações, buscando perceber novas oportunidades negociais, bem como desenvolver, implementar e avaliar produtos e serviços nas mais diversas áreas de atuação.

Busca-se despertar o aluno para a realidade gerada pelos mercados globalizados, potencializando oportunidades. O gestor público deve possuir expertises suficientes e capazes de trazer ao setor público a eficiência das mais modernas e competitivas empresas. (FUNDACE, 2005, p.13)

De forma a sistematizar a apresentação da paridade dos objetivos do curso de MBA Gestão Pública com as percepções do entrevistados, separou-se os objetivos do curso da seguinte forma: 
1. Formar profissionais para que atuem como transformadores e consultores em organizações públicas.

2. Os profissionais formados pelo curso devem ter a capacidade de oferecer aos clientes governamentais do Banco do Brasil produtos e serviços de qualidade que atendam as especificidades deste setor.

3. O curso busca capacitar o aluno para conhecer e avaliar o setor Governo e suas relações

4. Busca-se despertar o aluno para a realidade gerada pelos mercados globalizados, potencializando oportunidades.

5. O gestor público deve possuir expertises suficientes e capazes de trazer ao setor público a eficiência das mais modernas e competitivas empresas.

Analisando separadamente cada objetivo de treinamento, tem-se os seguintes resultados na realização dos grupos focais:

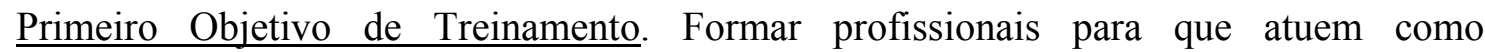
transformadores e consultores em organizações públicas.

Sobre este aspecto foram selecionados os seguintes comentários:

E7: O curso foi excelente também porque nos ajudou a entender as necessidades dos clientes - nem eles sabem direito o que querem.

E11: Muitas vezes, não digo que isso acontece aqui em Brasília, mas principalmente no interior, as prefeituras - mais as de pequeno porte - não têm noção nenhuma de administração pública, sendo que o banco na maioria vezes tem que atuar como consultor.

E9: Na época em que eu fiz o MBA, teve uma equipe que até se prontificou a dar consultoria às prefeituras, fazer cursos nas prefeituras chegando junto com os prefeitos, disseminando o conhecimento. $O$ banco não cobra nada, mas entra como parceiro, com o seu gestor maior.

E13: ...tem essa preocupação, com a sociedade, com a gestão pública, sendo que muitas vezes você acaba sendo consultor - o que é uma dificuldade que a gente tem por não ser uma das funções pré-determinadas. 
ESE1: em algumas situações você atua até como consultor do administrador público. Só o conhecimento que você adquire em sala de aula vai permitir essa atuação de consultor, porque o banco não oferece condições para você ser auto-didata nesse assunto, pois não é um assunto bancário, usual, espontâneo, não faz parte do seu negócio

Segundo Objetivo de Treinamento. Os profissionais formados pelo curso devem ter a capacidade de oferecer aos clientes governamentais do Banco do Brasil produtos e serviços de qualidade que atendam as especificidades deste setor.

Foram destacados os seguintes comentários:

E1: Alguns produtos surgiram nas discussões que se teve dentro do MBA. Por exemplo, o cartão de pagamentos do Governo Federal - como meio de pagamento do Governo, no qual se modernizou a forma de pagamento e a substituição das contas - foi uma mudança que se teve na discussão do curso, não sendo uma coisa nossa. Toda compra que se faz com o cartão, o banco ganha um percentual sobre as compras. Isso passa uma visão de modernidade para a sociedade, de maior controle. É um produto tema de monografia e que, de fato, já foi implementado.

E1: Cobrança da divida ativa foi algo que se pensou aqui (no curso) e depois se consolidou na área jurídica.

E7: ... sugerir alguns produtos mais apropriados.

E8: O curso deu mais segurança aos produtos em termos de imagem legal. Você diminui os seus riscos dentro dos seus processos.

E12: As pessoas da rede, que participaram do curso - das agências - apresentaram idéias, procurar saber se a gente precisava revisar algum produto.

Terceiro Objetivo de Treinamento. O curso busca capacitar o aluno para conhecer e avaliar o setor Governo e suas relações, buscando perceber novas oportunidades negociais.

Destacando-se os seguintes comentários:

E1: O curso dá essa visão de Ciências Politicas, Planejamento, Contabilidade Pública, Administração Financeira Orçamentária, Direito, sendo tudo muito importante para você criar uma massa crítica e poder dialogar com o cliente (setor público) no mesmo nivel.

E3: Isso (o curso) ajudou a eqüalizar o linguajar, o entendimento do que é o setor público. Com essa formação da massa crítica de Governo, o discurso era muito a limpo e o treinamento do MBA foi importantíssimo nessa questão.

E5: Acredito que foi uma decisão acertada fazermos essa especialização, para termos mais condições de estarmos no mercado, em melhores condições e com maior competitividade. 
E13 relata: Eu afirmo que sim, mudou muito. Mas, além disso, nós começamos a identificar mais oportunidades.

Quarto Objetivo de Treinamento. Busca-se despertar o aluno para a realidade gerada pelos mercados globalizados, potencializando oportunidades.

\section{Comentários:}

E13: Quando você trabalha com o Governo e propicia compras com agilidade, você também está gerando negócios para os fornecedores, com isso, você está criando oportunidades para fazer adiantamentos.

E15: Então o objetivo (do curso) era esse: conhecer onde o Governo estava caminhando, ter uma análise crítica desses movimentos que o Governo estava fazendo, e tentar transformar isso (o conhecimento) em oportunidade de negócio.

E16, ao tratar da questão relativa a mudança de comportamento em razão do treinamento:

Até o curso eu não tinha muita segurança de colocar em prática esse viés que eu tinha. Depois do curso eu tive mais conhecimento e segurança para propor algumas coisas; $e$ a gente consegue fazer uma leitura diferente não só das notícias, mas você às vezes pega o balanço orçamentário e consegue enxergar oportunidades que antes você não enxergava.

E12, ao tratar do contexto de levantamento da necessidade do treinamento na Diretoria de Governo,: (com o curso) começou toda a estruturação do conhecimento na diretoria de Governo, sendo que o primeiro curso para o qual os funcionários foram indicados foi o de nível estratégico, que é o MBA Gestão Pública.

E12, referente a questão que tratava de possiveis modificações de procedimentos internos em razão do treinamento respondeu que em sua avaliação isso não foi identificado, porém: O que eu vi foi mudança de atitude; houve um momento em que, até por conhecer melhor de orçamento público, passou-se a ser pró-ativo e preparar as ações estratégicas em cima do orçamento - buscar oportunidades dentro do orçamento público - isso no âmbito Federal.

Na questão que tratava da multiplicação de conhecimento interno dentro do Banco, E20 declarou:

eu estava trabalhando em uma área que me permitiu aplicar os conhecimentos que eu estruturei com o meu grupo na nossa monografia, a qual trata de você analisar os instrumentos de gestão pública e identificar oportunidades de negócios.

Quinto Objetivo de Treinamento. O gestor público deve possuir expertises suficientes e capazes de trazer ao setor público a eficiência das mais modernas e competitivas empresas. 
Destacam-se os seguintes comentários:

\begin{abstract}
E5: eu era gerente de negócios de uma agência do setor Público, trabalhava diretamente em Brasilia, e como tal havia a necessidade de ter uma especialização e de ter um aprimoramento maior, por exemplo em legislação, para a gente poder ir vender o produto para o cliente, porque somos linha-de-frente no atendimento ao cliente. Então acredito que foi uma decisão acertada fazermos essa especialização.

E5: o curso mostrou como é que a gente poderia trabalhar estrategicamente, para chegar a esse cliente e oferecer, até fazer, gestões antecipadas no exercício anterior para que se pudesse, no exercício seguinte, fazer o negócio para o cliente

E5: com relação aos clientes, absorvemos um monte de informações e conhecimentos que permitiram que a gente promovesse mudanças.

E20: constata-se a preocupação do Banco do Brasil em ser competitivo neste nicho de mercado: Na realidade, o grande foco começa em 1995, quando o banco dá uma grande guinada e foi nesse momento que realmente começamos a olhar para os nossos clientes e a buscar eficiência. Na seqüencia, a diretoria de Governo passa a existir, verifica a necessidade de conhecer melhor o seu cliente, busca a estruturação desse curso - ao mesmo tempo em que começa a mudança na estruturação do banco em pilares.
\end{abstract}

\title{
Resultados Obtidos para a segunda pergunta específica
}

A segunda pergunta específica do estudo é: Como se descrevem as etapas do programa de treinamento MBA Gestão Pública, tendo como referência o Modelo MAIS de avaliação de treinamento? (BORGES-ANDRADE, 1982).

Esta pergunta leva ao objetivo de descrever as fases do programa de treinamento MBA Gestão Pública tendo como referência o Modelo MAIS de avaliação de treinamento (BORGESANDRADE, 1982), explorado a página 85.

O modelo compreende os seguintes elementos de mensuração: insumo, procedimentos, processo, resultados e ambiente, sabendo-se que o elemento ambiente deve ser observado no aspecto da avaliação de necessidades, apoio, disseminação e resultados de longo prazo.

$\underline{\text { Insumos do Treinamento }}$ 
Os insumos compreendem fatores físicos e sociais e estados de comportamento pretérito relacionados ao público que fará parte do treinamento. Os seguintes dados dos participantes são significativos como resultados da pesquisa:

Conforme relatório do curso MBA gestão publica 5 deixar claro (FUNDACE, 2005: paginas 20 a 23), os participantes são em sua totalidade graduados, atuantes na área de governo há pelo menos 5 anos, têm em média 15 anos de experiência no Banco do Brasil. Exercem principalmente a função de agentes de negócio entre o Banco do Brasil e entidades de serviço público de natureza municipal, estadual ou federal, provenientes das esferas de poder executivo, legislativo ou judiciário.

Ainda no tocante aos insumos, os seguintes aspectos sociais merecem destaque, tendo sido extraídos de (FUNDACE, 2005):

"Não tenho nada a acrescentar (como sugestão ao curso).

“Acho um privilégio poder participar de um curso como este; Parabéns ao banco do Brasil e à Fundação".

“O Banco do Brasil, através da GEPES está de parabéns pela sua atuação. Para minha formação profissional o curso é útil e favorecerá as negociações com os gestores públicos. Estou mais segura e preparada para exercer meu cargo. O curso superou as expectativas".

Não houve coleta de dados sistematizada no sentido de se compreender os níveis de motivação dos treinandos antes da realização do curso pois não era objetivo deste trabalho.

\section{$\underline{\text { Procedimentos do Treinamento }}$}

Os procedimentos compreendem as estratégias didáticas utilizadas na realização do treinamento, incluem-se nesse aspecto procedimentos operacionais do treinamento, como o planejamento da ação e a atuação do instrutor. 
Conforme relatório, foram utilizadas as seguintes estratégicas didáticas no curso,

Aulas teóricas com apoio em retroprojetor, vídeos, data-show, flip-chart e lousa. Estes materiais deverão ser providenciados pelo Banco do Brasil. Aulas práticas através de resolução de exercícios, estudos de casos, elaboração de projetos, visitas a empresas, pesquisas de campo, pesquisas bibliográficas. Palestras de especialistas abordando assuntos relevantes na área de Gestão Empresarial (FUNDACE, 2005, p.16).

Fundace (2005) declara ainda que "o treinamento foi planejado para proporcionar o maior numero de interações possíveis entre alunos e professores. A seleção dos professores foi realizada com base em sua formação acadêmica e capacidade didática” (FUNDACE, 2005, p. 17).

O projeto pedagógico do programa em análise foi estruturado nos seguintes ciclos: $\mathrm{O}$ Estado e a Sociedade, O governo e seus Processos e Negócios com o Estado e o Governo.

- $\quad$ O Estado e a Sociedade: neste ciclo busca-se compreender a formação do Estado como uma forma de organização definida e representada pela sociedade. Destacam-se as características do Estado Brasileiro, as reformas recentes dadas pelo Plano Diretor da Reforma do Estado, e como o Estado relaciona-se com a sociedade no planejamento e execução de Políticas Públicas.

- $\quad$ O Governo e seus Processos: neste ciclo são apresentados e discutidos os diversos processos governamentais, como são instrumentalizados e operacionalizados. Destacamse a forma como o Estado materializa-se em uma organização de processos para realizar suas funções e como estes processos relacionam-se e são administrados.

- Negócios com o Estado e o Governo: neste ciclo explora-se a capacidade de negociação com os órgãos públicos ou com as organizações responsáveis pela execução de políticas públicas. Destacam-se as características específicas do sistema de marketing para atuar no setor público, as variáveis determinantes e a evolução recente da forma de relacionamento entre os agentes da cadeia produtiva governamental (FUNDACE, 2005, p. 6).

A grade horária do programa assim se encadeou cronologicamente: 


\begin{tabular}{|c|c|c|}
\hline \multicolumn{3}{|c|}{$1^{\circ} \mathrm{CICLO}$ - O Estado e a Sociedade } \\
\hline Aula manhã & Aula Tarde & $\mathbf{c} / \mathbf{h}$ \\
\hline Palestra Inicial - Abertura & Integração & 8 \\
\hline Defesa Pública Monografia & Defesa Pública Monografia (turma anterior) & 8 \\
\hline Defesa Pública Monografia & O NOVO GOVERNO & 8 \\
\hline Economia Contemporânea & Economia Contemporânea & 8 \\
\hline Economia, Estado e Sociedade & Economia, Estado e Sociedade & 8 \\
\hline Aspectos Organizacionais & Aspectos Organizacionais & 16 \\
\hline Evolução da Estrutura do Estado & Evolução da Estrutura do Estado & 16 \\
\hline Planejamento e Desenvolvimento & Planejamento e Desenvolvimento & 16 \\
\hline Action - Imperial & Action - Imperial & 8 \\
\hline Governo e Desenvolvimento & Governo e Desenvolvimento & 16 \\
\hline Metodologia - monografias & Metodologia - monografias & 8 \\
\hline Desenvolvimento e Sustentabilidade & Desenvolvimento e Sustentabilidade & 8 \\
\hline Metodol/Análise Dados & Metodol/Análise Dados & 8 \\
\hline Direito Constit./Admin & Direito Constit/Admin & 8 \\
\hline Direito Tributário & Direito Tributário & 8 \\
\hline PROVA PRIMEIRO CICLO & DEBATE - O FUTURO DO BB & 8 \\
\hline \multicolumn{3}{|c|}{$2^{\circ} \mathrm{CICLO}-\mathrm{O}$ Governo e seus Processos } \\
\hline Processos Licitatórios & Processos Licitatórios & 8 \\
\hline Contabilidade Pública & Contabilidade Pública & 16 \\
\hline Finanças Públicas & Finanças Públicas & 24 \\
\hline Financiamento Público e Fundos & Financiamento Público e Fundos & 8 \\
\hline Metodologia - monografias & Metodologia - monografias & 8 \\
\hline Instituições Fomento & Instituições Fomento & 8 \\
\hline Governo e Sociedade & Governo e Sociedade & 8 \\
\hline Finanças/Avaliação & Finanças/Avaliação & 8 \\
\hline Economia Solidária & Economia Solidária & 8 \\
\hline Rede de Segurança Social & Rede de Segurança Social & 8 \\
\hline Sistemas de Informações & Sistemas de Informações & 8 \\
\hline Gestão de Organizações Públicas & Gestão de Organizações Públicas & 24 \\
\hline Organizações da Sociedade Civil & Organizações da Sociedade Civil & 8 \\
\hline PROVA SEGUNDO CICLO & SEMINÁRIO - DESCENTRALIZAÇÃO & 8 \\
\hline \multicolumn{3}{|c|}{$3^{\circ}$ CICLO - Negócios com o Estado e o Governo } \\
\hline SEMINÁRIOS - PREVIDÊNCIA & SEMINÁRIOS - PREVIDÊNCIA & 8 \\
\hline Marketing & Marketing & 8 \\
\hline Ética e Gestão & Ética e Gestão & 8 \\
\hline Negociação & Negociação & 8 \\
\hline Orientação Monografias & Orientação Monografias & 8 \\
\hline PROVA TERCEIRO CICLO & PROVA TERCEIRO CICLO & 8 \\
\hline \multirow[t]{2}{*}{ Defesa Pública Monografia } & Defesa Pública Monografia & 16 \\
\hline & Carga Horária Total & 384 \\
\hline
\end{tabular}

Quadro 7 - Grade Horária MBA Gestão Pública

Fonte: Fundace (2005) 


\section{Processo do treinamento}

O estudo do processo abrange ocorrências resultantes dos procedimentos adotados no treinamento, relacionando-se com características comportamentais do treinando. Neste aspecto devem ser observados itens como motivação do participante (no aspecto de acompanhamento do treinamento), nível de dedicação e estudo e mesmo resultados obtidos em avaliações.

Segundo Fundace (2005), o índice médio de presença dos alunos esteve em torno de $85 \%$ (oitenta e cinco por cento) nas 5 turmas de realização do curso.

No aspecto de notas, revelou-se como notas médias o indicador de 8,87 na escala decimal, a tabela seguinte demonstra estes indicadores por turma.

Tabela 2 - Médias Acadêmicas dos Alunos do curso MBA Gestão Pública

\begin{tabular}{|c|c|c|c|c|}
\hline & Ciclo 1 & Ciclo 2 & Ciclo 3 & Média final da Turma \\
\hline Turma 1 & 8,93 & 9,36 & 8,83 & 9,04 \\
\hline Turma 2 & 8,45 & 9,14 & 9,14 & 8,91 \\
\hline Turma 3 & 8,11 & 8,99 & 9,24 & 8,78 \\
\hline Turma 4 & 8,34 & 8,79 & 9,12 & 8,75 \\
\hline Turma 5 & 8,35 & 8,80 & 9,13 & 8,76 \\
\hline Média das Turmas & 8,46 & 9,07 & 9,08 & 8,87 \\
\hline
\end{tabular}

Fonte: autor, baseado em Fundace (2005)

\section{$\underline{\text { Resultados Obtidos no treinamento }}$}

Conforme se viu em Borges-Andrade (1982), no tocante aos resultados examinam-se as habilidades ou atitudes desenvolvidas em razão do treinamento, o exame deste aspecto deve ocorrer após a realização do evento, e é preciso verificar que os comportamentos observados sejam compatíveis com aqueles definidos no planejamento do treinamento. Ampliando a 
compreensão do autor ao aspecto de resultados, inclue-se aqui a avaliação de reação (KIRKPATRICK, 1993).

\section{Reação}

A avaliação de reação foi aplicada nas cinco turmas de realização do programa por meio do documento: Controle de Qualidade de Aulas (FUNDACE, 2005). Este documento, aqui reproduzido como Anexo 1, constante a pagina 267 foi distribuído aos alunos em todas as aulas do programa, foram todos digitados com a finalidade de se te uma avaliação individual para cada uma das aulas do curso. Trata-se de uma avaliação com itens divididos em cinco partes, sendo a primeira parte a respeito da disciplina, a segunda uma avaliação do professor, a terceira uma auto-avaliação do aluno, a quarta uma avaliação da infra-estrutura do treinamento e quinta reservada a comentários gerais dos alunos.

Nesta avaliação os alunos atribuíram notas de 1 a 5 a cada um dos itens, sendo 1 a menor nota e 5 a maior, a digitação realizada foi finalizada obtendo-se a média aritmética simples de cada item.

De maneira consolidada, os seguintes indicadores foram obtidos:

\begin{tabular}{lccc}
\hline Turma & Disciplina & Professor & Aluno \\
\hline \multicolumn{4}{l}{} \\
\hline Turma 1 & 4,09 & 4,05 & 3,79 \\
\hline Turma 2 & 4,24 & 4,30 & 3,96 \\
\hline Turma 3 & 4,51 & 4,56 & 4,25 \\
\hline Turma 4 & 4,62 & 4,68 & 4,37 \\
\hline Turma 5 & 4,53 & 4,66 & 3,90 \\
\hline \multicolumn{4}{l}{} \\
\hline Média Final & 4,40 & 4,45 & 4,05 \\
\hline
\end{tabular}

Tabela 3: Avaliação de Reação - Turmas MBA Gestão Pública

Fonte: autor baseado em FUNDACE (2005) 
As referências à infra-estrutura não constam por serem respostas binárias simples, sim ou não, sem representatividade necessária ao presente estudo. Os comentários escritos são de extensão muito ampla relacionados principalmente a acontecimentos corriqueiros da aula, por esta razão também não se apresentam aqui.

Complementarmente a este dado, conforme FUNDACE (2005), ao final de cada uma das cinco turmas realizadas fez-se uma avaliação de reação sumarizada de todo o curso, cada um destes documentos tem aproximadamente 25 páginas, contendo 50 itens de avaliação. Para não estender este trabalho com uma longa discussão ou apresentação pormenorizada destes resultados, menciona-se apenas que na consolidação das avaliações das cinco turmas, $95 \%$ dos alunos declaram que o curso atendeu as suas expectativas e $98 \%$ (noventa e oito por cento) deles recomendariam o curso a seus colegas da mesma área.

\section{Comportamento}

A modificação de comportamento junto aos participantes do treinamento foi investigada nos Grupos Focais, Apêndice 1 pergunta 2, Quanto a mudança de comportamento em razão do treinamento: Vocês perceberam mudanças em seu próprio comportamento após a realização do treinamento?

Os participantes relatam os seguintes aspectos de mudanças de comportamento em razão do treinamento, destacando-se as respostas mais representativas:

E3: Acho que a mudança dava para ser percebida - sendo que a turma tinha aulas de uma semana por mês - no final de cada uma dessas semanas. Você voltava para trabalhar e já notava um conhecimento o qual abria os horizontes para alguns assuntos que, anteriormente, você não tratava da mesma forma ou, às vezes, nem tinha contato.

E1: Mesmo quando você recebia um projeto ou algum problema para solucionar, você já fazia um link com determinada teoria, determinada informação, sendo que você não precisava correr atrás daquilo porque já era capaz de analisar aquilo.

E12: ...sistematizar mais as informações que até então você tinha esparsas, através dos conhecimentos que o curso nos proporcionou. Isso fez com que você ficasse mais próativo em relação ao cliente, já que hoje você consegue até criar necessidades que os próprios clientes dos setores do Governo não tinham. Você, alinhando o conhecimento 
que tem de banco com o treinamento, facilita e ajuda a entender melhor e propor soluções e criar algumas necessidades que os clientes não tinham. Muda a forma de você conversar com o cliente; o diálogo fica transparente. O curso veio nos colocar no mesmo patamar dos gestores do Governo.

E9: O comportamento, com certeza, após a realização do $M B A$, é de segurança, pois ele te dá segurança até para você conversar com o seu cliente, que é o ente público. E eu acho que, quando você tem a informação - o conhecimento - até quando você vai negociar fica mais fácil, sendo que você não fica supondo situações, você vai direto na "ferida" juntamente com o cliente.

E8: Acho que, além disso, essa oportunidade que a gente tem de voltar ao ambiente acadêmico e conhecer as outras pessoas que trabalham no pilar com diversos $e$ diferentes trabalhos, também é uma coisa muito importante.

E15: A gente passou a ter uma visão mais crítica das situações e começou a interpretar melhor algumas posições de Governo. Até então a gente sabia o que estava acontecendo mais diretamente mas, da ramificação do porque que desembocava em uma determinada decisão, a gente começou a ter uma análise mais completa. E isso favoreceu a gente a tentar antever algumas ações negociais.

E17: Da minha parte eu senti uma interpretação melhor das decisões politicas, uma empatia com o administrador público ao administrar determinadas situações ou fazer determinados encaminhamentos. Então uma noticia que antes passava despercebida era agora notada; esses nomes (linguajar) e a compreensão de tudo o que representa para o Governo ampliou-se e clareou-se.

E14 declarou: No meu caso é mais ou menos a mesma coisa. Eu que trabalhava, que tinha um relacionamento direto com o Tesouro Nacional, comecei a entender algumas coisas que eles falam...

E21: Acho que você consegue identificar oportunidades de crescimento profissional e isso veio, de uma certa forma, influenciar o seu dia-a-dia. Você acaba adquirindo uma nova postura.

E19: Permitiu, também, a gente ter uma visão dos acontecimentos recentes da história do país, que diz respeito ao projeto de modernização da administração pública. O curso deu uma compreensão muito boa do funcionamento da máquina administrativa.

E20: eu consegui fazer uma ponte e trazer para a prática muito desse conhecimento.

As observações seguintes foram obtidas quando da pergunta sobre modificações de processos internos, sua reprodução se encontra aqui pela similaridade temática:

E19: Uma mudança também importante é a comportamental. O diretor passa a ter mais respeito com a exposição das idéias. Antes a coisa vinha de cima para baixo e o técnico não era muito levado em conta. Então houve uma mudança de atitude da diretoria em querer ouvir o que o técnico diz sobre os assuntos que conduz.

E20: Pode-se dizer que, com a democratização da informação, muda totalmente a relação de poder mesmo.

ESE1: Tem um deles (um trabalho de conclusão de curso) que foi descartado-porque o resultado me deu subsidio para poder descartar - no qual o pessoal previa que o relacionamento com a pessoa física ficasse na rede Governo. Então a gente descartou porque contrariava a premissa da empresa, na qual você tem o pilar Atacado, Varejo e Governo, sendo o cliente "pessoa física" deve ser atendido no pilar Varejo. Então, na verdade, o cliente tem que ser atendido onde ele vai ter a melhor condição de atendimento. 


\section{Resultado Final}

A primeira investigação a respeito dos resultados do treinamento se deu junto aos grupos

focais, objeto do apêndice 1, item 3a, onde se questionou dos participante de forma aberta: Qual sua percepção de resultados sobre o programa MBA Gestão Pública?

Os seguintes relatos foram obtidos em torno dos resultados do programa:

E2: Tem uma monografia que conjuga a questão da estratégia da própria diretoria que foi a criação de superintendências de governos e municípios - eu acho que as superintendências, na época, eram estaduais, o estudo de segmentação de clientes $e$ atendimento especializado foi feito no contexto do curso.

E1: A capacitação para você lidar com o setor público no âmbito dos Governos Federais e grandes Municípios é muito grande, ou seja, para o nosso negociador ir lá e conversar com o secretário de Fazenda, de Planejamento, é necessário que ele tenha um grau especialização considerável. Sem isso, fica não só difícil de se tirar negócio, mas também de se detectar possiveis problemas cujas soluções podem estar no banco.

E9: O resultado é você terminar um MBA desse com maior conhecimento, com maior segurança para ir ao mercado. Não posso dizer que nós não tínhamos conhecimento, já que paliativamente conhecíamos o mercado, mas não conhecíamos a questão cultural para que você agregasse conhecimento e fosse ao encontro do cliente para fazer o negócio. Então o resultado disso é a bagagem que você recebe de informação, sendo que ela te dá condição de você buscar novos negócios e novos conhecimentos dentro do mercado. O curso de Gestão Pública foi o grande ponta-pé do meu desenvolvimento, nesse segmento. Quanto mais você lê, mais você acha que não sabe, e ai é que você está descobrindo o real valor do conhecimento.

E12: Eu acho que o resultado principal é o conhecimento, até essa questão da cultura do nosso cliente, que nós não tínhamos. A gente tinha um conhecimento muito pontual de algumas situações, mas com o MBA você passou a ter uma visão maior do cliente. A própria qualificação também, que o MBA nos deu, de modo até a nos colocar perante o mercado, como profissional.

E15: principalmente para quem é de rede - quem trabalha nas nossas agências e está na ponta - a gente observou um ganho de qualidade fenomenal. Antes você entendia coisas básicas de Governo - e de legislação de Governo - como algo absurdo; a gente observa que isso foi equalizado. Hoje, quando uma pessoa nos liga, a gente já vem com uma interpretação. Foi fundamental, então, para a formação do nosso pilar, inclusive para as pessoas que vieram do Varejo, as quais enriqueceram bastante seus aprendizados.

E17: ...quanto a resultado, no meu caso particular, eu trabalhava em uma área que cuidava de estratégias para alguns segmentos - de Estados e Municípios. Então, esse conhecimento desenvolvido com o curso, eu apliquei na elaboração de estratégias, na forma de eu abordar esses entes públicos em alguns materiais que a gente elaborou. Então, desde o linguajar, desde os pontos que eu decidi abordar nesses materiais tudo levou em conta o treinamento.

E14: o curso concretizou o nosso pilar Governo.

E20: O crescimento nosso de resultados está ligado com os MBA's. Retomando a mesma fala em seguida: $O$ MBA surgiu depois da lei de responsabilidade fiscal e, a partir disso, o gestor público passou a ter a necessidade de se capacitar um pouco mais, 
de melhor a sua gestão e conhecer mais o que ele estava fazendo. Daí, veio a exigência maior tanto daqueles que preparam os negócios para o setor público, como daqueles que têm o contato direto com o gestor público. Então, o crescimento ou manutenção dos negócios pode ser atribuído, em grande parte, à capacitação do pessoal, principalmente quem está no pilar Governo.

E22: foi no sentido de capacitar melhor e dar uma abertura de visão, principalmente para os funcionários da diretoria de Governo. E ver, com isso, onde você pode atuar, colocar produtos do banco e oferecer o banco para suprir determinadas dificuldades que o Governo tenha.

E21: Tem uma variável importante, que eu acho, que é o aspecto estratégico da empresa, porque a gestão está voltada para um segmento do mercado da empresa, e você analisa qual o peso do curso na estratégia da empresa, no direcionamento dos recursos. Às vezes, você conseguiu constatar uma idéia interessante, mas será que para a empresa é interessante implantar aquela idéia naquele momento.

E20: Eu acho que o principal resultado imediato desse curso foi expor as nossas fragilidades, ficou visivel quando você passa por esse MBA. E, no momento em que você consegue identificar essas fragilidades, obviamente você começa a atuar pontualmente - focadamente - sendo que o resultado virá num médio e longo prazo.

ESE1: Conhecimento sobre o cliente, que leva você a ter uma melhor forma de se relacionar, ou seja, você conhece ele, se relaciona melhor com ele - com base nisso, você consegue perceber quais são as necessidades que ele tem e consegue gerar novos produtos, serviços, soluções (conversar com o cliente no mesmo tom).

Com estes indicadores, especialmente pela associação de alguns resultados observados com a realização de trabalho de conclusão de curso, pediu-se que a Diretoria de Governo indicasse, dentre os trabalhos de conclusão realizados, 41 ao todo (houve 183 participantes nas cinco turmas do curso, porém os trabalhos de conclusão foram realizados em grupos de até 5 participantes), quais geraram algum tipo de resultado objetivo que pudesse ser mencionado. A Diretoria de Governo declarou que não exerce uma gestão direta sobre a implantação ou não dos trabalhos de conclusão, e sugeriu que o pesquisador entrasse em contato direto com os participantes do programa.

Este contato foi realizado por meio do envio de correspondência eletrônica a todos os participantes do curso. A incorporação desta técnica de investigação à pesquisa exigiu a elaboração de mais um instrumento de análise o APÊNDICE 4 - Implementação Efetiva de 
Trabalhos de Conclusão de Curso, página 263. Por este meio foram obtidas as seguintes respostas:

\begin{abstract}
R1: Sobre a monografia: Capacitação do servidor Público Municipal: uma oportunidade de negócios. Desde de 2003, venho oferecendo alguns cursos do BB para servidores das prefeituras e temos tido muito sucesso, tanto na fidelização, quanto nos resultados.
\end{abstract}

São oferecidos os seguintes cursos: Formação para Pregoeiro, Oficina Pão e Beleza; Economia Aplicada.

R2: minha equipe tratou do tema "A Execução Orçamentária e Financeira no Âmbito do SIAFI - Sistema Integrado de Administração Financeira do Governo Federal - O caso de Goianésia $(G O) "$ ".

Como ambos os interessados, Governo Federal e Município de Goianésia, desistiram da experiência, e o Governo Federal também desistiu de implementar o Siafi em outros municípios, não foi possivel, ainda, utilizar o resultado de nosso trabalho no Banco.

R3: o meu objeto de estudo foi o caso dos precatórios da Bahia. A implementação da sugestão oferecida ao Banco depende de demanda na tecnologia, cujo acompanhamento fica a cargo da diretoria de Governo.

Ainda no tocante aos resultados do treinamento, fez-se uma pergunta de confirmação para a pergunta $3 \mathrm{a}$, a pergunta $3 \mathrm{c}$ usada nos grupos focais, APÊNDICE 1 - Guia para realização de grupo focal, página 259: Como se pode relacionar a realização do programa MBA Gestão Pública com seus resultados na área governo?

Os relatos dos participantes estão relacionados principalmente a aspectos do desenvolvimento estratégico da Diretoria de Governo, conforme os relatos a seguir:

E3: Acho que o curso nos proporcionou um envolvimento com assuntos gerais da diretoria - estratégia e planejamento - nos fornecendo ferramentas para se entender melhor a área e nos mostrando as condições de participarmos mais ativamente.

E1: Para mim, o ciclo de amizade fora do banco também foi importante - a gente tem colegas que trabalham no ministério do planejamento, na secretaria Tesouro - e esse curso facilita o diálogo com essas pessoas, facilita a troca de idéias. Isso a gente traz de volta para o banco e, de certa forma, molda o pensamento da gente até em ficar pensando em estratégias dentro do banco.

E8: O curso foi importante para mim justamente por eu passar a conhecer sobre os aspectos legais, de normativos - aquilo que o nosso cliente está sujeito - para poder aplicar isso aqui dentro.

E13: Acho que é mesmo a questão do relacionamento, já discutida bastante aqui.

E16: O que pode ser percebido é essa consistência que o curso deu para as pessoas, principalmente no movimento dos pilares já discutidos aqui. O curso deu segurança e condições para aquela idéia que o banco tinha de criar pilares negociais - e até o esforço que o próprio Governo fez - e que o setor público fosse um pilar a parte. $O$ 
curso ajudou as pessoas, aqui em Brasília e em todos os Estados, a solidificar essa posição do setor público no pilar negocial, diferente do pilar pessoa jurídica. Acho até que esse é um diferencial que o banco tem em relação a muitos outros bancos.

E15: Acho que o principal ganho é com relação à segurança no relacionamento com a entidade. O quanto isso se traduz em números, eu não tenho idéia; mas com certeza o relacionamento de quem fez $\mathrm{MBA}$ com seu cliente setor público está mais seguro e mais eficiente.

E17: Na diretoria, quem cuida de um produto - de um sistema - quem tem essa visão proporcionada pelo MBA entende muito melhor o seu processo - toda aquela lógica de empenho e dinâmica do setor público - e pode agregar valor na melhoria do produto. A capacitação veio ajudar a promover em n processos, inúmeras maneiras diferentes.

Finalizando a apresentação dos resultados de treinamento, os seguintes resultados foram obtidos quanto a este assunto nas entrevistas semi-estruturadas realizadas junto a UniBB:

ESE2: O maior resultado que mostra que ele atendeu muito a necessidade da área foi que agente realizou 5 turmas desse curso. Esse é a maior comprovação do resultado do treinamento.

6 meses depois que acabou o curso uma área da Unibb define quais curso serão avaliados quanto ao impacto e isso é feito com um questionário de avaliação de impacto do treinamento so que do gestão publica não foi feito.

ESE3: Com o MBA gestão Publica não foi feita a pesquisa, havia outras prioridades naquele momento e nos costumamos trabalhar com amostrar mais representativas,

Entrevistador: é, e a população total do MBA Gestão Pública foi de 183 pessoas

ESE3: isso, e agente tinha outras prioridades naquele momento, com treinamentos numericamente mais representativos.

Entrevistador: como é feita a escolha dos treinamentos que devem ser objeto de pesquisa de avaliação de impacto?

ESE3: A área de treinamento escolhe os cursos que são estratégicos para que se faça essa pesquisa.

\section{$\underline{\text { Ambiente - Avaliação de Necessidades }}$}

A fase do levantamento de necessidades em Borges-Andrade (1982) realiza-se seguindo os passos abordados neste referencial teórico, analisando-se a empresa, as necessidades das pessoas envolvidas no treinamento as competências a ser desenvolvidas, as tarefas a ser realizadas e as pessoas que realizarão o treinamento, deve-se concluir o processo com a especificação das necessidades de treinamento. 
Conforme prevê o Plano de Pesquisa as fontes de evidência para o Levantamento de

Necessidades são as entrevistas semi-estruturadas e o resultado do grupo focal.

Apêndice 3 - Item 1

1. Como se deu o processo de levantamento de necessidades de treinamento da área governo em função do programa MBA Gestão Pública?

A Universidade Corporativa Banco do Brasil esclareceu conforme ESE2:

não houve um processo sistemático e organizado de levantamento de necessidades, mas elas foram identificadas pela própria área demandante do treinamento, nós da universidade corporativa não influenciamos a decisão da área em determinar esta ou aquela pessoa, porque eles é que sabem quem precisam treinar.

\title{
Apêndice 1 - Item 1a
}

2.1. Quanto ao Levantamento de Necessidades do treinamento.

a. Como foi questionada a necessidade de se realizar um treinamento na Diretoria de

\section{Governo?}

Tendo sido obtidas as seguintes respostas:

\begin{abstract}
E2: A criação (do curso) é uma sinalização da área de que se queria segmentar as áreas de negócios. Então, iniciou-se segmentando as áreas de atacado e varejo. Já havia uma área de agronegócios que não propriamente foi constituida como pilar, mas era voltada para essa parte de fomento à agricultura porque o Banco é um banco também voltado para essa área. E como terceira etapa, foi instituído o pilar Governo justamente como necessidade de identificar um nicho que tivesse departamentos que existiam aqui no banco. Foi atendido ao Governo Federal e identificou-se que esses departamentos poderiam constituir uma diretoria. E aí, o banco enxergou também o mercado com relação aos Estados e Municípios.
\end{abstract}

E8: E principalmente, também, quando a gente foi entrar no segmento de Estados e Municipios. Porque antes havia um departamento - o DEFUP (Departamento de Fundos e Programas) que cuidava de políticas públicas, aplicação de fundos e administração de fundos do Governo Federal. Então a base da criação da diretoria de Governo foi esse departamento. Ai depois, quando foi estruturada a unidade Governo, inicialmente chamada de Unidade de Negócios, não existia a área de Estados e Municipios, a qual foi criada fazendo surgir ainda mais a necessidade do treinamento. Então você cria uma unidade e, conseqüentemente, uma necessidade de especialização. E depois essa unidade virou um pilar.

E9: Foi uma estratégia da área de Governo de profissionalizar ou melhor, especializar, seus profissionais na área, porque é uma área específica. Então a linguagem do setor público, no Judiciário, com esses entes, é que faria o mercado agir no varejão. Você tem 
que ter um conhecimento mais aprofundado, você tem que ter alguma bagagem cultural até para você se relacionar, porque essas pessoas com as quais conversamos no dia-adia são pessoas que já são bem mais evoluídas culturalmente - pessoas com pós graduação, mestrado, doutorado, viajadas - e conhecem o segmento na palma da mão. Não adianta você sentar para conversar e contar uma historinha, sendo que essa historinha não tem uma essência, um objetivo, que traga e aproxime o ente às necessidades do banco, e conseqüentemente do mercado. Então, para isso veio a necessidade, no meu modo de pensar, da diretoria para a especialização de seu profissional.

E8 declarou: era uma área nova que estava surgindo no banco, crescendo no banco essa especialização no segmento do setor público.

E15: o que a gente tinha eram os conhecimentos avulsos de cada um, que adquiria por si-de forma fragmentada - sendo que algumas vezes não se tinha a noção do todo, do conjunto...para ter uma visão completa.

E 20: na realidade, não existia nenhum treinamento voltado para o mercado Governo. Esse foi o fato do primeiro treinamento. É como se o banco identificasse, muito claramente, dois (2) tipos de clientes - pessoa física e pessoa jurídica; então esse MBA iniciou a discussão sobre um importante cliente que é o cliente Governo.

E21 complementa: (o curso) Foi concebido também com o objetivo de identificar oportunidades de negócio.

ESE1: Eu comecei a ter contato com isso quando eu cheguei na diretoria. E aí, a gente fica meio espantado com a quantidade de conhecimento e do negócio que esse mercado gera. E nós mesmos, dentro da diretoria, identificamos que a gente tinha uma renovação muito grande - o banco ficou um periodo sem contratar gente e isso foi ruim do ponto de vista do gerenciamento do conhecimento - então a gente identificou que havia gap de conhecimento muito grande dentro da diretoria, ou seja, a gente estava perdendo gente que tinha um conhecimento muito grande e não estava conseguindo repor com a mesma qualidade. Também a necessidade de você ter uma capacitação melhor para o atendimento do cliente - o cliente fim). E, em seguida, veio o projeto dos pilares que foi muito bom porque nos preparou para enfrentarmos esses desafios. Eu acho que, se a gente não tivesse feito o MBA, a gente estaria muito distante de conseguir suprir as nossas agências recém-criadas com o conhecimento que eles precisavam ter - eles precisavam ter muito conhecimento num espaço de tempo relativamente curto, sendo que só o MBA foi capaz de fazer isso, pelo menos para os nossos principais administradores.

ESE2: O maior limitador sempre foi o orçamento, agente sentava com a DIGOV, e eles nos diziam: "olha nos vamos treinar na diretoria x pessoas" e eles nos diziam também quantas pessoas das agencias deveriam ser treinados. Quem tinha o controle de priorização das vagas era a diretoria.

Depois foi implementado o processo de realização de provas, agente sempre pedia pra eles mandarem mais candidatos do que o número de vagas disponíveis. Mas quando havia agências definidas como necessárias para o treinamento, em que os candidatos não tinham tido um bom desempenho havia uma compensação de vagas, fazíamos uma ponderação para que uma agência, onde havia necessidade de pessoas treinadas não ficasse sem o treinamento.

Mas é importante frisar que as diretorias passavam as agencias que deveriam ter funcionários participando do treinamento.

\section{Apêndice 1 - Item 1b}




\section{b. Como vocês foram indicados para participarem deste treinamento?}

As respostas obtidas foram bastante similares neste ponto, destacam-se alguns exemplos que ilustram de maneira abrangente a constatação geral deste item.

E3: Do ponto de vista da diretoria, creio que ela determinou um público-alvo para poder fazer o treinamento, começando com os gerentes de agências e subindo até à direção.

E1: Eu, especificamente, vim para a diretoria de Governo, egresso da área da diretoria de Varejo... eu senti a necessidade de aprofundar mais em conceitos, e mais mesmo na questão de como se trabalhava, recebimento de tarifas...

E6: Eu trabalho no Varejo, na época trabalhava como parte do aplicativo, que é o de pagamento de proventos, e trabalho até hoje na área de conta corrente e tarifas. $O$ Varejo precisava entender um pouco mais do público para poder, dentro de tarifas, desenvolver algo que atendesse a esse público, ou seja, conhecer um pouco melhor para desenvolver soluções.

E2: Foi através da manifestação do interesse.

E4: Na época (da primeira turma), eu era analista não-sênior, então era algo que eles nem solicitavam. No momento em que eu fui nomeada sênior, eu fui indicada para o curso - já entrei direto no curso - nem cheguei a exercer aqui a função de analista sênior.

E8: não era a minha vontade fazer o MBA Gestão Pública, mas fui indicada e tive que fazer, o que para mim foi o melhor.

E9: Eu trabalhava na agência Tribunais e cuidava das pessoas físicas de todo o segmento judiciário - STF, STJ, TST.

E11: Nós tínhamos um conhecimento empírico do cliente, e a necessidade do treinamento foi justamente para sistematizar esse conhecimento.

E14: Eu, na época, trabalhava com o PROEX que é um programa do Governo. Nós tínhamos a intenção de propor a transformação do programa em um fundo. Para isso a gente precisava ter conhecimento e argumento para defender alguma coisa nessa linha.

E15: minha indicação foi por conta desse trabalho, para ter uma visão estratégica de novos mercados...

E17: Eu trabalhava na Fundação Banco do Brasil, já tinha trabalhado na diretoria de Governo, já tinha acontecido duas (2) turmas do MBA Gestão Pública, que estava sendo muito bem comentado. Ai eu defendi, por iniciativa própria, perante à presidência da fundação, que eu participasse desse MBA para agregar valor até na visão da fundação, porque a fundação é do banco, mas ela tem muitas parcerias com entes públicos, ministério do trabalho. Então foi nesse sentido de agregar valor.

E21: Acho que em relação à função que cada um exercia.

E20 Função e Cargos, eu acho. No início foram os gerentes executivos - gerentes de divisão - e depois os analistas seniores.

E5: Na realidade, como a priorização é dos executivos, da diretoria, os gerentes da agência, os gerentes de divisão, depois vêm os gerentes de negócios, os analistas seniores, pelo menos houve uma definição aqui de estratégia da diretoria de Governo, acho que é óbvio fazer isso mesmo. 
E1: abordou a ampliação do alcance do programa: Se você forma o pessoal de frente, mas se o que está na retaguarda não tiver a mesma conversa, isso vai ficar meio que inócuo. Você vai estar entendendo o linguajar do cliente e tudo mais, mas na hora de colocar em prática, se você não tem dentro das diretorias pessoas também com esse treinamento, não se tem efetividade.

\section{$\underline{\text { Ambiente - Apoio }}$}

O aspecto ambiente do modelo de Borges-Andrade (1982), diz respeito ao contexto organizacional em que se insere o treinando antes e depois do treinamento. Na visão do autor o ambiente compõe-se das necessidades que motivaram o treinamento, do apoio que se tem para que o treinando desenvolva uma boa relação de ensino-aprendizagem, da forma como se deu a disseminação da oportunidade do treinamento e por fim, como se verificam os resultados de longo prazo do programa, ou seja as conseqüências verificáveis do treinamento após um determinado período de tempo.

A pesquisa não sistematizou tratamento a este elemento do Modelo MAIS (BORGESANDRADE, 1982), porém alguns elementos podem ser destacados com referência a este assunto, por meio de outras fontes de evidência.

Em relatório da FUNDACE (2003), observou-se o seguinte relato: Os alunos têm pouco tempo disponível para leituras, trabalho de conclusão. Banco deveria instituir horários mais flexíveis para estes assuntos.

No aspecto de gestão da Universidade Corporativa do Banco do Brasil percebe-se a sua atuação por meio da seguinte exigência contratual: "Apresentar a GEPES em meio magnético e impresso todos os trabalhos de conclusão de curso, compreendidos em Trabalho em Grupo e Artigo Individual.”(FUNDACE, 2005, p. 23).

Destacam-se ainda os seguintes comentários sobre a necessidade de sistematização do conhecimento produzido pelo curso, os comentários foram realizados nos grupos focais 
E23: Eu acho que tem um problema: a gente faz o curso - tem uma série de monografias lá - mas o banco teria que ter um pessoal para estudar essas monografias e dizer se elas são viáveis ou não. Porque deve ter coisas nelas que são viáveis.

E20: Concordo plenamente contigo e acho que essas monografias deveriam ser entregues ao gestor da área específica, o qual teria que desenvolver um relatório formal sobre aquele tema. Temos temas riquíssimos que sequer foram lidos pelos executivos.

E19: Isso deveria ser feito de forma sistemática. Corre-se o risco de uma monografia ser aproveitada até pelo concorrente.

\section{$\underline{\text { Ambiente - Disseminação }}$}

A disseminação do treinamento foi estudada de maneira ampla na terceira pergunta específica, item 9, quando se perguntou aos entrevistados do grupo focal a respeito do desenvolvimento humano da área de governo em razão da realização do programa de treinamento MBA Gestão Pública, seus resultados estão expostos em seguida.

Conquanto a disseminação do treinamento, baseado no Apêndice 5 - Movimentação de Pessoal da Diretoria de Governo obteve-se os seguintes dados a respeito das pessoas que fizeram o MBA Gestão Pública:

$\checkmark \quad 92 \%$ ainda se encontram no Banco do Brasil.

$\checkmark \quad 8 \%$ aposentaram-se ou saíram do Banco do Brasil

Dentre os funcionários que permanecem no Banco do Brasil:

$\checkmark \quad 48 \%$ se encontram no Pilar Governo

$\checkmark 52 \%$ estão em outros pilares, que não o governo, no Banco do Brasil

$\checkmark 84 \%$ estão em posição gerencial

$\checkmark 16 \%$ não estão em posição gerencial

Dentre os funcionários que estão no pilar governo

$\checkmark \quad 84 \%$ ocupam posições gerenciais

$\checkmark \quad 16 \%$ não ocupam posições gerenciais

Dentre os funcionários que não estão no pilar governo 
$\checkmark \quad 85 \%$ ocupam posições gerenciais

$\checkmark \quad 15 \%$ não ocupam posições gerenciais

$\underline{\text { Ambiente - Resultado de Longo Prazo }}$

Os resultados de longo prazo serão estudados no contexto dos resultados da Quarto objetivo específic, esta pergunta estuda os atributos da vantagem competitiva sustentável.

\section{Resultados Obtidos para a Terceira pergunta específica}

A terceira pergunta específica que se investiga neste estudo é: Quais indicadores de resultado podem ser positivamente associados ao programa de treinamento, tendo como referência as fontes de observação, volume de negócios, satisfação de clientes da área governo, percepção da cadeia de valor da área governo, ampliação de negócios, desenvolvimento de estratégias de marketing, modificação de processos internos, desenvolvimento estratégico da área e desenvolvimento humano.

Desta pergunta surge o seguinte objetivo específico: Descrever possíveis indicadores de resultado que possam ser associados ao programa de treinamento, tendo como referência as mesmas fontes de observação anteriormente mencionadas.

A fonte de evidência definida para a investigação deste objetivo foi o resultado obtido na realização dos Grupos focais.

Cada um dos indicadores sugeridos foi analisado separadamente em cada um dos grupos focais, eles foram questionados pelo Apêndice 1, item b, sendo este item dividido em 9 subitens, os mesmos definidos nas perguntas e objetivos do trabalho. A pergunta de introdução do item foi: 
Qual a contribuição do MBA Gestão Pública nos seguintes aspectos... elencando-se em seguida os indicadores de interesse da pesquisa. Para que haja uma compreensão pormenorizada relatamse os resultados obtidos para cada item separadamente.

\title{
Volume de negócios - Apêndice 1 - Item 3b i
}

i. elevação de seu volume de negócios após a realização do curso;

A primeira observação a esse respeito se deu em continuidade da pergunta sobre percepção de resultados que os participantes tinham a respeito do curso:

E1 considerou o seguinte a respeito do Cartão de Pagamentos do governo Federal, produto criado como trabalho de conclusão de curso do MBA Gestão Pública:

\begin{abstract}
Ele (o cartão) tem potencial, as contas giram recursos em torno de $R \$ 200$ milhões por ano. Em tese, esses recursos poderiam ser integralmente movimentados. Hoje esse movimento está na faixa de $10 \%$, ainda incipiente, até mesmo porque você muda também a filosofia de quem está lá como ordenador de despesas devido ao fato de hoje ele ter uma conta e um talão de cheques, sendo que essas contas são utilizadas para se fazer pequenas compras. A grande vantagem disso é que o talão de cheques está com o ordenador de despesas, mas o controle do órgão vai depender desse ordenador de despesas passar as informações. Enquanto que com o cartão você tem condições de pegar essa fatura e jogar para o órgão. Qualquer cidadão pode acessar o portal e ver o que é gasto com o cartão.
\end{abstract}

Em seguida, em resposta a pergunta específica do guia para realização dos grupos focais:

E6: Que o banco e a diretoria cresceram com o treinamento, isso é bastante visivel até pelo aumento da importância da própria diretoria dentro do banco. Mas o problema é que esse não foi um resultado só por conta do curso; que o curso foi importante isso é claro, mas todas as outras ações também contribuíram para os resultados.

E4: Eu acho que se você puder tentar marcar o que o curso trouxe de vantagem, que também não é mensurável, é o fato de eu que fiz o curso estar em um setor com pessoas que vão participar desse conhecimento que eu tenho; isso é uma forma de você estar trazendo uma melhoria, a qual não é mensurável também. Mas o setor passa a funcionar de uma forma um pouco mais eficiente devido ao fato de você estar ali, porque você está trocando conhecimentos que adquiriu, dando apoio, compartilhando o aprendizado.

E12: Eu penso que, talvez, na área Federal, nós fizemos algo que seja mais de consolidação de ameaça. O curso serviu para a gente como uma barreira de entrada para os nossos concorrentes, já que o banco é o principal agente do Governo Federal. A gente passou a ter condições de formular políticas e contribuir para a formulação das ações do Governo. O curso possibilitou, também, que vários funcionários de agências 
do Governo pudessem ampliar e estreitar o relacionamento com os entes estaduais $e$ municipais.

E17: Eu acho que é complicado eu fazer uma vinculação direta, ou seja, "causa e efeito", mas eu posso afirmar que contribuiu. O mercado "setor público", nesse período, ficou muito mais concorrido, a iniciativa privada ficou com uma atuação muito mais forte e isso gerou uma necessidade de defesa do banco; ficou muito mais dificil ganhar o nosso "dinheirinho", porque nós temos novos players no mercado jogando pesado. Por isso, o curso auxiliou o banco, o qual vem conseguindo se manter e até elevar o próprio resultado global da instituição. Então eu enxergo que a capacitação pela qual passamos contribui com o resultado, mas não consigo afirmar quanto e em que proporção.

E15: A gente agregou conhecimento, valor ao negociador, mas não é possível identificar se sem isso (o curso) a gente teria perdido alguma coisa.

E22: Você capacitar o funcionário com esses cursos, sendo a intenção crescer, torna a capacitação um dos fatores que pode influenciar ou contribuir; então é preciso trabalhar isso. Se o meu objetivo é crescer em negócios, eu preciso capacitar as pessoas que estão atuando naquela área. Mas não tem como a gente medir qual o tamanho dessa contribuição.

E23: É. A diretoria de Governo tinha um indicativo de que iria crescer, tanto é que cresceu.

E23: Cresceu também pela necessidade. Se um banco vinha com uma proposta, nas tínhamos que saber dessa proposta através do cliente e já montar um contra-ataque, ou seja, a gente cresceu também em cima da concorrência.

E20: Um outro detalhe, também, é que no momento em que esse MBA se materializa (surge), já mostra o fato de nós estarmos crescendo nesse mercado, porque você já busca uma especialização - mostra que a gente caminhou um pouco mais na identificação do cliente, o que antes inexistia.

E13: Acho que não podemos dizer que aconteceu em função disso, mas o curso foi um dos fatores.

Neste sentido cabe considerar que E2 frisou a necessidade de cautela em torno da causalidade treinamento e negócios:

Fica dificil eu te dizer, especificamente por conta do curso, você materializar um resultado financeiro, o resultado de uma ação de modo isolado, se ela faz parte de um conjunto de ações - como a capacitação, a estruturação, a própria capilaridade - isso tudo contribui para esse resultado.

E5: Eu acho muito dificil mensurar isso, nem sei se existe como.

E20: Fazer essa relação é complicado, porque o mercado é muito dinâmico - ele sofre a interferência de inúmeros fatores. As práticas de Governo também estão mudando.

\section{$\underline{\text { Satisfação de clientes da área governo - Apêndice 1 - Item 3b ii }}$}

ii. melhora na satisfação de seus clientes da área governo; 
E5: Acho que é aquela questão da negociação que a gente fala já que todo mundo trabalha com cliente - a agência trabalha, a direção trabalha - e tem um relacionamento institucional e até negocial com o Governo. Eu acho que a abertura das portas daquela pessoa que tem um conhecimento maior, na própria forma de você conversar, dos próprios termos técnicos que você usa, tudo isso realmente facilita muito e de certa forma veio a ajudar também, dos dois lados; porque o cliente também nem sempre tem em mente o que ele precisa e isso permite que a gente ofereça uma solução para ele, conversando com ele, pois ele vai falando das suas dificuldades.

E7: Eu acho que a satisfação do cliente, além do conhecimento, é também uma questão muito de empatia, do cliente se sentir à vontade. Tem que haver uma empatia do gerente de contas, do gerente da agência, daquela pessoa que está mais ligada ao cliente, para que as portas não se fechem e você não consiga avançar muito, sendo necessário mudar o negociador. Então a gente observa muito essa questão da postura da pessoa, de chegar no cliente, da personalidade dela. Isso é bastante importante.

E2: Tem até uma monografia que fala sobre o comportamento diante de um desembargador. A maneira do trato, do conhecimento, dos termos usados - aquela coisa rebuscada - e aquilo entre você ser tolerado e aceito pelo cliente. Você ser aceito é estar participando dos eventos, ser convidado para o coquetel. E essa questão da capacitação, do conhecimento, foi fundamental para você criar a simpatia e ser aceito, e não apenas tolerado em determinados círculos.

E9: Volto a falar que com o fator do treinamento na cultura, é natural que o cliente sinta mais firmeza no trato da linguagem.

E12: Também tem a própria segurança que a gente passou a ter quando está se relacionando com o cliente, sendo isso algo concreto. O cliente levanta uma questão que você já viu no curso, ou seja, já tem o conhecimento acadêmico sobre aquilo.

E13: Um exemplo disso, para mim, é que antes eu não tinha o conhecimento total de como funciona o Estado. Com as aulas, você abre um pouco a mente e vai atrás de novos negócios, porque você sabe que existem outros negócios em outras áreas ali dentro do cliente. Com isso, o cliente te observa e começa a te enxergar e ai é que vem o resultado questionado.

E14: Eu senti, principalmente naquela questão que eu falei de você falar na mesma linguagem, você ir acompanhando o que o cliente vai falando. E é óbvio, porque é igual você entrar em uma loja e a vendedora já saber o seu tamanho, não precisa nem perguntar que número você veste, ou seja, é extremamente agradável você saber que está lidando com uma pessoa que entende o que ela está fazendo. Eu percebi isso nitidamente, porque mudou a conversa.

E16: É lógico que havia clientes que eram muito bem atendidos por aqueles que já tinham mais experiência, mas de uma forma geral todos os clientes - todos os órgãos do Governo - acabaram tendo uma melhora no relacionamento com o banco. Quando o cliente vinha com uma necessidade, a gente apresentava uma solução para ele quase que imediata. Isso já existia dentro da área Governo, mas não generalizadamente.

E15: É possivel que o cliente esteja se sentindo melhor atendido, porque hoje ele conversa coisas que fluem mais tranqüilamente. A gente não faz mais aquela cara de "paisagem".

E20: O que eu vi foram umas pesquisas apontando que, no Banco do Brasil, as pessoas que atendiam o gestor público tinham uma melhor qualificação do que a concorrência.

E20: Eu participei de alguns encontros -seminários e palestras - e quando eu me identificava como do Banco do Brasil, ouvi de muitos funcionários públicos elogios a respeito da rapidez com que o banco estava se especializando. 
E19: A minha experiência é que hoje eu estou do outro lado e vejo a brutal diferença entre o gestor do nosso banco e o que a gente encontra de serviço de modo geral. Lá eles não tiveram essa formação e o preparo que o curso de Gestão Pública permitiu. Acredito que, quem fizer esse curso e for para o serviço público, vai ser um administrador muito mais eficaz.

E23: Não sei se a causa foi o curso, mas teve um fato interessante. Certa vez, fomos fazer uma visita à prefeitura de Embu e eu vi o pessoal do Governo conversar com um secretário de Finanças e o cara falou, claramente, para esse pessoal que estava satisfeito com a postura do banco de tratar as prefeituras, sendo que eu vi o pessoal falar a mesma língua desse secretário como se trabalhasse na prefeitura. Ou seja, a linguagem desse pessoal estava apropriada e eu presenciei isso.

ESE 1: Na (pesquisa) qualitativa tem vários depoimentos de clientes dizendo sobre a satisfação deles em poder falar a mesma língua com a pessoa que está atendendo.

A respeito das pesquisas de satisfação do Banco do Brasil, houve o seguinte diálogo, oportunizado pela adequação do momento na entrevista do grupo focal 3:

Entrevistador: Vocês sabem se teve uma mudança de avaliação que pode ser relacionada mais objetivamente com as pessoas que fizeram o curso?

E17: Não. Porque é uma pesquisa de satisfação do cliente "setor público" feita em relação ao atendimento pela nossa rede.

Entrevistador: eu mudo a minha pergunta: antes do programa já tinha essa pesquisa que teve depois, e houve uma mudança de comportamento?

Todos: Não. Já era boa e continuou boa. Não teve um salto.

\section{Percepção da cadeia de valor da área governo - Apêndice 1 - Item 3b iv}

iii. incremento de relacionamento negocial junto a cadeia de valor da área governo;

E1: Já havia algumas cadeias de valor consolidadas. Um ponto é a questão da agricultura: o papel da diretoria de governo é captar para que o agronegócio estrategicamente vá e faça o uso daquele recurso para a agricultura, emprestando e tudo mais. Então enxergar essa cadeia foi importante e é o exemplo mais claro para nós. Tem também as novas como a questão de você ter o cadastro de fornecedores para disponibilizar os entes públicos na hora em que eles querem comprar; e ai entrou na jogada as licitações. Outra cadeia que passamos a enxergar foi a do servidor público ele é mais perene do que um cliente de compra de produtos do banco, ele dá um retorno maior do que o setor privado. Não adianta você querer captar um a um dos servidores sendo que aqui setor público eu não consigo. As associações também foram um ponto forte para o banco se aproximar.

E12: Acho que o curso auxiliou bastante na visão do que é uma política pública, qual a importância do Estado e qual o papel do banco na concepção dessa política. As micro empresas, por exemplo, para as quais nós emprestamos, através de recursos públicos, se tornam clientes do banco e vão ser aproveitadas como clientes em outras áreas.

E13: Acho que temos uma dificuldade em identificar isso, porque aqui dentro a gente trabalha com o Governo, e quando você vai para os fornecedores de Governo tem uma 
outra área que trabalha isso. Então você não pode atacar direto por aqui; você tem que vender junto aos Governos e convencer, internamente, que eles têm que atuar lá. Por exemplo, vamos pegar o caso típico de fornecedores, onde o Governo é o maior comprador de bens e serviços. Quando você trabalha com o Governo e propicia compras com agilidade, você também está gerando negócios para os fornecedores, com isso, você está criando oportunidades para fazer adiantamentos. Só que quem trabalha com os fornecedores são as outras áreas. Então a gente tem buscado muito essa integração para atacar a cadeia produtiva. Às vezes você precisa se relacionar para entender como é que funciona a máquina "setor público". Não é simplesmente ganhar dinheiro. Você tem que saber como ganhar dinheiro, o "negociar". Esse curso foi fundamental para isso, pois eu aprendi qual é o papel do Banco do Brasil.

E17: Como cadeia de valor a gente entende a cultura do servidor público e do fornecedor. Nesse contexto, ele se aplica aquele acirramento do mercado, onde o banco por ser líder tem que defender sua liderança, sendo ele muito atacado pela concorrência no sentido de disputa; então o que a gente sente é que o mercado modificou a maneira de lidar com essas coisas, por isso eu não consigo perceber que a nossa formação com o MBA tenha ajudado nesse assunto, porque esse assunto mudou a forma de ser tratado no mercado - antes você não ouvia falar de prefeitura vendendo folha de pagamento - é algo recente de quatro (4) anos. Foi uma quebra de paradigma, em que o ente público ele chega à conclusão de que uma instituição financeira que vai prestar o serviço de pagar os fornecedores dele, ele não vai pagar nada para essa instituição e ainda vai cobrar para que essa instituição financeira faça esse serviço para ele.

E15: No caso de repasses voluntários, o que a gente tem tentado manter é a participação do banco nesse mercado; então, se eu detenho $75 \%$ de domicílio dessas entidades que recebem transferências de Governo, eu brigo para manter isso no Banco do Brasil - que essa conta seja rentável e quando a gente negocia com entidades as contas devem ser abertas por nós, justamente para tentar criar barreiras de saída. Então isso confunde um pouco conhecimento com atividade bancária. O grau de conhecimento que você detém em alguns casos não se aplica porque os fornecedores, em sua maioria, são do setor privado, sendo que você tem um pilar inteiro que cuida de fornecedor do setor privado. A cadeia que a gente pode acompanhar e explorar é o setor público, onde o conhecimento seria aplicado. Então eu acredito que, hoje, a cadeia produtiva do setor público está melhor assistida - o Governo Federal tem pessoas capacitadas e Estado e Capitais também têm. Imagino que, hoje, eles têm uma capacidade maior de gerar negócios, tentando aproveitar a cadeia produtiva.

E16: A cadeia de valor que a gente mais aproveitou foi a de Estados e Municipios, que estão relacionados com o Governo Federal. A gente foi se aperfeiçoando para tratá-los como clientes e não como duas coisas isoladas.

E20: A cadeia, na realidade, é atendida por outros pilares do banco. A gente percebeu que cresceu muito a relação tanto com pessoa física como com pessoa jurídica, em função dos negócios da área de Governo. O não-governamental foi meio que fatiado dentro do banco; então não ficou "isso" na área de Governo, mas em outras áreas do banco.

ESE1: Em novos negócios eu diria. Ele consegue enxergar além daquilo que é o básico, que é você pagar a folha de pagamento e fazer a gestão financeira. A partir do momento que você enxerga que a gestão financeira pode ocorrer de diversas formas e a oportunidade que você tem de gerar novos negócios...

\section{Ampliação de negócios - Apêndice 1 - Item 3b ii}

iv. incremento de novas contas; 
E9: Ocorreu é óbvio. O concorrente assustou-se, pois nós ganhamos muito mercado e estamos ganhando cada vez mais.

E1: O que eu posso dizer é que alguns clientes que até então ficavam mais distantes da gente como, por exemplo, o Poder Legislativo, no qual só se via pessoas fisicas, hoje se percebe que ele pode, de alguma forma, estar nos auxiliando para que a gente receba informações, como projetos de leis e tudo mais. Então alguns públicos como Universidades - o que é esse universo de Universidades - o próprio INEPAD, as próprias fundações de apoio e pesquisa, podemos ter negócios com esses clientes, porque não? Então a gente passa a fazer um estudo maior sobre os nichos e dai não entender só o "poder esfera", a administração direta e indireta. Dentro da indireta, como é que funciona uma fundação pública, uma empresa pública, uma sociedade de economia mista. Isso faz com que a gente passe a enxergar determinados clientes que até então passavam despercebidos.

E9: Após o curso, até mesmo com a criação do pilar, adquirimos várias e várias contas, várias prefeituras aderiram à nova percepção de mercado. E eu acho que tudo isso vem da seqüência natural de você adquirir conhecimento, o relacionamento.

E13: Acho que não podemos dizer que aconteceu em função disso, mas o curso foi um dos fatores.

E9: O curso é um dos fatores que fortaleceu o banco na entrada do mercado. Foi a questão da aquisição do conhecimento, mas não é o único fator.

E12: Talvez para o pessoal da agência, essa questão de agregar clientes é muito mais visivel, tendo sido o curso muito mais importante nesse sentido.

E17: Nós temos uma situação relativamente atípica... o Banco do Brasil tem relacionamento negocial com todos os entes públicos, mas o nível desse relacionamento varia de lugar para lugar. O Banco do Brasil tem mantido a sua posição no mercado, mas não dá para registrar um incremento ou uma redução na quantidade de clientes.

E20: Na realidade, a gente tem observado recentemente que você perde uma conta aqui - eu sei que isso dá para associar com o MBA - e sabe que tem que arrumar uma ou duas para poder compensar aquela, surge um monte de idéias criativas para você conquistar.

E20: Eu não sei. Vamos imaginar o seguinte: nós temos a superintendência "rede Varejo" e outras regionais; uma forma talvez de você mensurar isso seria ver a evolução de negócios de Governo na área de atuação desses gerentes regionais que fizeram o MBA. Outra coisa também é ver novas prefeituras conquistadas e novas contas conquistadas, sempre olhando sobre esse prisma, porque na rede Governo só tem mesmo evolução de negócios, mas na rede Varejo esse crescimento possa ser mais palpável.

ESE 1: o que a gente percebe é que o gestor público valoriza muito a capacitação do interlocutor. Então eu acredito que a gente tenha, mas fica dificil para a gente, principalmente porque a gente não tem o relacionamento com o cliente, de quantificar isso. Porém, a qualificação do interlocutor e até a própria capacitação para que ele consiga enxergar negócios, onde antes ele não via, permite que você tenha novas contas, em função da capacitação.

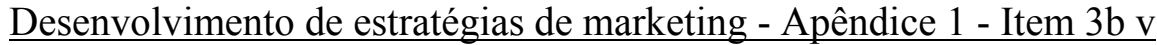

v. desenvolvimento novas estratégias de marketing junto aos clientes da área

\author{
governo;
}


E1: O marketing da área de Governo ainda, na nossa percepção, existe só como uma visão de valores do banco. Esse ano que a gente está tentando fazer algo mais palpável com nichos. Então, por exemplo, falar de um produto específico é mais uma questão institucional.

E1: Essa área faz um link com a diretoria de marketing. Então quando você tem que fazer alguma campanha ou divulgar algum produto, essa diretoria faz um link com a área de marketing, tendo ela, teoricamente, os conceitos de Governo. Algumas pessoas dessa área até fizeram o MBA, basicamente o Toninho. Acho que a mudança principal foi com relação à linguagem, porque antigamente se enxergava mais as pessoas físicas e jurídicas.

E7: Junto com o marketing fizemos folders, filmes, para o setor público e judiciário, na época (da realização do curso).

E13: Uma das matérias abordadas pelo curso fala sobre a questão da forma de atendimento, da parte de logística. Então a gente tenta seguir o material que foi repassado, pela área específica, para definições de análise de rede.

E9: Eu vou até mais longe. Havia uma necessidade de você implantar o nome "Poder Judiciário" do pilar Governo no mercado. E você faz isso mostrando a cara, indo ao encontro do cliente e conversando com ele. Mas você tem que ir a ele com um ingrediente maior, que é o conhecimento. Logo, isso gerou um marketing direto através do conhecimento e você conseguiu difundir tudo isso.

E14: Ai ela se confunde um pouco com a própria diretoria, porque como se criou a diretoria e aí veio a necessidade e a criação do curso, ao mesmo tempo a gente estava desenvolvendo o marketing. Então essa sua questão é meio difícil da gente conseguir separar.

E16: Foi o que ficou devendo o curso nesse ponto, pois eu esperava mais. A gente já tinha um trabalho incipiente e uma necessidade de fazer a segmentação, dar esse degrau em relação a Estados e Municípios - Poder Judiciário, Legislativo e Executivo ter uma visão mais segura sobre isso.

E15: As campanhas vão sempre melhorando, você percebe que agora é hora da gente falar de outra forma, então, hoje, quando você começa a preparar a campanha de abordagem, você pensa em não focar somente o produto, mas focar o meu papel como prestador de serviço e não vendedor de produto. O Estado mudou, então se eu conseguir me juntar a ele talvez eu tenha mais sucesso, do que eu teria se simplesmente dissesse a ele o que eu tenho para vender-lhe. Nesse ponto de vista eu acho que o conhecimento de setor público é relevante, ainda que não determinante.

E14: É exatamente isso: você tira o foco do produto e passa para o cliente; o banco passou por isso. Mas no curso, especificamente, essa abordagem eu não tenho.

E17: Mas assim... no contexto de campanha publicitária, dá para dizer sim que teve uma mudança na forma do banco abordar, tanto que nós somos uma campanha com foco no setor público - soluções para incrementar receitas e para reduzir despesas do ente público. E essas campanhas, como foram feitas dentro da diretoria, com certeza teve a influência da capacitação que a gente trabalhou. Então campanhas publicitárias com viés no setor público dá para dizer sim que teve uma mudança em função desse processo (do curso).

E20: É um tema delicado esse, mas que tem muito a ver com a propaganda institucional do banco mais diretamente com posição de marketing.

E21: As vezes até não teve... o cartão corporativo, por exemplo, como é que foi bombardeado em uma grande iniciativa; de repente faltou uma estratégia.

Entrevistador: Teve definição de segmentação que foi resolvida por trabalho de monografia? 
Todos: A gente não teve acesso direto a isso não.

E19: Funciona no caminho inverso: eu diria que muitos dos temas desenvolvidos no $M B A$ foram idéias aqui de dentro, algo que estava adormecido por alguma razão e que foi desenvolvido no curso; precisaria saber se foi aplicado.

ESE1: Marketing é uma coisa dificil porque a gente trabalha tão pouco. Mas quando você fala do projeto de encarteiramento (desenvolvido como Trabalho de Conclusão do Curso) acho que isso, basicamente, é marketing - modelo de relacionamento - que é um dos quatro (4) P's do Marketing. Basicamente, você está falando em praça aí, porque o banco adotou um modelo que consiste em você ter o encarteiramento... será implementado em 2006.

\section{$\underline{\text { Modificação de processos internos - Apêndice } 1 \text { - Item 3b vi }}$}

vi. modificação de processos internos a partir do aprendizado do curso;

E8: Na realidade, você conhecendo o cliente e os aspectos legais dos produtos, você acaba aplicando isso nos seus processos internos para instituir pontos de controle, por exemplo. Agora, uma ligação mais direta, acho mais difícil de dizer. O curso deu mais segurança aos produtos em termos de imagem legal. Você diminui os seus riscos dentro dos seus processos.

E13: Acho que o próprio trabalho de equipe também foi importante. A questão da normatização de assinaturas também - "quem é quem”, "o que autoriza o que”, "quem pode e quem não pode" e "qual o instrumento legal que pode ser utilizado".

E8: Acho que no pilar "licitações" isso é bastante interessante porque muita coisa mudou.

E17: Acho que a questão legal, a qual precede qualquer outra.

E15: O fato de você conhecer com maior ou menor profundidade não é relevante quando a lei determina o que você tem que fazer. E a característica nossa aqui é ser muito delimitado por lei. Como o Governo trabalha muito no conceito de caixa único, então não tem o que aponta negociar, sendo a lei mais de procedimento - é muito mecânico nesse aspecto. Logo eu não pude observar isso; a gente continuou com as rotinas e com a maneira de comunicar a rede da melhor forma.

E16: Acho que, o que pode ter contribuido é o fato de ter diminuído o stress que poderia haver com a rede de entender muito mais a resistência nossa de passar alguma coisa do que isso ser decorrência de uma característica do Governo Federal. Então como o pessoal da conta fez o curso também, acho que isso pode ter contribuído para dar claridade para eles do que porquê isso ocorre - não é por maior importância da diretoria - é uma característica própria do cliente mesmo.

E15: Acho que, quanto mais você disseminasse condições negociais, ou eventos com os quais lhe ocorreu, para servir de exemplo para outros - se as decisões fossem mais descentralizadas na Federação - talvez contribuísse.

E20: Eu acho que, na minha avaliação, objetivou muita coisa. Ficou muito clara a questão dos grandes processos do Governo - o Governo arrecada, gerencia, paga e presta contas. Então tudo foi muito estruturado. A gente começou a vender essa visão para as pessoas na medida em que começamos alocar as informações dessa forma. Você acabou produzindo uma visão dos grandes processos de Governo. Eu diria que os processos ficaram mais delineados (adequados).

E19: Houve sim mudança nos processos internos. 
ESE1: Com certeza isso influenciou. Tem uma coisa que me incomodava, particularmente, que a gente não tinha um LIC de abertura de conta corrente para entes públicos. Eu não fiz o curso, mas isso era uma coisa que me incomodava porque "como é que uma agência, lá do interior da Paraíba, ia saber se ela podia abrir uma conta para uma prefeitura /qual era a documentação que ela precisava exigir para abrir uma conta corrente de uma prefeitura?" Se você pegar o LIC existente hoje, você vai ver que ele tem consistência jurídica, tem quais são os documentos que você exige, como é que se movimenta uma conta.

Em continuação,

ESE1: A gente ouviu tanta gente para fazer esse LIC que, de uma forma ou de outra, o pessoal que fez o curso acabou contribuindo, por exemplo o Maurício e o Rabelo. Não dá para estabelecer um nexo de causalidade direto, mas com certeza tem influência

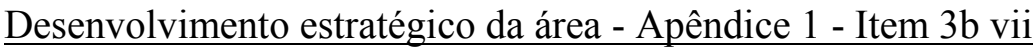

vii. planejamento ou da implementação de mudanças da área governo devido ao programa;

E2: Como já foi citada, a questão das superintendências que é uma nova proposta organizacional, um novo modelo. Até mesmo porque antes você via que o poder Federal demandava muito mais, mas hoje se tem a importância do Judiciário, dos Estados e Municípios.

E3: Podemos até dizer que houve uma reorganização interna em virtude disso tudo.

E17: A diretoria de Governo, nesses últimos quatro (4) anos, passou por várias mudanças na sua conformação - na sua estrutura. Continuo com aquela dificuldade de fazer qualquer vinculação com o conhecimento obtido no MBA, mas a diretoria em si teve muita mudança; tanto que a rede de agências foi criada nesse periodo, as superintendências Estaduais também (ano passado).

E17: Houve mudanças e essas mudanças foram sempre na busca da agilidade de se adequar à realidade do mercado, buscar melhor dinâmica de sinergia - de elo.

\section{Desenvolvimento humano - Apêndice 1 - Item $3 \mathrm{~b}$ viii}

viii. multiplicação de conhecimento interno após sua participação no MBA Gestão Pública;

E2: Foi encaminhada uma cópia da monografia do Ismael para diversas agências e equipes para conhecimento de todos.

E1: Com relação à nossa monografia, ela foi entregue para a área que cuida do atendimento, já rendendo uma visita e entrega desse trabalho. $O$ que se percebeu, pelo menos nas turmas iniciais, é que essa especialização estava em um nivel muito acima do que a gente precisava naquele momento, e ai que surgiu a idéia do auto-instrucional e 
do negócios com o setor público; você dá uma base para todo mundo e depois especializa.

E15: Eu, particularmente, acho que melhorou bastante, porque você tem o que compartilhar. Antes você associava à causa e efeito, mas agora você tem como trocar e passar informações já mais trabalhadas, com considerações.

E13: Principalmente na questão das monografias, as quais foram disponibilizadas intranet. Tiveram algumas apresentações, alguns casos críticos que foram priorizados por exemplo o de segmentação. Tem também a questão do relacionamento com a metodologia. Houve uma integração legal com o pessoal das agências.

E12: fora as monografias, eu não vi um esforço sistematizado de disseminação do curso internamente.

E20: eu fui indicada logo depois que eu conclui o MBA, até em função da monografia, para trabalhar no auto-instrucional, que é um curso para disseminar os conceitos do mercado "setor público". Eu acho que eu consegui materializar o que eu aprendi no $M B A$, sendo que depois eu ainda tive a oportunidade de trabalhar no desenvolvimento de outro treinamento de nivel instrumental, que foi o grande desafio e bastante interessante, que foi o tal do "Negócios com o Governo" (GOREN). Eu acho que é um conhecimento importantíssimo em qualquer área do banco, inclusive para a nossa área - quem está na EO - obrigatoriamente nosso planejamento tinha que passar pelo conhecimento de Governo.

E20: o auto-instrucional foi disponibilizado para o banco, não para a diretoria. $O$ segundo, de nível instrumental, foi para o nível gerencial - o primeiro para um público de 45.000 pessoas e o segundo para 3.500 pessoas.

ESE1: o próprio curso gerou a necessidade de você desenvolver alguma coisa intermediária, além da multiplicação natural - um gerente da agência, na hora em que ele vai tomar uma decisão ou orientar um comportamento da equipe dele, vai estar, a todo momento, se valendo do conhecimento dele para fazer isso - e isso vai acabar influenciando as demais pessoas. A grande sacada de ter disponibilizado o MBA foi ter gerado pressão para que a gente tivesse essa opção de treinamento mais disponível; as pessoas começaram a perceber que elas tinham que conhecer mais.

\section{Resultados Obtidos para a Quarta pergunta específica}

A quarta pergunta específica investigada é: Como se classificam os resultados obtidos no programa MBA Gestão Pública com base na Teoria da Vantagem Competitiva Sustentável? (BARNEY, 1991).

Desta pergunta deriva-se o objetivo específico de classificar os resultados obtidos no programa MBA Gestão Pública com base na Teoria da Vantagem Competitiva Sustentável (BARNEY, 1991). 
A classificação dos dados de pesquisa por meio da Teoria da Vantagem Competitiva Sustentável foi tomada em razão das características definidoras do presente estudo.

Seguem-se os relatos dos participantes dos grupos focais, cabe observar que, conforme previa a metodologia, antes de pedir que os participantes dos grupos focais relacionassem os resultados do treinamento com os atributos de VCS foi explicado a eles, sucintamente o significado deste conceito, exemplificando-o e esclarecendo dúvidas surgidas no decorrer das entrevistas.

\section{$\underline{\text { Atributos Valiosos }}$}

A presença de atributos valiosos na Diretoria de Governo, originados com base no treinamento foram investigados no Apêndice 1, item 4a:

a. Um projeto que seja considerado de valor diferenciado pela diretoria do Banco, vinculado ao treinamento e que possa ser considerado valioso.

Foram obtidas as seguintes respostas:

E1: O cartão de pagamento ainda está incipiente, um teste, mas depois com certeza será algo valioso.

E5: A segmentação entraria aí, porque a filosofia do banco era a de agregar valor. Não existia ali a pessoa física, a pessoa jurídica e o Governo. Não havia a especialização exigida, então você trabalhava tudo em um mesmo pacote. Na realidade, todo mundo cuidava de tudo.

E7: As exigências eram diferentes e muito grandes, e você focava mais uma área do que a outra. Então a segmentação tornou-se valiosa.

E1: Os próprios produtos voltados para a área de Governo agregam valor para conseguir captar clientes de outros pilares, assim como também os produtos de pessoa fisica agregam valor para a gente estar trabalhando com o segmento do setor público.

E3: quando o jogador Banco do Brasil entra ele tem uma capacidade de mobilizar e de fazer diferença.

E13: As pessoas certas nos lugares certos. E isso é uma dificuldade muito grande porque a gente tenta o mínimo possivel de rotatividade em função da especialização. Toda vez que vem uma nova pessoa para cá, a formação é complexa.

E13: O simples fato da questão da legalidade na área Governo: tem que, por lei, estar escrito, para você ter a possibilidade de trabalhar com algo. Então isso é valioso também. 
E12: A formação de novos funcionários é muito difícil e demorada. Talvez o curso tenha servido para acelerar esse processo, principalmente com relação a novos funcionários da área estratégica.

E15: a capacidade de propor soluções (em concordância com o entrevistador).

E14: É o conhecimento que você passa a ter do seu cliente que te proporciona, não só antecipar, mas entender o que ele está querendo de fato.

ESE1: Em cada um desses componentes eu só consegui pensar em uma coisa: conhecimento. Conhecimento do setor público, na indústria bancária, é raro, é valioso. Aonde que nós temos oportunidade de nos diferenciar dos concorrentes? É no gap que existe entre como eles enxergam o setor público e como nós enxergamos o setor público - só nesse gap é que nós vamos conseguir construir uma vantagem competitiva que seja sustentável. E hoje, o que eu vejo nesse gap é justamente o conhecimento, o qual permite que você enxergue necessidades onde os outros não consigam ver.

Mencionado no contexto de modificação de processos internos, E20 destacou "Está mais relacionado à forma de planejar".

\section{$\underline{\text { Atributos Raros }}$}

A presença de atributos raros na Diretoria de Governo, originados com base no treinamento foram investigados no Apêndice 1, item 4b:

b. Um projeto que seja considerado único no mercado bancário no contexto da Diretoria de Governo vinculado ao curso, que possa ser considerado raro.

As seguintes respostas foram obtidas:

E2: Dificilmente você vai encontrar uma outra empresa ou uma instituição financeira que tenha um núcleo institucional com a qualificação e conhecimento dessa área como o banco. Isso aí seria um atributo raro e valioso.

E3: O comprometimento também é um desses atributos.

E1: O cartão de pagamento, mencionado anteriormente, é um produto que pode ser considerado raro.

E4: Relacionando isso com o curso, o que se trabalhava antes era muito focado no credor - o nosso cliente é o Tesouro Nacional - e com o curso a gente passa a ter uma visão que é a do outro lado que é o devedor - Estado e Município que está em outra área. Você passa a enxergar o trabalho que você está fazendo de uma forma tão mais ampla, como aquilo interfere na situação do país.

E1: O banco forma e, em alguns casos, esse conhecimento está indo para a concorrência. A pessoa se torna mais competitiva. Ou seja, mobilidade do recurso, que deveria ser de difícil substituição, acaba sendo uma ameaça nessa situação. 
E13: Talvez aquela preocupação de você não sugar o seu cliente. Eu quero que ele fique satisfeito e, às vezes, até a gente acaba abrindo mão de muitas receitas em função disso. Eu acho que uma vantagem rara que a gente tem é exatamente o papel de servidor público; o fato de você, de um lado, ser o agente de políticas públicas do Governo e, de outro, você estar no mercado, é uma vantagem competitiva que a gente tem em relação à concorrência nossa. O curso veio a ajudar a gente nesse aspecto, de reforçar mais essa questão de auxiliar o Governo na importância do que é o Estado e a importância do Estado para a sociedade. Então você torna o papel do banco público muito mais importante na visão do cliente.

E17: Não sei se fica algo muito abrangente, mas a especialização e a experiência do Banco do Brasil no atendimento ao setor público é uma peça rara em termos de mercado, tanto que o mercado demora anos para desenvolver ou compra profissionais que têm a visão do setor público para irem trabalhar com ele (Governo).

E16: Eu acho que o que temos de raro na vantagem competitiva é a questão da marca do banco. Tanto que todos chamam o Banco do Brasil de banco, sendo que os outros são "os outros". Mas a gente vê o esforço de modernizar a relação do Tesouro com outros bancos, buscando outras parcerias. Porém, se antes nós éramos a única opção, hoje realmente nós somos a melhor - o Tesouro pode deixar de fazer comigo e buscar uma relação com outros bancos, mas não porque busca algo melhor, mas porque procura algo novo - modernizar.

E15: Por ser um banco público, a vinculação com o Governo caminhava sempre em uma linha muito tênue. Em uma hora o gestor público quer eficiência e baixo custo, e vai ao mercado - você não quer fazer para mim então eu vou ao mercado-mas se você fizer eu fico com você. Então, nós temos produtos exclusivos, funcionários preparados e conhecemos que o ente público é importante para nós - quando você alia esse modo de ver do ente público, você tem uma concepção diferente de banco (rara).

E20: Nessa área de Governo a gente sai na frente em muitos itens, mas que acabam sendo copiado. Porém, há ainda um respeito pelo conhecimento técnico nosso, até porque a gente recebe muitas ligações de outros bancos, as quais funcionam como consultoria. Mas eu não sei se isso está associado com o MBA.

\section{$\underline{\text { Atributos de difícil imitação }}$}

A presença de atributos de difícil imitação na Diretoria de Governo, originados com base no treinamento foram investigados no Apêndice 1, item 4c:

c. Um projeto que por suas características seja de difícil imitação por outra instituição

bancária, que tenha sido gerado no contexto do curso, que seja difícil de imitar.

Foram obtidas as seguintes respostas:

E1: É como eu te falei: o conhecimento é dificil de imitar, mas de repente a mão de obra sai daqui e...

E4: Acho que além do conhecimento, seria essa sintonia que você fecha com o grupo. Porque você vai interagindo em tantas áreas e com outras pessoas tão diferentes, que você acaba formando um comportamento mais similar. 
E13: Um papel que é dificil de imitar também é o conhecimento que a gente tem do mercado, porque quando você compara com outros bancos, eles são regionais. O nosso banco não, ele tem que falar a língua do país inteiro. Então cada Governo tem uma intenção diferente, cada partido tem uma intenção diferente. Uma hora a prioridade é a educação, na outra hora são os repasses. O Banco do Brasil faz tudo, sendo difícil você conseguir isso em um outro banco.

E13: As soluções para o Governo que nós temos aqui, de repasse aos Estados $e$ Municípios. E isso está relacionado com o curso, na forma do funcionamento do Estado, na questão da República, o que são os tributos estaduais e municipais, qual tributo que é federal, por que ocorrem esses repasses federais, tudo isso - onde há espaço para crescer, a questão da riqueza do país. Licitações também é algo raro que dificilmente algum outro banco vai querer atacar.

E15: Não é fácil você tirar um clube - tirar um banco - vir para outro clube de banco e colocar o Governo Federal. A maturação de um produto para o Governo Federal é algo dificil de imitar.

E14: Uma vez em que eu participei de um programa do Governo, o Tesouro resolveu chamar outros bancos para participar de uma reunião e todos foram unânimes em dizer que quem entende do assunto "Governo" é o Banco do Brasil; para sair rodando de pronto, nenhum deles tinha estrutura, nem conhecimento para desenvolver o produto. Então, conhecer aspectos do setor público é próprio dessa diretoria. Tanto é que eles estão levando o pessoal daqui, porque é mais fácil.

Entrevistador: Isso é difícil de substituir, então essa é uma ameaça - é o que torna alguns atributos de vocês mais vulneráveis. É verdade isso?

E17: Mas você tem uma bolsa, ou seja, você tem um contingente grande o que é diferente de você ter um pequeno número que, se for embora, foi-se a inteligência.

E14: Não é uma vulnerabilidade do banco nesse sentido que ele está falando, até porque como a gente começou a equalizar os conhecimentos aqui dentro, não existe hoje a figura do insubstituível aqui dentro do banco. Agora, por outro lado, isso fez com que os profissionais daqui fossem mais visados.

E21: Eu acho que o relacionamento com o Governo Federal.

E19: Diria também a segurança implícita.

ESE1: dificil de imitar - hoje ela seria. Eu julgo que o grande diferencial que a gente tem em relação à concorrência é essa visão ampla do cliente (conseguir enxergá-lo como um todo). Não tenho nenhum medo de afirmar que os bancos privados ainda sabem pequena parte do que significa o cliente público, mas eles estão correndo e indo muito mais rápido do que a gente está sendo capaz de andar, sendo que, daqui a pouco, eles vão chegar lá

\section{No contexto de elevação do volume de negócios da área de governo, E9 colocou:}

O mercado Poder Judiciário ele enfatiza-se muito na questão relacional, e você tendo um relacionamento forte junto com conhecimento, você consegue colocar barreiras para a não-entrada dos concorrentes. Então isso foi a nossa defesa de tese e, com certeza, gerou bons resultados, até porque eu aprendi com os meus outros colegas do mesmo segmento do Judiciário.

\section{$\underline{\text { Atributos de difícil substituição }}$}


A presença de atributos de difícil substituição na Diretoria de Governo, originados com base no treinamento foram investigados no Apêndice 1, item 4d:

d. Um projeto que também em razão de suas características, gerado no contexto do curso, se extinto seria de difícil substituição.

Tendo sido obtidas as respostas da seqüência seguinte:

E7: Isso é difícil porque essa área de governo é muito duradoura. Para você conquistar a confiança do pessoal que está ali, são anos de trabalho. Então existe uma dificuldade em substituir algo no qual o cliente já confia, embora a gente tente criar um meio que substitua um recurso existente.

E1: Têm determinados produtos que foram construídos ao longo do tempo. Normalmente no Governo Federal você tem um cliente e um produto. Agora a customização no que tange os Estados e Municípios é difícil, não vou dizer que pode imitar. Agora tem produtos de prateleiras, como a própria divida ativa que surgiu daqui, mas quando foi um funcionário nosso para o Santander, ele replicou o produto.

E13: Acho que difícil de ser substituído é a base de confiança e relacionamento que a gente tem. Fora isso eu não vejo nada mais.

E23: Tem que ser uma coisa mais focada no relacionamento. O que é material, hoje, pode ser descartável. Acho que a qualidade do relacionamento pode ser considerada assim.

E22: Eu acho que uma coisa difícil de substituir hoje é a própria diretoria de Governo. Você não volta mais atrás de ter uma área especializada para o atendimento desse público - não tem como você pensar o banco hoje sem ter uma área voltada para esse negócio.

E20: Mas é a mesma coisa que você afirmar que também não pode substituir o pessoal do Atacado.

E22: Não. Estou dizendo que é dificil.

E21: Está consolidado e não dá para mudar muito mais.

Em seguida houve um diálogo sobre apoio a marca:

E8: A própria marca também.

E13: Aqueles princípios fundamentais, a gente não pode abrir mão deles, segurança, por exemplo. Porque ai você sabe que, mais cedo ou mais tarde, se acaba perdendo cliente. Ás vezes é melhor você falar "não", mas ganhar a confiança do cliente, do que dizer "sim" e perder a confiança dele.

E12: Acho que isso está ligado muito à marca Banco do Brasil, pois a própria marca traduz todos esses valores citados. Ela talvez seja alguma coisa insubstituível.

Entrevistador: Mas ela não está relacionada com o curso!?

E13: Ela está relacionada com o curso na forma organizacional do Governo. A marca é do Governo, a confiança, o relacionamento e o marketing que foi apresentado. Naquela questão da forma da sociedade, do equilíbrio do mercado, tudo isso está relacionado. $A$ marca é simpática porque você está colocando o Governo com o privado. O Banco do Brasil tenta reunir as duas coisas: a modernidade e o tradicional, e o curso ensina isso 
porque ele traz todo um histórico de mercado e você acaba fazendo um link legal de como evoluir.

E15: A própria diretoria de Governo do banco representa isso, esse canal único. O ente público sabe com quem falar. Logo, se você reconhece o ente público como tal, você tem um diferencial de mercado, uma vantagem competitiva. Não posso dizer que ela seja insubstituível.

Ainda com relação ao diálogo envolvendo a marca, destaca-se E23, portanto no último grupo focal: "A marca BB de novo. Mas não está associada ao curso". 


\section{ANÁLISE DOS RESULTADOS OBTIDOS}

A metodologia do presente estudo previu que para se identificar os resultados do curso em análise fossem utilizadas as seguintes fontes de evidências: Documentos de proposição do curso MBA Gestão Pública, Grupos Focais, Entrevistas semi-estruturadas junto a UniBB e a Diretoria de Governo, além de indicadores oferecidos pelos participantes do (indicadores Diretoria de Governo, Diretoria de Marketing e Universidade Corporativa do Banco do Brasil).

Estas evidências foram demonstradas no capítulo de Resultados Obtidos na Pesquisa de Campo à página 156. Os resultados foram organizados conforme o encadeamento lógico da pesquisa, norteados pela analise seqüencial dos dados obtidos para cada uma de suas fases, iniciando pelo objetivo geral e em seguida pela ordem de aparecimento dos objetivos específicos.

Aqui se analisam os resultados obtidos, tendo como referência a proposta metodológica do estudo, o referencial teórico utilizado e as evidências demonstradas.

Quanto à apresentação das evidências e proposição das reflexões apresentadas, cabe recuperar a apropriação da técnica de estudo de caso preconizando que, ao se realizar estudos de caso, não se trata de enumerar freqüências para produzir generalizações estatísticas, e sim de expandir e generalizar teorias, tornando os achados do estudo, generalizantes e não particularizantes (YIN, 2001).

Procedendo-se a análise dos resultados, para que a compreensão do leitor seja facilitada repetir-se-á ainda uma vez cada pergunta e objetivo específico do estudo, apresentando-os conforme encadeamento lógico da pesquisa. 


\subsection{OBJETIVO GERAL}

O objetivo geral deste trabalho é conhecer os resultados do programa MBA Gestão Pública, no contexto da Diretoria de Governo do Banco do Brasil.

Antes de se proceder a análise dos resultados de pesquisa, relativos ao seu objetivo geral, cabe relembrar que conforme se explicitou na definição da metodologia da presente pesquisa, a escolha pela utilização do método do estudo de caso, é válida quando se está estudando questões do tipo "como" (YIN, 2001). A razão para esta determinação é que a questão do tipo como, é mais explanatória, pois se relaciona com questões que precisam ser exploradas no decorrer de um período de tempo, elencando os motivos pelos quais algo se deu.

É precisamente por esta razão que se escolheu esta técnica, a demonstração dos resultados corrobora o acerto do método para a exploração da pergunta de pesquisa.

Tal como se previu na metodologia da pesquisa e na apresentação dos resultados da pesquisa de campo, a análise dos dados relativos ao objetivo geral será realizada junto aos objetivos específicos e demonstram como se apresentam os resultados do curso MBA Gestão Pública, oferecendo conhecimento sobre estes resultados.

\subsection{OBJETIVOS ESPECÍFICOS}

Inicia-se a análise dos resultados obtidos, tendo em vista os objetivos específicos propostos pelo estudo.

\subsubsection{Primeiro objetivo específico}


O primeiro objetivo específico do trabalho é verficar se os objetivos de aprendizagem propostos pelo programa de treinamento MBA Gestão Pública foram atingidos como resultados na Diretoria de Governo.

Para esta finalidade, as fontes de evidências definidas como apropriadas pelo projeto de pesquisa foram os Documentos de proposição do curso MBA Gestão Pública em comparação com as informações obtidas nos grupos focais e nas entrevistas semi-estruturadas.

As evidências observadas apontam para uma similaridade entre os resultados obtidos pelo curso, declarados pelos participantes dos grupos focais, e aqueles constantes nos documentos de proposição do curso.

Considerando o primeiro objetivo do treinamento, declarações como: "entender as necessidades dos clientes...", "atuar como consultor...", "realizar cursos para prefeituras", demonstram o atingimento deste objetivo do curso que era de formar profissionais para que atuassem como transformadores e consultores em organizações públicas.

No contexto do segundo objetivo do curso, que determina que os profissionais formados pelo curso devem ter a capacidade de oferecer aos clientes governamentais do Banco do Brasil produtos e serviços de qualidade que atendam as especificidades deste setor, parece suficientemente corroborada pelas declarações: “Alguns produtos surgiram nas discussões que se teve dentro do MBA...”. "Cobrança da dívida ativa foi algo que se pensou aqui (no curso)...”. "O curso deu mais segurança aos produtos em termos de imagem legal”.

Este objetivo de treinamento encerra uma necessidade institucional da Diretoria de Governo, já que atender as especificidades do setor significa não somente suprir o mercado com soluções, mas que elas sejam legalmente adequadas.

Para o terceiro objetivo do curso, capacitar o aluno para conhecer e avaliar o setor Governo e suas relações, buscando perceber novas oportunidades negociais, um objetivo de 
treinamento claramente comercial. As declarações "termos mais condições de estarmos no mercado...", "nós começamos a identificar mais oportunidades" dentre diversas outras que constam na apresentação dos resultados corroboram o atingimento deste objetivo.

No caso do quarto objetivo do curso, que era despertar o aluno para a realidade gerada pelos mercados globalizados, potencializando oportunidades, evidencia que o programa não visa apenas identificar oportunidades, mas utilizá-las. Este objetivo parece corroborado pelas declarações: "transformar isso (o conhecimento) em oportunidade de negócio...", "segurança para propor algumas coisas".

No caso do quinto objetivo de treinamento, fala-se diretamente às organizações públicas, o gestor público deve possuir expertises suficientes e capazes de trazer ao setor público a eficiência das mais modernas e competitivas empresas. As declarações “o curso mostrou como é que a gente poderia trabalhar estrategicamente...”, “conhecimentos que permitiram que a gente promovesse mudanças" poderiam ser entendidas como uma corroboração dos objetivos de treinamento, porém, é preciso refletir sobre o objetivo declarado: “o gestor público deve possuir”.

Este objetivo de aprendizagem só poderia ser analisado quanto ao atingimento de seus resultados, se investigado junto a gestores públicos que tivessem realizado o treinamento, como não é esse o caso do MBA Gestão Pública, optou-se por interpretar este objetivo como sendo um objetivo do curso, a capacidade que este tem, de desenvolver, no participante do MBA realizado no Banco do Brasil, a competência de levar competitividade às organizações públicas junto as quais atua. Admitindo esta adaptação, pode-se dizer que o programa desenvolveu nos alunos esta capacidade, porém a mensuração deste objetivo em sentido lato está irremediavelmente prejudicada. 
No referencial teórico, viu-se em Bohlander, Snell e Sherman (2003), que uma formulação clara dos objetivos instrucionais fornecerá uma base segura para escolher métodos e materiais instrucionais e para selecionar os meios de avaliar se o treinamento terá êxito ou não.

O que se percebe no programa MBA Gestão Pública é que a formulação dos objetivos do curso tem um caráter abstrato e de difícil comparação com os resultados coletados, pode-se observar inclusive duas repetições de objetivos, sendo a primeira: objetivo 2 e objetivo 4 e a segunda objetivo 3 e objetivo 5. Entretanto, os elementos destacados pelos participantes dos grupos focais guardam forte relacionamento com a definição de objetivos do programa.

Os objetivos do programa MBA Gestão Pública, observados à luz dos resultados dos grupos focais, parecem ter sido atingidos, todos os objetivos declarados têm um conteúdo bastante voltado à capacidade de tornar o funcionário do Banco do Brasil um agente de negócios voltado ao setor público, apoiando seu desenvolvimento e criando produtos. As declarações dos participantes corroboram a afirmação de que eles foram atingidos.

\subsubsection{Segundo objetivo específico}

O segundo objetivo específico do trabalho é descrever as fases do programa de treinamento MBA Gestão Pública tendo como referência o Modelo MAIS de avaliação de treinamento (BORGES-ANDRADE, 1982), explorado na página 85. Conforme foi dito, o modelo compreende os seguintes elementos de mensuração: insumo, procedimentos, processo, resultados e ambiente, sabendo-se que o elemento ambiente deve ser observado no aspecto da avaliação de necessidades, apoio, disseminação e resultados de longo prazo.

Cabe ressalvar que neste item, a análise dos resultados de pesquisa foi fracionada. $\mathrm{O}$ aprofundamento no modelo MAIS de Borges-Andrade (1982), analisado neste estudo, assim 
como Kirkpatrick (1993), Abbad (1999) e Hamblin (1978), influenciou a composição da definição da pergunta de pesquisa e, sobretudo das perguntas específicas do trabalho, desse modo, neste tópico, em que se estuda o curso MBA Gestão Pública à luz do Modelo MAIS, em alguns momentos preferiu-se remeter o leitor aos objetivos específicos de pesquisa, que exploram determinadas questões de maneira mais abrangente e sobretudo mais aplicadas, sempre que esta necessidade se verificar será apontada no texto.

Poderia ter-se analisado todos os resultados passando pelas fases do Modelo MAIS, porém, optou-se pela análise dos resultados conforme o encadeamento que a pesquisa exigia, mais uma vez para privilegiar o aspecto de seqüenciamento lógico do estudo, facilitando a compreensão do leitor em face do referencial teórico utilizado.

No sentido de facilitar a leitura, conforme surgem as fases do Modelo MAIS (BORGESANDRADE, 1982), serão repetidas as informações que compreendem cada elemento do modelo, dessa forma não é necessário que o leitor tenha que procurar no referencial teórico o que significam quais elementos.

\subsubsection{Insumos}

Os insumos compreendem fatores físicos e sociais e estados de comportamento pretérito relacionados ao público que fará parte do treinamento.

As características dos participantes do curso revelam que o treinando deste curso tinha bom grau de maturidade profissional e gerencial, em razão dos 15 anos de experiência profissional média da turma, além de terem envolvimento com a área governo.

Ainda no tocante aos insumos, os aspectos sociais merecem destaque pelo alto nível de envolvimento observado entre os participantes e por terem apresentado elevados índices de 
motivação, tanto no decorrer do programa quanto na realização das entrevistas. Os relatórios de avaliação do curso revelam um participante extremamente satisfeito com a organização, pela realização do curso em si.

Conforme se disse, não houve coleta de dados sistematizada no sentido de se compreender os níveis de motivação dos treinandos antes da realização do curso, por inferência da análise dos dados demonstrados, acredita-se que havia bons indicadores neste sentido.

Os elementos de envolvimento e motivação são importantes preditores de sucesso de programas de treinamento conforme observado por Abbad (1999).

\subsubsection{Procedimentos}

Os procedimentos compreendem as estratégias didáticas utilizadas na realização do treinamento, incluem-se nesse aspecto procedimentos operacionais do treinamento, como o planejamento da ação e a atuação do instrutor.

O treinamento foi planejado tendo como meio a utilização de adequadas estratégias didáticas a um curso de formação de gerencial.

Foi visto no tópico Aprendizagem Individual que adultos em situação de aprendizado interessam-se por situações práticas e aplicáveis às suas necessidades (MALGLAIVE, 1995).

O adulto é capaz de tomar suas próprias decisões e por ser responsável por enfrentar as conseqüências de seus atos, desse modo, relaciona-se com o aprendizado de maneira freqüentemente questionadora (KNOWLES, 1981).

O projeto pedagógico do curso foi estruturado de forma que os ciclos fossem seqüenciais e interdependentes, possibilitando que o participante do treinamento compreendesse como o 
estado se relaciona com a sociedade, como o governo realiza seus processos e efetivamente administra, e como se realizam negócios com o estado.

Segundo relatório da Fundace (2005), este seqüenciamento permite que o aluno compreenda o ambiente macroeconômico, os aspectos organizacionais de constituição e evolução do estado brasileiro e como ele se organiza para administrar, planejar e se desenvolver. Em seguida, abordam-se nos conceitos relativos aos processos realizados pelo Estado, compras, contabilidade, finanças, financiamentos e por fim como se dá a administração das organizações públicas. Por fim o aluno compreende como se realizam os negócios do Estado.

À luz da teoria que se utilizou, pode considerar que o programa MBA Gestão Pública atendeu aos pré-requisitos básicos de realização de um treinamento, tendo sido bem planejado e bem executado.

\subsubsection{Processo}

O estudo do processo abrange ocorrências resultantes dos procedimentos adotados no treinamento, relaciona-se com características comportamentais do treinando durante o processo de treinamento. Neste aspecto, devem ser observados itens como motivação do participante (no aspecto de acompanhamento do treinamento), nível de dedicação e estudo e mesmo resultados obtidos em testes.

Neste aspecto o curso revelou um processo equilibrado e eficiente, obtendo como resposta dos alunos elevados índices de presença, em suas 5 turmas, o que reflete sua motivação em participar do treinamento.

No aspecto de notas também se pode observar a motivação e o envolvimento dos alunos considerando que tiveram 8,87 como média de suas notas. 
No tocante aos resultados de aprendizado, cabe rememorar que, para Hamblin (1978), prover o participante de um programa de aprendizado parece constituir-se no objetivo precípuo da realização de um programa de treinamento.

O programa MBA Gestão Pública cumpriu este requisito, as médias dos alunos e seus índices de freqüência apóiam esta afirmação.

\subsubsection{Resultados}

Para Borges-Andrade (1982), no tocante aos resultados, examinam-se as habilidades ou atitudes desenvolvidas em razão do treinamento, o exame deste aspecto deve ocorrer após a realização do evento e é preciso verificar que os comportamentos observados sejam compatíveis com os objetivos definidos no planejamento do treinamento. Confirmando a ressalva feita na apresentação dos resultados, também na Análise dos Resultados, inclue-se aqui a avaliação de reação (KIRKPATRICK, 1993).

\section{Reação}

Conforme se observou na apresentação dos resultados, a avaliação de reação ao treinamento revelou-se consistentemente positiva, tanto no que concerne à avaliação diária de aulas, quanto na pesquisa realizada ao final de cada turma.

O resultado demonstra um elevado índice de reação positiva dos alunos quanto ao treinamento.

Hamblin (1978) propunha que havia relação direta entre os indicadores de reação e aprendizado, já se disse que essa hipótese foi confrontada por Alliger e Janak (1989) e Abbad, Gama e Borges-Andrade (2000) que não conseguiram confirmar empiricamente a relação de 
interdependência entre reação e aprendizado, ou seja, para que o participante do programa de treinamento tenha um bom aprendizado ele não necessita ter tido uma reação favorável, ou seja, ter gostado do treinamento.

No caso do MBA Gestão Pública esta relação existe. Não se pode afirmar que uma é causa da outra, mas que ambas estão presentes. Os participantes do MBA Gestão Pública tiveram uma reação positiva ao treinamento e conforme se viu na demonstração dos resultados aprenderam com ele.

Abbad (1999) observou que uma reação positiva ao treinamento não cria relação causal de efeitos objetivos, ou impacto no trabalho, mas a autora concorda que um treinamento que foi fruto da reação positiva entre seus participantes tem uma aceitação social maior e isso torna a reflexão sobre seus efeitos menos sujeita a críticas internas de implementação, podendo se dizer que estão relacionadas a reação positiva e os resultados do treinamento.

\section{Comportamento}

Quando se estuda a modificação de comportamento de participantes de programa de treinamento pretende-se compreender o quanto o treinamento foi capaz de influenciar as atitudes das pessoas que dele fizeram parte.

Neste estudo, a atitude foi abordada com base em Dutra (2001), associado ao conceito de entrega, cabe observar que está se falando de entrega e não de resultado, ou seja, neste momento a preocupação é saber se as pessoas que participaram do treinamento modificaram seu comportamento, oferecendo uma entrega diferenciada à organização.

A idéia central de mudança de comportamento associa-se a idéia da transferência que se dá com a aplicação dos conhecimentos absorvidos no treinamento para o ambiente de trabalho. 
A análise dos depoimentos dos participantes leva a concluir que a ampliação de horizontes, a capacidade de análise de projetos, a sistematização de informações, a pró-atividade junto ao cliente, a compreensão das necessidades dos clientes e identificação de soluções, são alterações de comportamento objetivas e da forma como foram relatadas pelos participantes estão associadas com a sua participação no treinamento.

Outro aspecto de mudança de comportamento muito mencionado pelos participantes foi a mudança de linguagem e capacidade de diálogo com clientes, adotando uma postura mais segura, ampliando até mesmo sua capacidade de negociação, algumas vezes com a antecipação desta capacidade.

Os participantes mencionaram ainda a capacidade de observar mais criticamente as ações do Governo, interpretando decisões políticas e desenvolvendo maior empatia com o administrador público com maior visão histórica sobre os acontecimentos da gestão e da política nacional.

Foi relatada ainda a mudança de comportamento ao identificar oportunidades de crescimento profissional, o que nas palavras dos participantes provoca a aquisição de uma nova postura.

Finalmente houve relatos que podem ser relacionados a modificações na auto-estima dos participantes do programa ao afirmarem, por exemplo, que houve mudanças na relação de poder da diretoria em razão do conhecimento obtido e que passou a haver maior relação de consideração entre os membros da diretoria e os técnicos, detentores de maiores conhecimentos.

Conforme Kirkpatrick (1993) a mudança de comportamento refere-se à transferência do que foi aprendido num curso e que se possa exigir de comportamento no trabalho. Na mesma linha Milione (1999) considera para a mensuração de comportamento, o mais indicado é obter indicadores de mudanças junto àqueles que participaram do treinamento, partindo-se do princípio 
de que ninguém melhor do que o ocupante do cargo para compreender as transformações de seu comportamento em razão do treinamento.

Mais recentemente, Pantoja e Borges-Andrade (2004) explicaram que a transferência pode ser verificada quando a mudança de comportamento ocorre em atividades "não equivalentes às anteriores, ou é verificada em situações distintas daquelas em que ocorreu uma transferência de aprendizagem", ou seja a transferência só pode ser confirmada quando enfrenta a dificuldade que a constitui, quando um conhecimento é adquirido e incorporado por uma pessoa em uma situação de aprendizagem stricto sensu e transferida para uma situação de trabalho.

As evidências observadas como resultados da pesquisa de campo são consistentes e permitem afirmar que o programa de treinamento causou mudança de comportamento nos participantes do treinamento.

Cabe observar que conforme adverte Hamblin (1978) a mudança de comportamento deve ser minimamente programada, ou seja, o programa de treinamento deve propor uma modificação de comportamento e posteriormente verificar se ela ocorreu. No caso do MBA Gestão Pública, não havia um roteiro de comportamentos que deveriam ser modificados, tão menos um perfil de quais comportamentos deveriam ser exibidos. Em que pese o fato de o treinamento ser novo e não haver indicadores pretéritos que pudessem ser comparados, não houve a sistematização ou delimitação de quais comportamentos deveriam ser modificados ou como eles deveriam se apresentar em observação final.

Para fazer justiça à atividade prática, que nem sempre se irmana da organização dos procedimentos científicos, pode-se dizer que a declaração de objetivos do treinamento, apresenta um conteúdo comportamental e conforme já se disse há evidencias para observar que, com base nos relatos observados, os objetivos do treinamento foram alcançados. 
Ainda neste contexto vale relembrar que Farnsworth (1976) observou que treinamentos de cunho gerencial, muitas vezes trazem mudanças de comportamento inesperadas e que o desenvolvimento da visão gerencial, se houver, por si só, é uma importante mudança de comportamento provocada pelo treinamento.

\section{Resultados}

Os resultados apontados pelos participantes podem ser divididos em resultados de apoio e resultados tangíveis. Os resultados de apoio estão relacionados à formulação de estratégias da Diretoria de Governo e do próprio Banco do Brasil, de capacitação de longo prazo, de planejamento, e os resultados tangíveis são aqueles imediatamente obtidos com a realização do treinamento.

Classificados aqui, como resultados de apoio mencionou-se a capacitação para lidar com o setor público sem a qual seria mais difícil a possibilidade de realização de negócios, tendo sido mencionada ainda a capacidade de detectar problemas cujas soluções podem estar no banco.

A ampliação do conhecimento, com maior segurança para ir ao mercado ou ainda a bagagem obtida que oferece condições de buscar novos negócios e novos conhecimentos no mercado foi outro resultado apontado, bem como a compreensão da cultura do cliente governo.

Os participantes mencionaram ainda um ganho de qualidade no relacionamento da Diretoria com os profissionais da Rede do Banco (agências), considerando que a partir da realização do programa aqueles dele participaram, passaram a ter capacidade de interpretar pedidos de clientes governo que antes eram apenas encaminhados a Diretoria de Governo, sem que houvesse análise prévia de viabilidade.

Foram apontados como resultado do curso a estruturação do Pilar Governo, uma consolidação organizacional do Banco do Brasil por segmentação de atendimento. 
Foi mencionada ainda a capacidade de formulação de estratégias de abordagem ao ente público.

Destaque-se ainda que houve diversas menções à abertura de visão dos participantes, em outro momento mencionada como ampliação de horizontes, identificando oportunidade de atuação do Banco junto ao ente público.

A capacidade de análise para o direcionamento de recursos foi apontada como resultado do treinamento, indicando que o participante do treinamento teria um maior preparo para analisar a concessão de recursos.

Dessa forma, os participantes dos grupos focais atribuíram resultados diretamente ao treinamento sem contudo, estabelecer um nexo de ligação causal entre ele e o resultado. Ao afirmar, por exemplo, que o crescimento dos resultados da Diretoria está ligado aos MBA's, E20 reputa estes resultados ao curso, esclarecendo que ele se encontra "num contexto de maior exigência por capacitação" concluindo que o "crescimento ou manutenção dos negócios da Diretoria pode ser atribuído, em grande parte, à capacitação do pessoal”.

Ruas (2001) considerou que a transferência mútua de conhecimento da organização com o mercado está relacionada com os resultados de um treinamento empresarial.

Observa-se, pelos relatos das entrevistas realizadas na UniBB que não houve a sistematização dos resultados do treinamento, já que apontou-se como maior resultado do treinamento sua repetição em cinco turmas.

Conforme Mager (1977), a falta de definição de objetivos claros na elaboração do treinamento dificulta a mensuração de seus resultados.

Ainda por meio da análise dos resultados das entrevistas da UniBB, em ESE3 observou-se a não avaliação dos resultados do treinamento MBA Gestão Pública, já que o curso não foi definido como objeto de avaliação desta área. 
Eboli (1999) define a importância da universidade corporativa na gestão dos resultados de treinamento, no caso do curso estudado, não houve a realização desse estudo pois o curso não foi definido como prioritário para se avaliar seu resultado final.

Quanto aos resultados tangíveis, analisando o que foi dito pelos participantes, em nível mais objetivo, podem ser mencionadas a estruturação da segmentação das superintendências, a criação do cartão de pagamentos do governo federal e a cobrança da dívida ativa, mencionados nas respostas dos participantes ao item que tratava da primeira pergunta específica, que comparou os resultados do treinamento com os objetivos propostos pelo treinamento.

Estes resultados podem ser isolados e positivamente associados ao programa MBA Gestão Pública, pois foram gerados a partir de trabalhos de conclusão deste curso, disponíveis na intranet do Banco do Brasil.

De forma espontânea foi se firmando a conclusão de que os principais resultados obtidos de maneira sistematizada estavam associados à realização dos trabalhos de conclusão de curso. A partir dessa conclusão chegou-se a necessidade de ampliar a coleta de dados junto a esta fonte de evidências.

Houve a demonstração de poucos resultados, confirmando-se a implementação de dois projetos, a desistência de um deles (motivado pela falta de interesse da prefeitura beneficiada) e tendo-se um deles sem informações conclusivas.

Destaca-se que alguns participantes demonstraram receio em definir que a ação de treinamento, de maneira isolada, tenha gerado resultados diretos, neste sentido:

\footnotetext{
E2: Essa questão do resultado da educação é complicada como uma outra questão que a gente tem com relação aos resultados de marketing e propaganda. Como é que você mensura uma ação de Propaganda e Marketing? Tem a questão da imagem, a questão do Top of Mind, de você ter a sua empresa vista pelo mercado como sólida. Então você mensurar isso objetivamente - esse ganho aqui foi em função daquele comercial - é bastante dificil.
} 
Foi esclarecido neste ponto que o que se buscava era indicadores de relação e não o estabelecimento de nexos de causalidade que pudessem ser considerados frágeis.

A dificuldade no estabelecimento da causalidade entre o resultado observado e a realização do treinamento foi prevista na composição da metodologia do estudo. Como meio de prevenir esta dificuldade, a questão foi abordada individualizadamente nas entrevistas e grupos focais, por meio da pergunta "Como se pode relacionar a realização do programa MBA Gestão Pública com seus resultados na área governo?” elaborada no Apêndice 1 - Item 3c.

No referencial teórico viu-se, por exemplo, em Baldwin e Ford (1988) ${ }^{11}$ apud Pantoja e Borges-Andrade (2004), que a transferência do treinamento para o trabalho pode ser vista como uma aplicação, uma generalização ou como a manutenção, no ambiente de trabalho de um conhecimento, habilidade ou atitude adquirido por meio da ação de treinamento e desenvolvimento.

Alguns dos resultados relatados relacionam-se com a manutenção o desenvolvimento de novos conhecimentos, habilidades e atitudes, neste aspecto os participantes os relataram em associação direta do curso com resultados da diretoria, envolvidos com a estratégia e o planejamento da DIGOV.

Foi mencionada de forma reiterada a capacidade de ampliação do relacionamento dos participantes do treinamento com profissionais do governo externos ao Banco do Brasil, relacionamento este facilitado pela capacidade de interlocução, ampliada em razão do treinamento, com a conseqüente elaboração de estratégias de abordagem originadas pelo relacionamento em desenvolvimento.

O conhecimento de legislação foi apontado como resultado associado ao curso.

11 BALDWIN, T.T.; FORD, J.K. Transfer of training: a review and directions for future research. Personnel Psychology, v. 41, n. 1, p. 63 - 105, abr 1988 
Novamente mencionou-se a consistência de conhecimento dos participantes ao proporem soluções junto às questões relacionadas ao cliente governo, fortalecendo o Pilar governo, organizacionalmente no contexto do banco.

Finalmente observou-se no relato dos participantes que, a gestão de produtos e sistemas por alunos do programa foi profissionalizada em razão do treinamento, de forma que a capacitação apoio o desenvolvimento dos processos internos do Banco.

Ainda quanto aos resultados obtidos, vale observar que é preciso ter cautela ao criar a relação de causalidade direta entre o curso e estes resultados, os participantes apontaram caminhos que podem ser utilizados como condutores entre o resultado e sua causa, sem que contudo possam ser apontados como geradores únicos e diretos.

A exploração dos resultados finais do treinamento está contida na terceira e quarta perguntas especificas, constantes respectivamente às páginas: 220 e seguintes e páginas 229 e seguintes.

\subsubsection{Ambiente - Avaliação de Necessidades}

O levantamento de necessidades pelo Modelo MAIS (Borges-Andrade, 1982), ampliado pelo presente referencial teórico, analisando-se a empresa, as necessidades das pessoas envolvidas no treinamento as competências a ser desenvolvidas, as tarefas a ser realizadas e as pessoas que realizarão o treinamento, devendo-se concluir o processo com a especificação das necessidades de treinamento.

Conforme prevê o Plano de Pesquisa as fontes de evidência para o Levantamento de Necessidades foram entrevistas semi-estruturadas e o resultado dos grupos focais. 
Os resultados indicaram que não houve um processo sistematizado e organizado de levantamento de necessidades, mas elas foram identificadas pela própria área demandante do treinamento.

Anteriormente apontou-se que a ASTD, (BOHLANDER; SNELL; SHERMAN, 2003), demonstrou por meio de suas pesquisas, que em razão das dificuldades de implementação a maioria das organizações não realiza o levantamento sistematizado das necessidades de treinamento, esse fato se confirmou no caso do Banco do Brasil.

No caso do MBA Gestão Pública, a identificação das necessidades, ainda que sem sistematização, foi realizada. Havia como projeto a implantação de uma nova diretoria no Banco do Brasil. Essa implantação representava a entrada do banco com maior ênfase em uma nova área de atuação e esta ação deveria ser apoiada por pelo treinamento e desenvolvimento de recursos humanos capazes de suportar seu crescimento, porém provavelmente em razão de se tratar de uma área nova, em fase de implementação e sem políticas de avaliação definidas, o processo sistemático de identificação de necessidades foi preterido. A sistematização do processo, definindo indicadores, conforme recomenda Dessler (2003), é de extrema importância, pois estes indicadores serão os mesmos a serem comparados no processo de avaliação dos resultados do treinamento. Esta especificação deve considerar objetivos e resultados esperados após o treinamento, para que se tenha conhecimento do quanto estes objetivos foram atingidos (DeCENZO; ROBINS, 1999; ABNT, 2001), no presente caso essa sistematização não ocorreu.

Ao constatar que o programa MBA Gestão Pública, surgiu como decorrência de parte da estratégia de implantação da Diretoria de Governo do Bando do Brasil, ele se apóia no referencial teórico que evidencia que as necessidades de treinamento se representam quando há um gap de competências na organização, uma diferença entre o desempenho esperado e o desempenho observado (NOGUEIRA; 1980; MILIONI, 2003). Incluindo-se ai a preparação de empregados 
para novas funções, (ABBAD, 1999). Essa visão coloca o treinamento vinculado ao de desenvolvimento das capacidades humanas instaladas na empresa como apoio às estratégias da empresa (DUTRA, 1999).

O Banco do Brasil segmentou suas áreas de atuação e criou a Diretoria de Governo com o objetivo de construir uma vantagem competitiva, simultaneamente planejou a realização de um programa de treinamento para o desenvolvimento desta área, O MBA Gestão Pública , tendo para isso analisado o ambiente externo da organização, conforme previne Cascio (1995).

Feito da forma como se observou o treinamento coloca-se como uma forma de apoio ao desenvolvimento organizacional, realçando sua validade e apoiando o alcance de objetivos estratégicos da organização.

O processo de indicação para realização do treinamento também foi investigado, sumarizando as falas dos participantes, pode-se observar a indicação para participação no programa MBA Gestão Pública pelas seguintes razões: posicionamento organizacional, necessidade de aprofundamento conceitual pela função exercida, manifestação de interesse, necessidade de sistematização e ampliação de conhecimentos relativos a área de governo por pessoas alocadas em posições estratégicas nesta área.

Uma das premissas evidenciadas pelo referencial teórico adotado (DeCENZO; ROBBINS, 1999) é que os participantes do treinamento devem estar relacionados com as necessidades verificadas e terem capacidade suficientemente representativa de, a partir do treinamento, produzir resultados que ajam sobre o foco do problema identificado no levantamento de necessidades.

Neste aspecto a técnica de levantamento de necessidades do treinamento foi exitosa, as escolhas de profissionais realizadas pelo Banco do Brasil pautaram por pessoas que estavam na 
área de governo, em níveis hierárquicos onde o treinamento seria capaz de surtir efeito e funções onde ele seria necessário.

DeCenzo e Robbins (1999), lembram que na análise das pessoas que devem realizar o treinamento deve-se optar por aqueles suficientemente relacionados à finalidade do treinamento e com boa capacidade de transformação organizacional, sabendo-se que o Banco do Brasil realizou a priorização hierárquica dos participantes da Diretoria de Governo, para em seguida ampliar o treinamento à sua base de suporte pode-se afirmar que adotou esta premissa.

No momento do levantamento das necessidades, ainda que de forma não sistemática, atrelada apenas à adequação organizacional, analisou-se o perfil de competências das pessoas que realizaram o treinamento e identificou-se a necessidade de sua participação.

Não se constatou qualquer manifestação dos participantes no tocante a necessidades surgidas no tocante à realização de tarefas, confirmando o pressuposto do referencial teórico que aproxima o conceito de análise da tarefa ao treinamento de cunho operacional (BOHLANDER; SNELL; SHERMAN, 2003)

\subsubsection{Ambiente - Apoio}

O aspecto ambiente do modelo de Borges-Andrade (1982), diz respeito ao contexto organizacional em que se insere o treinando antes e depois do treinamento. Na visão do autor o ambiente compõe-se das necessidades que motivaram o treinamento, do apoio que se tem para que o treinando desenvolva uma boa relação de ensino-aprendizagem, da forma como se deu a disseminação da oportunidade do treinamento e por fim, como se verificam os resultados de longo prazo do programa, ou seja as conseqüências verificáveis do treinamento após um determinado período de tempo. 
As necessidades que motivaram o treinamento foram estudadas pelo item anterior, aqui a técnica prevê que o foco é identificar o apoio e a gestão que se deu a realização do treinamento, antes e depois de sua realização.

A pesquisa não sistematizou a investigação deste aspecto, conceituado por Abbad (1999) e Pantoja e Borges Andrade (2004), como suporte a transferência.

O referencial teórico no tocante a este assunto lembra que o suporte a transferência tornase representativo quando o treinando retorna ao ambiente de trabalho, neste momento o detentor de novos conhecimentos deseja implementar estes conhecimentos, mas é necessário que haja suporte para isso, que chefes colegas de trabalho, subordinados e mesmo a estrutura organizacional sejam apoiadores das mudanças propostas.

No contexto do programa MBA Gestão Pública, apesar de não ter havido a sistematização do estudo do suporte, conforme se previne na metodologia no tocante aos condicionantes da pesquisa, pode-se inferir que os participantes encontraram um ambiente fértil para transferência de seus conhecimentos à organização.

É válido observar que o curso aconteceu no contexto de implantação da Diretoria de Governo e a necessidade de contingente humano preparado para dar suporte ao crescimento e ao desenvolvimento desta área foram uma das razões da realização do treinamento, é de se concluir que a organização contava com a influência dos participantes do treinamento para realizar estas modificações e implementar suas estratégias, oferecendo para tal o devido ambiente de suporte.

Os relatos expostos no capítulo de apresentação dos resultados são representativos de alguns outros na mesma linha de argumentação, por isso foi destacado. Neste aspecto alguns participantes relataram nas pesquisas de reação que havia necessidade de maior tempo para a análise e implementação dos saberes adquiridos. 
Ao estudar o ambiente deve-se falar também no contexto da Universidade Corporativa e de como ela influenciou a condução do programa MBA Gestão Pública.

No aspecto de gestão da Universidade Corporativa do Banco do Brasil percebe-se uma atuação bastante profissionalizada junto ao parceiro fornecedor do curso, visto ser exigência contratual: “Apresentar a GEPES em meio magnético e impresso todos os trabalhos de conclusão de curso, compreendidos em Trabalho em Grupo e Artigo Individual.” (FUNDACE, 2005, p. 23).

Conforme Éboli (1999), as Universidades Corporativas devem tratar do desenvolvimento de competências críticas, com foco no aprendizado organizacional, tendo escopo estratégico, enfatizando as estratégias de negócio, treinando publico Interno e externo procurando obter como resultado aumento de desempenho.

Conforme relato de diversos entrevistados o curso proveu seus participantes de uma "linguagem apropriada", apoiando ainda a "ampliação de horizontes" e a "identificação de oportunidades" facilitando seu relacionamento e sua negociação com o mercado governo, estes são exemplos do desenvolvimento de competências críticas do executivo que tem por finalidade o desenvolvimento de negócios com este mercado.

Ao constatar-se que foram modificados procedimentos internos em razão do treinamento observa-se claramente a ocorrência do aprendizado organizacional.

Neste mesmo sentido o fato de o programa de treinamento estar alinhado às necessidades de desenvolvimento estratégico da DIGOV, resultado da macro estratégia do Banco do Brasil, qualifica o escopo do treinamento como estratégico.

O curso atendeu a público externo em somente uma de suas turmas, com duas participantes, preferindo não dar continuidade a esta política.

A UniBB procurou obter como resultado do treinamento o aumento do desempenho de seus funcionários já que alinhou o treinamento às suas necessidades e gerenciou o 
direcionamento de trabalhos de conclusão de curso para que fossem orientados área de governo, como de fato aconteceu em diversos dos casos relatados.

Não obstante a profissionalização da UniBB, há que se considerar que no aspecto de gestão de conhecimento é preciso revisar a forma como a Universidade Corporativa Banco do Brasil aplica na organização, os conteúdos desenvolvidos.

Apresenta-se desse modo, a gestão do conhecimento como uma política de gestão que deve se incorporar à prática gerencial da organização, criando, facilitando o acesso, tornando o ambiente propício e sendo capaz de controlar o conhecimento da organização, (DAVENPORT et alii 1998).

Na mesma linha Spender (2001), considera a organização como um sistema capaz de gerar, comunicar e aplicar o conhecimento, tornando-os novas práticas de mercado, fazendo da gestão de conhecimento um instrumento de competitividade empresarial.

O Banco do Brasil, de alguma forma procura gerenciar este conhecimento, mas é preciso fazê-lo de maneira sistematizada, em consonância com esta percepção, alguns participantes relataram esta necessidade.

No caso do MBA Gestão Pública, o Banco do Brasil gera, comunica e aplica novos conhecimentos, mas não faz isso de maneira sistematizada, a implementação de alguns trabalhos de conclusão deu-se mais por mérito, interesse e muitas vezes, por capacidade de movimentação organizacional, de seus autores do que pela gestão da organização. Além disso, muitas vezes essa implementação atem-se a alcances regionais, limitando o alcance de resultados de diversos projetos que poderiam ser multiplicadores de resultados de larga escala.

\subsubsection{Ambiente - Disseminação}


A disseminação do treinamento foi estudada de maneira ampla na terceira pergunta específica, item 8 , à página 226, quando se perguntou aos entrevistados do grupo focal a respeito do desenvolvimento humano da área de governo em razão da realização do programa de treinamento MBA Gestão Pública.

Relacionado ao aspecto de disseminação do conteúdo, no decorrer do agendamento das entrevistas dos grupos focais percebeu-se alguma dificuldade em localizar diversos participantes do curso, em razão de sua mudança de diretoria.

Baseado na percepção de que esse número pudesse ser representativo elaborou-se um instrumento de investigação de apoio, o Apêndice 5 - Movimentação de Pessoal da Diretoria de Governo constante a página 266.

Os resultados demonstrados permitem a inferência de algumas conclusões. A maioria das pessoas que fizeram o MBA Gestão Pública permanecem no Banco do Brasil, pois apenas 48\% dos alunos que fizeram o curso, se encontram no Pilar Governo, este dado provoca a necessidade de reflexão.

Todo o referencial teórico abordado, Borges-Andrade (1982), Bohlander, Snell e Sherman (2003), Abbad (1999), é unânime em afirmar que na fase do levantamento de necessidades é necessário indicar para o treinamento, pessoas que efetivamente, estejam vinculadas às funções para as quais estão sendo preparadas. No caso do Banco do Brasil, após 5 anos de realização do curso, apenas metade deste contingente permanece na Diretoria de Governo.

Meister (1999) e Éboli (2004) advertem que o treinamento na organização deve atender às necessidades de desenvolvimento estratégico da área treinada, no caso do Banco do Brasil, conforme se viu pelo levantamento de necessidades, ele atendeu, porém um grande contingente do recurso preparado não está mais relacionado às atividades para as quais o curso os preparou.

A formação do MBA Gestão Pública não é a única dos participantes deste treinamento. 
Conforme Fundace (2005) 15\% dos alunos das 5 turmas do programa possuíam outra especialização, a diversidade de áreas de formação em graduação permite concluir por amplas possibilidades de atuação, o que se quer anotar aqui é que do contingente formado, metade não está mais na Diretoria de Governo.

Cabe a ressalva de que muitos dos participantes que não estão diretamente associados ao Pilar Governo, estão em agências da rede Banco do Brasil, e muitas vezes exercem o relacionamento com entes ou representantes de entes públicos, havendo o aproveitamento do conteúdo aprendido, uma investigação mais detalhada neste sentido permitiria novas conclusões sobre o tema.

Cabe ainda a conclusão, de que o treinamento proporcionou, a maioria dos participantes, a ocupação de posições gerenciais, visto que em média 85\% dos ex-alunos do curso, que se encontram no Banco do Brasil, independente de estarem ou não no Pilar Governo, ocupam posições gerenciais.

Muitos dos participantes já ocupavam cargos gerenciais, conforme Fundace (2005), cerca de $45 \%$ dos participantes das 5 turmas do MBA Gestão Pública, possuíam cargo gerencial ao iniciarem o curso, contudo após a realização do curso, este numero saltou para 85\%.

\subsubsection{Ambiente - Resultado de Longo Prazo}

Os resultados de longo prazo serão estudados na Quarto objetivo específic à página 229, esta pergunta estuda os atributos da vantagem competitiva sustentável. 


\subsubsection{Terceiro objetivo específico}

O terceiro objetivo específico da pesquisa é descrever possíveis indicadores de resultadoque possam ser associados ao programa de treinamento, tendo como referência as seguintes fontes de observação:

1. volume de negócios;

2. Satisfação de clientes da área governo;

3. percepção da cadeia de valor da área governo;

4. ampliação de negócios;

5. desenvolvimento de estratégias de marketing;

6. modificação de processos internos ;

7. desenvolvimento estratégico da área;

8. desenvolvimento humano.

Tal como na apresentação dos resultados, cada um dos indicadores sugeridos foi analisado separadamente em cada um dos grupos focais, eles foram questionados pelo Apêndice 1, item b, sendo este item dividido em por meio dos subitens apresentados.

\subsubsection{1.volume de negócios}

\section{Apêndice 1 - Item 3b i}

elevação de seu volume de negócios após a realização do curso;

Com referência aos resultados obtidos para o item elevação do volume de negócios, observou-se que os participantes apontaram alguns indicadores que podem ser interpretados como elevadores do volume de negócios em razão do treinamento, como por exemplo a 
implantação do cartão corporativo, que foi desenvolvido como trabalho de conclusão do curso e movimenta R \$200 milhões ao ano.

A maioria dos comentários dos participantes dos grupos nesta área considerou elementos que podem ser associados ao curso, mas que, em sua opinião, não podem ser reputados a ele como único fator de causa.

Nesta linha foram apontadas capacidade de melhorias organizacionais que seriam geradoras de resultados.

Foi observado o desenvolvimento de estratégias de barreiras a novos entrantes e a especialização de executivos que, em razão do nível de competitividade do setor, precisam da preparação oferecida pelo treinamento para manter-se adequado aos níveis de competitividade da área.

Estes elementos foram todos considerados à luz da precaução necessária que se deve observar ao concluir por nexos de causalidade diretos entre a ação de treinamento e resultados de negócios da área.

Conclui-se a esse respeito que os participantes apontaram indicadores de elevação de volume de negócios, sem contudo, defini-los como produto direto do treinamento.

\subsubsection{2. satisfação de clientes da área governo}

\section{Apêndice 1 - Item 3b iii}

melhora na satisfação de seus clientes da área governo;

Quanto a melhora da satisfação dos clientes da área de governo, falou-se que um dos fatores a ser considerado é a capacidade de provocar a intensificação do relacionamento por pessoas que detenham maior preparo, sendo a formação uma facilitadora do processo de empatia, o que provocaria melhores indicadores de satisfação. Ainda como elemento de reforço da empatia 
considerou-se que o treinamento teria sido responsável por identificar mudanças de comportamento e ampliação das capacidades culturais dos participantes do curso, o que é outro facilitador para a intensificação de relacionamento com profissionais do poder público.

Apontou-se que é provável que o atendimento do cliente tenha melhorado já que o preparo dos interlocutores, inclusive em termos de nível de linguagem lexical empregada, gera como resultado maior capacidade de resposta e respostas mais assertivas aos pedidos formulados.

As pesquisas de satisfação de clientes do Banco do Brasil não podem ser consideradas elementos de análise válida para este estudo, pois tem uma grande generalidade de público, e apesar se ser possível separar apenas as respostas do cliente do setor público, não se poderia aproximar qualquer resultado do treinamento pois não há meio para se aproximar estas respostas dos participantes do curso.

Conclui-se que há indícios de melhora da satisfação dos clientes da área governo, atendidos por participantes do programa MBA Gestão Pública, sem contudo ser possível encontrar indicadores de suporte a esta conclusão.

\subsubsection{3.percepcão da cadeia de valor da área governo}

Apêndice 1 - Item 3b iv

incremento de relacionamento negocial junto a cadeia de valor da área governo;

Quanto a percepção de cadeia de valor observou-se que houve entre os participantes o desenvolvimento de uma visão sistêmica do Banco, que capta junto ao poder público para emprestar às empresas do Agronegócio.

Os depoimentos dos participantes revelam que o desenvolvimento do conhecimento quanto a formulação e desenvolvimento de políticas públicas denota uma destacada capacidade 
de análise da cadeia de valor do mercado governo, identificando novas oportunidades de atuação junto aos integrantes desta cadeia.

Por outro lado, os negócios identificados pela Diretoria de Governo são levados à frente por diretorias específicas, ou seja, quando a Diretoria de Governo, conquista uma folha de pagamento de um município, muitas vezes em razão do relacionamento desenvolvido, o impacto da folha de pagamentos se dá na rede de agências de varejo, diretoria diferente da Governo.

Mencionou-se ainda a mudança na forma de realização dos negócios, considerando o papel social do Banco do Brasil, o que dá à visão de cadeia de valor, importância e qualificação diferenciadas.

Pode-se concluir que houve a percepção de negócios junto a cadeia de valor do mercado governo, mas os negócios oriundos ficam fora da Diretoria de Governo.

\subsubsection{4. ampliação de negócios}

\section{Apêndice 1 - Item $3 b$ ii}

incremento de novas contas;

Verificou-se que pelos depoimentos do participantes nos grupos focais ocorreu o incremento de novas contas na área de governo, sendo detectadas oportunidades de relacionamento com instituições periféricas ao governo.

Os participantes observaram que, provavelmente dentre os participantes do MBA Gestão Pública que atuam na rede de agências, a ampliação de negócios deve ter sido mais evidente.

Foi considerado ainda que o treinamento despertou as capacidades criativas de seus participantes para a conquista de novas contas. 
Foi novamente considerada a necessidade de cautela ao se criar um nexo de causalidade único entre a ampliação do volume de negócios e a realização do treinamento. $\mathrm{O}$ curso foi reputado como fator desta ampliação, mas não como causa única.

\subsubsection{5.desenvolvimento de estratégias de marketing}

\section{Apêndice 1 - Item $3 \mathrm{~b} \mathrm{v}$}

desenvolvimento novas estratégias de marketing junto aos clientes da área governo;

A respeito do desenvolvimento de estratégias de marketing, os participantes observaram que o marketing do Banco conta com uma diretoria própria, mas que em alguns aspectos há a participação da DIGOV.

Foram lembradas a elaboração de novos folders para a área, a forma de atendimento do cliente governo, moldados pelos conhecimentos originados no curso. Outro ponto foi a melhor capacidade técnica para venda individual de cada participante do curso, classificada como marketing direto por E9.

Considerou-se que o curso poderia ter oferecido uma abordagem mais voltada ao marketing, especialmente segmentando oportunidades de relacionamento.

Pode-se concluir que a forma de comunicar as campanhas direcionadas ao público governo sofreu a influência do treinamento.

\subsubsection{6. modificação de processos internos}

Apêndice 1 - Item 3b vi

modificação de processos internos a partir do aprendizado do curso; 
Os participantes consideraram que ao conhecer aspectos legais dos clientes e de seus próprios processos internos foram identificadas oportunidades de melhorias internas, inclusive com a determinação de alçadas possíveis a cada gestor, sendo que a área jurídica da área foi a mais impactada.

Pode-se inferir, com base no depoimento dos participantes dos grupos focais, que houve modificação nos processo internos da área em razão do treinamento, especialmente no aspecto normativo.

\subsubsection{7. desenvolvimento estratégico da área}

\section{Apêndice 1 - Item 3b vii}

planejamento ou da implementação de mudanças da área governo devido ao programa;

Quanto ao desenvolvimento estratégico da Diretoria de Governo, foi mencionada a segmentação do Pilar Governo em superintendências, definindo-se responsabilidades e formas pelas quais o cliente governo em estados e municípios deveria ser atendido.

Foi mencionada a organização da Diretoria de Governo no contexto do curso, o que é natural já que a própria criação do curso surge como efeito da necessidade de organização da Diretoria de Governo, conforme foi mencionado na análise do curso pelo modelo MAIS (BorgesAndrade, 1982). Pode-se concluir que de maneira binária, a Diretoria de Governo identificou a necessidade de um curso, que após a sua criação resultou em influencia para sua estratégia e dimensionamento organizacional. 


\subsubsection{8.desenvolvimento humano}

\section{Apêndice 1 - Item $3 \mathrm{~b}$ viii}

multiplicação de conhecimento interno após sua participação no MBA Gestão Pública;

Quanto a disseminação do conhecimento levando ao desenvolvimento humano da Diretoria de Governo após a realização do curso foram mencionadas a distribuição e apresentação de alguns trabalhos de conclusão de curso de maneira sistematizada mas pontual pela diretoria, tendo sido priorizadas as apresentações relativas a trabalhos que representassem necessidades de transformações organizacionais mais imediatas, além disso houve a disponibilização dos trabalhos de conclusão dos alunos na intranet do banco.

Foi considerado que o processo de disseminação do conhecimento ocorreu de maneira natural por meio dos participantes do curso, que passaram a atuar como veiculadores deste conhecimento em suas funções.

Um resultado do curso nesse sentido foi a criação e realização de três cursos internos da Diretoria de Governo após a realização do MBA Gestão Pública. Estes cursos foram elaborados por participantes de algumas das turmas MBA, sendo voltados ao nível operacional (autoinstrucional) e desenvolvimento de negócios (Finanças Públicas e Governo e Relacionamento GOREN).

Por meio das evidências apresentadas, identificam-se sólidos indícios que o programa MBA Gestão Pública gerou a disseminação de conhecimento interno em diversas esferas.

\subsubsection{Análise geral dos indicadores obtidos}


Sumarizando os indicadores obtidos por meio dos grupos focais percebeu-se que houve elevação do volume de negócios da Diretoria de Governo do Banco do Brasil em função do treinamento, sem que este possa ser apontado como causa única e direta deste fato.

A respeito da ampliação da satisfação dos clientes, pelo depoimento dos participantes, percebeu-se que em razão do preparo oferecido pelo curso o processo de empatia tornou-se mais intenso, guardando assim maior probabilidade de geração de resultado.

Observou-se que os depoimentos indicam que os participantes desenvolveram a capacidade de identificar negócios junto a cadeia de valor que se vincula ao mercado governo, porém estes negócios são conduzidos por outras diretorias, observa-se assim que, apesar de não haver ampliação de resultado da Diretoria de Governo, provavelmente houve ampliação de resultado do Banco do Brasil.

Quanto ao incremento de novas contas e ampliação de negócios em razão do treinamento afirmou-se que de fato ocorreram sem que seja possível isolar o resultado advindo do treinamento das demais ações promovidas pela diretoria de governo, que também agiram para a ampliação destes indicadores.

A respeito da elaboração de estratégias de marketing pode-se concluir que houve influência do treinamento, especialmente no tocante a segmentação interna da área, havendo também influência do treinamento na elaboração de folders e peças de comunicação da diretoria, sendo assim um reflexo da estratégia na comunicação.

No aspecto de modificação de procedimentos internos houve a influência do treinamento especialmente no âmbito legal, pois o setor público é muito regulado e os participantes trouxeram para a operação da área as adequações de legislação necessárias. 
O curso teve ainda influência no desenvolvimento estratégico da área, como não poderia deixar de ser, pois a sua realização foi motivada pela necessidade estratégica de ter um corpo funcional formado. Tendo sido obtida a formação ela se refletiu em modificações estratégicas.

Houve ampla disseminação do conteúdo do curso, com conseqüente impacto de desenvolvimento humano no âmbito da Diretoria de Governo, essa disseminação realizou-se por meio da formatação de três cursos internos: Auto-instrucional em Gestão Pública, Finanças Públicas e Governo e Relacionamento (GOREN).

Os indicadores apresentados como resultados do treinamento guardam aproximação com o que recomenda o referencial teórico do presente estudo. Apresenta indicadores financeiros (HAMBLIN, 1978) e indicadores de desenvolvimento que se adequam às necessidades que o treinamento pretendia solucionar (KIRKPATRICK, 1993).

Pode-se considerar, a respeito da terceira pergunta específica, que há elementos de correspondência apoiando a verificação de indicadores para todos os aspectos sugeridos, volume de negócios, satisfação de clientes da área governo, percepção da cadeia de valor da área governo, ampliação de negócios, desenvolvimento de estratégias de marketing, modificação de processos internos, desenvolvimento estratégico da área e desenvolvimento humano.

Em todos estes aspectos foram observados elementos que indicam a influência do curso no indicador observado, no entanto cabe ressaltar mais uma vez que a relação do item treinamento com o item resultado, não significa causa, alguns dos resultados observados poderiam ter ocorrido sem que houvesse a realização do treinamento, não se sabendo a extensão que poderiam ter tido alcançado. Finalmente, apesar de não se poder estabelecer o nexo de causalidade direta nos elementos citados não se pode negar sua influência. 


\subsubsection{Quarto objetivo específico}

O quarto objetivo específico da pesquisa é classificar os resultados obtidos no programa MBA Gestão Pública com base na Teoria da Vantagem Competitiva Sustentável (BARNEY, 1991).

A classificação dos dados de pesquisa por meio da Teoria da Vantagem Competitiva Sustentável foi tomada em razão das características definidoras do presente estudo.

O objeto em análise, o MBA Gestão Pública, é um fenômeno contemporâneo, que deu origem a diversos resultados de natureza qualitativa, o que situou a pesquisa neste campo.

Cabe observar que a atribuição de classificação dos resultados do treinamento dentre os atributos da Vantagem Competitiva Sustentável, foi dada pelos participantes dos grupos, tendo assim, sofrido a influência do viés pessoal de cada um deles para esta classificação.

Cabe ressalvar ainda, que a espelho das análises anteriores, a análise dos resultados relacionados a aquisição da Vantagem Competitiva Sustentável, recebeu cauteloso tratamento, tendo sido confirmada a dificuldade, prenunciada pela metodologia, de que a separação dos resultados obtidos pelo treinamento dos resultados gerais da Diretoria de Governo, seria de difícil execução, especialmente por tratar-se de um curso de formação de natureza gerencial, destinado a um público que já contava com ampla capacidade de transformação organizacional.

Neste sentido vale lembrar que, a respeito da liquidez que se deve apontar no tocante aos ativos intangíveis, no caso a formação das pessoas, Kaplan e Norton (2004), apresentam o conceito de prontidão estratégica, como a capacidade que um ativo intangível tenha de suportar com maior aderência a estratégia da organização. 
Pode-se inferir que o desenvolvimento de novas capacidades por meio de um programa de treinamento amplia, dentre os participantes do treinamento, a capacidade de prontidão estratégica.

Conforme mencionado, Porter (1989), situa o conceito de vantagem competitiva entre elementos ligados a custo e elementos ligados a diferenciação.

Em se tratando neste estudo do posicionamento e da competitividade de uma área específica e estratégica de um banco, não há que se falar em vantagens associadas a custos, sendo necessário o investimento das melhores capacidades da organização nos elementos ligados a diferenciação.

Observando as associações feitas pelos participantes quanto aos elementos que podem ser considerados VCS na Diretoria de Governo, desenvolvido em razão do treinamento, cabe considerar que a maioria destes resultados associa-se de maneira inicial com a VBR - Visão Baseada em Recursos, conforme Fernandes (2004) a diferenciação que se estabelece na VBR situa a competitividade das empresas no aproveitamento dos recursos da organização.

Sendo presente o desenvolvimento de recursos internos, é oportuno classificá-los em sua forma de apresentação, nesse contexto classificar os dados por meio da Teoria de VCS surge com a finalidade de alcançar e compreender os resultados proporcionados pelo curso, tendo como referência sua característica diferenciadora de atributos de Barney (1991). Conforme E19:

...não é muito fácil de você mensurar os resultados em um prazo tão curto. Nós fizemos o curso em 2002, então eu acredito que esse é um aspecto que deve ser considerado, até mesmo em termos de metas para o banco... Acredito que esse é um processo o qual vai se refletir mais no médio e longo prazo, com mais clareza.

A classificação dos resultados do MBA Gestão Pública por meio dos atributos de VCS (BARNEY, 1991), serve à verificação dos resultados do curso e a exploração da perenização 
destes resultados junto a organização, sendo um reflexo do programa de treinamento, assim declarado pelos participantes e associados ao desenvolvimento das capacidades pessoais (COYNE, 1986), instaladas na organização .

Identificar estes reflexos e analisa-los é o objetivo que se pretende atingir a partir daqui.

\subsubsection{Atributos Valiosos}

A presença de atributos valiosos na Diretoria de Governo, originados com base no treinamento foram investigados no Apêndice 1, item 4a:

a. Um projeto que seja considerado de valor diferenciado pela diretoria do Banco, vinculado ao treinamento e que possa ser considerado valioso.

Cabe rememorar que conforme prevê Barney (1991) Recursos Valiosos, podem ser associados às idéias de raridade e escassez, combinadas a possibilidade de obtenção de altas margens de retorno que ele propicie, criando oportunidades e neutralizando ameaças (BARNEY, 1995).

Exemplificado por Kretzer (2002) um recurso valioso pode ser físico ou intangível.

Tendo estas imagens como referência, foram apontados os seguintes elementos como valiosos:

O cartão de pagamentos do governo federal, a segmentação do pilar governo e os produtos voltados para a área de Governo.

Apontou-se ainda como recurso valioso, ter, as pessoas certas nos lugares certos, ou seja, recursos treinados e preparados para atuar junto ao mercado setor público.

A capacidade de atender às necessidades de legalidade do governo, propondo soluções à medida que os desafios se apresentam. 
Por fim o conhecimento e capacidade de planejamento, também foram apontado como recursos valiosos, por funcionar como um filtro às necessidades de clientes com necessidades tão especificas.

Elementos como o cartão de pagamentos do governo federal ou mesmo a elevação do volume de negócios, considerada com a ressalva de não se poder apontar o treinamento como causa única de sua ocorrência, são valiosos, e na primeira condição definida por Barney (1991) capazes de gerar altos retornos financeiros.

Conforme se observa na definição de produtos essenciais de Prahalad e Hamel (1990), estes produtos são criados pela externalização das competências essenciais da organização, elaborados pela especialização da mão-de-obra da organização, considerados assim externalidades de sua vantagem competitiva.

Avançando na exploração conceitual, não se pode mencionar que algum dos resultados do grupo focal, associado ao conceito de recursos valiosos, seja um neutralizador de ameaças como prevê Barney (1991), mas certamente podem ser classificados como geradores de oportunidades.

Quando se associa os elementos valiosos às capacidades humanas da Diretoria de Governo, e esta foi uma associação clara dada pelos participantes, eles se colocam no campo da intangibilidade, exemplificado por Kretzer (2002).

Baseado nesta análise pode-se concluir que há elementos de observação suficientes para considerar que o treinamento apoiou o desenvolvimento de recursos valiosos junto a Diretoria de Governo do Banco do Brasil.

\subsubsection{Atributos Raros}


A presença de atributos raros na Diretoria de Governo, originados com base no treinamento foram investigados no Apêndice 1, item 4b:

b. Um projeto que seja considerado único no mercado bancário no contexto da diretoria de governo vinculado ao curso, que possa ser considerado raro.

Conforme apontou Barney (1991) recursos são considerados raros quando não estiverem disponíveis ou acessíveis a um grande número de concorrentes num mesmo mercado de atuação, sendo que a raridade ano precisa estar associada ao recurso em si, mas a forma como ele se integra a organização, diferenciado-a.

Os elementos seguintes se destacam como atributos raros:

Foi considerada como atributo raro, reiteradamente a qualificação dos funcionários e seu comprometimento com a área, ainda o cartão de pagamento, além de valiosos foi também considerado raro.

$\checkmark$ O desenvolvimento da visão organizacional do que representam Estados e Municípios no Estado brasileiro.

$\checkmark$ Foi lembrada a capacidade de realizar negócios sustentáveis, que não foram classificados dessa forma pelos entrevistados, mas que certamente assim podem ser classificados.

$\checkmark$ A marca do Banco do Brasil foi lembrada como um atributo raro, sem que contudo fosse associada a realização do treinamento.

Foi considerado como um atributo raro do Banco do Brasil, objetivamente relacionamento ao treinamento, as características de arquitetura organizacional da Diretoria de Agronegócio, em razão da capacidade de desenvolvimento de produtos, de funcionários preparados pelo conhecimento que se tem do ente público. 
Conforme se viu, a forma como um atributo se integra à organização pode ser considerada rara, e isto ocorre na Diretoria de Governo, o curso parece ter sido um propulsor de características organizacionais diferenciadoras e da forma como elas se integram para a realização de bons negócios desta diretoria.

Dierickx e Cool (1989), apud Kretzel (2002), colocam as pessoas como recursos raros das organizações. Conforme se viu a qualificação das pessoas foi considerada rara pelos participantes dos grupos focais. Se as pessoas podem ser academicamente classificadas como raras, seu desenvolvimento pode ser considerado a acentuação desta característica.

Cabe observar, no entanto, que recursos podem ser considerados raros como resultado da conexão entre capacidade, durabilidade e natureza de um recurso. Os recursos que aqui se apresentam são raros no mercado governo de hoje, tal como se apresenta sua configuração, conforme relatam os próprios entrevistados em outros momentos, o avanço da concorrência tem se dados de diversas formas, a perenização destes atributos como raros e o desenvolvimento de outros, é crucial para a sustentação de resultados de longo prazo desta diretoria.

Pode-se concluir que há elementos raros, componentes da Diretoria de Governo do Banco do Brasil, relacionados ao programa MBA Gestão Pública.

\subsubsection{Atributos de difícil imitação}

A presença de atributos de difícil imitação na Diretoria de Governo, originados com base no treinamento foram investigados no Apêndice 1, item 4c:

c. Um projeto que por suas características seja de difícil imitação por outra instituição bancária, que tenha sido gerado no contexto do curso, que seja difícil de imitar. 
Recursos difíceis de imitar são aqueles em que se reconhece a existência de atributos que os tornam caros para imitação pelos concorrentes (BARNEY, 1991), envolve as habilidades, capacidades e recursos únicos numa organização, reflexo de suas escolhas estratégicas durante seu desenvolvimento, são difíceis de imitar porque fazê-lo pode representar uma desvantagem de custo em seu desenvolvimento.

Os seguintes elementos se destacam nas falas dos participantes:

$\checkmark$ Novamente a aquisição de conhecimento surge como atributo de VCS, agora considerada como um atributo de difícil imitação, sendo reiteradamente apontada assim. Cabe observar que não somente por haver recursos treinados, mas por terem sido treinados em grande quantidade, formando uma reserva constante de desenvolvimento.

$\checkmark$ A sintonia do grupo, acentuada pela convivência no ambiente acadêmico do curso.

$\checkmark$ A capacidade de desenvolver produtos e soluções para o gestor público, de longa maturação, foi classificada como um recurso difícil de imitar.

$\checkmark$ A qualidade dos relacionamentos foi considerada um atributo de difícil imitação.

A aquisição de conhecimentos em si, tal como apontada pelos participantes, não pode ser considerada de difícil imitação, já que outro concorrente poderia realizar programas de treinamento em larga escala e obter como resultado recursos treinados, o que torna este atributo de difícil imitação é seu relacionamento com a diretoria de governo e seu envolvimento com a disposição organizacional instalada.

De maneira bastante objetiva classificam-se como recursos difíceis de imitar os relacionamentos da Diretoria de Governo.

Envolvem-se uma característica da própria diretoria, o relacionamento em si, e a qualidade técnica destes relacionamentos, apoiada pelo curso. 
Em diversos momentos os participantes citaram que a adequação da linguagem funcionou como uma alavanca para os relacionamentos estabelecidos, gerando respeito e adequação social dos participantes do curso, estando presentes na DIGOV. Atributos de difícil imitação, gerados no contexto do treinamento.

\subsubsection{Atributos de difícil substituição}

A presença de atributos de difícil substituição na Diretoria de Governo, originados com base no treinamento foram investigados no Apêndice 1, item 4d:

d. Um projeto que também em razão de suas características, gerado no contexto do curso, se extinto seria de difícil substituição.

Para Barney (1991), o recurso só pode ser considerado de difícil substituição quando não puder ser alvo desse tipo de estratégia de equiparação, já que a teoria prevê que organizações com potencial de concorrência, que não disponham de recursos que contemplam os atributos de VCS como ser valiosos, raros e difíceis de imitar podem apelar para a estratégia de tornar o recurso da organização que detém VCS substituível.

A Diretoria de Governo possui os atributos da VCS, sendo, dessa maneira, um possível alvo de estratégia equiparadora.

Foram obtidos os seguintes elementos, classificados como de difícil substituição:

A longevidade e qualidade dos relacionamentos da Diretoria de Governo foram consideradas um recurso de difícil substituição, em razão da relação de confiança que se estabelece.

A capacidade de customização de produtos foi considerada de difícil substituição. Observe-se que está se falando em customização, pois o mercado governo conta com 
diversos produtos de prateleira, copiáveis pela concorrência, mas a capacidade de customizar soluções é muito difícil de substituir.

$\checkmark$ A especialização da Diretoria de Governo foi considerada um atributo difícil de substituir.

$\checkmark$ A marca foi novamente lembrada como atributo de difícil substituição, mas desta vez associada ao treinamento. Os participantes observaram que a marca do Banco do Brasil é forte de per si, porém numa área especializada como a pública, a capacidade de atendimento diferenciado pode ser considerada um elemento apoiador da solidificação da marca, sendo difícil de substituir.

A longevidade dos relacionamentos pode ser considerada de difícil substituição, ou seja, um relacionamento só pode ser longevo baseado no tempo, um concorrente só pode obter um recurso como este baseado no tempo.

Neste aspecto cabe observar, conforme relataram os participantes dos grupos focais, que as próprias pessoas podem ser substituídas, pois a concorrência, numa estratégia de ataque pode “adquirir" estes recursos na forma de contratação. Este risco é real, baseado no fato de que os relacionamentos profissionais, apesar de se darem no âmbito institucional, são realizados por pessoas, que tem liberdade de escolha.

A capacidade de customização de produtos pode ser considerada de difícil substituição em razão de combinar características intrínsecas do Banco do Brasil e dos resultados obtidos com o treinamento. É intrínseca do Banco do Brasil a capilaridade e a antiguidade do relacionamento do banco com o ente público, porém o desenvolvimento de soluções em nível estratégico foi fortemente apoiado pela realização do curso, podendo dessa forma ser considerado um recurso de difícil substituição relacionado ao treinamento. 
A marca do Banco do Brasil é sólida por si, trata-se de um banco bicentenário presente na maior parte dos municípios brasileiros, porém conforme declararam os participantes dos grupos focais, o relacionamento com o ente público exige uma ampla capacidade técnica de manutenção, e o desenvolvimento desta capacidade associa-se ao curso.

Por meio dos resultados obtidos, há elementos para considerar que a Diretoria de Governo do Banco do Brasil possui recursos difíceis de imitar que em certa medida associam-se a realização do treinamento. 


\section{CONCLUSÕES}

Como primeiro elemento destas conclusões, cabe considerar que os objetivos da pesquisa foram atingidos. A análise dos resultados demonstra que a pergunta geral foi respondida tendo-se identificado diversos elementos de resultado associados ao programa MBA Gestão Pública, coletados por meio das respostas obtidas para cada uma das perguntas específicas.

Estes resultados verificaram-se por meio da associação de indicadores apontados como resultados, ainda que indiretos, do treinamento realizado.

A primeira medida apontada pelo referencial teórico, como necessariamente verificável em um treinamento, é a identificação da correspondência entre os resultados do treinamento e os objetivos de aprendizagem que justificaram sua realização. No caso em estudo, verificou-se que o MBA Gestão Pública atingiu os objetivos de aprendizagem inicialmente propostos, para cada objetivo proposto no documento de apresentação do curso, foram identificadas, nos grupos focais afirmações de sustentação desta conclusão.

A luz do Modelo MAIS (BORGES-ANDRADE, 1982) observou-se que o curso cumpriu diversas das etapas previstas por este modelo de implementação e avaliação de treinamento. Verificou-se a necessidade de implantação de um treinamento, e neste momento não houve a apuração técnica desta necessidade, mas havia a evidência da implantação de uma nova Diretoria no banco e esta implantação necessitaria de suporte técnico para seu desenvolvimento, o que se constitui numa abrangente e sustentável identificação de necessidade de treinamento.

Neste contexto vale considerar que o treinamento estava totalmente alinhado às estratégias da organização, conforme prevê a técnica, tendo sido realizado como elemento deste desenvolvimento estratégico, sendo assim um resultado de natureza binária, ou seja, o 
treinamento ocorreu como passo da estratégia da Diretoria de Governo e por ter ocorrido gerou modificações em sua estratégia.

Os participantes estavam motivados a participar do treinamento e este elemento foi importante para o sucesso de sua realização.

Observou-se que os procedimentos de aplicação do curso foram suficientemente sistematizados e adequados ao perfil de alunos que o realizaria, o que facilitou o processo de aprendizagem.

Houve um bom aprendizado por parte dos alunos e este indicador é um importante elemento de avaliação de um curso. Os alunos gostaram do treinamento e conforme se viu a reação positiva é apoiadora dos resultados de um curso.

O programa modificou o comportamento de seus participantes, da forma esperada em um treinamento de cunho gerencial, garantindo segurança, ampliando a linguagem, fortalecendo a capacidade de relacionamentos, ampliando o conhecimento, entre outros, mas é preciso observar que esta mudança não foi programada, ou seja, não havia uma relação definida de comportamentos a serem modificados e como isso deveria acontecer, o atingimento dos objetivos de treinamento parece aparar esta aresta, mas cabe observar que, como previne a técnica, este deve ser um cuidado para realização de próximos treinamentos.

Como resultados diretos do treinamento observou-se o desenvolvimento e a implantação de produtos, desenvolvimento de estratégias organizacionais e uma série de outros benefícios relatados, diretamente associados à realização do curso, por terem sido observados após seu tratamento por meio de trabalhos de conclusão do curso.

Infere-se a partir deste fato que a maximização do uso de trabalhos de conclusão como meio de obtenção de resultados diretos de treinamento, deve ser incentivada. 
O conteúdo aprendido no curso foi disseminado, por meio da realização de cursos instrucionais internos e de outras contratações, além da disseminação direta promovida pelos participantes.

Percebeu-se a elevação do volume de negócios e a ampliação da satisfação dos clientes da Diretoria de Governo, sem que seja possível determinar montantes que possam ser apontados como causa do treinamento realizado.

Quanto à percepção da cadeia de valor e ampliação de negócios desta área, verificou-se que houve a correspondência entre estes elementos e o treinamento, contudo os resultados desta percepção alocam-se nas outras diretorias do banco, responsáveis pelos negócios identificados, sendo dessa forma, não um resultado da diretoria, mas do Banco do Brasil.

Foram identificadas a implementação de estratégias de marketing e a modificação de processos internos, associadas ao treinamento, especialmente quanto a modificação de processos, por estar associada aos aspectos legais, constitui-se num importante ganho para a diretoria, pois como se sabe o setor de governo é extremamente regulado.

Foram identificados junto a Diretoria de Governo, associados a realização do curso, atributos de Vantagem Competitiva Sustentável (BARNEY, 1991). Como atributos valiosos mencionou-se os rentáveis produtos criados no contexto do curso, a capacidade de atender necessidades de legalidade do governo e a capacidade de planejar o crescimento da área. Como atributos raros foram consideradas a qualificação do corpo funcional, a capacidade de realizar negócios sustentáveis, e as características da arquitetura organizacional. Como atributos dificeis de imitar foram considerados o conjunto de conhecimento instalado na diretoria e a qualidade dos relacionamentos estabelecidos por ela junto ao mercado governo. Como atributo de dificil substituição foi apontada a longevidade do relacionamento da diretoria como o setor público e 
especialização geral da diretoria e por fim foi apontado o apoio à marca, necessário para confirmar junto ao ente público as conhecidas qualidades do Banco do Brasil.

A análise dos resultados aqui apresentada baseou-se fortemente nas informações obtidas junto aos grupos focais realizados, podendo-se assim questionar estas conclusões, pois estão baseadas em elementos subjetivos dos entevistados.

O referencial teórico apresentado preveniu, em seu mais referenciado autor (KIRKPATRICK, 1994), que na maioria das vezes a mensuração de resultados de treinamento é preterida, pois, mesmo que sejam identificadas evidências de resultado na organização onde se realizou o treinamento, não se pode afirmar que está claro o relacionamento positivo do treinamento com estes resultados.

Classificar os resultados do curso MBA Gestão Pública, por meio dos atributos da Vantagem Competitiva Sustentável (BARNEY, 1991) constitui-se numa busca por indicar que os resultados de treinamento de nível gerencial podem ser avaliados por meio de critérios válidos para a atividade gerencial: geração de valor e resultados de longo prazo para a organização, as vantagens competitivas sustentáveis.

No caso da Diretoria de Governo do Banco do Brasil, a investigação realizada identificou elementos que permitem inferir que houve o desenvolvimento de VCS relacionada ao treinamento.

\section{Contribuições Acadêmicas}

Como contribuição para o avanço acadêmico na área de treinamento, há elementos que permitem considerar (estando resguardadas condições semelhantes as que se descreveu aqui) que o treinamento pode ser visto como uma fonte de Vantagem Competitiva Sustentável. Por meio 
das evidências observadas, pode-se inferir que ao se treinar pessoas com boa capacidade de modificação organizacional, é possível obter-se como resultado a construção de uma organização que seja portadora de Vantagens Competitivas Sustentáveis, desenvolvendo, por meio destes recursos humanos, elementos diferenciadores, objetivamente classificáveis como valiosos, raros, difíceis de imitar e difíceis de substituir.

No contexto de um mercado altamente competitivo esta capacidade constitui-se num interessante atrativo para a realização de programas de educação executiva.

Ainda como contribuição acadêmica pode-se mencionar a sistematização do referencial teórico aqui apresentado, partindo dos aspectos do aprendizado do aluno adulto, do aprendizado organizacional e da necessidade da gestão do conhecimento nas empresas, passando então às fases de elaboração, planejamento e implementação, levantamento de necessidades e em especial da avaliação de treinamento, finalizando pelos conteúdos relativos à vantagem competitiva sustentável.

\section{Contribuições Práticas}

A Universidade Corporativa do Banco do Brasil poderia considerar as seguintes recomendações, como meio de acentuar a já reconhecida excelência na gestão de seus treinamentos:

Primeiramente seria interessante refletir sobre o desenvolvimento de uma metodologia de trabalho que permeasse os treinamentos da instituição, partindo o levantamento de necessidades de treinamento, passando pelas fases de implementação e chegando a avaliação do treinamento. Essa reflexão poderia evoluir para o desenvolvimento de um modelo de implementação de treinamento próprio do Banco do Brasil, onde as caractersiticas da instituição fossem 
contempladas e por meio do qual a técnica científica pudesse apoiar a execução desta atividade no banco.

A definição e o detalhamento de objetivos que devem ser atingidos ao final do treinamento podem ser considerados uma boa medida para se mensurar o sucesso do programa.

Da mesma forma, o detalhamento de comportamentos que devem ser observados ao final do treinamento, deveria ter sido preteriamente elencado, identificando o quanto o treinamento atingiu suas meta de modificação de comportamento, importante medida de resultado conforme se revelou pelo referencial teórico.

Para todas estas medidas de resultado, seria interessante obter indicadores de desempenho pré-treinamento, para que os indicadores revelados após o curso pudessem ser a estes comparados, ampliando assim a capacidade de inferência a respeito do sucesso do programa realizado.

Quanto aos trabalhos de conclusão, cabe observar que sua realização quando há efetiva substância de conhecimento dos participantes do treinamento, se constitui em importante meio de desenvolvimento da área treinada, assim seria interessante desenvolver estratégias de torná-los sistematicamente proveitosos para a organização.

Uma gestão mais direta da Universidade Corporativa e da área interessada no treinamento, em torno dos trabalhos de conclusão de curso dos alunos, provavelmente ampliaria o aproveitamento destes trabalhos como meio de desenvolvimento institucional e certamente tornaria mais evidente a relação entre resultados do grupo treinado e o sucesso do treinamento.

Ainda neste contexto, observou-se que não há políticas definidas de disseminação do conhecimento obtido por meio da realização dos trabalhos de conclusão, a Universidade Corporativa poderia refletir sobre este tema para que uma gestão mais efetiva do conhecimento produzido pudesse se confirmar. 
Seria interessante explorar meios de se obter a ampliação do conhecimento gerado nos cursos para os demais funcionários relacionados a área de governo.

A respeito das pessoas que realizaram o programa MBA Gestão Pública observou-se um alto índice de rotatividade interno, pois mais da metade das pessoas treinadas num espaço de quatro anos, não se encontram vinculadas a Diretoria de Governo. Seria interessante a reflexão do Banco do Brasil acerca deste fato para que possa haver o aproveitamento mais racional do recurso investido em treinamento. Futuras pesquisas poderiam indicar as razões desta rotatividade e meios de minimizá-la. No entanto, cabe observar que o rodízio de funções pode ser parte da estratégia de encarreiramento do banco, permanecendo aqui a sugestão de reflexão em torno do tema, sobretudo no tocante a realização de cursos vinculados a áreas especificas do banco como é o caso do MBA Gestão Pública.

\section{Recomendações para futuras pesquisas}

Futuras pesquisas são recomendadas para aspectos não abordados por este trabalho: o estudo do suporte organizacional para implementação do conhecimento adquirido e; o estudo das variáveis ambientais capazes de influenciar os resultados produzidos pelos treinandos após o treinamento.

\section{Limitações do estudo}

Os limites da pesquisa encontram-se em sua capacidade de afirmar que, sendo encontrados resultados na área de governo, por mais que possam ser relacionados ao curso, seria uma exacerbação da técnica cientifica dizer que o treinamento é causa dos resultados que se 
apresentaram, contudo, não se pode negar a relação entre os fenômenos curso e os resultados observados. Deve-se guardar diferença para quando há nexo de causalidade direta entre um fenômeno e outro e quando se constata apenas a relação entre eles. Se não se pode afirmar contundentemente que a primeira possibilidade é verdadeira, não se pode deixar de notar a evidente presença da segunda. Dentre os resultados, há diversos que só poderiam ser verificados no contexto da realização do curso, não se pode afirmar que não aconteceriam, mas certamente a ausência do programa de treinamento lhes teria dado contornos diferentes, nem melhores nem piores, mas certamente diferentes.

O grupo de alunos estudado, ao enfrentar novos desafios e imposições do mercado bancário, talvez reagisse em média da mesma forma, às mesmas variáveis ambientais, sem terem participado do treinamento mas, por meio da análise dos resultados obtidos, partindo do conhecimentos adquiridos, seu estofo para o enfrentamento do mercado governo, é diferenciado.

Deve-se enfatizar que os resultados aqui obtidos não podem ser inferidos no contexto de outras organizações, o estudo de caso teve por objetivo estudar em profundidade o fenômeno do Banco do Brasil e estes resultados podem servir como base para futuras pesquisas.

Se por um lado, não se pode generalizar a apreensão da realidade observada no contexto do estudo de caso apresentado, também não se pode deixar de reconhecer sua capacidade de demonstrar indicadores de resultado pela ampla exploração da realidade observada. 


\section{REFERÊNCIAS BIBLIOGRÁFICAS}

ABBAD, G. Um modelo de Avaliação do Impacto do treinamento no trabalho IMPACT. Tese (Doutorado em Psicologia) - Instituto de Psicologia. Universidade de Brasília, Brasília: 1999.

ABBAD, G. GAMA, A.L.G. e BORGES-ANDRADE, J. E. Treinamento: Análise do Relacionamento da Avaliação nos Níveis de Reação, Aprendizagem e impacto no trabalho. Revista de Administração Contemporânea, v. 4, n. 3, p. 24 - 45, set/dez 2000.

ALLIGER. G.M.; JANAK, E.A. Kirkpatrick's levels of training criteria: Thirty years later. Personnel Psychology, 42, 1989, 331-342.

ABNT - Associação Brasileira de Normas Técnicas. NBR 10015. Gestão da Qualidade Diretrizes para Treinamento, Rio de Janeiro, 2001.

ALLEN, R. J. Picadeiro de Resultados Reais. Revista HSM Management, São Paulo, ano 5, v. 6, n.29, p. 102-114, nov./dez. 2001.

ANTUNES, M. T. P. Capital Intelectual. São Paulo, Atlas: 2000.

ANTUNES, A. B. A dinâmica de sistemas e a compreensão da estrutura de negócios. 2003. 135 f. Dissertação (Mestrado em Administração) - Faculdade de Economia, Administração e Contabilidade, Universidade de São Paulo, São Paulo.

ARGYRIS, C. Knowledge For Action : A Guide to Overcoming Barriers to Organizational Change. New York: John Wiley, 1993.

ÁVILA et alii. Formação do Capital Humano e Retorno dos Investimentos Feitos em Treinamento na Embrapa. Brasília: Departamento de Documentação e Informação da Embrapa, 1983.

BANCO DO BRASIL, Universidade Corporativa Banco do Brasil. Relatórios Internos, Brasília, 2004. 
Apresentação Diretoria de Governo 2004, disponível em:

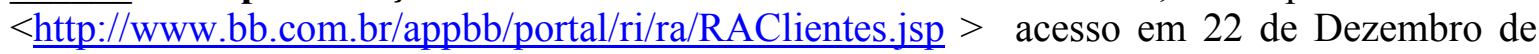
2004.

BARNEY, J. B. Firm resources and sustained competitive advantage. Journal of Management, vol. 17, n. 1, pp. 99-120, 1991.

"Looking inside for competitive advantage". The Academy of Management Executive. Briarcliff Manor: v. 9, n. 4; 49-62, nov, 1995.

BASTOS, A.V.B. O suporte oferecido pela pesquisa na área de treinamento. Revista de Administração, São Paulo, v.26. n.4, p. 87 - 102, out/dez. 1991.

BOHLANDER, A.; SNELL, S.; SHERMAN, A. Administração de Recursos Humanos. Tradução de Maria Lúcia G. Leite. São Paulo: Thomson, 2003.

BOOG, G. Manual de Treinamento e Desenvolvimento. São Paulo: Makron Books, 1999.

. Manual de Treinamento e Desenvolvimento - Um guia de Operações. São Paulo: Makron Books, 2001.

BORGES-ANDRADE, J.E.. Avaliação somativa de sistemas instrucionais: integração de três propostas. Tecnologia Educacional, 11(46), 29-39, 1982.

BORGES-ANDRADE, J.E. Desenvolvimento de Medidas de Avaliação de Treinamento. Enanpad, 23. Florianópolis: 2000. Ri de Janeiro: ENANPAD. 1 Cd Room: 2000.

BORGES-ANDRADE, J.E. \& OLIVEIRA-CASTRO, G.. Treinamento no Brasil: reflexões sobre suas pesquisas. Revista de Administração, v. 31, n.2, p. 112-125, 1996.

BOYDELL, T.H. Una guia a la identificación de necessidades de adiestramiento. Londres: Baciel, 1972.

BRASIL, SESU - Secretaria de Educação Superior, CNE - Conselho Nacional de Educação. Estabelece normas para o funcionamento de cursos de pós-graduação. Resolução CNE/CES No 1, Brasília, 3 de abril de 2001. 
BRESSAN, F. O Método do Estudo de Caso. Revista Administração On Line. Prática Pesquisa - Ensino, vol. 1, n. 1: jan./fev./mar. 2000.

BRUNER, J.S. Process of Education. Boston: Harvard University Press, 1977.

BYHAN, W.C. Changing supervisory and managerial behavior: II. Training and Development Journal, 1977, v. 31, p. $10-16$.

CAPPELLI, P. Políticas e programas de treinamento profissional. In EBOLI, M. Coletânea Universidades Corporativas - Educação para as Empresas do Século XXI, São Paulo: Schmukler, 1999.

CASCIO, W.F. Managing Human Resources. New York: McGraw Hill, 1995.

CAVALCANTI, R. de A. “Andragogia: A Aprendizagem nos Adultos".Revista de Clínica Cirúrgica da Paraíba. João Pessoa, n. 6: jul. 1999.

COOK, J. M. “On Showing ROI” Training Supplement. In BOHLANDER, A.; SNELL, S.; SHERMAN, A. Administração de Recursos Humanos. Tradução de Maria Lúcia G. Leite. São Paulo: Thomson, 2003.

DAVENPORT, T. H.; DELONG, D. W.; BEERS, M. C. Successful knowledge management projects. Sloan Management Review, v. 39, n. 2, 1998, p. 43-57.

DeCENZO, D.; ROBBINS, S. Administração de Recursos Humanos. Tradução de Alfredo Barcellos Pinheiro de Lemos. Rio de Janeiro. LTC, 1999.

DESSLER, G. Administração de Recursos Humanos. Tradução de Cecília Leitão Oderich. São Paulo. Pearson, 2003.

DIMENSTEIN, G. Alta escolaridade é o mínimo para conseguir emprego. Folha UOL, São Paulo, 2002. Disponível em:

$<\mathrm{http}$ ://www1.folha.uol.com.br/folha/dimenstein/imprescindivel/mes/maio02.htm>. Acesso em: 17 de maio de 2003. 
DRUCKER, P. F. Sociedade pós-capitalista. Tradução Nivaldo Montinegelli. São Paulo: Pioneira, 1993.

DUTRA, H. F. O.; OLIVEIRA, P. A. S.; E GOUVEIA, T. B. Avaliando a Qualidade de Serviço numa Instituição de Ensino Superior. Anais: ENANPAD. Rio de Janeiro, ENANPAD, 2002.

DUTRA, J. S. "Desenhando Programas de Desenvolvimento a partir da identificação de competências essenciais" pp 136-147. In EBOLI, M.. Coletânea Universidades Corporativas - Educação para as Empresas do Século XXI, São Paulo: Schmukler, 1999.

. Gestão de Pessoas com Base em Competências. In DUTRA, J.S. (Coord.) Gestão por Competências: um modelo avançado de gerenciamento de pessoas. São Paulo: Gente, 2001.

.Competências - Conceitos e Instrumentos para a Gestão de Pessoas na Empresa Moderna, São Paulo: Atlas, 2004.

EBOLI, M. Educação Corporativa no Brasil: Mitos e Verdades. São Paulo: Gente, 2004.

Coletânea Universidades Corporativas - Educação para as Empresas do Século XXI, São Paulo: Schmukler, 1999.

EDVINSSON, L. MALONE, M.S. Capital Intelectual. Tradução de Roberto Galman. São Paulo: Makron Books, 1998.

FARNSWORTH, T. Formação e Treinamento de Executivos na Empresa: Soluções práticas para o autodesenvolvimenteo e treinamento de executivos eficazes. Tradução de Gert Meyer, revisão técnica de Darci Garçon., São Paulo, McGraw-Hill do Brasil: 1976.

FERNANDES, B.H. Competências de Performance Organizacional: Um Estudo Empírico. Tese de Doutorado. Faculdade de Economia, Administração e Contabilidade da Universidade de São Paulo, São Paulo: 2004.

FLEURY, M. T.; OLIVEIRA JR. M. de M (Coords.). Gestão Estratégica do Conhecimento, integrando aprendizagem, conhecimento e competências. São Paulo: Atlas, 2001. 
FREITAS, I. A. BORGES - ANDRADE, J. E. "Os efeitos do treinamento no desempenho individual e organizacional". Revista de Administração de Empresas. São Paulo, v. 44, n. 3 jul./set. 2004.

FITZ-ENZ, J. Retorno do Investimento em Capital Humano. Tradução de Celso Roberto Páscoa. São Paulo: Makron Books, 2001.

FUNDACE - Fundação para a Pesquisa e o Desenvolvimento da Administração, Contabilidade e Economia. Relatórios Internos - Pesquisa de Satisfação, 2003.

. Relatórios Internos - Pesquisa de Satisfação. Ribeirão Preto, 2005.

2005

Relatórios Internos - Proposta - MBA Gestão Pública - Turma 005. Ribeirão Preto,

Relatórios Internos - Perfil da Turma. Ribeirão Preto, 2005.

GARVIN, D.; NAYAK, P.R.; MAIRA, A.N.; BRAGAR, J. Aprender a aprender. HSM Management, n. 9, p. 58-64, junho-agosto, 1998.

GARVIN, D. A. Construção da organização que aprende. In: GESTÃO DO CONHECIMENTO. Rio de Janeiro: Campus, 2001.

GIL, A.C. Como elaborar projetos de pesquisa. São Paulo: Atlas, 2002.

GIOVINAZZO, R.A. Focus Group em Pesquisa Qualitativa - Fundamentos e Reflexões. Revista Administração On Line. Prática - Pesquisa - Ensino, vol. 2, n. 4, out./nov./dez. 2001. Disponível em : http://www.fecap.br/adm_online/art24/renata2.htm, Acesso: 10/11/04

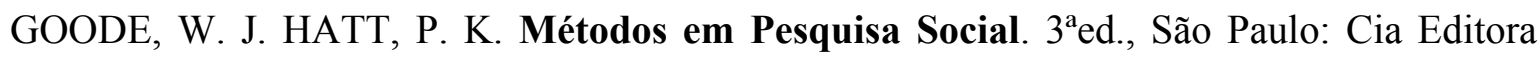
Nacional, 1969 in BRESSAN, F. O Método do Estudo de Caso. Revista Administração On Line. Prática - Pesquisa - Ensino, vol. 1, n. 1: jan./fev./mar. 2000.

GREEN, P.C. Building Robust Competencies. San Francisco: Jossey-Bass , 1999. 
HAMBLIN, A.C. Avaliação e controle do treinamento. São Paulo: McGraw-Hill do Brasil, 1978.

HILL, C. JONES, G. Strategic Management: na integrated approach. 4. ed Boston: Houghton Mifflin Company, 1998.

KAPLAN, R.S.; NORTON, D.P. "The balanced scorecard - Measures that drive performance”. Harvard Business Review, Boston, v. 70, n.1: 70-79, jan./fev. 1992.

Mapas Estratégicos. Convertendo ativos intangíveis em resultados tangíveis. Tradução de Afonso Celso da Cunha Serra. São Paulo, Campus, 2004.

KIM, D. The Link Between Individual and Organizational Learning. Sloan Management Review, Massachusetts, v. 35, n. 1, p. 37-50, 1993.

KOLB, D. A. Experimental Learning: Experience as the Source of Learning and Development, Prentice Hall, Englewood Cliffs, New Jersey, 1984.

KNOWLES, M. The Modern Practice of Adult Education - Andragogy versus Pedagogy. New York: Association Press, cap.3, p.39-53.

KROEHNERT, G. Instruções Básicas para Treinamento em Empresas. Tradução de Reinaldo Guarany. São Paulo: Manole, 2001.

KRETZER, J. Capacidades de desenvolvimento como fonte da sustentabilidade da vantagem competitiva: uma contribuição à visão baseada em recursos da firma. Tese de Doutorado, Programa de Pós-Graduação em Engenharia de Produção da Universidade Federal de Santa Catarina, Florianópolis, 2002.

KIRKPATRICK, D. Evaluating Training Programs: Four Levels. San Francisco: BerrettKoehler, 1993. . “Great ideas revisited”.Training \& Development.v. 50. n.1: 54 - 60, jan. 1996.

MAGER, R.F. Medindo os Objetivos de Ensino ou "conseguiu um par adequado?". Tradução de Maria Ângela Almeida, Porto Alegre: Globo, 1977. 
McGREGOR, S. R. O lado humano da empresa. São Paulo: Martins Fontes, 1992.

MILIONE, B. Integrando o Levantamento de Necessidades com a Avaliação e Validação do Treinamento, In: BOOG, Gustavo . Manual de Treinamento e Desenvolvimento. São Paulo: Makron Books, 1999.

Avaliação e Validação dos Resultados dos Investimentos em T \& D, In: BOOG, G. Manual de Treinamento e Desenvolvimento - Um guia de Operações. São Paulo: Makron Books, 2001.

MAlglaive, G. Ensinar Adultos. Tradução de Maria Luisa Álvares Pereira, Manuel Antonio de Oliveira e Silva e Maria Manuela Martinho Ferreira. Porto: Porto, 1995.

MATTAR, F. N. Pesquisa de Marketing. São Paulo: Atlas, 1993.

MEISTER, J C. A gestão do Capital intelectual através das universidades corporativas. Tradução: Maria Claudia S. R. Ratto. São Paulo: Makron Books, 1999.

MEISTER, J. C. Educação Corporativa. Tradução: São Paulo: Makron Books, 1999.

MEISTER, J.C. Expandindo o Raio de Ação: forjando parcerias com fornecedores, clientes e instituições de ensino superior. In EBOLI, M. Coletânea Universidades Corporativas Educação para as Empresas do Século XXI, São Paulo: Schmukler, 1999.

MENESES, P.P.M. Auto-eficácia, Locus de Controle,Suporte à Transferência e Impacto do Treinamento no Trabalho. Dissertação (Mestrado em Psicologia) - Universidade de Brasília, 2002.

MILKOVITCH, G. Human Resource Management. Chicago, Irwin, 1997.

MILKOVITCH, G. T. ; BOUdREAU, J.W. Administração de Recursos Humanos. São Paulo: Atlas, 2000. 
MONTGOMERY, C. A. PORTER, M. E. Estratégia: A busca da vantagem competitiva . Rio de janeiro: Campus, 1998.

MOREIRA, D. A Potencializacão do Capital Humano. São Paulo: Makron Books, 1999.

MORIN, E. Os Sete Saberes da Educação do Futuro. Tradução de Catarina Eleonora F. da Silva e Jeanne Sawaya. São Paulo: Cortez, 2001.

NOBREGA JUNIOR, F. O impacto de Cursos Comportamentais no fator Liderança da pesquisa de Clima e da Avaliação de Desempenho de uma Instituição Financeira. Dissertação (Mestrado em Administração), Faculdade de Estudos Sociais Aplicados, Universidade de Brasília, Brasília, 2003

NOGUEIRA, P.R. Identificação das Necessidades de Treinamento: Um estudo sobre os efeitos da posição hierárquica. 1980. 132 f. Dissertação (Mestrado em Psicologia) Universidade de Brasília, Brasília.

NONAKA, I.; TAKEUCHI, H. Criação de conhecimento na empresa: como as empresas japonesas geram a dinâmica da inovação. Rio de Janeiro: Campus, 1997.

OHMAE, K. Voltando a estratégia. In: MONTGOMERY, C. A. PORTER, M. E. Estratégia: A busca da vantagem competitiva . Rio de janeiro: Campus, 1998.

OLIVEIRA JR., M. de M. “Competências essenciais e conhecimento na empresa páginas” In: FLEURY, M. T.; OLIVEIRA JR. M. de M. Gestão Estratégica do Conhecimento, integrando aprendizagem, conhecimento e competências. São Paulo: Atlas, 2001.

PANTOJA, M.J. BORGES-ANDRADE, J.E. Contribuições Teóricas e Metodológicas da Abordagem Multinível para o Estudo da Aprendizagem e sua Transferência nas Organizações. Revista de Administração Contemporânea, v. 8, n. 4, Out-Dez 2004 : 115 138.

PARENTE, J. Varejo no Brasil: Gestão e Estratégia. São Paulo: Atlas, 2000. 
PARASURAMAN, A. Marketing Research. Toronto: Addison-Wesley Publishing company, 1986.

PENROSE, E. Theory of the growth of the firm. N.Y., Wiley, 1959, in FERNANDES, B.H. Competências de Performance Organizacional: Um Estudo Empírico. Tese de Doutorado. Faculdade de Economia, Administração e Contabilidade da Universidade de São Paulo, São Paulo: 2004.

PERRENOUD, P. et alii . Formando Professores Profissionais. Quais Estratégias? Quais Competências. Porto Alegre: Artmed: 2001.

PFEFFER, J. "Pitfalls on the road to measurement:the dangerous liaision of human resources with the ideas of accounting and finance" Human Resource Management, v.36, n.3: 357365, 1997.

PHILIPS. M, J. Handbook of training evaluation and measurement methods. Houston: Gulf, 1997.

PIAGET, J. Biologia e Conhecimento. São Paulo, Ed. Vozes, 1973.

POPPER, K. A lógica da pesquisa científica. Tradução de Leônidas Resemberg e Octanny Silveira da Motta. São Paulo: Cultrix, 1975.

PORTER, M. E. Vantagem Competitiva. Rio de Janeiro: Campus, 1989.

PORTER , M. E. Estratégia: A busca da vantagem competitiva . Rio de Janeiro: Campus, 1998.

STERN S. Inovação e Localização de Mãos Dadas. Revista HSM Management, São Paulo, n.30, p. 118, jan./fev. 2002.

PRAHALAD, C.K.; HAMEL, G. "The core competece of the corporation". Harvard Business Review, Boston, v.68, n.3: 79-91, maio/jun. 1990. 
QUINN, J. B.; ANDERSON, P.; FINKELSTEIN, S. "Gerenciando o Intelecto profissional, obtendo o máximo dos melhores" In: ULRICH, D. Recursos Humanos Estratégicos. Traduação de Bazán Tecnologia e Lingüística. São Paulo: Futura, 2000.

RICHARDSON, R. J. e colaboradores. Pesquisa social: métodos e técnicas. São Paulo: Atlas, 1999.

ROMIZOWSKI, A. J. Designing Instructional Systems. London: Kogan Page Nichols, 1981.

ROGERS, C. Liberdade para aprender. Belo Horizonte: Interlivros, 1975.

RUAS, R. "Desenvolvimento de Competências Gerencias" In: FLEURY, M. T.; OLIVEIRA JR. M. de M. Gestão Estratégica do Conhecimento, integrando aprendizagem, conhecimento e competências. São Paulo: Atlas, 2001.

SALAS, E. CANNON-BOWERES, J.A. The Sciense of training: a decade of progress. Ann. Rev. Psychol, Palo Alto, n.52, p. 471-449, 2001.

SCHÖN, D. Educando o Profissional Reflexivo um novo design para o ensino e a aprendizagem. Tradução de Roberto Cataldo Costa. Porto Alegre: Artmed, 2000.

SELLTIZ, C. et alii. Métodos de pesquisa nas relações sociais. São Paulo: E. P. U., 1974.

SENGE, P. M. Fifth Discipline, The Art And Practice of the Learning Organization. New York: Doubleday, 1994.

SPENDER, J. “Gerenciando Sistemas de Conhecimento". In: FLEURY, M. T.; OLIVEIRA JR. M. de M. Gestão Estratégica do Conhecimento, integrando aprendizagem, conhecimento e competências. São Paulo: Atlas, 2001.

SILVA, M.E. Relações Entre Impacto do Treinamento e Estratégia Empresarial: O Caso Eletronorte. 135 f. Dissertação (Mestrado em Administração) - faculdade de Estudos Sociais Aplicados, Universidade de Brasília, Brasília, 2002. 
STAMMERS, R. PATRICK, J. Psicologia do Treinamento. Tradução de Eduardo d' Almeida. Rio de Janeiro: Zahar, 1978.

STEWART, T. A. Capital Intelectual, A nova vantagem competitiva das empresas. São Paulo: Campus, 1998.

SHOEMAKER, P.J. H.; AMIT, R. The competitive Dynamics of capabilities: developing strategic assets for multiple futures, In: DAY, G.S.: REIBSTEIN, D.J. Ed. Wharton on dynamic competitive strategy. New York: John Wiley, 1997.

TANENBAUM, S. I.; YUKL, G. Training and development in work organizations. Ann. Rev. Psychol, Palo Alto, n.43, p. 399 - 441, 1992.

TEIXEIRA DE OLIVEIRA, M. R. de C., ITUASSU, C. T. Uma Análise dos Impactos do Treinamento e Desempenho de Profissionais e Gerentes. Anais do XXVIII ENANPAD, Curitiba, Paraná, 2004.

TEIXEIRA, J.E. (1999). T \& D e as Relações Sociais. In: BOOG, Gustavo . Manual de Treinamento e Desenvolvimento. São Paulo: Makron Books, 1999.

TURRA, G. et alii Planejamento de Ensino e Avaliação. Porto Alegre: Emma, 1975.

TRIVIÑOS, A. N. Introdução a pesquisa em Ciências Sociais: a pesquisa qualitativa em educação. São Paulo, Atlas: 1992.

ULRICH, D. "Measuring human resources: An overview of practice and prescription for results".Human Resource Management, New York, v. 36, n. 3: 303-321, Fall 1997.

Recursos Humanos Estratégicos. Traduação de Bazán Tecnologia e Lingüística. São Paulo: Futura, 2000.

UNIVERSIDADE DE SÃO PAULO. Sistema Integrado de Bibliotecas. Grupo DiTeses. Diretrizes para apresentação de dissertações e teses da USP: documento eletrônico e impresso / Vânia M.B. de Oliveira Funaro, coord et al. São Paulo, SIBi - USP, 2004. 
VERGARA, S. C. Universidade Corporativa: a parceria possível entre empresa e a universidade tradicional. Revista de Administração Pública. Rio de Janeiro, v. 34, n.5, p. 181-188, set./out. 2000.

VYGOTSKY. L., LURIA, LEONTIEV, N. Linguagem, desenvolvimento da aprendizagem. São Paulo: Ícone: EDUSP, 1988.

YIN, ROBERT K. Estudo de caso: planejamento e métodos. Tradução de Daniel Grassi. 2. ed. Porto Alegre: Bookman, 2001.

ZEMKE, R. ZEMKE, S. Putting Competences to Work. In: BOHLANDER, A.; SNELL, S.; SHERMAN, A. Administração de Recursos Humanos. Tradução de Maria Lúcia G. Leite. São Paulo: Thomson, 2003. 


\section{APÊNDICES}

\section{APÊNDICE 1 - Guia para realização de grupo focal}

Uso das dimensões do Modelo MAIS (BORGES - ANDRADE, 1982)

\section{Quanto ao Levantamento de Necessidades do treinamento.}

a. Como foi questionada a necessidade de se realizar um treinamento na Diretoria de Governo?

b. Como vocês foram indicados para participarem deste treinamento?

\section{Quanto a mudança de comportamento em razão do treinamento.}

a. Vocês perceberam mudanças em seu próprio comportamento após a realização do treinamento?

\section{Quanto aos resultados do treinamento.}

a. Qual sua percepção de resultados sobre o programa MBA Gestão Pública?

b. Qual a contribuição do MBA Gestão Pública nos seguintes aspectos:

i. elevação de seu volume de negócios após a realização do curso;

ii. incremento de novas contas;

iii. melhora na satisfação de seus clientes da área governo;

iv. incremento de relacionamento negocial junto a cadeia de valor da área governo;

v. desenvolvimento novas estratégias de marketing junto aos clientes da área governo;

vi. modificação de processos internos a partir do aprendizado do curso;

vii. planejamento ou da implementação de mudanças da área governo devido ao programa;

viii. multiplicação de conhecimento interno após sua participação no MBA Gestão Pública;

c. Como se pode relacionar a realização do programa MBA Gestão Pública com seus resultados na área governo? 
Uso dos Atributos da Vantagem Competitiva Sustentável (BARNEY, 1991).

\section{Quanto a construção da vantagem competitiva sustentável.}

A partir do programa MBA Gestão Pública foram implementados projetos com as seguintes características:

a. Um projeto que seja considerado de valor diferenciado pela diretoria do Banco, vinculado ao treinamento e que possa ser considerado valioso.

b. Um projeto que seja considerado único no mercado bancário no contexto da Diretoria de Governo vinculado ao curso, que possa ser considerado raro.

c. Um projeto que por suas características seja de difícil imitação por outra instituição bancária, que tenha sido gerado no contexto do curso, que seja difícil de imitar.

d. Um projeto que também em razão de suas características, gerado no contexto do curso, se extinto seria de difícil substituição. 


\section{APÊNDICE 2 - Guia para realização de entrevista - Diretoria de Governo}

1. Qual a percepção de resultados da diretoria da Diretoria de Governo em razão da realização do programa MBA Gestão Pública?

2. Após a realização do curso foram percebidas:

a. elevação do volume de negócios da Diretoria de Governo.

b. incremento de novas contas?

c. percepção de melhora na satisfação dos clientes da área governo?

d. incremento de relacionamento negocial junto a cadeia de valor da área governo?

e. desenvolvimento novas estratégias de marketing junto aos clientes da área governo?

f. reposicionamento estratégico da área após a realização do curso?

g. modificação de processos internos?

h. multiplicação de conhecimento interno?

3. Quais as relações positivas que você pode traçar entre os indicadores apresentados no item 2 e a realização do programa MBA Gestão Pública?

\section{Quanto a construção da vantagem competitiva sustentável.}

A partir do programa MBA Gestão Pública foram implementados projetos com as seguintes características:

a. Um projeto que seja considerado único no mercado bancário relacionado a governo. Que possa ser considerado raro.

b. Um projeto que seja considerado de valor diferenciado pela diretoria do Banco.Que possa ser considerado valioso.

c. Um projeto que por suas características seja de difícil imitação por outra instituição bancária. Que seja difícil de imitar.

d. Um projeto que também em razão de suas características, se extinto seria de difícil substituição. 


\section{APÊNDICE 3 - Guia para realização de entrevista Universidade Corporativa}

2. Como se deu o processo de levantamento de necessidades de treinamento da área governo em função do programa MBA Gestão Pública?

3. Como se deu o processo de elaboração do treinamento MBA Gestão Pública?

4. Como se deu a implementação do programa de treinamento MBA Gestão Pública?

5. Como a Universidade Corporativa percebe os resultados do programa MBA Gestão Pública?

6. Quais indicadores podem ser apresentados para suportar estas afirmações? 


\section{APÊNDICE 4 - Implementação Efetiva de Trabalhos de Conclusão de Curso}

Pessoal,

Sem querer abusar, ainda mais com os amigos que compareceram no focus group de 25/11.

Gostaria de saber de vocês qual dos trabalhos abaixo foi efetivamente implementado e com que resultados, se puderem citar indicadores objetivos agradeço. Exemplos de indicadores: financeiros, quantas famílias foram atendidas, alternativas de negociação que foram implementadas, fidelização, volume de negócios por produtos novos, implementação de procedimento, implementação de medidas como: atendimento por perfil, segmentação... entendam estes indicadores como sugestões, a relevância de informação neste momento é compreender o que foi implementado e com que resultados.

Agradeço os retornos,

Abraço

David

1 A Contribuição do FUNPROGER para a Política Pública de Geração de Emprego

2 A Dívida Pública Mobiliária Federal Interna no Governo FHC e as Alternativas para sua Gestão

3 A Execução Orçamentária e Financeira no Âmbito do SIAFI - Sistema Integrado de Administração Financeira do Governo Federal - O caso de Goianésia (GO)

4 A Importância dos Instrumentos de Gestão Pública para a Identificação de Oportunidades Negociais com o Setor Público

5 A Lei de Responsabilidade Fiscal e os Municípios Pequenos e Médio: Limitações e Oportunidade

6 Análise do desempenho da arrecadação de ISSQN da Prefeitura de São Luis (MA), após a utilização de Tecnologia da Informação

7 Arrecadação Administrativa da Dívida Ativa no Âmbito Federal - Análise e Perspectivas

8 As Experiências de Cuiabá (MT) e Campo Grande (MS) na Arrecadação do IPTU e INSS

9 Alternativas para o Incremento das Receitas Municipais: A Experiência de Canoas (RS)

10 Análise das Dificuldades de Crédito das Empresas Exportadoras Paranaenses 
11 Arrecadação de IPTU: A Experiência em Pequenos Municípios de Alagoas, Rio Grande do Norte e Paraíba

12 Buscando a Fidelização do Ente Público Municipal Atendido pela Rede de Varejo

13 Capacitação do Servidor Público Municipal: Uma Oportunidade de Negócios

14 Cartão Corporativo de Governo - A experiência paranaense

15 CRM: Conquistando Clientes e Realizando Negócios com o Setor Público, no Banco do Brasil

16 Compenet: Uma Solução E-Government

17 Contrato de Gestão: Possibilidades no Banco do Brasil

18 Desafios, Propostas e Ações do Tribunal de Justiça do Estado do Rio de Janeiro

19 Discursos versus Praxes - Estudo da Execução Financeira da Funções de Educação, Saúde, Previdência e Assistência Social no Governo FHC

20 Estratégia de Foco - O Relacionamento do Banco do Brasil com o Poder Judiciário Estadual e Trabalhista

21 Leilão Reverso A Oferta Pública de Recursos no Governo de Minas Gerais

22 Modelo de Segmentação Aplicado à Administração Pública Indireta Federal

23 O Ecoturismo como Força Motriz do Desenvolvimento Sustentável do Estado do Amazonas

24 O Impacto das Políticas Públicas de Crédito na Geração de Emprego e Renda: Estudo Sobre o Projeto Agropolos de São Luiz de Montes Belos - Goiás

25 O Incremento de Receitas de Municípios e a Parceria com a Rede Bancária

26 O Marketing de Localidades e a Administração Municipal: Uma Nova Perspectiva em Gestão Pública

27 O Papel do Banco do Brasil Diante do Cenário Rural

28 Oportunidade Negociais com o Terceiro Setor no Contexto de uma Fundação da Área de Saúde

29 Os impactos da Lei de Responsabilidade Fiscal para a Administração Municipal: O Caso do Município de Vitória (ES)

30 Os impactos do crédito para a agricultura familiar no Projeto Açai de Igarapé Miri

31 Parcerias Público-Privadas

32 Precatórios: Estudo de Caso do Tribunal Regional do Trabalho $5^{\mathrm{a}}$ Região 
33 Pregão Eletrônico: A experiência do Estado de Pernambuco

34 Previdência para Servidores Públicos: Avaliando os Serviços e Identiificando Oportunidades Negociais para o Conglomerado Banco do Brasil

35 PROEX

36 Programa cozinha em família

37 Proposta de Segmentação do Mercado aplicada ao Terceiro Setor

38 Reforma Tributária - Uma Análise das Principais Propostas

39 Segmentação de Mercado para o Setor Público: Uma Nova Proposta para o Banco do Brasil

40 Universidade Públicas: Como o Banco do Brasil poderá Incrementar seus negócios com este segmento

41 Vilas Rurais: A Experiência Paranaense de Desenvolvimento Local Sustentável 
APÊNDICE 5 - Movimentação de Pessoal da Diretoria de Governo

\begin{tabular}{|l|l|c|c|c|c|c|c|}
\hline & & \multicolumn{2}{|c|}{$\begin{array}{c}\text { Ainda Está no } \\
\text { BB }\end{array}$} & \multicolumn{2}{c|}{$\begin{array}{c}\text { Está no Pilar } \\
\text { Governo }\end{array}$} & \multicolumn{2}{c|}{$\begin{array}{c}\text { Posição } \\
\text { Gerencial }\end{array}$} \\
\cline { 5 - 9 } & Turma & $\operatorname{sim}$ & não & $\operatorname{sim}$ & não & sim & não \\
\hline Nomes, 0 até 183 & & & & & & & \\
\hline & & & & & & & \\
\hline & & & & & & & \\
\hline & & & & & & & \\
\hline
\end{tabular}


$\underline{\text { Anexo } 1 \text { - Controle de Qualidade das Aulas - FUNDACE }}$

\begin{tabular}{|l|}
\hline 1 = Péssimo \\
\hline 2 = Ruim \\
\hline 3 = Regular \\
\hline 4 = Bom \\
\hline 5 = Ótimo
\end{tabular}

Professor:

Curso:

Data:

Ano: Semestre:

\section{A- AVALIAÇÃO DA DISCIPLINA}

1- O programa da disciplina é bem estruturado

2- A disciplina trouxe um grande número de informações relevantes

3- Esta disciplina é relevante para o curso

4- Esta disciplina está bem integrada no conjunto do curso

5- Esta disciplina atendeu às minhas expectativas

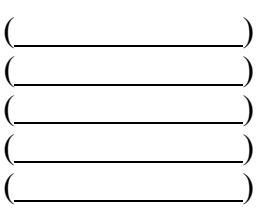

\section{B- AVALIAÇÃO DO PROFESSOR}

1- Prepara adequadamente suas aulas

2- Cria interesse pela matéria e estimula a participação

3- Demonstrou segurança e perfeito domínio da matéria

4- Foi claro e objetivo em suas exposições

5- O material didático foi adequado

6- Utiliza bem o tempo em sala de aula

7- Esclareceu bem as dúvidas surgidas

8- Cumpriu o programa apresentado no início da aula

9- Respeita os horários de aula

10- Eu faria outra disciplina ministrada por este professor

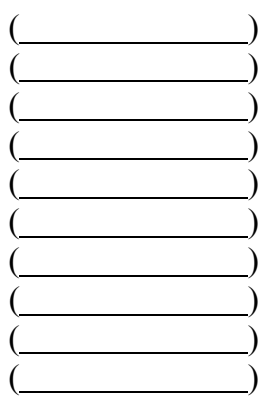

\section{C- AVALIAÇÃO DO ALUNO}

1- Preparei-me bem para esta aula

2- Procurei ler todo material distribuído

3- Meus conhecimentos foram suficientes para acompanhar a disciplina

4- Tive um bom aproveitamento na disciplina

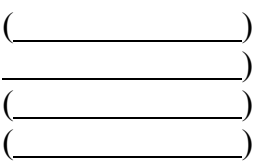

\section{D- INFRAESTRUTURA}

1- O material de aula foi enviado com uma semana de antecedência ?

$\square \operatorname{sim} \square$ não

2- O material de apoio do professor teve alguma deficiência ou problema?

$\square \operatorname{sim} \square$ não

3- Houve algum evento externo ou interno que atrapalhou o andamento da aula?

$\square \operatorname{sim} \square$ não

\section{E - COMENTÁRIOS GERAIS}

